\title{
Metabolic Syndrome and Its Associations with Psychological Distress and Subclinical Cardiovascular Disease Among Police Officers
}

\author{
Tara Autumn Hartley \\ West Virginia University
}

Follow this and additional works at: https://researchrepository.wvu.edu/etd

\author{
Recommended Citation \\ Hartley, Tara Autumn, "Metabolic Syndrome and Its Associations with Psychological Distress and \\ Subclinical Cardiovascular Disease Among Police Officers" (2011). Graduate Theses, Dissertations, and \\ Problem Reports. 4731. \\ https://researchrepository.wvu.edu/etd/4731
}

This Dissertation is protected by copyright and/or related rights. It has been brought to you by the The Research Repository @ WVU with permission from the rights-holder(s). You are free to use this Dissertation in any way that is permitted by the copyright and related rights legislation that applies to your use. For other uses you must obtain permission from the rights-holder(s) directly, unless additional rights are indicated by a Creative Commons license in the record and/ or on the work itself. This Dissertation has been accepted for inclusion in WVU Graduate Theses, Dissertations, and Problem Reports collection by an authorized administrator of The Research Repository @ WVU.

For more information, please contact researchrepository@mail.wvu.edu. 


\title{
Metabolic Syndrome and Its Associations with Psychological Distress and Subclinical Cardiovascular Disease Among Police Officers
}

\section{Tara Autumn Hartley, M.P.A., M.P.H.}

\author{
Dissertation submitted to the \\ School of Medicine \\ at West Virginia University \\ in partial fulfillment of the requirements for the degree of \\ Doctor of Philosophy \\ in \\ Public Health Sciences
}

\author{
Cecil M. Burchfiel, Ph.D., M.P.H., Chair \\ Michael E. Andrew, Ph.D. \\ Desta Fekedulegn, Ph.D. \\ Sarah S. Knox, Ph.D. \\ John M. Violanti, Ph.D.
}

Department of Community Medicine

Morgantown, West Virginia

2011

Keywords: Metabolic Syndrome, Psychological Stress, Law Enforcement, Cardiovascular Disease 


\begin{abstract}
Metabolic Syndrome and Its Associations with Psychological Distress and Subclinical Cardiovascular Disease Among Police Officers
\end{abstract}

Tara Autumn Hartley, M.P.A., M.P.H.

Police officers are a vital part of every community in the U.S. Officers are routinely exposed to numerous types of stressors, including traumatic events, shift work and organizational issues. The impact of this exposure can lead to chronic physical and psychological health problems. Police officers have been reported to have higher rates of cardiovascular disease (CVD). Previous studies have found associations between work stress and CVD, and this association may be mediated by the metabolic syndrome (MetSyn). MetSyn is a clustering of metabolic abnormalities, including abdominal obesity, hypertension, glucose intolerance and dyslipidemia, that has been associated with CVD and Type II diabetes. The goal of this dissertation was to utilize cross-sectional data to determine whether the stressful events of policing and depressive symptomatology were associated with MetSyn, and whether MetSyn was associated with an established and valid measure of subclinical CVD, carotid artery intima media thickness (IMT). In the first study, the association between police stress, as measured by the Spielberger Police Stress Survey, and MetSyn were examined separately in male and female police officers. The multivariate-adjusted number of MetSyn components significantly increased across tertiles of perceived stress and the stress index for the past month in female officers. Police stress was consistently associated with abdominal obesity and reduced high density lipoprotein cholesterol (HDL-C). In the second study, participants included police officers from two geographically separate cohorts, Buffalo NY and Spokane WA. For Spokane men, the multivariate-adjusted number of MetSyn components increased significantly across categories of depressive symptoms, as measured by the Center for Epidemiologic Studies-Depression (CES-D). For each 5-unit increase in CES-D score, the multivariate adjusted odds for having elevated triglycerides increased by $47.6 \%$, by $51.8 \%$ for having hypertension, and by $56.7 \%$ for having glucose intolerance. The association between MetSyn and carotid IMT was examined in the third study. Among women, the multivariate-adjusted mean common carotid and maximum 36 carotid IMT were significantly and positively associated with number of MetSyn components. Carotid IMT was significantly associated with having low HDL cholesterol and hypertension. Given the significant role of police officers in our local communities, it is important to understand the complex relationship between the specific types of police stress and early CVD. Results from these studies will optimize the ability to intervene early before overt disease is present. This may have a greater impact on improving police officers' physical and mental health and decreasing the health consequences of police stress. 


\section{DEDICATION}

I dedicate this dissertation to Mallory and Ethan.

I am honored to be your momma. 


\section{ACKNOWLEDGEMENTS}

I would like to acknowledge the National Institute for Occupational Safety and Health (NIOSH) for providing funding and support for my doctoral training. The work in this dissertation was supported by NIOSH contract number 200-2003-01580. The findings and conclusions in this dissertation are those of the authors and do not necessarily represent the views of NIOSH.

I would like to recognize and express my gratitude to the following individuals.

Dr. Cecil Burchfiel my dissertation chair, my supervisor and mentor. You are a wonderful teacher. I am amazed by the breadth and depth of your knowledge of epidemiology and cardiovascular disease. Thank you for your dedication, guidance, encouraging words, and for supporting "work-life" balance.

Drs. Michael Andrew, Desta Fekedulegn, Sarah Knox and John Violanti, thank you for challenging me and for all of the time and effort you have invested while serving on my committee.

Dr. Keith Zullig, Director of the PhD Program in Public Health Sciences, thank you for your leadership, guidance and support.

My fellow doctoral students, especially Brent Doney, Ruchi Bhandari and Karen Manzo, who are like family to me. We have experienced much joy and deep loss in the past three years. Thank you for always standing together.

The police officers from Buffalo, New York and Spokane, Washington, thank you for participating in these research studies.

My parents Keith and Carrie Williams, the Armstrong family, and the Hartley family for their love and prayers.

Above all, I would like to thank my husband Dan for his encouragement and support, for proofreading and pep talks, and for always standing by my side. I am truly blessed to have you in my life. 


\section{TABLE OF CONTENTS}

CHAPTER 1. INTRODUCTION .......................................................................................................................

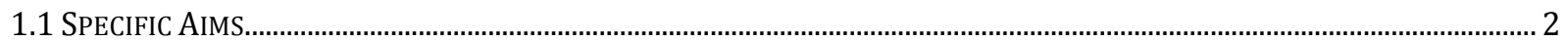

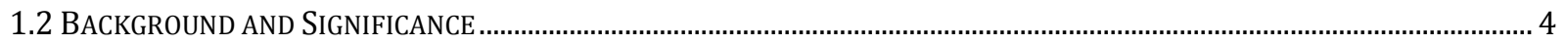

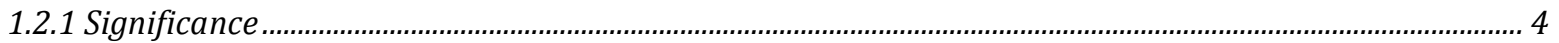

1.2.2 The Stress of Policing and Its Impact on Officer Health ….......................................................................... 5

1.2.3 Work Stress and Cardiovascular Disease: Identifying a Model .................................................................. 9

Figure 1. Conceptual framework of stress and disease............................................................................................................ 10

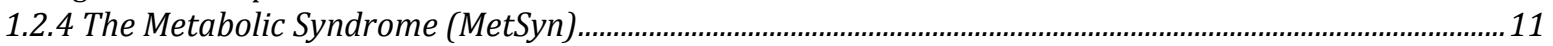

Table 1. Comparison of metabolic syndrome definitions.................................................................................................12

Figure 2. Interactions of MetSyn components in diabetes and cardiovascular disease...............................................14

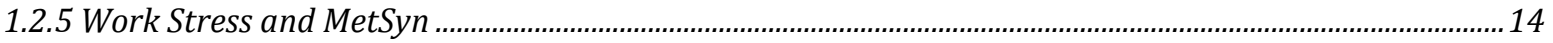

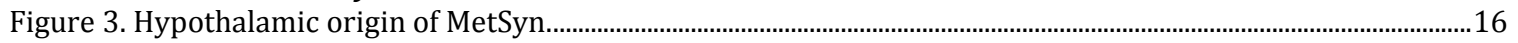

1.2.6 MetSyn and Subclinical Cardiovascular Disease ........................................................................................17

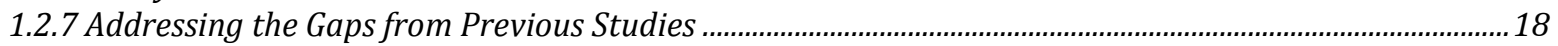

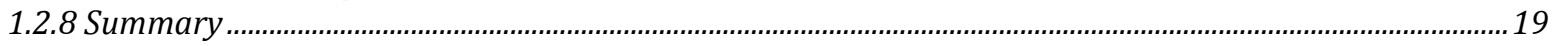

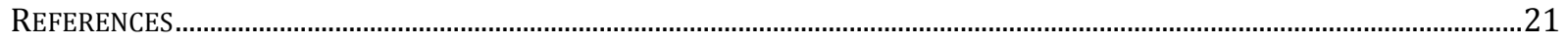

CHAPTER 2. ASSOCIATION BETWEEN POLICE OFFICER STRESS AND METABOLIC SYNDROME.............. 29

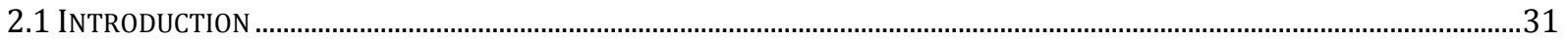

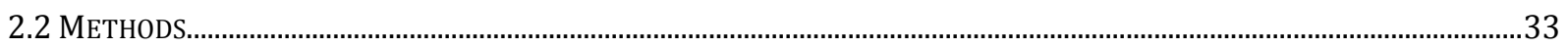

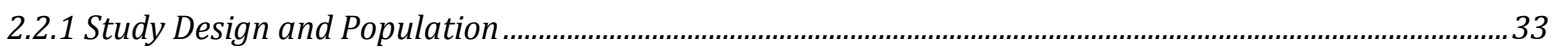

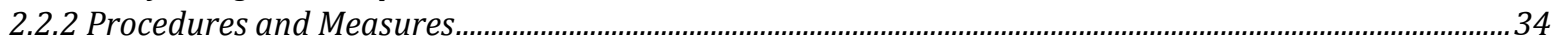

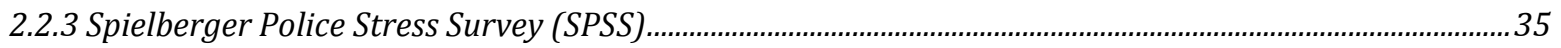

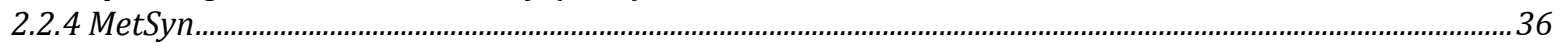

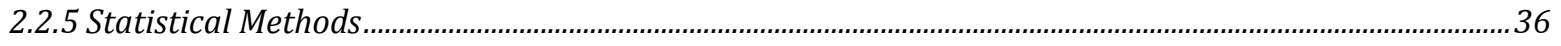

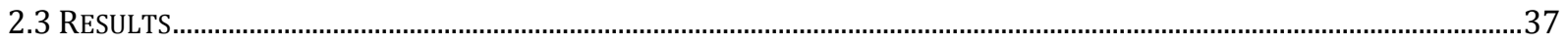

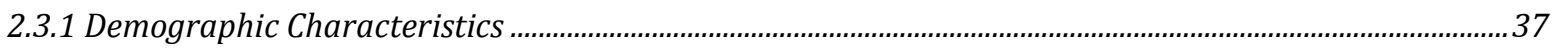

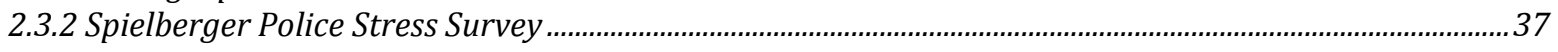

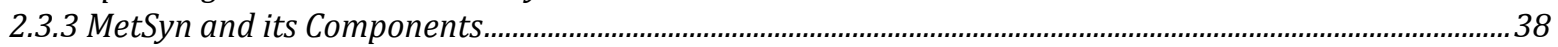

2.3.4 Association Between Police Stress and Number of MetSyn Components....................................................39

2.3.5 Odds Ratios for Individual MetSyn Components with Police Stress ..............................................................40

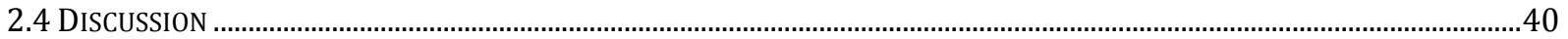

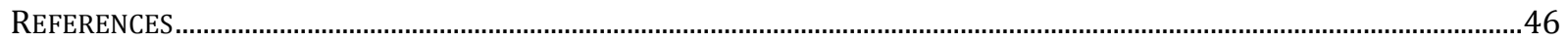

Table 2.1. Demographic and lifestyle characteristics by gender. .....................................................................................50

Table 2.2. Mean values of the Spielberger Police Stress Survey for the total and subscale scores by gender..........51

Table 2.3. Mean levels and prevalence of metabolic syndrome components by gender................................................52

Table 2.4a. Unadjusted and adjusted number of metabolic syndrome components by tertiles of Spielberger

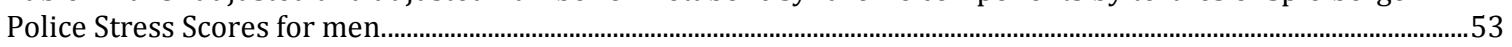

Table 2.4b. Unadjusted and adjusted number of metabolic syndrome components by tertiles of Spielberger

Police Stress Scores for women. .............................................................................................................................................. 54

Table 2.5. Multivariate adjusted* odds ratios for MetSyn components by Spielberger Police Stress score for

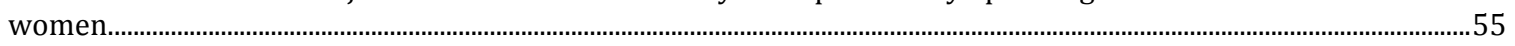

\section{CHAPTER 3. ASSOCIATION BETWEEN DEPRESSION AND METABOLIC SYNDROME AMONG TWO}

COHORTS OF POLICE OFFICERS ......................................................................................................... 56

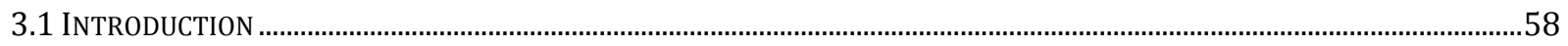

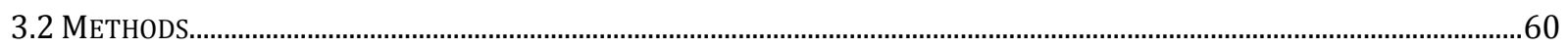

3.2.1 Buffalo Cardio-Metabolic Occupational Police Stress (BCOPS) Study .........................................................60

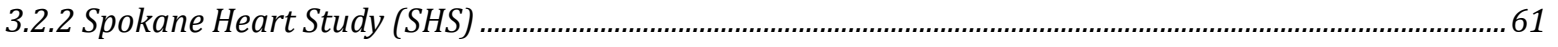

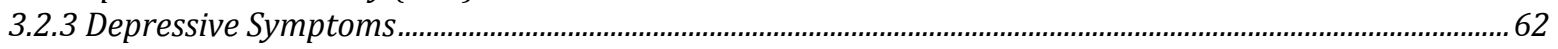

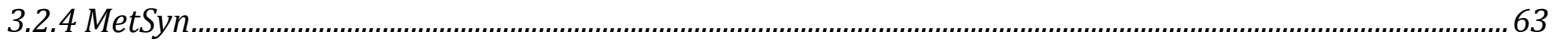

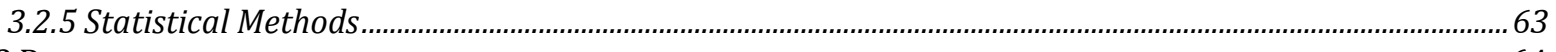

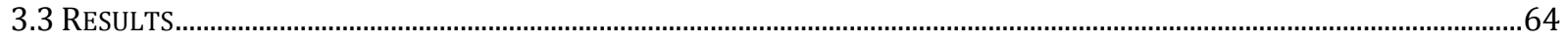

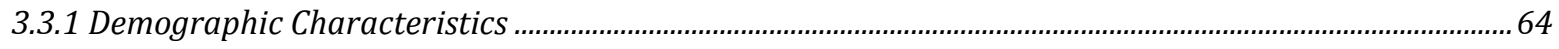




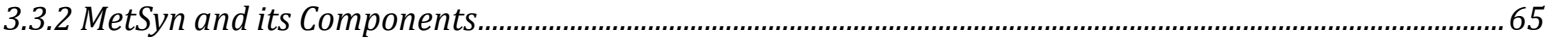

3.3.3 Association between Number of MetSyn Components and Categories of CES-D Score .............................66

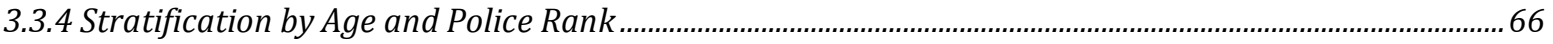

3.3.5 Odds Ratios for Individual MetSyn Components by CES-D Score ................................................................67

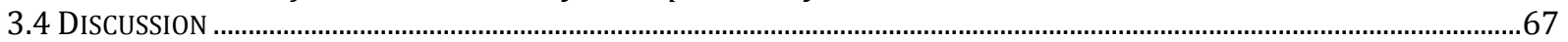

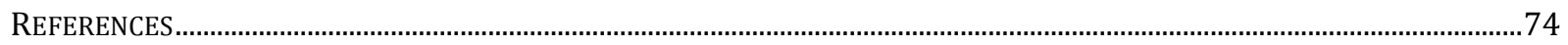

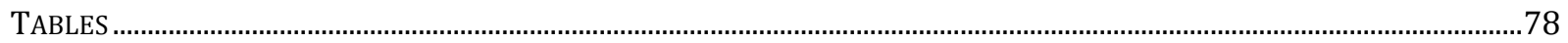

Table 3.1. Demographic characteristics by location and gender........................................................................................79

Table 3.2. Mean levels and prevalence of metabolic syndrome by gender and geographic location. ........................81

Table 3.3. Unadjusted and adjusted number of metabolic syndrome components by categories of CES-D score by

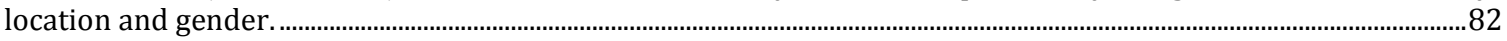

Table 3.4. Multivariate adjusted* number of metabolic syndrome components by categories of CES-D score by

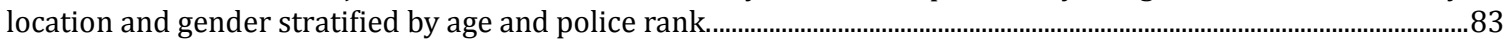

Table 3.5. Unadjusted and adjusted odds ratios for MetSyn components by CES-D score for Spokane men...........84

CHAPTER 4. METABOLIC SYNDROME AND CAROTID INTIMA MEDIA THICKNESS IN URBAN POLICE OFFICERS

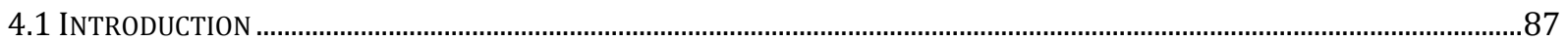

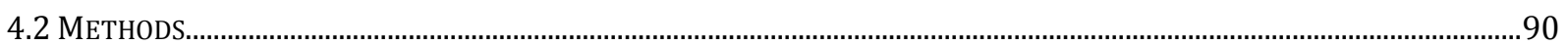

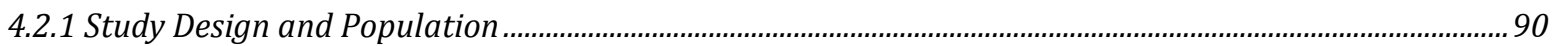

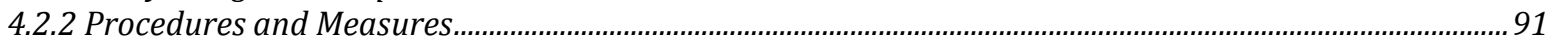

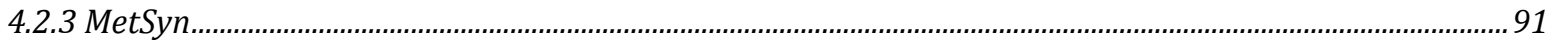

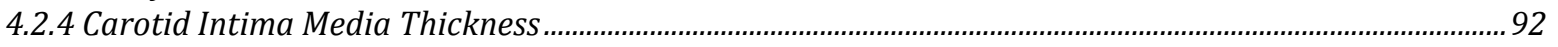

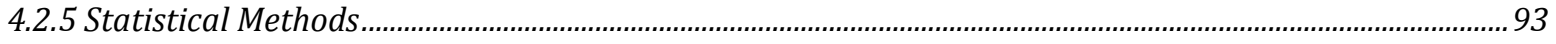

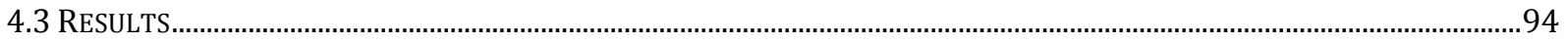

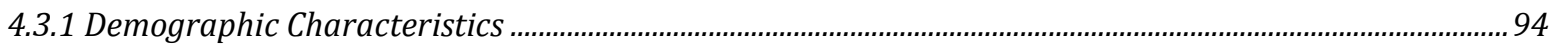

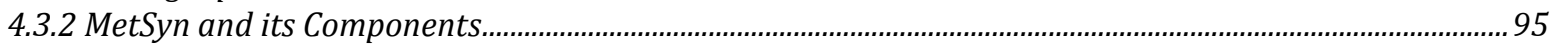

4.3.3 Association between Carotid IMT and Number of MetSyn Components....................................................95

4.3.4 Association between Carotid IMT and Individual MetSyn Components....................................................96

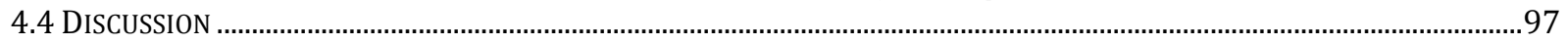

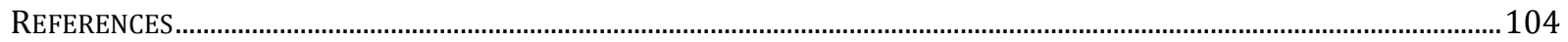

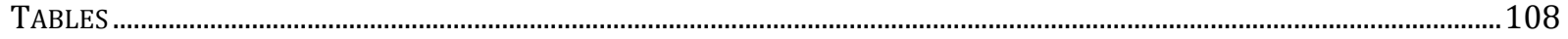

Table 4.1. Demographic characteristics and selected anthropometric, blood and ultrasound measures by gender.

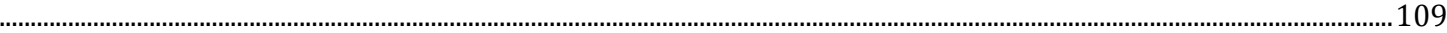

Table 4.2. Mean levels and prevalence of metabolic syndrome components by gender..........................................111

Table 4.3. Unadjusted and adjusted mean values of carotid artery thickness by number of metabolic syndrome components and gender......................................................................................................................................................112

Table 4.4. Unadjusted and adjusted mean values of carotid artery thickness by presence or absence of individual

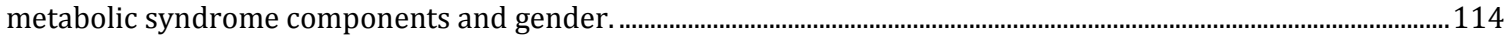

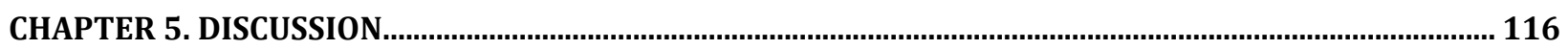

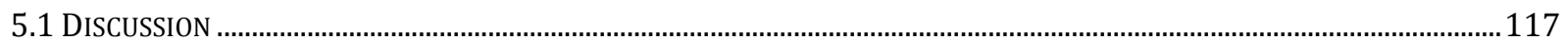

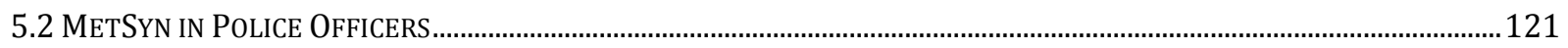

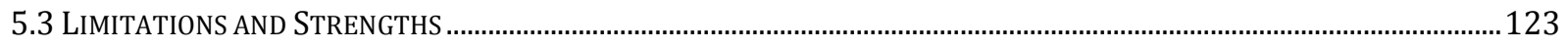

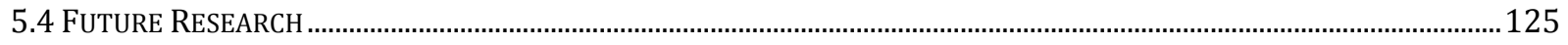

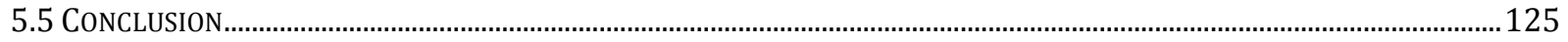

Table 5.1. Mean levels and prevalence of metabolic syndrome components by gender............................................131

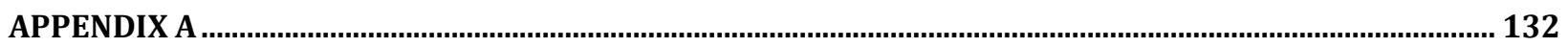

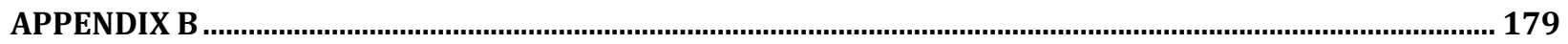

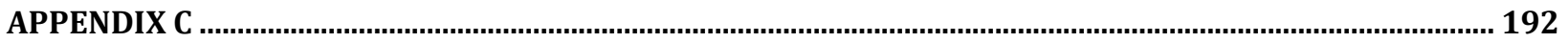


CHAPTER 1. INTRODUCTION 


\subsection{SPECIFIC AIMS}

Police officers are exposed to numerous types of stressors. These stressors range from traumatic events such as witnessing death or serious injury, to shift work and organizational issues including excessive paperwork and staffing shortages. ${ }^{1,2,3}$ The impact of this high rate of chronic stress can lead to chronic health problems, both physical and psychological. Police officers have been reported to have higher levels of cardiometabolic disease, elevated risk for and higher mortality rates of cardiovascular disease (CVD), higher cancer mortality rates, and higher suicide rates, although studies of the health effects of policing are limited. ${ }^{4-9}$

Numerous studies have found associations between work stress and CVD. ${ }^{10-13}$ In particular, Chandola and colleagues found a dose-response relationship between work stress and the metabolic syndrome (MetSyn), suggesting biological plausibility of a causal association. ${ }^{12}$ Work stress affects the autonomic nervous system and neuroendocrine activity directly contributing to MetSyn. ${ }^{12}$ MetSyn is a clustering of metabolic abnormalities, including abdominal obesity, hypertension, glucose intolerance and dyslipidemia, that has been associated with both CVD and Type II diabetes mellitus. ${ }^{14}$

The goal of this dissertation is to examine cross-sectional associations of MetSyn with psychological distress and subclinical CVD among police officers. The specific aims will determine whether the stressful events associated with police work and depressive symptomatology are associated with MetSyn, and whether MetSyn is associated with an established and valid measure of subclinical CVD. 
Specific Aim \#1: To characterize and compare the MetSyn and its individual components among police officers who participated in the Buffalo Cardio-Metabolic Occupational Police Stress (BCOPS) Study and the Spokane Heart Study.

Hypothesis \#1: Officers, regardless of location, will have a higher prevalence of MetSyn and its individual components than the general population.

Specific Aim \#2: To investigate the association between MetSyn, its individual components, and psychological distress.

Hypothesis \#2: The number of MetSyn components will increase across increasing levels of work stress.

Hypothesis \#3: The number of MetSyn components will increase across increasing levels of depressive symptoms.

Specific Aim \#3: To investigate the association between MetSyn, its individual components, and carotid intima media thickness (IMT) among the BCOPS Study participants.

Hypothesis \#4: A dose-response relationship will be observed for MetSyn and carotid IMT such that carotid IMT increases in a stepwise fashion with increasing number of MetSyn components.

Police officers are a vital part of every community in the United States. Understanding the impact of work stress on the physical and psychological health of police officers is a significant public health need, yet they are an understudied occupational cohort. ${ }^{15}$ The types of early or subclinical measures (i.e. depressive symptomatology, MetSyn, carotid IMT) proposed in the 
current study would optimize the ability to discover associations if they exist. If the hypotheses are correct, this would serve as a basis for creating prevention programs to intervene before overt symptoms or disease is present. This would increase the likelihood of improving police officer physical and mental health and decrease the health consequences of work stress.

\subsection{BACKGROUND AND SigNIFICANCE}

\subsubsection{SIGNIFICANCE}

What is it about policing that is stressful? In June 2008, Dr. Cecil Burchfiel, Dr. John Violanti, and I posted the topic "Police and Stress" to the NIOSH Science Blog (http://www.cdc.gov/niosh/blog/nsb063008_policestress.html) asking the public this very question. Here are a few of the comments received.

"We believe the greatest stressors on a police officer are of the "cumulative" kind. Traditional belief (and current prevention programs) holds that those in greatest danger of suicide are those who are involved in catastrophic trauma, such as shootings, multiple-death accidents, loss of a child, etc. We are noting the contrary, based on this year's experience that suicides are generally unexpected and/or no precipitating event is identified."

"The biggest stressors were the administration... Rotating shifts were a big issue and the cause of much of the police stress within the family and the officer, working conditions, and the body not being able to adapt... The health issues from police job stress remain with most officers until they draw their last breath. Much of the officers' stress is brought about by not being able to effectively communicate with others, namely their significant other, more likely than not trying to shield them from some of the gruesome events encountered."

"I am 39.7 years old, I have over ten years on the job. It's true. I get more tension and stress from the Management (at) my Dept, THAN I DO DEALING WITH GANG MEMBERS in the streets..."

Police officers were eager to share the types and severity of health problems they encounter and attribute to policing. 
"My husband... has over 30 years on the 'Force' [and] ... has been diagnosed with sleep apnea, depression, hypertension, acid reflux in abundance, and does not know how to relax."

"I am a retired California Highway Patrol officer and am currently being treated by a LMFC for anxiety and PTSD...I suffer from sleep apnea/snoring, hypertension, excessive weight with weight loss being very difficulty, even with exercise and diet. I was borderline diabetes at one point, but am OK now."

"As for me after 20+ years of civil service I have high blood pressure/hypertension (controlled with meds) un[known] stress disorder (controlled by will power, diet, exercise and rest)... and numerous failed relationships...nobody understands US but US."

\subsubsection{THE STRESS OF POLICING AND ITS IMPACT ON OFFICER HEALTH}

In general, emergency responders, including police officers, are reported to be relatively healthy, yet policing is widely recognized as one of the most dangerous and stressful occupations., ${ }^{3,16-20}$ Exposure to potentially traumatic and life threatening events, such as public disorder and violence, traumatic events and human misery and injury or death of oneself or a fellow officer, is dangerous but it is part a police officer's professional duty. ${ }^{2,16,21}$ Policing is stressful due to the combination of these traumatic events and the more organizational aspects (e.g. high demand/low control, shift work, and frequent contact with the general public). ${ }^{2,19}$ The scientific literature identifies numerous sources of police officer stressors and there is lengthy debate as to the type of event that is most stressful.

Inherent stressors have the highest potential for psychological trauma. ${ }^{2,22}$ According to previous research, the most stressful include hostage situations, arresting a violent perpetrator, shootings particularly if it results in injury or death of a fellow officer or self, involvement in a hostage crisis, the arrest of a violent perpetrator, and threats to themselves. ${ }^{19,23-25}$ In their survey of 103 
police officers, Violanti and Aron found the top work stressors to be killing someone while on duty, physical attack, seeing abused children, and as supported by Gershon et al. the most stressful experience is the death of a fellow officer. ${ }^{19,22}$ These inherent traumatic stressors ranked higher than organizational stressors such as shift work and work load and appear to predispose officers to post-traumatic stress disorder (PTSD). ${ }^{3,17,22,26-28}$ Additionally, the traumatic event may affect sleep quality and overall physical health, increasing the likelihood of physical injury to the officer, other officers, or the public. ${ }^{29}$

Another source of police officer stress involves the internal police organization. This includes lack of supervisor and coworker support, insufficient manpower, job insecurity, insufficient pay and excessive paperwork. ${ }^{2,19,21,30}$ Previous research has indicated that organizational stressors are perceived to be more stressful to officers than the operational aspects of the job. ${ }^{2,18,31}$ Violanti and Aron found that organizational stressors increased psychological distress over six times more than the operational or inherent stressors. ${ }^{31}$

Shift work and extended working hours are integral components of policing and among the most difficult requirements of the job. ${ }^{19}$ Officers must contend with off-duty court appearances, working double shifts, shift changes, and the demands for additional training and education. ${ }^{32,33}$ These features have both physical and psychological consequences for the officer. First, officers who work shifts are constantly rearranging their awake and sleep times leading to decreased sleep quantity and quality, circadian rhythm disruption, internal de-synchronization and subsequent health problems, including fatigue, depression, hypertension, metabolic syndrome (MetSyn), Type II diabetes mellitus and CVD. ${ }^{10,34-40}$ In addition, officers lose opportunities to be 
with their families at night and on weekends resulting in a negative attitude toward their job. ${ }^{21,35,41}$ This negative attitude has been associated with more sleep complaints, poor self-rated health, poor recovery and stress. ${ }^{34,41,42}$ Work stress can have a strong impact on the vitality of the police department. ${ }^{19}$ Previous studies have found associations between work stress and job dissatisfaction, reduced productivity, absenteeism, high turnover, early retirement, high accident rates, poor public relations, a high incidence of lawsuits, and inappropriate behavior putting themselves, their coworkers and the general public at risk. ${ }^{19,21}$

Regardless of its origins, perceived stress among police officers can be a significant predictor of future health consequences. ${ }^{43}$ Perceived work stress has been shown to be significantly associated with anxiety, depression, somatization, PTSD, burnout, chronic back pain, alcohol abuse, hypertension, and inappropriately aggressive behavior. ${ }^{19}$ Belkic et al. suggested a doseresponse relationship exists between greater job strain and greater risk for development of CVD. ${ }^{10}$ While studies have identified policing as a stressful occupation, few studies have explored the effects of the police stressors on the long-term physical and emotional well-being of officers. ${ }^{16}$ Yet officers acknowledge the link between policing and poor health: $38 \%$ of officers believe employment as a police officer, particularly the stress of policing, increased their CVD risk. ${ }^{4}$ Franke et al. found that among police officers there was an association between greater perceived stress and CVD prevalence and its risk factors and that duration of time in policing, and not aging alone, contributed to CVD and higher perceived stress levels. ${ }^{20}$ In a separate study of police women, $68 \%$ felt being a police officer, and $42 \%$ felt that being a police officer and being female contributed to their risk of chronic disease. ${ }^{44}$ 
Police officers have been reported to have more adverse CVD risk factor profiles, higher prevalence rates of CVD, and higher CVD mortality than the general population. ${ }^{4,7,45,46}$ Franke et al. found that officers had a higher prevalence of obesity, hypercholesterolemia, and hypertension compared to a general population. ${ }^{20}$ Approximately three-quarters of emergency responders, including police officers, have elevated blood pressure (prehypertension or hypertension) and are overweight or obese. ${ }^{45}$ Several studies have found that police officers have a significantly elevated risk for, higher incidence of, and higher mortality rates from arteriosclerotic heart disease. ${ }^{4,6-8,46}$ Specifically, Vena, et al. found that Buffalo, NY police officers had increased mortality rates from arteriosclerotic heart disease, and Violanti et al. found that the average age of death was nine years younger for Buffalo police officers compared with the general population (66 vs. 75 years). ${ }^{5,15}$ Previous studies have found younger officers and those with fewer years of service to have higher rates of CVD, indicating greater susceptibility of CVD among police officers early in their careers. ${ }^{15,46,47}$

Not surprisingly, police officers frequently experience chronic psychological disorders, including depression and PTSD. Collins and Gibbs found $41 \%$ of police officers had stress-related mental ill-health and that the proportion of British police officers with measurable mental illness had doubled over the past 10 years. ${ }^{18}$ In that same study, they reported that over one-quarter of all medical retirements were due to psychological ill-health. ${ }^{18}$ Police officers exposed to the Amsterdam air disaster reported significantly more PTSD symptoms and psychological distress over eight years after the disaster compared to non-exposed officers. ${ }^{17}$ Chronic psychological stress is associated with the development of depression. ${ }^{21}$ Chen et al. found that work and family problems were the strongest predictors of depression. ${ }^{21}$ Work problems were related to 
competition, honor and high workloads, and interestingly, the family problems were an indirect result of their work and included having little time to spend with family and child-rearing problems. ${ }^{21}$ Depression has been linked with increased risk of CVD outcomes; depressed individuals are 1.5 to 2.0 times more likely to die from CVD than non-depressed individuals. ${ }^{48-53}$ Further, individuals with major depressive disorder were between three times more likely to die of cardiac causes compared with those who did not have depression. ${ }^{54}$

\subsubsection{WORK STRESS AND CARDIOVASCULAR DISEASE: IDENTIFYING A MODEL}

Conceptual frameworks for the relationship between work stress and poor health outcomes have been in existence for decades. One framework by Israel and colleagues demonstrates a complex, dynamic process where stressors, perceived stress, short-term responses and modifying factors are intertwined and may result in long-term health outcomes (See Figure 1). ${ }^{55}$ As described above, officers may experience a myriad of potential stressors. According to Israel, events become "stressors" if they are perceived by the officer as harmful, threatening or bothersome, or if they result in a physiological adaptational response. ${ }^{55}$ The perceived severity of the event is influenced by its intensity, chronicity, complexity, novelty, ambiguity, unpredictability and uncontrollability and thus is dependent upon the individual. 


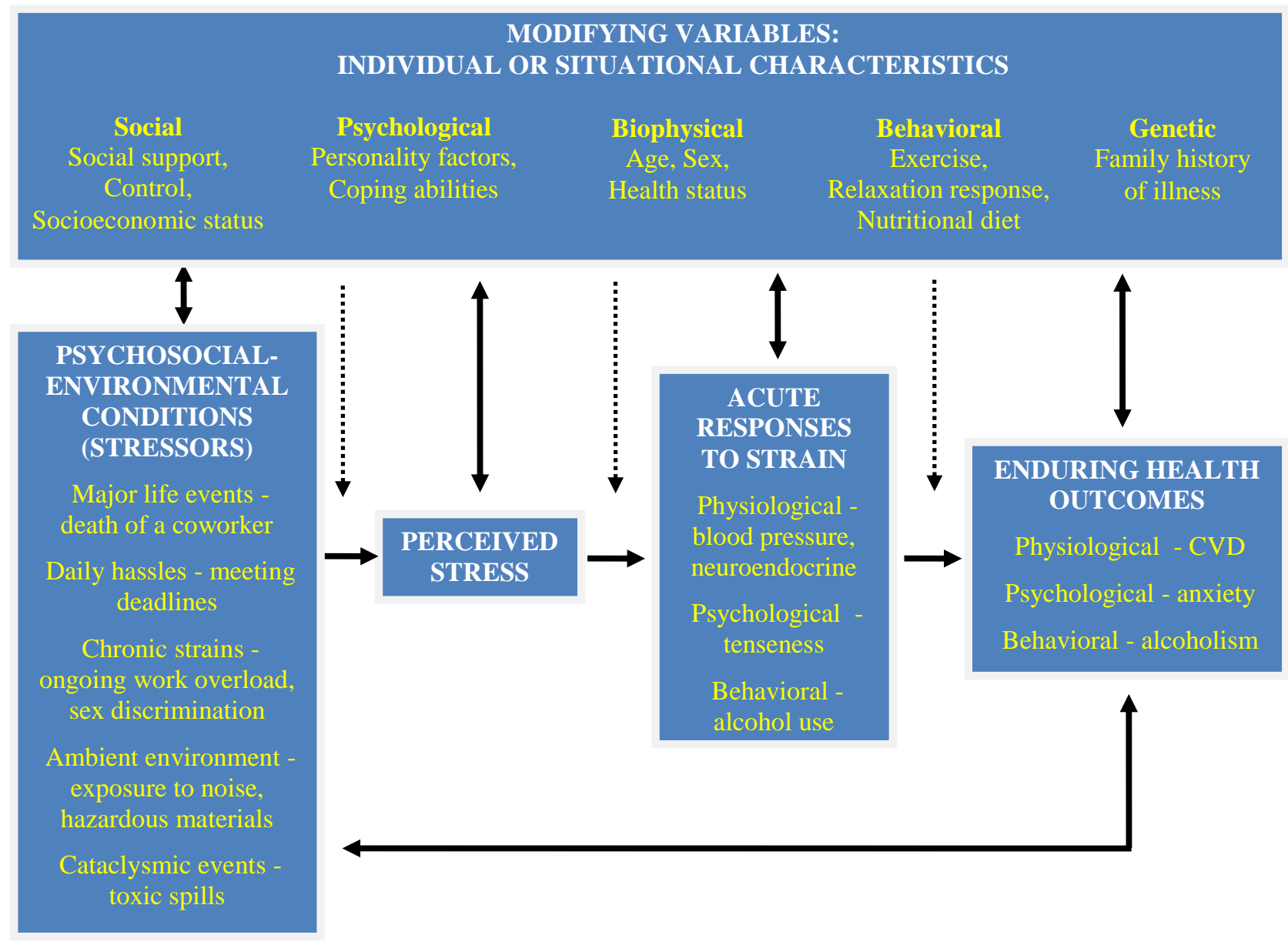

\section{Figure 1. Conceptual framework of stress and disease.}

Source: Israel BA, Baker EA, Goldenhar LM, et al. Occupational stress, safety and health: Conceptual framework and principles for effective prevention interventions. J Occup Health Psychol. 1996;1(3):261-286.

Events that lead to perceived stress can have acute and/or chronic physiological, psychological or behavioral responses. Physiological responses include autonomic nervous system and neuroendocrine mediators that influence most major organ systems and result in a broad range of somatic dysfunction. Psychological responses can either place an individual at a heightened risk for depression or heighten their perception of self as sick. Behavioral responses include altered eating and sleeping patterns or heavier consumption of alcohol. Acute responses include a rise in blood pressure or heart rate, or difficulty sleeping, yet the individual recovers from such 
responses rather quickly if the stress is alleviated. Long-term responses can lead to negative health outcomes, such as CVD, depression and alcoholism. Modifying factors, such as coping strategies, social support and an individual's genetic makeup, can directly affect any of the components or the relationship of the components to each other. ${ }^{19,55}$ These can be adaptive such as making a plan of action for addressing a particular situation, or maladaptive such as cigarette smoking or alcohol abuse. ${ }^{19}$ Therefore, no stressor is likely to have the same effect on everyone exposed to it; rather, certain individual or situational factors modify how an individual experiences the stress process.

\subsubsection{THE METABOLIC SYNDROME (METSYN)}

The concept of MetSyn was first proposed by Kylin in the 1920s as the clustering of hypertension, hyperglycemia and gout. ${ }^{56}$ In 1988 , Reaven identified insulin resistance as the driving force for developing the syndrome, which he referred to as "syndrome X" and included impaired glucose intolerance, hyperinsulinemia, reduced high-density lipoprotein cholesterol (HDL-C), increased very low-density lipoprotein triglycerides and arterial hypertension. ${ }^{57}$ Additional national and international definitions of the MetSyn have been proposed over the past ten years (See Table 1). ${ }^{58}$ The most widely used definition of the MetSyn in the United States is the National Cholesterol Education Program Adult Treatment Panel III. ${ }^{14}$ In 2005 the American Heart Association and the National Heart, Lung, and Blood Institute, National Institutes of Health issued a joint scientific statement along with revised criteria for defining the MetSyn. The criteria, which includes the same five components in the NCEP ATP III but with stricter cutpoints, are abdominal obesity (gender-specific waist circumference), impaired fasting blood 
glucose, elevated triglycerides, elevated blood pressure, and reduced gender-specific HDL cholesterol. $^{59}$

Table 1. Comparison of metabolic syndrome definitions.

\begin{tabular}{|c|c|c|c|c|c|c|}
\hline $\begin{array}{l}\text { Guide- } \\
\text { line }\end{array}$ & Glucose/insulin abnormality & $\begin{array}{l}\text { Obesity/central } \\
\text { adiposity }\end{array}$ & Dyslipidemia & $\begin{array}{l}\text { Hypertension } \\
\text { (with or without } \\
\text { medication) }\end{array}$ & Other & $\begin{array}{l}\text { Minimum } \\
\text { criteria for } \\
\text { diagnosis }\end{array}$ \\
\hline $\begin{array}{l}\text { WHO } \\
(1999)^{3}\end{array}$ & $\begin{array}{l}\text { Type } 2 \text { diabetes, impaired } \\
\text { fasting glucose (FBG } \\
\geq 6.1 \text { mmol/h), impaired } \\
\text { glucose tolerance ( } 2 \mathrm{~h} \text { PPG } \\
\geq 7.8 \mathrm{mmol} / \mathrm{h}) \text {, or lowest } 25 \% \text { for } \\
\text { hyperinsulinemic euglycemic } \\
\text { clamp-glucose uptake }\end{array}$ & $\begin{array}{l}\text { Waist-to-hip ratio } \\
>0.9(\mathrm{M}) \text { or }>0.85(\mathrm{~F} \\
\text { and/or } \mathrm{BM}=30 \mathrm{~kg} / \mathrm{m}^{2}\end{array}$ & $\begin{array}{l}\text { Triglycerides } \\
\geq 1.7 \mathrm{mmol} / \\
\text { and/or } \mathrm{HDL}-\mathrm{C} \\
<0.9 \mathrm{mmoh} / \mathrm{M}) \\
\text { or }<1.0 \mathrm{mmol} / \mathrm{F})\end{array}$ & $\begin{array}{l}\mathrm{BP} \\
\geq 14 \mathrm{Q} / 90 \mathrm{mmHg} \\
\text { (and/or } \\
\text { medication) }\end{array}$ & $\begin{array}{l}\text { Microalbuminuria } \\
(\geq 20 \mu \mathrm{g} / \mathrm{min} \\
\text { albumin excretion } \\
\text { rate or albumin: } \\
\text { creatinine ratio } \\
\geq 30 \mathrm{mg} / \mathrm{g})\end{array}$ & $\begin{array}{l}\text { Glucose } \\
\text { intolerance/ } \\
\text { insulin } \\
\text { resistance, } \\
\text { plus two } \\
\text { other } \\
\text { features }\end{array}$ \\
\hline $\begin{array}{l}\mathrm{EGIR}^{\mathrm{a}} \\
(1999)^{6}\end{array}$ & $\begin{array}{l}\text { Insulin resistance: } \\
\text { hyperinsulinemia (nondiabetic } \\
\text { fasting insulin in top 25\%) } \\
\text { and impaired fasting glucose } \\
\text { (FBG } \geq 6.1 \mathrm{mmol} / \mathrm{\text {) }}\end{array}$ & $\begin{array}{l}\text { Waist circumference } \\
\geq 94 \mathrm{~cm} \text { (M) or } \\
280 \mathrm{~cm} \text { (F) }\end{array}$ & $\begin{array}{l}\text { Triglycerides } \\
>2 \mathrm{mmol} / / \text { and/or } \\
\mathrm{HDL}-\mathrm{C}<1.0 \mathrm{mmol} / \mathrm{l}\end{array}$ & $\begin{array}{l}\mathrm{BP} \\
\geq 140 / 90 \mathrm{mmHg} \\
\text { (and/or } \\
\text { medication) }\end{array}$ & - & $\begin{array}{l}\text { Insulin } \\
\text { resistance, } \\
\text { plus two } \\
\text { other } \\
\text { features }\end{array}$ \\
\hline $\begin{array}{l}\text { NCEP } \\
\text { ATP III } \\
(2001)^{4}\end{array}$ & $\begin{array}{l}\text { Impaired fasting glucose (FBG } \\
\geq 6.1 \mathrm{mmo} / / \text { ) }\end{array}$ & $\begin{array}{l}\text { Waist circumference } \\
>102 \mathrm{~cm}(\mathrm{M}) \text { or } \\
>88 \mathrm{~cm}(\mathrm{~F})\end{array}$ & $\begin{array}{l}\text { Triglycerides } \\
\geq 1.69 \mathrm{mmol} / \mathrm{HDL}-\mathrm{C} \\
<1.04 \mathrm{mmol} /(\mathrm{M}) \text { or } \\
<1.29 \mathrm{mmol} / \mathrm{F})\end{array}$ & $\begin{array}{l}\mathrm{BP} \\
\geq 130 / \geq 85 \mathrm{mmHg} \\
\text { (and/or } \\
\text { medication) }\end{array}$ & - & $\begin{array}{l}\text { Any three } \\
\text { features }\end{array}$ \\
\hline $\begin{array}{l}\text { AACE } \\
(2003)^{7}\end{array}$ & $\begin{array}{l}\text { Glucose intolerance (FBG } \\
\geq 6.1 \mathrm{mmol} / / \text { or } 2 \mathrm{~h} \mathrm{PPG} \\
>7.8 \mathrm{mmo} / / \text { ) }\end{array}$ & $\mathrm{BMI} \geq 25 \mathrm{~kg} / \mathrm{m}^{2}$ & $\begin{array}{l}\text { Triglycerides } \\
\geq 1.69 \mathrm{mmol} / \mathrm{HDL}-\mathrm{C} \\
<1.04 \mathrm{mmol} /(\mathrm{M}) \text { or } \\
<1.29 \mathrm{mmol} / \mathrm{F})\end{array}$ & $\begin{array}{l}\mathrm{BP} \\
\geq 130 / \geq 85 \mathrm{mmHg}^{\mathrm{b}}\end{array}$ & $\begin{array}{l}\text { Family history } \\
\text { of or high-risk } \\
\text { ethnic group for } \\
\text { type } 2 \text { diabetes, } \\
\text { hypertension or } \\
\text { CVD; polycystic } \\
\text { ovarian syndrome; } \\
\text { sedentary lifestyle; } \\
\text { advancing age }\end{array}$ & $\begin{array}{l}\text { Clinical } \\
\text { judgment } \\
\text { based on } \\
\text { all features }\end{array}$ \\
\hline $\begin{array}{l}\text { IDF } \\
(2005)^{5}\end{array}$ & $\begin{array}{l}\text { Glucose intolerance (FBG } \\
25.6 \mathrm{mmol} / / \text { ) or pre-existing } \\
\text { diabetes }\end{array}$ & $\begin{array}{l}\text { Waist circumference: } \\
\text { European } \geq 94 \mathrm{~cm}(\mathrm{M}) \\
\text { or } \geq 80 \mathrm{~cm} \text { (F); South } \\
\text { Asian and Chinese } \\
\geq 90 \mathrm{~cm}(\mathrm{M}) \text { or } \geq 80 \mathrm{~cm} \\
\text { (F); Japanese } \geq 85 \mathrm{~cm} \\
\text { (M) or } \geq 90 \mathrm{~cm} \text { (F) }\end{array}$ & $\begin{array}{l}\text { Triglycerides } \\
\geq 1.7 \mathrm{mmoh}, \mathrm{HDL}-\mathrm{C} \\
<1.0 \mathrm{mmoh} /(\mathrm{M}) \text { or } \\
<1.3 \mathrm{mmoh} / \mathrm{F})\end{array}$ & $\begin{array}{l}B P \\
\geq 130 / 285 \mathrm{mmHg} \\
\text { (and/or } \\
\text { medication) }\end{array}$ & - & $\begin{array}{l}\text { Central } \\
\text { adiposity } \\
\text { plus two } \\
\text { other } \\
\text { features }\end{array}$ \\
\hline
\end{tabular}

Source: Pollex RL, Hegel RA. Genetic determinants of the metabolic syndrome. Nature Clin Prac Card Med. 2006;3(9):482-9.

From a clinical perspective it is important to consider serum cholesterol or blood pressure individually for prevention or treatment. However, from an epidemiologic perspective, summary indices of risk, such as the MetSyn, provide a more global assessment of disease that individual risk factors do not capture. ${ }^{60}$ It is estimated that approximately 47 million or $22 \%$ American adults have MetSyn, including approximately $25 \%$ of adults over age 20 and $45 \%$ of those over age $50 .{ }^{61,62}$ In the United States, the prevalence of MetSyn is on the rise. ${ }^{63}$ In a study of healthy males and females, Adolphe and colleagues found the prevalence to be around $17 \% .{ }^{64}$ A study of 
male police officers found the prevalence of MetSyn to be $27.4 \%$; while a study of Indian police officers found the prevalence to be $57 \% .^{65,66}$

Studies utilizing the various MetSyn definitions have found associations of the prevalence of MetSyn and increased number of MetSyn components with type II diabetes, CHD, CVD, target organ damage, cardiovascular and all-cause mortality. ${ }^{67-71}$ A recent meta-analysis of twenty-one studies found an increased incidence of CVD, CHD and stroke among individuals with MetSyn compared to those without the syndrome. ${ }^{72}$ An 11-year follow-up of the Atherosclerosis Risk in Communities (ARIC) study found that men and women with MetSyn were approximately 1.5 to 2 times more likely to develop CHD than those without the syndrome after adjustment for age, smoking, LDL cholesterol, and race. ${ }^{73}$ In the 22-year follow-up of the Helsinki Policemen Study, Pyorala and colleagues found insulin resistance was a significant predictor of CHD and stroke. ${ }^{74}$

Figure 2, adapted from Lusis and colleagues demonstrates how the interactive effects of each of the five MetSyn components (indicated in the green boxes) lead to CVD and diabetes. ${ }^{57}$ Visceral adiposity stimulates the production of triglycerides and lowers HDL-cholesterol, excess fat leads to a pro-inflammatory state, and excess adipose tissue increases the release of free fatty acids and cytokines. Insulin resistance activates the sympathetic nervous system resulting in a rise in blood pressure and beta cells become impaired as they attempt to compensate. These changes ultimately result in atherosclerosis, a precursor to stroke, myocardial infarction, and heart failure. $^{57}$ 


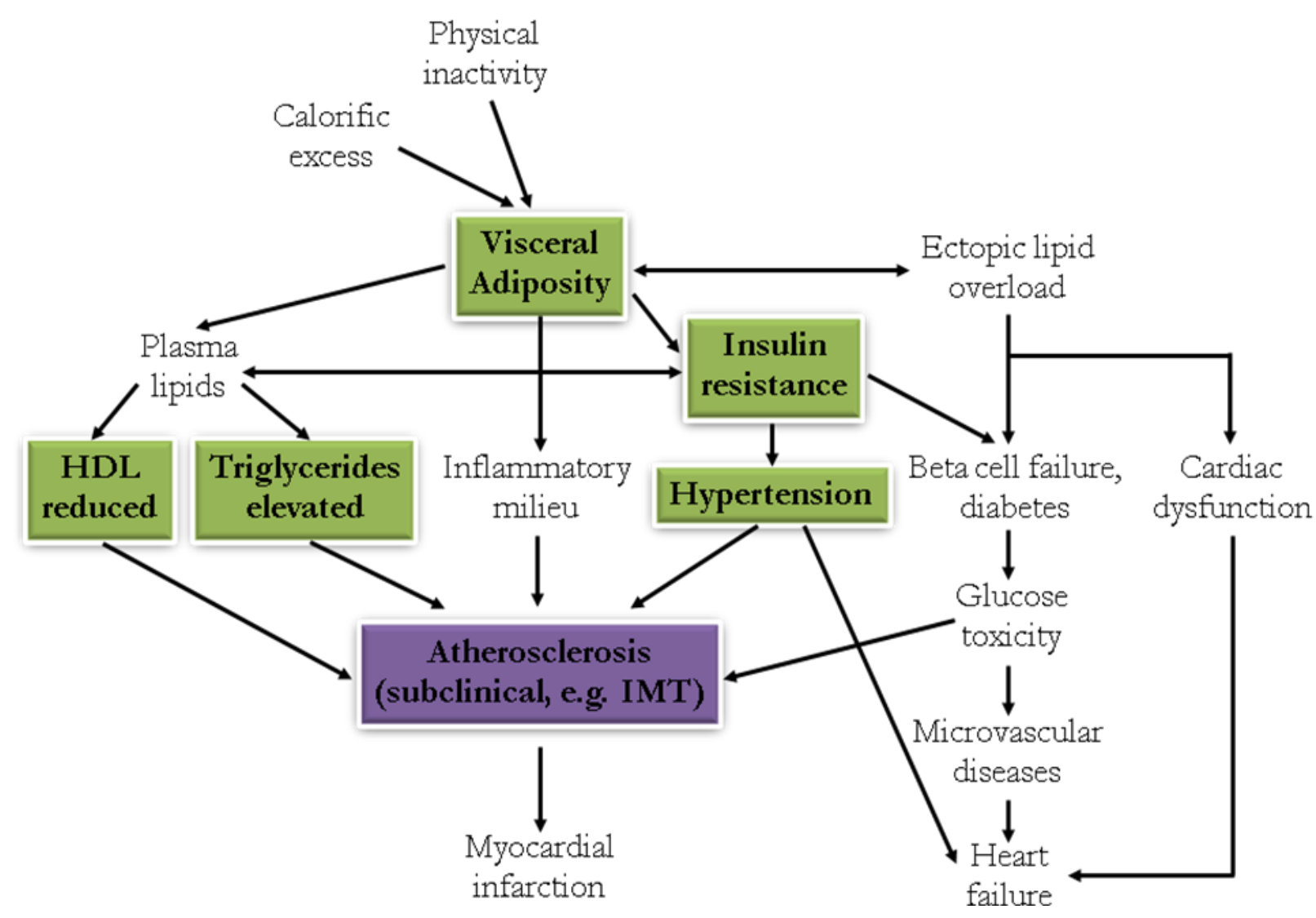

Figure 2. Interactions of MetSyn components in diabetes and cardiovascular disease.

Source: Lusis AJ, Attie AD, Reue K. Metabolic syndrome: from epidemiology to systems biology. Nature Reviews Genetics. 2008;9:820.

\subsubsection{WORK STRESS AND METSYN}

Previous studies have found associations between work-related stress and CVD, and several researchers have suggested that the relationship between work-related stress and CVD is mediated by MetSyn. ${ }^{60,75}$ Positive associations have been found between various stressors (i.e. chronic work stress, change in job type) and MetSyn. ${ }^{12,76}$ Chandola and colleagues found that $16 \%$ of the effect of work stress on CHD was explained by MetSyn.$^{77}$ In the Whitehall II study, men with three or more exposures of chronic work stress were more than twice as likely to 
develop MetSyn as those with no work stress, while women with chronic work stress were over five times more likely to develop MetSyn; this dose response relationship may reflect the

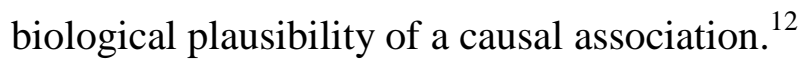

Several potential mechanisms between work stress and MetSyn have been proposed. The most frequently cited mechanism is a neuroendocrine response - overactivation of the hypothalamicpituitary-adrenal (HPA) axis (See Figure 3). Chronic stress leads to hypothalamic arousal resulting in continuous HPA axis stimulation and excess cortisol secretion. ${ }^{78}$ Excess cortisol is associated with low HDL-C and glucose intolerance, and stimulates fat accumulation leading to lipid abnormalities and general and central obesity. ${ }^{79-83}$ Moreover, excess cortisol is also associated with a variety of clinical endpoints, including depression, diabetes and CVD. ${ }^{53,84-86}$ Hypothalamic arousal can also lead to autonomic nervous system dysregulation. Specifically, increased sympathetic nervous system activity may cause systemic production of the catecholamines epinephrine and norepinephrine resulting in central adiposity, increased insulin resistance and hypertension. ${ }^{12,78}$

Inflammation may also play a key role in the association between work stress and MetSyn. White blood cell counts and fibrinogen levels rise with increased stress and promote platelet activation leading to atherosclerotic plaque formation. ${ }^{13}$ Perceived stress may increase proinflammatory cytokines, such as interleukin (IL)-1 and IL-6, leading to hypertriglyceridemia, reduced HDL-C, insulin resistance, vascular damage and increased C-reactive protein. ${ }^{13,78} \mathrm{CRP}$ has been shown to promote insulin resistance, hypertriglyceridemia and hypertension, and may 
be a considered a hallmark of MetSyn and a more specific marker of CV risk than other inflammatory markers. ${ }^{78}$

A possible indirect mechanism is having poor health behaviors. Reactions to work stress may lead to unfavorable changes in health behaviors, including adoption of a sedentary lifestyle, excessive alcohol intake, poor nutrition or inadequate sleep. These behaviors may be used as coping mechanisms for work stress and each health behavior has been associated with MetSyn. ${ }^{11,12,77}$

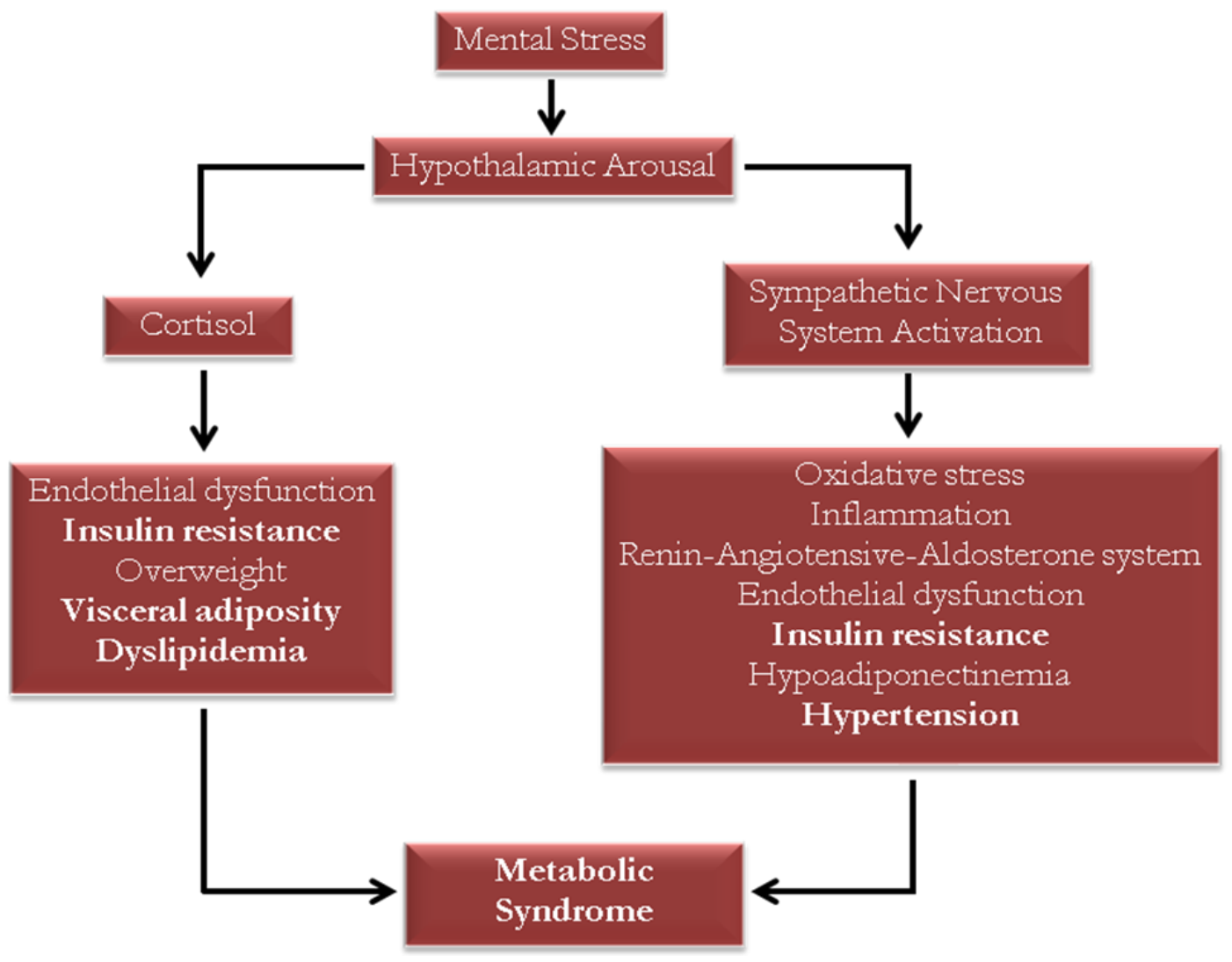

Figure 3. Hypothalamic origin of MetSyn.

Source: Levine TB, Levine AB. Mental stress and the metabolic syndrome. In: Metabolic syndrome and cardiovascular disease. pp. 37-88. Philadelphia, PA: Saunders 2006. Bjorntorp P, Rosmond R. Hypothalamic origin of the metabolic syndrome X. Ann NY Acad Sci. 1999;892;297-307. 


\subsubsection{METSYN AND SUBCLINICAL CARDIOVASCULAR DISEASE}

Endothelial damage and thickening of the intima media layers of the arterial wall are early atherosclerotic events. ${ }^{87}$ Alterations in vascular structure, including increased arterial wall thickness, are increasingly recognized as significant independent predictors of adverse cardiovascular outcomes. ${ }^{88,89}$ As a result, carotid intima media thickness (IMT) is considered a valid index of subclinical atherosclerosis, a precursor of overt atherosclerosis, and a predictor of CHD and ischemic stroke. ${ }^{69,90,91}$ Carotid IMT is defined as the combined thickness of the intima and media layers of the arterial wall and is obtained by B-mode ultrasound. It is used as a structural subclinical marker for atherosclerosis and CVD and has been demonstrated to be a useful tool in predicting clinical CVD outcomes like myocardial infarction and stroke, and in monitoring the progression of arterial wall thickening over time ${ }^{87,92-97}$ Increased carotid IMT has been associated with a history of hypertension, diabetes and cigarette smoking in male Canadian firefighters, and with various measures of work stress (i.e. job strain, work organization, work demand, work control, and decision latitude)..$^{98-103}$

As shown in Figure 2 above, all five of the MetSyn components are directly or indirectly linked to atherosclerosis. Therefore, MetSyn has been considered to be a strong predictor in the progression of carotid IMT. ${ }^{97,104-107}$ Recent studies have found that the association between MetSyn and carotid IMT is more pronounced in women than in men. ${ }^{108,109}$ Individual MetSyn components, most frequently elevated blood pressure, have been independently associated with carotid IMT. ${ }^{69,90,104,106,110-115}$ 


\subsubsection{ADDRESSING THE GAPS FROM PREVIOUS STUDIES}

Based on the review of the scientific literature, several gaps and inconsistencies are evident. One of the proposed studies in this dissertation will utilize a validated measure of specific police stressors that other studies have lacked, a weakness noted by Berg and colleagues. ${ }^{26}$ Franke et al also acknowledged that a limitation of his police officer study was that the Perceived Stress Scale did not allow for the identification of specific sources of police stress. ${ }^{20}$ Using the Spielberger Police Stress Scale will provide the opportunity to identify the types and frequencies of stressors experienced by the officers in association with MetSyn.

Previous studies have examined the effects of stressors on clinical CVD and CVD mortality in the general population. Fewer studies have examined the association between MetSyn and subclinical CVD particularly in known high stress occupational cohorts. Even fewer have explored the relationship between types of stressors and MetSyn, depression and MetSyn, and MetSyn and carotid IMT in police officers, specifically differences between male and female officers. Yet, based on police mortality studies officers have an elevated risk of atherosclerotic heart disease. ${ }^{116}$

Few studies examining these three associations have been conducted among younger adults. The development of subclinical atherosclerosis as a result of having risk factors such as the MetSyn components begins early in life. ${ }^{104}$ Therefore, understanding and diagnosing MetSyn in young adults would be beneficial to identifying those at risk for future CVD and importantly, subclinical atherosclerosis which could potentially be reversed. ${ }^{104,105}$ Such epidemiological 
studies may provide a better understanding of the pathophysiological processes involved in the early stages of atherosclerosis. ${ }^{114}$

Inconsistencies have been observed in the literature regarding the association between work stress and MetSyn, and MetSyn and carotid IMT. One reason for these discrepancies is the varying definitions of MetSyn that have been used by each study. For the current study, the National Cholesterol Education Program Adult Treatment Panel III definition with more sensitive cutpoints as recommended by the American Heart Association and the National Heart, Lung, and Blood Institute will be utilized. ${ }^{59}$ This new definition incorporates more inclusive cutpoints for blood pressure and glucose intolerance, uses waist circumference instead of body mass index as the measure of abdominal obesity, and does not place emphasis on requiring glucose intolerance plus two other components but instead requires any combination of three or more components. As a result, this definition will strengthen associations with MetSyn and increase the potential for a disproportionate number of false positives. However, if the ultimate goal of primary prevention of CVD is considered, it would be in the interest of public health scientists to rely on this more sensitive definition.

\subsubsection{SUMMARY}

Given the important roles of police officers in our local communities, it is important to understand the complex relationship between the specific types of police stress and early CVD. The types of early or subclinical measures (i.e. depressive symptomatology, MetSyn, carotid IMT) proposed in the current studies would optimize the ability to intervene earlier in the 
process before overt disease is present. This would increase the likelihood of improving police officer physical and mental health and decrease the health consequences of work-related stress. 


\section{REFERENCES}

1. Kop N, Euwema M. Occupational stress and the use of force by Dutch police officers. Crime Justice Behav. 2001;28:631-652.

2. Patterson GT. Reconceptualizing traumatic incidents experienced by law enforcement personnel. Australian J Disaster Trauma Studies. 2001;2.

3. Marmar CR, McCaslin SE, Metzler TJ, et al. Predictors of posttraumatic stress in police and other first responders. Ann NY Acad Sci. 2006;1071:1-18.

4. Franke WD, Collins S, Hinz PN. Cardiovascular disease morbidity in an Iowa law enforcement cohort, compared with the general population. J Occup Environ Med. 1998;40:441-444.

5. Vena JE, Violanti JM, Marshall J, Fiedler RC. Mortality of a municipal worker cohort: III. Police officers. Am J Ind Med. 1986;10(4):383-397.

6. Sardinas A, Miller JW, Hansen H. Ischemic heart disease mortality of firemen and policemen. Am J Public Health. 1986;76(9):1140-1141.

7. Dubrow R, Burnett CA, Gute DM, et al. Ischemic heart disease and acute myocardial infarction mortality among police officers. J Occup Med. 1988;30(8):650-654.

8. Quire D, Blount W. A coronary risk profile study of male police officers: focus on cholesterol. J Pol Sci Admin. 1990;17:89-94.

9. Violanti JM, Vena JE, Marshall JR. Suicides, homicides, and accidental death: A comparative risk assessment of police officers and municipal workers. Am J Ind Med. 1996;30:99-104.

10. Belkic K, Landsbergis $\mathrm{P}$, Schnall $\mathrm{P}$, et al. Research findings linking workplace factors to CVD outcomes: Psychosocial factors: Review of the empirical data among men. In Schnall PL, Belkic K, Landsbergis P, Baker D (Eds.), Occupational medicine: State of the art reviews. Vol 15, pp 24-68. Philadelphia: Hanley and Belfus.

11. Brunner EJ, Chandola T, Marmot M. Prospective effect of job strain on general and central obesity in the Whitehall II study. Am J Epidemiol. 2007;165:828-837.

12. Chandola T, Brunner E, Marmot M. Chronic stress at work and the metabolic syndrome: prospectivestudy. BMJ. 2006;332(7540):521-525.

13. Everson-Rose SA, Lewis TT. Psychosocial factors and cardiovascular diseases. Annu Rev Public Health. 2005;26:469-500.

14. Third Report of the National Cholesterol Education Program (NCEP) Expert Panel on Detection, Evaluation, and Treatment of High Blood Cholesterol in Adults (Adult Treatment Panel III) Final Report. Circulation. 2002;106:3143.

15. Violanti JM, Vena JE, Petralia S. Mortality of a police cohort: 1950-1990. Am J Ind Med. 1998;33(4):366-373. 
16. Deschamps F, Paganon-Badinier I, Marchand AC, et al. Sources and assessment of occupational stress in the police. J Occup Health. 2003;45:358-364.

17. Witteveen AB, Bramsen I, Twick JWR, et al. Psychological distress of rescue workers eight and one-half years after profession involvement in the Amsterdam air disaster. J Nerv Ment Dis. 2007;195:31-40.

18. Collins PA, Gibbs AC. Stress in police officers: a study of the origins, prevalence and severity of stress related symptoms within a county police force. Occup Med (Lond). 2003;53:256-264.

19. Gershon RR, Lin S, Li X. Work stress in again police officers. J Occup Environ Med. 2002;44:160-167.

20. Franke WD, Ramey SL, Shelley MC. Relationship between cardiovascular disease morbidity, risk factors, and stress in a law enforcement cohort. J Occup Environ Med. 2002;44:1182-1189.

21. Chen HC, Chou FHC, Chen MC, et al. A survey of quality of life and depression for police officers iN Kaohsiung, Taiwan. Qual Life Res. 2006;15:925-932.

22. Violanti JM, Aron F. Ranking police stressors. Psychol Rep. 1994;75:824-826.

23. Robinson H, Sigman M, Wilson J. Duty related stressors and PTSD symptoms in suburban police officers. Psychol Rep. 1997;81:835-845.

24. Regehr C, Johanis D, Dimitropoulos G, et al. The police officer and the public inquiry. Brief Treatments Crisis Intervention. 2003;3:383-96.

25. Gersons B. Patterns of PTSD among police officers following a shooting incident: a twodimensional model and treatment implications. J Trauma Stress. 1989;2:247-257.

26. Berg AM, Hem E, Lau B, et al. Stress in the Norwegian police service. Occup Med (Lond). 2005;55(2):113-120.

27. Ward CL, Lombard CJ, Gwebushe N. Critical incident exposure in South African emergency services personnel: prevalence and associated mental health issues. Emerg Med J. 2006;23:223-231.

28. Hodgins G, Creamer M, Bell R. Risk factors for posttrauma reactions in police officers: a longitudinal study. J Nerv Ment Dis. 2001;189:541-547

29. Carvalho AL, Del Bel Cury AA, Garcia RCMR. Prevalence of bruxism and emotional stress and the association between them in Brazilian police officers. Braz Oral Res. 2008;22(1):31-35.

30. Spielberger CD, Westberry LG, Grier KS, et al. The Police Stress Survey: sources of stress in law enforcement (Human Resources Institute Monograph Series Three, No. 6). Tampa, FL: University of South Florida, College of Social and Behavioral Sciences; 1981.

31. Violanti JM, Aron F. Sources of police stressors, job attitudes, and psychological distress. Psychol Rep. 1993;72:899-904.

32. Duggan P. D.C. Losing in overtime: officers wait to testify - at $\$ 30$ an hour. Washington Post. 1993;A1. 
33. Harriston K. Kelly calls for clampdown on police: those who abuse overtime should expect harsher penalty, she says. Washington Post. 1993;B3.

34. Axelsson J, Akerstedt T, Kecklund G, et al. Tolerance to shift work - how does it relate to sleep and wakefulness? Int Arch Occup Environ Health. 2004;77:121-129.

35. Charles L, Burchfiel C, Fekedulegn D, et al. Shift Work and sleep: The Buffalo police health study. Policing. 2007;30:215-227.

36. Karlsson B, Knutsson A, Lindahl B. Is there an association between shift work and having a metabolic syndrome? Results from a population based study of 27,485 people. Occup Environ Med. 2001;58(11):747-752.

37. Kawachi I, Colditz GA, Stampfer MJ, et al. Prospective study of shift work and risk of coronary heart disease in women. Circulation. 1995;92(11):3178-3182.

38. Knutsson A, Hallquist J, Reuterwall C, et al. Shiftwork and myocardial infarction: a casecontrol study. Occup Environ Med. 1999;56(1):46-50.

39. Nakamura K, Shimai S, Kikuchi S, et al. Shift work and risk factors for coronary heart disease in Japanese blue collar workers: serum lipids and anthropometric characteristics. Occup Med (Lond). 1997;47(3):142-146.

40. Scott AJ, Monk TH, Brink LL. Shiftwork as a risk factor for depression: a pilot study. Int J Occup Environ Health. 1997;3(Supplement 2):S2-S9.

41. Kecklund G, Eriksen CA, Akerstedt T. Police officer attitudes to different shift systems: Associations with age, present shift schedule, health and sleep/wake complaints. Appl Ergon. 2008;39:565-571.

42. Axelsson J, Akerstedt T, Kecklund G, et al. Hormonal changes in satisfied and dissatisfied shift workers across a shift cycle. J Appl Physiol. 2003;95:2099-1205.

43. Hills H, Novell N. An examination of hardiness and neuroticism as potential moderators of stress outcomes. Behav Med. 1991;17:31-38.

44. Yoo H, Franke WD. Stress and cardiovascular disease risk in female law enforcement officers. Int Arch Occup Environ Health. 2011;84(3):279-286.

45. Kales SN, Tsismenakis AJ, Zhang C, et al. Blood pressure in firefighters, police officers, and other emergency responders. Am J Hypertens. 2008;22(1):11-20.

46. Feuer E, Rosenman K. Mortality in police and firefighters in New Jersey. Am J Ind Med. 1986;9(6):517-527.

47. Forastiere F, Perucci CA, Di PA, et al. Mortality among urban policemen in Rome. Am J Ind Med. 1994;26(6):785-798.

48. Ferketich AK, Schwartzbaum JA, Frid DJ, et al. Depression as an antecedent to heart disease among women and men in the NHANES I study. National Health and Nutrition Examination Survey. Arch Intern Med. 2000;160(9):1261-1268.

49. Anda R, Williamson D, Jones D, et al. Depressed Affect, Hopelessness, and the Risk of Ischemic-Heart-Disease in A Cohort of United-States Adults. Epidemiology. 1993;4(4):285293. 
50. Aromaa A, Raitasalo R, Reunanen A, et al. Depression and Cardiovascular-Diseases. Acta Psychiatr Scand. 1994;89:77-82.

51. Ford DE, Mead LA, Chang PP, et al. Depression is a risk factor for coronary artery disease in men - The precursors study. Arch Intern Med.1998;158(13):1422-1426.

52. Hippisley-Cox J, Fielding K, Pringle M. Depression as a risk factor for ischaemic heart disease in men: population based case-control study. BMJ. 1998;316(7146):1714-1719.

53. Lett HS, Blumenthal JA, Babyak MA, et al. Depression as a risk factor for coronary artery disease: Evidence, mechanisms, and treatment. Psychosom Med. 2004;66(3):305-315.

54. Penninx BW, Beekman AT, Honig A, et al. Depression and cardiac mortality: results from a community-based longitudinal study. Arch Gen Psychiatry. 2001;58(3):221-227.

55. Israel BA, Baker EA, Goldenhar LM, et al. Occupational stress, safety and health: Conceptual framework and principles for effective prevention interventions. J Occup Health Psychol. 1996;1(3):261-286.

56. Eckel RH, Grundy SM, Zimmet PZ. The metabolic syndrome. Lancet. 2005;365:1415-1428.

57. Lusis AJ, Attie AD, Reue K. Metabolic syndrome: from epidemiology to systems biology. Nat Rev Genet. 2008;9:820.

58. Pollex RL, Hegel RA. Genetic determinants of the metabolic syndrome. Nat Clin Pract Cardiovasc Med. 2006;3:428-429.

59. Grundy SM, Cleeman JI, Daniels SR, et al. Diagnosis and management of the metabolic syndrome. An American Heart Assocation/National Heart, Lung, and Blood Institute Scientific Statement. Circulation. 2005;112:2735-2752.

60. Abraham NG, Brunner EJ, Eriksson JW, et al. Metabolic syndrome: Psychosocial, neuroendocrine, and classical risk factors in type 2 diabetes. Ann NY Acad Sci. 2007;1113:256-275.

61. Ford ES, Giles WH, Dietz WH. Prevalence of the metabolic syndrome among US adults: findings from the third National Health and Nutrition Examination Survey. JAMA. 2002;287(3):356-359.

62. Reilly MP, Rader DJ. The metabolic syndrome: more than the sum of its parts? Circulation. 2003;108(13):1546-1551.

63. Ford ES, Giles WH, Mokdad AH. Increasing prevalence of the metabolic syndrome among U.S. adults. Diabetes Care. 2004;27:2444-2449.

64. Adolphe A, Cook LS, Huang X. A cross-sectional study of intima-media thickness, ethnicity, metabolic syndrome, and cardiovascular risk in 2268 study participants. Mayo Clin Proc. 2009;84(3):221-228.

65. Humbarger CD, Crouse SF, Womack JW, et al. Frequency of metabolic syndrome in police officers compared to NCEP III prevalence values. Med Sci Sports Exerc. 2004;36:S161.

66. Tharkar S, Kumpatla S, Muthukumaran P, et al. High prevalence of metabolic syndrome and cardiovascular risk among police personnel compared to general population in India. $J$ Assoc Physicians India. 2008;56:845-849. 
67. Alexander CM, Landsman PB, Teutsch SM, et al. NCEP-defined metabolic syndrome, diabetes, and prevalence of coronary heart disease among NHANES III participants age 50 years and older. Diabetes. 2003;52:1210-1214.

68. Malik S, Wong ND, Franklin SS, et al. Impact of the metabolic syndrome on mortality from coronary heart disease, cardiovascular disease, and all causes in United States adults. Circulation. 2004;110:1245-1250.

69. Fan AZ. Metabolic syndrome and progression of atherosclerosis among middle-aged US adults. J Atheroscler Thromb. 2006;13;1:46-54.

70. Ingelsson E, Sullivan LM, Murabito JM, et al. Prevalence and prognostic impact of subclinical cardiovascular disease in individuals with the metabolic syndrome and diabetes. Diabetes. 2007;56:1718-1726.

71. Ford ES. The metabolic syndrome and mortality from cardiovascular disease and all-causes: findings from the National Health and Nutrition Examination Survey II Mortality Study. Atherosclerosis. 2004; 173:309-314.

72. Galassi A, Reynolds K, He J. Metabolic syndrome and risk of cardiovascular disease: a meta-analysis. Am J Med. 2006;119(10):812-819.

73. McNeill AM, Rosamond WD, Girman CJ, et al. The metabolic syndrome and 11-year risk of incident cardiovascular disease in the atherosclerosis risk in communities study. Diabetes Care. 2005;28(2):385-390.

74. Pyorala M, Miettinen $\mathrm{H}$, Halonen $\mathrm{P}$, et al. Insulin resistance syndrome predicts the risk of coronary heart disease and stroke in healthy middle-aged men: the 22-year follow-up results of the Helsinki Policemen Study. Arterioscler Thromb Vasc Biol. 2000;20(2):538-544.

75. Norberg MH, Stenlund H, Lindahl B, et al. Components of metabolic syndrome predicting diabetes: no role of inflammation or dyslipidemia. Obesity (Silver Spring). 2007;15(7):18751885 .

76. Mikurube H, Kaneko M, Murata C, et al. Association of change in the type of job with prevalence of components of the metabolic syndrome special reference to job stress. Nippon Koshu Eisei Zasshi. 2005;52(11):987-993.

77. Chandola T, Britton A, Brunner E, et al. Work stress and coronary heart disease: what are the mechanisms? Eur Heart J. 2008;29:640-648.

78. Levine TB, Levine AB. Mental stress and the metabolic syndrome. In: Metabolic syndrome and cardiovascular disease. pp. 37-88. Philadelphia, PA: Saunders 2006.

79. Phillips DIW, Barker DJP, Fall CHD, et al. Elevated plasma cortisol concentrations: a link between low birth weight and insulin resistance syndrome? J Clin Endocrinol Metab. 1998;82:757-760.

80. Kitaoka-Higashigushi K, Morikawa Y, Miura K, et al. Burnout and risk factors for arteriosclerosis disease: Follow-up study. J Occup Health. 2009;51:123-131.

81. Bjorntorp P, Rosmond R. Hypothalamic origin of the metabolic syndrome X. Ann NY Acad Sci. 1999;892;297-307. 
82. Rosmond R, Bjorntorp P. The hypothalamic-pituitary-adrenal axis activity as a predictor of cardiovascular disease, type 2 diabetes and stroke. J Intern Med. 2000;247:188-197.

83. Anagnostis P, Athyros VG, Tziomalos K, Karagiannis A, Mikhailidis DP. The pathogenetic role of cortisol in the metabolic syndrome: A hypothesis. J Clin Endocrinol Metab. 2009;94:2692-2701.

84. Chrousos GP. Stress as a medical and scientific idea and its implications. Adv Pharmacol. 1998;42:552-556.

85. Chrousos GP. The role of stress and the hypothalamic-pituitary-adrenal axis in the pathogenesis of the metabolic syndrome: neuro-endocrine and target tissue-related causes. Int J Obes Relat Metab Disord. 2000;24 Suppl 2:S50-S55.

86. Rosmond R, Dallman MF, Bjorntorp P. Stress-related cortisol secretion in men: relationships with abdominal obesity and endocrine, metabolic and hemodynamic abnormalities. J Clin Endocrinol Metab. 1998;83(6):1853-1859.

87. Thomas GN, Chook P, Ziao M, et al. Deleterious impact of "high normal" glucose levels and other metabolic syndrome components on arterial endothelial function and intima-media thickness in apparently healthy Chinese subjects: The CATHAY Study. Arterioscler Thromb Vasc Biol. 2004;24:739-743.

88. Scuteri A, Najjar SS, Muller DC, et al. Metabolic syndrome amplifies the age-associated increases in vascular thickness and stiffness. J Am Coll Cardiol. 2004;43:1388-1395.

89. Riley WA. Carotid intima-media thickness: Risk assessment and scanning protocol. Eur Heart J. 2002;23(12):916-918.

90. Eguchi K, Schwartz JE, Roman MJ, et al. Metabolic syndrome less strongly associated with target organ damage than syndrome components in a healthy, working population. J Clin Hypertens. 2007;9;5:337-344.

91. Heiss G, Sharrett AR, Barnes RW, et al. Carotid atherosclerosis measured by B-mode ultrasound in populations: associations with cardiovascular risk factors in the ARIC study. Am J Epidemiol. 1991;134(3):250-256.

92. Burke GL, Evans GW, Riley WA, et al. Arterial wall thickness is associated with prevalent cardiovascular disease in middle-aged adults: the Atherosclerosis Risk in Communities (ARIC) study. Stroke. 1995;26(3):386-391.

93. Chambless LE, Heiss G, Folsom AR, et al. Association of coronary heart disease incidence with carotid arterial wall thickness and major risk factors: the Atherosclerosis Risk in Communities (ARIC) study, 1987-1993. Am J Epidemiol. 1997;146(6):483-494.

94. Grobbee DE, Bots ML. Carotid artery intima-media thickness as an indicator of generalized atherosclerosis. J Intern Med. 1994;236:567-573.

95. Hodis HN, Mack WJ, LaBree L, et al. The role of carotid arterial intimamedia thickness in predicting clinical coronary events. Ann Intern Med. 1998;128(4):262-269. 
96. Howard G, Sharrett AR, Heiss G, et al. Carotid artery intimal-medial thickness distribution in general populations as evaluated by B-mode ultrasound: ARIC investigators. Stroke. 1993;24(9):1297-1304.

97. Hassinen M, Komulainen P, Lakka TA, et al. Metabolic syndrome and the progression of carotid intima-media thickness in elderly women. Arch Intern Med. 2006;166:444-449.

98. Yan RT, Anderson TJ, Charbonneau F, et al. Relationship between carotid artery intimamedia thickness and brachial artery flow mediated dilation in middle-aged healthy men. $J$ Am Coll Cardiol. 2005;45:1980-1986.

99. Hintsanen M, Kivimaki M, Elovainio M, et al. Job strain and early atherosclerosis: the Cardiovascular Risk in Young Finns study. Psychosom Med. 2005;67(5):740-747.

100. Nordstrom CK, Dwyer KM, Merz CN, et al. Work-related stress and early atherosclerosis. Epidemiology. 2001;12(2):180-185.

101. Muntaner C, Nieto FJ, Cooper L, et al. Work organization and atherosclerosis: findings from the ARIC study. Atherosclerosis Risk in Communities. Am J Prev Med. 1998;14(1):918.

102. Rosvall M, Ostergren PO, Hedblad B, et al. Work-related psychosocial factors and carotid atherosclerosis. Int J Epidemiol. 2002;31(6):1169-1178.

103. Fujishiro K, Roux AVD, Landsbergis P, et al. Associations of occupation, job control and job demands with intima-media thickness: The Multi-Ethnic Study of Atherosclerosis (MESA). Occup Environ Med. 2011;68:319-326.

104. Mattsson N, Ronnemaa T, Juonala M, et al. Arterial structure and function in young adults with the metabolic syndrome: the Cardiovascular Risk in Young Finns Study. Eur Heart J. 2008;29:784-791.

105. Tzou WS, Douglas PS, Srinivasan SR, et al. Increased subclinical atherosclerosis in young adults with metabolic syndrome: The Bogalusa Heart Study. J Am Coll Cardio. 2005;46:457-463.

106. Wallenfeldt K, Hulthe J, Faberberg B. The metabolic syndrome in middle-aged men according to different definitions and related changes in carotid artery intima-media thickness (IMT) during 3 years of follow-up. J Intern Med. 2005;258:28-37.

107. Pollex RL, Al-Shali KZ, House AA, et al. Relationship of the metabolic syndrome to carotid ultrasound traits. Cardiovasc Ultrasound. 2006;4:28.

108. Kawamoto R, Tomita H, Inoue A, Ohtsuka N, Kamitani A. Metabolic syndrome may be a risk factor for early carotid atherosclerosis in women but not in men. J Atheroscler Thromb. 2007; 14:36-43.

109. Iglseder B, Cip P, Malaimare L, et al. The metabolic syndrome is a stronger risk factor for early carotid atherosclerosis in women than in men. Stroke. 2005;36:1212-1217

110. Czernichow S, Bertrais S, Blacher J, et al. Metabolic syndrome in relation to structure and function of large arteries: A predominant effect of blood pressure: A report from the SU.VI.MAX. Vascular Study. Am J Hypertens. 2005;18:1154-1160. 
111. Irace C, Cortese C, Fiaschi E, et al. Components of the metabolic syndrome and carotid atherosclerosis: Role of elevated blood pressure. Hypertension. 2005;45:597-601.

112. Kawamoto R, Tomita H, Oka Y, et al. Metabolic syndrome amplifies the LDL-cholesterol associated increases in carotid atherosclerosis. Intern Med. 2005;44:1232-1238.

113. Ahluwalia N, Drouet L, Ruidavets JB, et al. Metabolic syndrome is associated with markers of subclinical atherosclerosis in a French population-based sample. Atherosclerosis. 2006; 186:345-353.

114. Knoflach M, Kiechl S, Penz D, et al. Cardiovascular risk factors and atherosclerosis in young women: Atherosclerosis Risk Factors in Female Youngsters (ARFY Study). Stroke. 2009;40:1063-1069.

115. Gustiene O, Slapikas R, Marcinkeviciene J, et al. Relationship between the metabolic syndrome, endothelial function and intima-media thickness in asymptomatic middle-aged individuals. Medicina (Kaunas). 2005;41(10):825-836.

116. Violanti JM, Fekedulegn D, Hartley TA, et al. Police trauma and cardiovascular disease: association between PTSD symptoms and metabolic syndrome. Int J Emerg Ment Health. 2006;8:227-237. 


\section{CHAPTER 2. ASSOCIATION BETWEEN POLICE OFFICER STRESS AND METABOLIC SYNDROME}




\section{Coauthors}

Tara A. Hartley, M.P.A., M.P.H.

Biostatistics and Epidemiology Branch, Health Effects Laboratory Division, National Institute for Occupational Safety and Health and the Department of Community Medicine, School of Medicine

Cecil M. Burchfiel, Ph.D., M.P.H.

Biostatistics and Epidemiology Branch, Health Effects Laboratory Division, National Institute for Occupational Safety and Health

Desta Fekedulegn, Ph.D.

Biostatistics and Epidemiology Branch, Health Effects Laboratory Division, National Institute for Occupational Safety and Health

Michael E. Andrew, Ph.D.

Biostatistics and Epidemiology Branch, Health Effects Laboratory Division, National Institute for Occupational Safety and Health

Sarah S. Knox, Ph.D.

Department of Community Medicine, School of Medicine and the Mary Babb Randolph Cancer Center, West Virginia University

John M. Violanti, Ph.D.

Department of Social and Preventive Medicine, School of Public Health and Health Professions, University at Buffalo

\section{Funding Support}

This work was supported by the National Institute for Occupational Safety and Health (NIOSH) contract number 200-2003-01580.

\section{Disclaimer}

The findings and conclusions in this report are those of the authors and do not necessarily represent the views of NIOSH. 


\subsection{INTRODUCTION}

Policing has long been considered one of the most stressful occupations. ${ }^{1,2}$ Previous studies have found that levels of high stress range from $33 \%$ to $46 \%$ among police officers and the proportion of officers with measurable mental illness has doubled over the past ten years. ${ }^{3-5}$ Police officers are exposed to numerous and varying types of stressors: 1) inherent stressors, such as traumatic events and threats of danger; and 2) organizational and administrative pressures and demands, shift work and high work load. ${ }^{6,7}$ Violanti and Aron found that events where an officer is physically threatened, such as killing someone while on duty or being physically attacked, and those which are psychologically challenging, seeing abused children or a fellow officer being killed while on duty, were perceived to be the most stressful. ${ }^{8}$ Yet, Taylor found that organizational stressors ranked significantly higher and have been associated with greater psychological distress compared with operational or inherent stressors. ${ }^{6,7}$

There is a strong body of research which suggests that exposure to both chronic stress and work stress are associated with higher prevalence of cardiovascular disease (CVD) morbidity and mortality, including the metabolic syndrome (MetSyn). ${ }^{9-12}$ The MetSyn is a clustering of metabolic abnormalities significantly associated with increased risk for CVD morbidity and mortality and type II diabetes mellitus. ${ }^{13}$ The age-adjusted prevalence of MetSyn is estimated at $20.6 \%$ for U.S. workers overall but $26.1 \%$ for protective service workers, including police officers. ${ }^{14}$ The components of MetSyn include abdominal obesity, hypertriglyceridemia, reduced high density lipoprotein (HDL) cholesterol, glucose intolerance and hypertension. ${ }^{15}$ 
A few studies have examined the association between stress and CVD in police officers. Greater perceived stress has been associated with increased prevalence of CVD and its risk factors. ${ }^{16,17}$ It is estimated that between $25-30 \%$ of police officers have a stress-related physical health problem, such as hypertension or coronary heart disease. ${ }^{18}$ Police officers have a more adverse CVD risk factor profile and higher CVD mortality rates compared to other occupations and the general population. $^{16,19}$

Potential biological mechanisms for this association have been posited. Belkic suggested that work stress increases blood pressure, glucose levels and triglyceride levels, catecholamine levels remain elevated, which leads to overactivity of the sympathetic nervous system. ${ }^{9}$ Rosmond and Bjorntorp hypothesized that chronic stress leads to hyperactivity of the hypothalamic pituitary adrenal (HPA) axis, thereby elevating cortisol levels and leading to the development of visceral adiposity, hypertension and dyslipidemia, components of the MetSyn. ${ }^{12,20}$ Others have suggested that work stress leads to deleterious health behaviors, including cigarette smoking, physical inactivity and poor diet, which increase abdominal obesity and insulin resistance. ${ }^{12}$ Prior research on work stress or chronic stress among women, particularly police women, is limited.21 Female officers may experience higher levels of stress due to the challenges of working in a male dominated occupation $\cdot{ }^{17,22-24} \mathrm{~A}$ few previous studies have found that female officers experience higher levels of work-related stress, while others have reported no differences between male and female officers. ${ }^{7,17,25}$ Studies of CVD morbidity and mortality have focused on mostly male officers or included mixed populations, yet CVD risk differs by gender. The current study will contribute to this body of literature by examining the association between police stressors and MetSyn separately for male and female officers. Additionally, the use of a police-specific 
questionnaire will provide the opportunity to investigate whether specific types of stressors, specifically organizational and administrative pressures, threats of physical and psychological danger, and lack of support, are associated with the clustering of CVD risk factors referred to as MetSyn.

The purpose of the current study is to examine the association of police stress with the MetSyn and its individual components. No previous studies were identified which have examined this. The specific hypotheses are: 1) higher levels of police stress will be associated with a greater number of MetSyn components, 2) the association with the number of MetSyn components will be highest for the organizational and administrative pressures subscale compared to the physical and psychological threats or lack of support subscales, and 3) the association between police stress and MetSyn will differ between male and female police officers.

\subsection{METHODS}

\subsubsection{STUdy DESIGN AND POPULATION}

The Buffalo Cardio-Metabolic Occupational Police Stress (BCOPS) Study was conducted between 2004 and 2009 to assess whether workplace stress is associated with adverse subclinical metabolic and CVD outcomes. The Center for Health Research, School of Public Health and Health Professions, State University of New York at Buffalo in Buffalo, NY served as the data collection site. All 710 active duty police officers from the Buffalo, NY Police Department were invited to participate in the study. Recruitment was conducted by open enrollment during the study period. Between 2004 and 2007, the number of active duty officers decreased to 
approximately 600 due to retirements and officers leaving the force with no new hiring until January 2008 when 80 recruits were added. No specific inclusion criteria were used for the study, other than that the participant would be a sworn police officer and willing to participate in the study. Women officers pregnant at the time of examination were excluded $(n=2)$. Of the 464 officers examined at a single time during this period, 74 were removed from analyses (33 retired, 2 missing demographic information, 16 recruits with less than one year of experience, 11 missing Spielberger Police Stress Survey, 12 missing MetSyn) leaving a final sample of 390 officers (288 men, 102 women). All participants provided informed consent and all phases, testing, and reports of the study were approved by the State University of New York at Buffalo Internal Review Board and the National Institute for Occupational Safety and Health Human Subjects Review Board.

\subsubsection{PROCEDURES AND MEASURES}

Questionnaires were administered to collect demographic information on age, gender, education, rank, marital status, psychosocial factors (including stress and support), and health behaviors (e.g., physical activity, smoking, and alcohol use). Participants provided a medical history (including history of heart disease) and were required to fast 12 hours prior to blood sample collection by a certified phlebotomist. Medication use was ascertained through self-report and by inventory of current medications brought to the clinic. Blood parameters for the MetSyn were measured by standard laboratory techniques on the Beckman Coulter LX20 clinical chemistry analyzer and included a blood lipid panel for HDL-C and triglycerides, and chemistry panels for glucose. ${ }^{26}$ Anthropometric measures were conducted by trained clinic personnel. Waist circumference was measured as abdominal girth at the highest point of the iliac crest and the 
lowest point of the costal margin in the mid-axillary line. Blood pressure was determined using the average of the second and third of three separate measurements of resting systolic and diastolic blood pressure obtained with a standard sphygmomanometer.

\subsubsection{SPIELBERGER POLICE STRESS SURVEY (SPSS)}

The Spielberger Police Stress Survey is a 60-item measure for assessing specific sources of stress in police work. ${ }^{27}$ For each item, the officer rates the stressfulness of experiencing the event from $0-100(0=$ no stress, $100=$ maximum stress $)$. The officer also provides the frequency of occurrence of each event over the past month and past year. The mean rating and frequencies were calculated for each officer and reported as the total rating, total frequency in past month, and total frequency in past year. Three subscales were also calculated: administrative and organizational pressure (23 items) which includes satisfaction with departmental policies and procedures, fairness of rewards, performance and the judicial system; physical and psychological threat (24 items) which includes dangerous situations and experiences; and lack of support (13 items) which includes political pressures and relationships with supervisor and coworkers. The subscales have acceptable internal consistency scores (Cronbach's alpha $>0.90$ ). For each subscale, the mean rating and the frequencies were calculated. Indices, the exposure weighted by the rating, were calculated to measure event impact: index for past month (rating $\mathrm{x}$ frequency in past month), and index for past year (rating $\mathrm{x}$ frequency in past year). These indices were calculated for the total score and the three subscales. 


\subsubsection{METSYN}

The MetSyn criteria were based on the National Cholesterol Education Program Adult Treatment Panel guidelines with recent modifications from the American Heart Association and the National Heart, Lung, and Blood Institute. ${ }^{15}$ The individual MetSyn components included: 1) abdominal obesity (gender-specific waist circumference $\geq 102 \mathrm{~cm}$ in males, $\geq 88 \mathrm{~cm}$ in females), 2) hypertension (systolic blood pressure $\geq 130 \mathrm{mmHg}$, diastolic blood pressure $\geq 85 \mathrm{mmHg}$ or reported physician-diagnosed hypertension and antihypertensive treatment), reduced HDL-C (gender-specific fasting HDL-C $\leq 40 \mathrm{mg} / \mathrm{dL}$ in $\mathrm{men}, \leq 50 \mathrm{mg} / \mathrm{dL}$ in women or reported treatment with nicotinic acid or fibrates), elevated triglycerides (fasting triglycerides $\geq 150 \mathrm{mg} / \mathrm{dL}$ or reported treatment with nicotinic acid or fibrates), and glucose intolerance (fasting serum glucose $\geq 100 \mathrm{mg} / \mathrm{dL}$ or reported treatment for diabetes). Participants were categorized according to the number of MetSyn components (0-5). MetSyn was considered present in individuals with three or more components.

\subsubsection{STATISTICAL METHODS}

Descriptive statistics were used to characterize the study population. Gender-specific tertiles were created for each police stress variable. Means (standard deviations, SD) and prevalence were calculated for each MetSyn component and overall prevalence was determined for the MetSyn. Analysis of variance and covariance were used to estimate the unadjusted and multivariate adjusted mean count of MetSyn components across police stress tertiles. Tests for trend were obtained from linear regression analyses with continuous police stress score as the independent variable and count of MetSyn components as the dependent variable. The 
multivariate models were adjusted for age and smoking. The covariates to adjust for were chosen based on their association with police stress and MetSyn and evidence in the literature. Logistic regression was used to calculate the odds for having each of the MetSyn components by tertiles of police stress. Odds ratios were calculated for a 10-unit increase in the ratings. Due to the large range of values for the indices, the odds ratios are based on a 1-SD increase in the index. The tests for interaction of gender with the ratings were significant $(\mathrm{p}<0.05)$. The results are stratified by gender in order to compare associations between male and female officers. All analyses were conducted using the SAS software, Version 9.1 (SAS Institute, Cary NC).

\subsection{RESULTS}

\subsubsection{DEMOGRAPHIC CHARACTERISTICS}

Demographic characteristics of the study population are shown in Table 2.1. Male and female officers were generally similar in age, ethnicity and educational levels. More male officers were married than female officers $(78.8 \%$ vs. $59.8 \%)$. Male officers had more years of police service (mean 15.4 vs. 13.8 years) and held higher rank than female officers (32.7\% vs. $20.6 \%$ at the level of Sergeant or higher). Male officers consumed approximately six alcoholic drinks per week compared to 3.3 for female officers. The prevalence of current smoking was $13.2 \%$ in male officers compared with $27.3 \%$ in female officers.

\subsubsection{SPIELBERGER POLICE STRESS SURVEY}

The scores for the Spielberger Police Stress Survey are shown in Table 2.2. In general, physical and psychologically threatening events were perceived to be the most stressful (42.9 in men, 47.9 
in women). For example, among men, exposure to dead or battered children (mean=65.4) and killing someone in the line of duty (mean=63.2) were reported to be the most stressful events, while women report killing someone in the line of duty (mean=70.1) and fellow officer killed in the line of duty (mean=69.9) as the most stressful (data not shown). Officers reported experiencing approximately three or more events per day in the past month (95.9 events for men, 89.8 events for women) with events involving organizational and administrative pressure occurring more often than other events. Similarly, officers reported experiencing at least one event per day in the past year (380.5 events for men, 358.0 events for women). Female officers reported slightly higher mean ratings than male officers with lack of support being significantly higher for women than men $(p$-value $=0.04)$. Male officers reported experiencing slightly more events than female officers. The indices (the product of the rating and frequency) also varied by gender. Although not statistically significant, male officers tended to have a higher index for organizational and administrative pressures in the past month and past year; women officers had a higher index score for physical and psychological threats and lack of support.

\subsubsection{METSYN AND ITS COMPONENTS}

The prevalence for each of the five MetSyn components ranged from $23.6 \%$ for glucose intolerance to $42.6 \%$ for reduced HDL cholesterol (Table 2.3). The overall prevalence of MetSyn was $26.7 \%$. The prevalence for each component was greater, most often two-fold higher, for male compared to female officers and correspondingly, the prevalence of MetSyn $(\geq 3$ components) was $33.0 \%$ for males and $8.8 \%$ for females. Nearly half of the female officers had zero MetSyn components compared to $16.3 \%$ of male officers. Nearly all officers with a 
particular component met the criteria for that component via the measurement level compared with the self-report medication criteria.

\subsubsection{ASSOCIATION BETWEEN POLICE STRESS AND NUMBER OF METSYN COMPONENTS}

The unadjusted and multivariate adjusted number of MetSyn components by tertiles of police stress are shown in Table 2.4a for men and Table 2.4b for women. Among men, there was no association between the number of MetSyn components and the rating or indices for the total score or three subscales. In women, the number of MetSyn components significantly increased across increasing tertiles of the rating for the total score (multivariate adjusted p-trend $=0.004$ ), administrative and organizational pressure subscale (multivariate adjusted p-trend $=0.003$ ), physical and psychological threat subscale (multivariate adjusted p-trend $=0.007$ ), and lack of support subscale (multivariate adjusted p-trend $=0.006$ ). Similar associations were found between the index for the past month and the number of MetSyn components with the exception of the physical and psychological threat subscale. No association was found with the index for the past year. No association was found between the number of MetSyn components and the frequency in the past month or past year for men or women (data not shown). The association between number of MetSyn components and police stress was also stratified by police variables: years of police service - 1-15 years vs. >15 years, and police rank - police officer vs. all higher ranks (data not shown). No evidence of effect modification by years of service and police rank, indicating associations did not differ significantly across years of service (1-15 and >15) and rank (police officer vs. all higher ranks). 


\subsubsection{OdDS RATIOS FOR INDIVIDUAL METSYN COMPONENTS WITH POLICE STRESS}

Odds ratios were calculated for having each individual MetSyn component with the rating and the index for the past month for women (Table 2.5). The odds ratios for the multivariate models were similar to the unadjusted and age-adjusted models. The odds of having abdominal obesity increased $37 \%$ for each 10 -unit increase in the total rating. Similar increases were found for the administrative and organizational pressures $(\mathrm{OR}=1.38)$, physical and psychological threats ( $\mathrm{OR}$ $=1.29)$, and lack of support $(\mathrm{OR}=1.34)$ ratings. The odds of having reduced HDL-C were significantly higher for each 10 -unit increase in the ratings (range $23 \%$ to $41 \%$ ). The odds of having elevated triglycerides increased $57 \%$ for each 10 -unit increase in the total rating, and $66 \%$ for each 10-unit increase in the physical and psychological threat rating. For each 10-unit increase in the lack of support rating, the odds of having glucose intolerance increased $37 \%$. The odds of having abdominal obesity and reduced HDL-C were significantly higher for each standard deviation increase in the total, administrative and organizational pressures, and lack of support indices for the past month.

\subsection{DiSCUSSION}

Few studies have examined the relationship between stressors and the physical health of police officers. ${ }^{3}$ Yet, the broader scientific literature has reported associations of work stress and chronic stress with MetSyn and other CVD risk factors. ${ }^{28-30}$ Given the higher rates of CVD mortality among police officers, understanding how policing contributes to CVD outcomes is important. The current study addressed this gap by exploring the association between specific types of perceived and experienced police stress and subclinical CVD. 
As hypothesized, police stress was positively associated with the number of MetSyn components. However, this association was found only in female officers. Specifically, perceived stress and the index for the past month, a product of the event rating and frequency, were positively, significantly and independently associated with the number of MetSyn components in women but not in men. No association was found between MetSyn components and the index for the past year or the frequency of events. The index may present a better picture of the stress experience since this measure incorporates both the event frequency and the perceived stressfulness of that event. Also, the association was found for the index for the past month, which may represent a more acute stress reaction than the past year.

As suggested by Spielberger, the 60 -item Police Stress Survey was divided into three subscales representing broad categories of police-specific stressors supported by the literature: organizational and administrative pressures, physical and psychological threats, and lack of support. ${ }^{27}$ As would be expected, physically and psychologically threatening events, such as killing someone in the line of duty or participating in a high speed chase, were perceived as the most stressful by officers compared to other events. However, the organizational and the lack of support indices were higher for officers than the threatening events. This reinforces the fact that repeated exposure to the "smaller" scale events, such as insufficient manpower and feeling that one's fellow officers are not doing their job, are also stressful to officers. ${ }^{18}$

It is interesting that the significant associations were in female officers only. Previous studies report inconsistencies in the association of work stress and chronic stress with the MetSyn or 
CVD among women while the association among men is more consistent. ${ }^{12,21}$ Gender-specific differences in the association between police stress and MetSyn have not been explored in previous studies, although Collins and Gibbs note the weakness of previous studies in addressing gender patterns due to predominantly male study populations. ${ }^{5}$

Policing is a male-dominated occupation with women accounting for only $11.2 \%$ of all sworn law enforcement personnel in the United States and typically holding lower ranks than male officers. ${ }^{31}$ As a result, female officers may be exposed to discrimination and lack of acceptance within the organization and by their male colleagues. ${ }^{17,32,33}$ In the current study, the level of perceived stress associated with administrative and organizational pressure s, physical and psychological threats and total events were slightly higher for female officers than their male counterparts and significantly higher for lack of support. This finding is in agreement with Berg and colleagues who found that female Norwegian police officers perceived events as more severe than their male counterparts, while Yoo and Franke found that female officers had significantly higher levels of perceived stress but similar levels of social support than male officers. ${ }^{17,34}$ Regarding our study hypotheses, each subscale and the total perceived ratings were significantly associated with the number of MetSyn components among women. However, only the organizational and lack of support indices for the previous month were associated with the number of MetSyn components. Although no significant gender differences were found for the acute index, it appears that these types of police stressors are negatively impacting the health of the female officers. 
Of the five MetSyn components, abdominal obesity and reduced HDL-C were consistently associated with police stress in women. For each 10-unit increase in the total rating, the odds of having abdominal obesity increased $37 \%$ and reduced HDL-C increased $33 \%$. The odds of having these components were also significantly elevated for each of the subscales. A similar association was found between the index for the past month and the abdominal obesity and reduced HDL-C components.

Chronic work stress was predictive of obesity in the 19-year Whitehall II Study, and low job control and low decision latitude have been associated with lower levels of HDL-C in middleaged and perimenopausal women. ${ }^{10,35,36}$ Others have suggested the lipid levels are more affected by perceived versus experienced stress. ${ }^{37}$ One potential mechanism for this association is hyperactivation of the hypothalamic-pituitary adrenal (HPA) axis. Rosmond and Bjorntorp have suggested that HPA axis overactivity leads to increased cortisol secretion. ${ }^{20}$ Increased cortisol output is associated with MetSyn and has been linked specifically with low HDL-C concentrations and central adiposity. ${ }^{38}$

Reactions to police stress may have led to unfavorable changes in the health behaviors of female officers. In fact, Chandola found that $32 \%$ of the association between work stress and coronary heart disease could be accounted for by health behaviors. ${ }^{11}$ This can be only partially true for the current study. Female officers in the current study reported low levels of alcohol intake, three drinks per week, had similar levels of physical activity as male officers, and had a mean body mass index (BMI) of 26, just over the threshold for being overweight. However, twice as many female officers were current smokers compared to male officers (27\% vs. $13 \%$ ), although 
adjustment for smoking status affected the association between police stress and MetSyn only minimally for both genders. Other health behaviors such as sleep duration and dietary patterns were not included in the current study, and therefore, we cannot determine the extent to which these factors may have influenced the association between police stress and MetSyn.

Limitations of this study include the cross-sectional study design, which precludes causal inferences and the potential concern for generalizability of the findings to other police officers and emergency responders. Additionally, the Spielberger Police Stress Survey is a self-report measure of police stress and subject to recall bias and socially desirable responding, although it has been frequently used by others to describe sources of police stress. ${ }^{6,8,34,39-41}$

Several summary measures of police stress including the perceived rating and the frequencies of the event in the past month and past year were included in the current study. Previous studies have used only one these measures while citing the potential limitations of the other. For example, the perceived rating is a subjective measure of how stressful an event would be. It does not provide information on the number of times the officer has experienced the event and may be subject to biases including socially desirable responses or conformity with police culture. ${ }^{7,34}$ Conversely, the frequency of the event is subject to recall bias and provides no information on the intensity of the event. In addition to these two measures, we calculated the index, the product of the rating and frequency. This measure provides an impact score with a higher score indicative of both experience and perception. ${ }^{39}$ We were also able to look at two periods of occurrence, the past month and the past year, which could serve as proxy measures of acute and chronic stress. 
In the current study, MetSyn was defined as the count of the number of components for each individual instead of limiting the assessment to the presence or absence of MetSyn. This was particularly important for the current study, since the prevalence of MetSyn was low for female officers $(8.8 \%)$ compared to male officers $(33.0 \%)$ and other studies of police officers. ${ }^{14}$ Nearly half of the female officers had zero MetSyn components. Using the count of components provides an interpretable measure of association and is more sensitive in the detection of associations. $^{42}$

In summary, the perceived rating and index were positively associated with the number of MetSyn components among female but not male police officers. This association was strongest for both the organizational and administrative pressures and lack of support stressors. Of the five MetSyn components, police stress was associated with having abdominal obesity and reduced HDL-C. This study contributes to the growing number of studies which have found associations between work stress and MetSyn. However, it may be the first study to distinguish sources of police stress in relation to subclinical CVD and to examine this relationship among female police officers. However, future studies with more female officers are desirable given the low prevalence of MetSyn among the women in this study. Longitudinal studies would be beneficial in determining the specific pathways and mechanisms involved. Given the stress of policing and the adverse CVD risk factors prevalent among police officers, exploring this association between sources of police stress and MetSyn is important. 


\section{REFERENCES}

1. Gershon RRM, Lin S, Li X. Work stress in aging police officers. J Occup Environ Med. 2002;44:160-167.

2. Marmar CR, McCaslin SE, Metzler TJ, et al. Predictors of posttraumatic stress in police and other first responders. Ann NY Acad Sci. 2006;1071:1-18.

3. Deschamps F, Paganon-Badinier I, Marchand A-C, Merle C. Sources and assessment of occupational stress in the police. J Occup Health. 2003;45:358-364.

4. Carvalho AL, Del Bel Cury AA, Garcia RCMR. Prevalence of bruxism and emotional stress and the association between them in Brazilian police officers. Braz Oral Res. 2008;22:31-35.

5. Collins PA, Gibbs ACC. Stress in police officers: a study of the origins, prevalence and severity of stress-related symptoms within a county police force. Occup Med (Lond). 2003;53:256-264.

6. Violanti JM, Aron F. Sources of police stressors, job attitudes, and psychological distress. Psychol Rep. 1993;72:899-904.

7. Taylor A, Bennel C. Operational and organizational police stress in an Ontario Police Department: A descriptive study. Canadian J Police Security Services. 2006;4:223-234.

8. Violanti JM, Aron F. Ranking police stressors. Psychol Rep. 1994;75:824-826.

9. Belkic K, Landsbergis $\mathrm{P}$, Schnall $\mathrm{P}$, et al. Research findings linking workplace factors to CVD outcomes: Psychosocial factors: Review of the empirical data among men. In Schnall PL, Belkic K, Landsbergis P, Baker D (Eds.), Occupational medicine: State of the art reviews. Vol 15, pp 24-68. Philadelphia: Hanley and Belfus.

10. Brunner EJ, Chandola T, Marmot MG. Prospective effect of job strain on general and central obesity in the Whitehall II Study. Am J Epidemiol. 2007;165:828-837.

11. Chandola T, Brunner E, Marmot M. Chronic stress at work and the metabolic syndrome: prospective study. BMJ doi:10.1136/bmj.38693.435301.80.

12. Everson-Rose SA, Lewis TT. Psychosocial factors and cardiovascular disease. Аnпи Rev Public Health. 2005;26:469-500.

13. Third Report of the National Cholesterol Education Program (NCEP) Expert Panel on Detection, Evaluation, and Treatment of High Blood Cholesterol in Adults (Adult Treatment Panel III) Final Report. Circulation. 2002;106:3143.

14. Davila EP, Florez H, Fleming LE, et al. Prevalence of the metabolic syndrome among US workers. Diabetes Care. 2010;33(11):2390-2395.

15. Grundy SM, Cleeman JI, Daniels SR, et al. Diagnosis and management of the metabolic syndrome. An American Heart Assocation/National Heart, Lung, and Blood Institute Scientific Statement. Circulation. 2005;112:2735-2752.

16. Franke WD, Ramey SL, Shelley MC. Relationship between cardiovascular disease morbidity, risk factors, and stress in a law enforcement cohort. J Occup Environ Med. 2002;44:1182-1189. 
17. Yoo H, Franke WD. Stress and cardiovascular disease risk in female law enforcement officers. Int Arch Occup Environ Health. 2011;84(3):279-286.

18. Van Hasselt VB, Sheehan DC, Malcom AS, Sellers AH, Baker MT, Couwels J. The Law Enforcement Officer Stress Survey (LEOSS): Evaluation of psychometric properties. Behav Modif. 2008;32:133-151.

19. Vena JE, Violanti JM, Marshall J, Fiedler RC. Mortality of a municipal worker cohort: III. Police officers. Am J Ind Med. 1986;10(4):383-397.

20. Rosmond R, Bjorntorp P. The hypothalamic-pituitary-adrenal axis activity as a predictor of cardiovascular disease, type 2 diabetes and stroke. J Intern Med. 2000;247:188-197.

21. Puustinen PJ, Koponen H, Kautiainen H, Mantyselka P, Vanhala M. Gender-specific association of psychological distress with cardiovascular risk scores. Scand J Prim Health Care. 2010;28:36-40.

22. Rozanski A, Blumenthal JA, Kaplan J. Impact of psychological factors on the pathogenesis of cardiovascular disease and implications for therapy. Circulation. 1999;99:2192-2217.

23. Tennant C. Work stress and coronary heart disease. J Cardiovasc Risk. 2000;7(4):273-276.

24. Rosvall M, Ostergren P-O, Hedblad B, Isacsson S-O, Janzon L, Berglund G. Work-related psychosocial factors and carotid atherosclerosis. Int J Epidemiol. 2002;31:1169-1178.

25. Martin M, Marchand A, Boyer R. Traumatic events in the workplace: Impact on psychopathology and healthcare use of police officers. Int J Emerg Ment Health. 2009;11:165-176.

26. Mikolaenko I, Benson E, Konrad RJ, Chaffin C, Robinson CA, Hardy RW. Evaluation of the Beekman Coulter LX20 clinical chemistry analyzer. Lab Med. 2000;31(7):387-393.

27. Spielberger CD, Westberry LG, Grier KS, et al. The Police Stress Survey: sources of stress in law enforcement (Human Resources Institute Monograph Series Three, No. 6). Tampa, FL: University of South Florida, College of Social and Behavioral Sciences; 1981.

28. Branth S, Ronquist G, Stridsberg M, et al. Development of abdominal fat and incipient metabolic syndrome in young healthy men exposed to long-term stress. Nutr Metab Cardiovasc Dis. 2007; 17:427-435.

29. Chandola T, Britton A, Brunner E, et al. Work stress and coronary heart disease: what are the mechanisms? Eur Heart J. 2008;29:640-648.

30. Pyykkonen A-J, Raikkonen K, Tuomi T, Eriksson JG, Groop L, Isomaa B. Stressful life events and the metabolic syndrome: The Prevalence, Prevention and Prediction of Diabetes (PPP)-Botnia Study. Diabetes Care. 2010;33:378-384.

31. National Center for Women and Policing (NCWP). Equality denied: the status of women in policing: 2001. New York, NY: Columbia University 2002.

32. Morash M, Haarr RN. Gender, workplace problems, and stress in policing. Justice $Q$. $1995 ; 12: 113-140$.

33. Rabe-Hemp. Survival in an "all boys club": policewomen and their fight for acceptance. Policing. 2008;31:251-270. 
34. Berg AM, Hem E, Lau B, Haseth K, Ekeberg O. Stress in the Norwegian police service. Occup Med (Lond). 2005;55:113-120.

35. Evolahti A, Hultcrantz M, Collins A. Psychosocial work environment and lifestyle as related to lipid profiles in perimenopausal women. Climacteric. 2009;12:131-145.

36. Wamala SP, Wolk A, Schrnvk-Gustafsson, Orth-Gomer K. Lipid profile and socioeconomic status in healthy middle aged women in Sweden. J Epidemiol Community Health. 1997;51:400-407.

37. McCann BS, Warnick GR, Knopp RH. Changes in plasma lipids and dietary intake accompanying shifts in perceived workload and stress. Psychosom Med. 1990;52:97-108.

38. Anagnostis P, Athyros VG, Tziomalos K, Karagiannis A, Mikhailidis DP. The pathogenetic role of cortisol in the metabolic syndrome: A hypothesis. J Clin Endocrinol Metab. 2009;94:2692-2701.

39. Aaron JDK. Stress and coping in police officers. Police Quarterly. 2000;3:438-450.

40. Martelli TA, Waters LK, Marelli J. The Police Stress Survey: Reliability and relation to job satisfaction and organizational commitment. Psychol Rep. 1989;64:267-273.

41. Patterson BL. Job experience and perceived job stress among police, correctional, and probation/parole officers. Crim Justice Behav. 1992;19:260-285.

42. Fekedulegn D, Andrew M, Violanti J, Hartley T, Charles L, Burchfiel C. Comparison of statistical approaches to evaluate factors associated with metabolic syndrome. J Clin Hypertens. 2010;12:363-373. 


\section{Tables}

* The working tables can be found in Appendix A. 
Table 2.1. Demographic and lifestyle characteristics by gender.

\begin{tabular}{|c|c|c|c|c|}
\hline \multirow{2}{*}{ Characteristic or Measure } & \multicolumn{2}{|c|}{$\operatorname{Men}(\mathrm{N}=288)$} & \multicolumn{2}{|c|}{ Women $(\mathrm{N}=102)$} \\
\hline & $\mathrm{N}$ & Mean (SD) or \% & $\mathrm{N}$ & Mean (SD) or $\%$ \\
\hline \multicolumn{5}{|l|}{ Age Group } \\
\hline Mean Age & 288 & $41.7(7.0)$ & 102 & $41.0(5.7)$ \\
\hline$<40$ years & 117 & 40.6 & 41 & 40.2 \\
\hline $40-49$ years & 126 & 43.8 & 52 & 51.0 \\
\hline $50+$ years & 45 & 15.6 & 9 & 8.8 \\
\hline \multicolumn{5}{|l|}{ Ethnicity } \\
\hline White & 226 & 79.9 & 73 & 71.6 \\
\hline African American & 50 & 17.7 & 29 & 28.4 \\
\hline Hispanic & 7 & 2.5 & 0 & 0.0 \\
\hline \multicolumn{5}{|l|}{ Education } \\
\hline Less than 12 years, High School/GED & 38 & 13.2 & 4 & 3.9 \\
\hline College $<4$ years & 151 & 52.6 & 63 & 61.8 \\
\hline College $4+$ years & 98 & 34.2 & 35 & 34.3 \\
\hline \multicolumn{5}{|l|}{ Marital Status } \\
\hline Single & 25 & 8.7 & 22 & 21.6 \\
\hline Married & 226 & 78.8 & 61 & 59.8 \\
\hline Divorced & 36 & 12.5 & 19 & 18.6 \\
\hline \multicolumn{5}{|l|}{ Years of Police Service } \\
\hline Mean & 288 & $15.4(7.4)$ & 102 & $13.8(6.4)$ \\
\hline $1-5$ years & 21 & 7.3 & 7 & 6.9 \\
\hline $6-10$ years & 69 & 24.0 & 35 & 34.3 \\
\hline $11-15$ years & 54 & 18.8 & 14 & 13.7 \\
\hline $16-20$ years & 71 & 24.7 & 29 & 28.4 \\
\hline $20+$ years & 73 & 25.4 & 17 & 16.7 \\
\hline \multicolumn{5}{|l|}{ Rank } \\
\hline Police Officer & 194 & 67.4 & 81 & 79.4 \\
\hline Sergeant / Lieutenant & 44 & 15.3 & 11 & 10.8 \\
\hline Captain / Detective / Chief / Commissioner & 50 & 17.4 & 10 & 9.8 \\
\hline Alcohol Intake (drinks/week) & 285 & $5.8(9.2)$ & 101 & $3.3(4.7)$ \\
\hline \multicolumn{5}{|l|}{ Smoking Status } \\
\hline Current & 38 & 13.2 & 27 & 27.3 \\
\hline Former & 58 & 20.1 & 30 & 30.3 \\
\hline Never & 192 & 66.7 & 42 & 42.4 \\
\hline Physical Activity (METS/week) & 286 & $283.2(44.4)$ & 102 & $285.9(43.9)$ \\
\hline \multicolumn{5}{|l|}{ Body Mass Index $\left(\mathrm{kg} / \mathrm{m}^{2}\right)$} \\
\hline Mean & 288 & $30.5(4.2)$ & 102 & $26.1(4.7)$ \\
\hline$<25$ & 20 & 6.9 & 50 & 49.0 \\
\hline $25-30$ & 127 & 44.1 & 35 & 34.3 \\
\hline$>30$ & 141 & 49.0 & 17 & 16.7 \\
\hline
\end{tabular}


Table 2.2. Mean values of the Spielberger Police Stress Survey for the total and subscale scores by gender.

\begin{tabular}{|c|c|c|c|c|}
\hline \multirow[t]{2}{*}{ Characteristic } & \multicolumn{2}{|c|}{$\begin{array}{c}\text { Men } \\
(\mathrm{N}=288)\end{array}$} & \multicolumn{2}{|c|}{$\begin{array}{l}\text { Women } \\
(\mathrm{N}=102)\end{array}$} \\
\hline & Mean & SD & Mean & SD \\
\hline \multicolumn{5}{|l|}{ Rating } \\
\hline Total (60 items) & 37.9 & 20.8 & 41.8 & 22.0 \\
\hline Organizational/Administrative Pressure (23 items) & 33.7 & 19.8 & 35.6 & 20.2 \\
\hline Physical/Psychological Threat (24 items) & 42.9 & 23.6 & 47.9 & 25.1 \\
\hline Lack of Support (13 items) & 36.0 & 22.8 & 41.6 & 24.0 \\
\hline \multicolumn{5}{|l|}{ Frequency during past month } \\
\hline Total (60 items) & 95.9 & 61.2 & 89.8 & 61.5 \\
\hline Organizational/Administrative Pressure (23 items) & 42.2 & 30.8 & 37.7 & 29.0 \\
\hline Physical/Psychological Threat (24 items) & 36.8 & 24.8 & 34.9 & 25.4 \\
\hline Lack of Support (13 items) & 17.2 & 14.4 & 17.1 & 14.0 \\
\hline \multicolumn{5}{|l|}{ Frequency during past year } \\
\hline Total (60 items) & 380.5 & 214.9 & 358.0 & 213.3 \\
\hline Organizational/Administrative Pressure (23 items) & 165.7 & 101.9 & 154.6 & 98.1 \\
\hline Physical/Psychological Threat (24 items) & 149.2 & 88.6 & 141.2 & 87.8 \\
\hline Lack of Support (13 items) & 66.7 & 49.5 & 62.2 & 44.1 \\
\hline \multicolumn{5}{|l|}{ Indices, past month } \\
\hline Total (60 items) & 77.8 & 68.8 & 81.6 & 73.8 \\
\hline Organizational/Administrative Pressure (23 items) & 87.5 & 83.8 & 84.2 & 86.4 \\
\hline Physical/Psychological Threat (24 items) & 70.3 & 66.6 & 77.9 & 71.9 \\
\hline Lack of Support (13 items) & 75.1 & 86.2 & 83.1 & 92.3 \\
\hline \multicolumn{5}{|l|}{ Indices, past year } \\
\hline Total (60 items) & 308.3 & 245.7 & 319.8 & 257.3 \\
\hline Organizational/Administrative Pressure (23 items) & 343.2 & 293.4 & 337.2 & 296.2 \\
\hline Physical/Psychological Threat (24 items) & 288.6 & 238.8 & 317.7 & 252.8 \\
\hline Lack of Support (13 items) & 283.3 & 284.7 & 290.9 & 282.7 \\
\hline
\end{tabular}

* Scores for the lack of support rating were significantly different between male and female officers, $\mathrm{p}$-value $=0.04$. 
Table 2.3. Mean levels and prevalence of metabolic syndrome components by gender.

\begin{tabular}{|c|c|c|c|c|c|c|c|c|c|}
\hline \multirow{3}{*}{ Metabolic Syndrome Component } & \multirow{3}{*}{$\begin{array}{l}\text { Component Cutpoint } \\
\text { (Must meet } \geq 1 \text { of the } \\
\text { cutpoints per component) }\end{array}$} & \multicolumn{6}{|c|}{ Prevalence } & \multicolumn{2}{|c|}{ Mean $(\mathrm{SD}) *$} \\
\hline & & \multicolumn{2}{|c|}{ Men } & \multicolumn{2}{|c|}{ Women } & \multicolumn{2}{|c|}{ Overall } & \multirow{2}{*}{$\begin{array}{c}\text { Men } \\
(\mathrm{N}=288)\end{array}$} & \multirow{2}{*}{$\begin{array}{l}\text { Women } \\
(\mathrm{N}=102)\end{array}$} \\
\hline & & $\mathrm{N}$ & $\% *$ & $\mathrm{~N}$ & $\% *$ & $\mathrm{~N}$ & $\% *$ & & \\
\hline Abdominal obesity & & 112 & 38.9 & 18 & $\mathbf{1 7 . 7}$ & 130 & 33.3 & & \\
\hline Waist circumference, $\mathrm{cm}$ & $\geq 102$ Men, $\geq 88$ Women & & & & & & & $99.8(11.3)$ & $80.2(11.6)$ \\
\hline Elevated triglycerides & & 114 & 39.6 & 9 & 8.8 & 123 & 31.5 & & \\
\hline Triglycerides, mg/dL & $\geq 150$ & 110 & 38.2 & 9 & 8.8 & & & $156.1(127.4)$ & $90.0(132.3)$ \\
\hline Reduced HDL cholesterol & & 139 & 48.3 & 27 & 26.5 & 166 & 42.6 & & \\
\hline HDL cholesterol, mg/dL & $<40$ Men, <50 Women & 138 & 47.9 & 27 & 26.5 & & & $41.9(12.0)$ & $58.4(15.9)$ \\
\hline Self-reported fibrates or nicotinic acid medication, $\%$ & Yes & 6 & 2.1 & 1 & 1.0 & 7 & 1.8 & & \\
\hline Glucose intolerance & & 80 & 27.8 & 12 & 11.8 & 92 & 23.6 & & \\
\hline Fasting glucose, mg/dL & $\geq 100$ & 78 & 27.1 & 11 & 10.8 & & & $94.8(14.2)$ & $86.4(8.5)$ \\
\hline Self-reported diabetes medication, $\%$ & Yes & 7 & 2.4 & 1 & 1.0 & 8 & 2.1 & & \\
\hline Hypertension & & 127 & 44.1 & 27 & 26.5 & 154 & 39.5 & & \\
\hline Systolic blood pressure, $\mathrm{mmHg}$ & $\geq 130$ & 68 & 23.6 & 18 & 17.7 & & & $122.6(11.3)$ & $116.9(13.5)$ \\
\hline Self-reported hypertension with antihypertensive medication, $\%$ & Yes & 45 & 15.6 & 7 & 6.9 & 52 & 13.3 & & \\
\hline \multirow{8}{*}{ Number of Components } & & & & & & & & $2.0(1.4)$ & $0.9(1.1)$ \\
\hline & 0 & 47 & 16.3 & 50 & 49.0 & 97 & 24.9 & & \\
\hline & 1 & 68 & 23.6 & 24 & 23.5 & 92 & 23.6 & & \\
\hline & 2 & 78 & 27.1 & 19 & 18.6 & 97 & 24.9 & & \\
\hline & 3 & 48 & 16.7 & 6 & 5.9 & 54 & 13.9 & & \\
\hline & 4 & 31 & 10.8 & 2 & 2.0 & 33 & 8.5 & & \\
\hline & 5 & 16 & 5.6 & 1 & 1.0 & 17 & 4.4 & & \\
\hline & Prevalence $(\geq 3)$ & 95 & 33.0 & 9 & 8.8 & 104 & 26.7 & & \\
\hline
\end{tabular}

* Mean levels of the continuous variables were significantly different between men and women, $\mathrm{p}$-value $<0.0001$. 
Table 2.4a. Unadjusted and adjusted number of metabolic syndrome components by tertiles of Spielberger Police Stress Scores for men.

\begin{tabular}{|c|c|c|c|c|c|c|c|c|c|c|c|c|}
\hline \multirow[b]{2}{*}{$\begin{array}{l}\text { Spielberger } \\
\text { Police Stress } \\
\text { Survey }\end{array}$} & \multicolumn{3}{|c|}{ Total Score } & \multicolumn{3}{|c|}{$\begin{array}{l}\text { Administrative/Organizational } \\
\text { Pressure Score }\end{array}$} & \multicolumn{3}{|c|}{$\begin{array}{c}\text { Physical/Psychological } \\
\text { Threat Score }\end{array}$} & \multicolumn{3}{|c|}{$\begin{array}{l}\text { Lack of Support } \\
\text { Score }\end{array}$} \\
\hline & Range & Unadjusted & $\begin{array}{l}\text { Age and } \\
\text { Smoking- } \\
\text { Adjusted }\end{array}$ & Range & Unadjusted & $\begin{array}{l}\text { Age and } \\
\text { Smoking- } \\
\text { Adjusted }\end{array}$ & Range & Unadjusted & $\begin{array}{l}\text { Age and } \\
\text { Smoking- } \\
\text { Adjusted }\end{array}$ & Range & Unadjusted & $\begin{array}{l}\text { Age and } \\
\text { Smoking- } \\
\text { Adjusted }\end{array}$ \\
\hline \multicolumn{13}{|l|}{ Rating } \\
\hline Low & $0-26.5$ & $2.03(1.42)$ & $2.10(0.15)$ & $0-23.7$ & $2.03(1.40)$ & $2.13(0.15)$ & $0-31.9$ & $2.13(1.40)$ & $2.19(0.16)$ & $0-21.2$ & 1.99 (1.35) & $2.10(0.15)$ \\
\hline Middle & $26.5-47.7$ & $2.00(1.43)$ & $2.15(0.16)$ & $23.9-43.5$ & $2.01(1.38)$ & $2.13(0.15)$ & $32.7-57.9$ & $1.91(1.41)$ & $2.03(0.17)$ & $21.5-48.1$ & $2.02(1.49)$ & $2.15(0.15)$ \\
\hline High & $47.8-83.0$ & $1.93(1.39)$ & $2.04(0.15)$ & $43.7-84.6$ & $1.91(1.46)$ & $2.03(0.15)$ & $58.3-86.5$ & $1.93(1.42)$ & $2.01(0.16)$ & $48.5-90.4$ & $1.95(1.40)$ & $2.04(0.16)$ \\
\hline$p$-value* & & 0.420 & 0.539 & & 0.657 & 0.767 & & 0.231 & 0.322 & & 0.667 & 0.659 \\
\hline \multicolumn{13}{|c|}{ Index for Past Month } \\
\hline Low & $0-40.2$ & $2.06(1.27)$ & $2.12(0.16)$ & $0-35.4$ & $2.12(1.31)$ & $2.20(0.16)$ & $0-32.1$ & $2.01(1.33)$ & $2.07(0.17)$ & $0-24.6$ & $1.95(1.27)$ & $2.07(0.16)$ \\
\hline Middle & $40.5-89.6$ & $1.91(1.44)$ & $2.05(0.16)$ & $35.9-101.5$ & $1.91(1.42)$ & $2.02(0.16)$ & $32.3-74.4$ & $2.17(1.48)$ & $2.27(0.17)$ & $25.4-82.3$ & $2.03(1.44)$ & $2.17(0.15)$ \\
\hline High & $90.4-406.0$ & $1.99(1.52)$ & $2.11(0.15)$ & $102.4-427.4$ & $1.95(1.50)$ & $2.08(0.15)$ & $74.8-375.9$ & $1.77(1.40)$ & $1.91(0.16)$ & $83.1-509.8$ & $1.98(1.53)$ & $2.04(0.16)$ \\
\hline$p$-value* & & 0.992 & 0.882 & & 0.883 & 0.760 & & 0.287 & 0.447 & & 0.223 & 0.427 \\
\hline \multicolumn{13}{|c|}{ Index for Past Year } \\
\hline Low & $0-160.2$ & $2.03(1.29)$ & $2.11(0.16)$ & $0-156.9$ & $2.12(1.34)$ & $2.21(0.16)$ & $0-144.1$ & $2.02(1.36)$ & $2.10(0.17)$ & $0-106.3$ & $1.99(1.31)$ & $2.09(0.16)$ \\
\hline Middle & $161.1-352.5$ & $1.96(1.46)$ & $2.06(0.15)$ & $157.1-393.2$ & $2.00(1.43)$ & $2.08(0.15)$ & $144.1-341.1$ & $2.21(1.45)$ & $2.28(0.16)$ & $108.5-295.6$ & $2.16(1.50)$ & $2.29(0.15)$ \\
\hline High & $353.1-1435$ & $1.97(1.48)$ & $2.12(0.15)$ & 405.4-1619 & $1.85(1.47)$ & $2.02(0.15)$ & $342.5-1198$ & $1.72(1.40)$ & $1.88(0.16)$ & $296.2-1548$ & $1.81(1.42)$ & $1.88(0.15)$ \\
\hline$p$-value* & & 0.503 & 0.653 & & 0.453 & 0.625 & & 0.152 & 0.260 & & 0.418 & 0.654 \\
\hline
\end{tabular}

Unadjusted values include mean and standard deviation. Adjusted values include mean and standard error.

* p-values are for the linear trend. 
Table 2.4b. Unadjusted and adjusted number of metabolic syndrome components by tertiles of Spielberger Police Stress Scores for women.

\begin{tabular}{|c|c|c|c|c|c|c|c|c|c|c|c|c|}
\hline \multirow[b]{2}{*}{$\begin{array}{l}\text { Spielberger } \\
\text { Police Stress } \\
\text { Survey }\end{array}$} & \multicolumn{3}{|c|}{ Total Score } & \multicolumn{3}{|c|}{$\begin{array}{c}\text { Administrative/Organizational } \\
\text { Pressure Score }\end{array}$} & \multicolumn{3}{|c|}{$\begin{array}{c}\text { Physical/Psychological } \\
\text { Threat Score }\end{array}$} & \multicolumn{3}{|c|}{$\begin{array}{l}\text { Lack of Support } \\
\text { Score }\end{array}$} \\
\hline & Range & Unadjusted & $\begin{array}{l}\text { Age and } \\
\text { Smoking- } \\
\text { Adjusted }\end{array}$ & Range & Unadjusted & $\begin{array}{l}\text { Age and } \\
\text { Smoking- } \\
\text { Adjusted }\end{array}$ & Range & Unadjusted & $\begin{array}{l}\text { Age and } \\
\text { Smoking- } \\
\text { Adjusted }\end{array}$ & Range & Unadjusted & $\begin{array}{c}\text { Age and } \\
\text { Smoking- } \\
\text { Adjusted }\end{array}$ \\
\hline \multicolumn{13}{|l|}{ Rating } \\
\hline Low & $0.4-29.1$ & $0.53(0.83)$ & $0.45(0.20)$ & $0-23.5$ & $0.62(0.85)$ & $0.59(0.20)$ & $0-37.9$ & $0.50(0.83)$ & $0.45(0.20)$ & $0-25.0$ & $0.62(0.92)$ & $0.57(0.20)$ \\
\hline Middle & $29.8-55.1$ & $0.82(1.00)$ & $0.90(0.19)$ & $23.9-45.7$ & $0.88(1.09)$ & $0.92(0.20)$ & $38.2-62.7$ & $0.88(1.01)$ & $0.93(0.19)$ & $26.2-57.7$ & $0.76(0.96)$ & $0.82(0.19)$ \\
\hline High & $55.8-86.8$ & $1.38(1.33)$ & $1.32(0.19)$ & $46.1-84.1$ & $1.24(1.30)$ & $1.19(0.19)$ & $63.5-89.8$ & $1.35(1.32)$ & $1.31(0.19)$ & $58.5-85.8$ & $1.35(1.32)$ & $1.30(0.19)$ \\
\hline$p$-value* & & 0.002 & 0.004 & & 0.002 & 0.003 & & 0.007 & 0.007 & & 0.004 & 0.006 \\
\hline \multicolumn{13}{|c|}{ Index for Past Month } \\
\hline Low & $0-29.4$ & $0.71(0.84)$ & $0.70(0.20)$ & $0-23.9$ & $0.65(0.81)$ & $0.65(0.21)$ & $0-30.6$ & $0.79(0.84)$ & $0.77(0.21)$ & $0-30.0$ & $0.68(0.91)$ & $0.70(0.20)$ \\
\hline Middle & 29.4-94.5 & $0.79(1.20)$ & $0.78(0.19)$ & $25.7-99.1$ & $0.97(1.24)$ & $0.96(0.20)$ & $33.9-88.8$ & $0.88(1.23)$ & $0.88(0.20)$ & $30.8-83.5$ & $0.76(0.96)$ & $0.74(0.19)$ \\
\hline High & $95.3-359.0$ & $1.24(1.23)$ & $1.22(0.19)$ & $101.5-365.4$ & $1.12(1.23)$ & $1.10(0.19)$ & $94.6-372.1$ & $1.06(1.25)$ & $1.07(0.19)$ & $85.6-483.3$ & $1.29(1.36)$ & $1.27(0.19)$ \\
\hline$p$-value* & & 0.041 & 0.040 & & 0.021 & 0.023 & & 0.239 & 0.229 & & 0.042 & 0.043 \\
\hline \multicolumn{13}{|c|}{ Index for Past Year } \\
\hline Low & $0-145.8$ & $0.76(0.85)$ & $0.72(0.21)$ & $0-141.2$ & $0.74(0.86)$ & $0.72(0.21)$ & $0-146.9$ & $0.91(1.11)$ & $0.87(0.21)$ & $0-121.0$ & $0.74(0.93)$ & $0.72(0.21)$ \\
\hline Middle & $150.4-385.2$ & $0.82(1.19)$ & $0.86(0.20)$ & $144.4-378.5$ & $0.88(1.20)$ & $0.86(0.20)$ & $158.3-412.7$ & $0.71(1.09)$ & $0.76(0.20)$ & $128.5-293.7$ & $0.85(1.18)$ & $0.83(0.20)$ \\
\hline$p$-value* & & 0.166 & 0.175 & & 0.110 & 0.118 & & 0.403 & 0.435 & & 0.143 & 0.144 \\
\hline
\end{tabular}

Unadjusted values include mean and standard deviation. Adjusted values include mean and standard error.

* p-values are for the linear trend. 
Table 2.5. Multivariate adjusted* odds ratios for MetSyn components by Spielberger Police Stress score for women.

\begin{tabular}{|c|c|c|c|c|c|c|c|c|c|c|}
\hline \multirow[b]{2}{*}{$\begin{array}{l}\text { Spielberger Police } \\
\text { Stress Survey }\end{array}$} & \multicolumn{2}{|c|}{$\begin{array}{c}\text { Abdominal } \\
\text { Obesity }\end{array}$} & \multicolumn{2}{|c|}{$\begin{array}{c}\text { Elevated } \\
\text { Triglycerides }\end{array}$} & \multicolumn{2}{|c|}{$\begin{array}{c}\text { Reduced } \\
\text { HDL-C }\end{array}$} & \multicolumn{2}{|c|}{$\begin{array}{c}\text { Glucose } \\
\text { Intolerance }\end{array}$} & \multicolumn{2}{|c|}{ Hypertension } \\
\hline & $\begin{array}{l}\text { Odds } \\
\text { Ratio }\end{array}$ & $95 \% \mathrm{CI}$ & $\begin{array}{l}\text { Odds } \\
\text { Ratio }\end{array}$ & $95 \% \mathrm{CI}$ & $\begin{array}{l}\text { Odds } \\
\text { Ratio }\end{array}$ & $95 \% \mathrm{CI}$ & $\begin{array}{l}\text { Odds } \\
\text { Ratio }\end{array}$ & $95 \% \mathrm{CI}$ & $\begin{array}{l}\text { Odds } \\
\text { Ratio }\end{array}$ & $95 \%$ CI \\
\hline \multicolumn{11}{|l|}{ Rating ** } \\
\hline Total & 1.37 & $1.04-1.81$ & 1.57 & $1.02-2.43$ & 1.33 & $1.06-1.69$ & 1.28 & $0.93-1.76$ & 1.02 & $0.83-1.26$ \\
\hline Administrative/Organizational & 1.38 & $1.04-1.84$ & 1.41 & $0.96-2.08$ & 1.41 & $1.11-1.83$ & 1.29 & $0.94-1.79$ & 1.02 & $0.81-1.28$ \\
\hline Physical/Psychological Threat & 1.29 & $1.01-1.64$ & 1.66 & $1.05-2.62$ & 1.27 & $1.03-1.55$ & 1.16 & $0.90-1.52$ & 1.02 & $0.84-1.23$ \\
\hline Lack of Support & 1.34 & $1.04-1.72$ & 1.40 & $0.98-1.97$ & 1.23 & $1.00-1.50$ & 1.37 & $1.01-1.84$ & 1.01 & $0.83-1.22$ \\
\hline \multicolumn{11}{|l|}{ Index for Past Month $* *$} \\
\hline Total & 1.80 & $1.08-3.00$ & 1.56 & $0.80-3.00$ & 1.67 & $1.00-2.59$ & 1.34 & $0.74-2.41$ & 0.93 & $0.55-1.45$ \\
\hline Administrative/Organizational & 1.68 & $1.00-2.80$ & 1.68 & $0.92-3.05$ & 1.54 & $1.00-2.57$ & 1.19 & $0.65-1.99$ & 1.09 & $0.65-1.68$ \\
\hline Physical/Psychological Threat & 1.43 & $0.87-2.36$ & 1.24 & $0.65-2.36$ & 1.33 & $0.87-2.05$ & 1.24 & $0.75-2.20$ & 0.93 & $0.56-1.43$ \\
\hline Lack of Support & 1.90 & $1.10-3.29$ & 1.32 & $0.69-2.29$ & 1.74 & $1.10-2.75$ & 1.59 & $0.91-2.75$ & 0.69 & $0.40-1.20$ \\
\hline
\end{tabular}

* Multivariate model adjusted for age and smoking status

** Odds ratios for the ratings are for a 10-unit increase. Odds ratios for the index in the past month are for a 1-SD increase. 


\section{CHAPTER 3. ASSOCIATION BETWEEN DEPRESSION AND METABOLIC SYNDROME AMONG TWO COHORTS OF POLICE OFFICERS}




\section{Coauthors}

Tara A. Hartley, M.P.A., M.P.H.

Biostatistics and Epidemiology Branch, Health Effects Laboratory Division, National Institute for Occupational Safety and Health and the Department of Community Medicine, School of Medicine

Sarah S. Knox, Ph.D.

Department of Community Medicine, School of Medicine and the Mary Babb Randolph Cancer Center, West Virginia University

Desta Fekedulegn, Ph.D.

Biostatistics and Epidemiology Branch, Health Effects Laboratory Division, National Institute for Occupational Safety and Health

Celestina Barbosa-Leiker, PhD

Washington State University

John M. Violanti, Ph.D.

Department of Social and Preventive Medicine, School of Public Health and Health Professions, University at Buffalo

Michael E. Andrew, Ph.D.

Biostatistics and Epidemiology Branch, Health Effects Laboratory Division, National Institute for Occupational Safety and Health

Cecil M. Burchfiel, Ph.D., M.P.H.

Biostatistics and Epidemiology Branch, Health Effects Laboratory Division, National Institute for Occupational Safety and Health

*Finalist for the 2011 National Institute for Occupational Safety and Health and American Psychological Association Work, Stress and Health Conference Student Research Competition.

\section{Funding Support}

This work was supported by the National Institute for Occupational Safety and Health (NIOSH) contract number 200-2003-01580.

\section{Disclaimer}

The findings and conclusions in this report are those of the authors and do not necessarily represent the views of NIOSH. 


\subsection{INTRODUCTION}

Police officers are members of a unique occupational population whose exposure to potentially traumatic and life threatening events is part of their professional duty. ${ }^{1}$ Additionally, officers routinely encounter organizational stressors, such as court appearances, excessive paperwork and shift work. ${ }^{1}$ Higher levels of perceived work stress have been associated with depression among older police officers. ${ }^{2}$ Work stress and depression are risk factors for the development of CVD and diabetes. ${ }^{2-16}$ Police officers have higher rates of cardiovascular disease (CVD) morbidity and mortality compared to the general population. ${ }^{17,18}$

The MetSyn is a clustering of abnormalities (abdominal obesity, hypertension, dyslipidemia, glucose intolerance) that has been associated with increased risk for subclinical atherosclerosis, CVD, diabetes, target organ damage, and total mortality. ${ }^{19}$ The association between depression and the MetSyn has been studied over the past decade. ${ }^{4,5,7,9,10,14,15,20-27}$ More recently, it has been suggested that MetSyn may be intermediate in the pathway between depression and CVD. $7,9,11,14,15,28,29$

Multiple pathophysiological mechanisms underlying the association between depression and MetSyn have been proposed. One of these is neuroendocrine and involves overstimulation of the hypothalamic-pituitary adrenal (HPA) axis which leads to excess cortisol secretion, and has been associated with both the development of the depression and the MetSyn components. ${ }^{30,31}$ Another, indirect pathway is through adverse health behaviors associated with depression, such as cigarette smoking, excessive use of 
alcohol and a sedentary lifestyle, which may be used as coping responses and subsequently, increase risk of MetSyn and CVD. ${ }^{4,7,15}$

The association between depression and MetSyn appears to be stronger in women, although the explanation for this gender difference is somewhat unclear. ${ }^{7,11,14,21,23,24}$ One possible explanation involves the role of sex hormones. Overactivation of the HPA axis due to stress or depression may result in decreased levels of sex hormones. ${ }^{32}$ Menopause and decreased estradiol concentrations elevate visceral fat mass, a component of MetSyn. $^{32}$

The purpose of this study was to examine the association between depressive symptoms and the MetSyn separately among male and female police officers from two geographically different cohorts. No known studies were identified which examined this association in police officers. Participants are police officers from two geographically different locations, which may make the findings more generalizable to other groups of police officers. Police officers are considered to be a relatively young and presumably healthy occupational group (i.e. healthy worker effect), yet they suffer from high levels of stress and CVD. Based on the literature, the specific study hypotheses were: 1) depressive symptoms would be associated with a larger number of MetSyn components in male and female police officers, 2) the association of depressive symptoms with MetSyn and its components would differ between male and female police officers, and 3) the association between depressive symptoms and MetSyn would not differ by geographic location. 


\subsection{METHODS}

Participants in this study included those from two studies at two separate locations: Buffalo, New York and Spokane, Washington.

\subsubsection{BufFalo CARDio-METABOLIC OCCUPATIONAL POLICE STRESS (BCOPS) STUdY}

The Buffalo Cardio-Metabolic Occupational Police Stress (BCOPS) Study, a crosssectional study of urban police officers, was conducted between 2004 and 2009. The purpose of the BCOPS Study was to examine the association between police stressors and physiological and psychological health consequences. The Center for Preventive Medicine, School of Public Health and Health Professions, State University of New York at Buffalo in Buffalo, NY served as the data collection site. All 710 active duty police officers from the Buffalo, NY Police Department were invited to participate and the recruitment was ongoing for five-years. No specific inclusion criteria were used for the study, other than that the participant would be a sworn police officer and willing to participate in the study. Women officers who were pregnant at the time of examination were excluded $(n=2)$. All participants provided informed consent and all phases, testing, and reports of the study were approved by the State University of New York at Buffalo Internal Review Board and the National Institute for Occupational Safety and Health Human Subjects Review Board. Of the 464 officers examined, 54 were removed from analyses (33 retired, 1 missing demographic information, 3 missing CES-D, 17 missing MetSyn) leaving a final sample of 410 officers (304 men, 106 women; age range 21-66). 
Questionnaires were administered to collect demographic and lifestyle information and psychosocial measures. Participants provided a medical history (including history of heart disease) and were required to fast 12 hours prior to blood sample collection by a certified phlebotomist. Medication use was ascertained through self-report and by inventory of current medications brought to the clinic. Blood parameters for the MetSyn were measured by standard laboratory techniques on the Beckman Coulter LX20 clinical chemistry analyzer and included a blood lipid panel for high-density lipoprotein (HDL)cholesterol and triglycerides, and chemistry panels for glucose. ${ }^{33}$ Anthropometric measures were conducted by trained clinic personnel. Waist circumference was measured as abdominal girth at the highest point of the iliac crest and the lowest point of the costal margin in the mid-axillary line. Blood pressure was determined using the average of the second and third of three separate measurements of resting systolic and diastolic blood pressure obtained with a standard sphygmomanometer.

\subsubsection{SPOKANE HEART STUDY (SHS)}

The Spokane Heart Study (SHS) was a prospective, longitudinal study investigating the natural history of preclinical atherosclerosis. Over a 12-year period, 1,000 asymptomatic men and women were enrolled and followed every two years, generating an extensive data set of medical and lifestyle histories, blood and urine measurements, and Electron Beam Computed Tomography (EBCT) measures of CAC. At baseline, all participants completed a comprehensive questionnaire which measured key behavioral, social and lifestyle domains. Blood samples and anthropometric measures were taken prior to the EBCT scan. Routine assays for blood chemistries, lipid profile and hematology were 
performed. The sample was almost equally divided between men and women. All participants provided informed consent and all phases, testing, and reports of the study were approved by the Washington State University Institutional Review Board. For the current study, data collection years 2003 - 2006, years most comparable to the BCOPS study, were used. Based on the questions, "what is the name of your current employer" and "what is your current job title," 134 police officers (124 male, 10 female) were identified. Of the 134 officers participating in the study, four were removed from analyses (two missing CES-D and two missing MetSyn) leaving a final sample of 130 Spokane police officers (121 men, 9 women; age range 35-62).

\subsubsection{DEPRESSIVE SYMPTOMS}

In both studies, depressive symptoms were measured using the Center for Epidemiologic Studies-Depression (CES-D) scale. The CES-D is a short 20-item scale designed to measure symptoms of depression (e.g., poor appetite, restless sleep, sadness) in the general population on a 4-point scale. ${ }^{34}$ The 4-point scale represents how much each symptom occurred during the past 7 days as follows: 0 (rarely or none of the time, less than 1 day); 1 (some or little of the time, 1-2 days); 2 (occasionally or a moderate amount of time, 3-4 days); and 3 (most or all of the time, 5-7 days). The CES-D is scored by reverse coding the appropriate items and summing the scores to obtain an overall score. Respondents with scores between 0 and 15 are unlikely to be clinically depressed, scores of 16 to 21 indicate mild to moderate depression, and scores of 22 or greater are associated with major depression. ${ }^{34}$ The CES-D has acceptable reliability, Cronbach alpha of 0.85 , and a split-half reliability ranging from 0.76 to $0.85 .^{34}$ For the 
current study, the continuous CES-D and three categories of CES-D were used: low (0 $8)$, middle $(9-15)$, high (16 or greater).

\subsubsection{METSYN}

The MetSyn criteria were based on the National Cholesterol Education Program Adult Treatment Panel guidelines with recent modifications from the American Heart Association and the National Heart, Lung, and Blood Institute. ${ }^{35}$ The individual MetSyn components included: 1) abdominal obesity (gender-specific waist circumference $\geq 102$ $\mathrm{cm}$ in males, $\geq 88 \mathrm{~cm}$ in females), 2) hypertension (systolic blood pressure $\geq 130$ $\mathrm{mmHg}$, diastolic blood pressure $\geq 85 \mathrm{mmHg}$ or reported physician-diagnosed hypertension and antihypertensive treatment), reduced HDL-C (gender-specific fasting $\mathrm{HDL}-\mathrm{C} \leq 40 \mathrm{mg} / \mathrm{dL}$ in men, $\leq 50 \mathrm{mg} / \mathrm{dL}$ in women or reported treatment with nicotinic acid or fibrates), elevated triglycerides (fasting triglycerides $\geq 150 \mathrm{mg} / \mathrm{dL}$ or reported treatment with nicotinic acid or fibrates), and glucose intolerance (fasting serum glucose $\geq 100 \mathrm{mg} / \mathrm{dL}$ or reported treatment for diabetes. Participants were categorized according to the number of MetSyn components (0-5). MetSyn was considered present in individuals with three or more components.

\subsubsection{STATISTICAL METHODS}

Descriptive statistics were used to characterize the study population. The number of MetSyn components and the prevalence of MetSyn and each individual component were calculated. Analysis of variance and covariance were used to estimate the unadjusted and multivariate adjusted mean count of MetSyn components across CES-D categories. 
Tests for trend were obtained from linear regression analyses with continuous CES-D as the independent variables and count of MetSyn components as the dependent variable. The multivariate models were used to adjust for age, smoking status and marital status. The covariates to adjust for were chosen based their association with depression and MetSyn and evidence in the literature. Logistic regression was used to calculate the odds for having each of the five MetSyn components by categories of CES-D score. Even though the tests of interaction for gender and location (Buffalo, Spokane) were not statistically significant, results were stratified in order to provide comparisons between locations and between male and female officers. All analyses were conducted using the SAS software, Version 9.2 (SAS Institute, Cary NC). Due to the small number of Spokane women in this study, the primary analysis of the association between CES-D and MetSyn could not be conducted in this group; however, descriptive statistics for these nine participants are reported.

\subsection{RESULTS}

\subsubsection{DEMOGRAPHIC CHARACTERISTICS}

Demographic characteristics of the Buffalo, NY and Spokane, WA police cohorts are shown in Table 3.1. The Spokane officers were between six and eight years older than the Buffalo officers (Spokane range $=35-62$, Buffalo range $=21-66$ ) and nearly all white (1/130) compared to approximately $22 \%$ of Buffalo officers who were black or Hispanic. More Spokane officers had completed at least four years of college (44\% vs. $34 \%$ ) and the Spokane men held higher ranks (above police officer) than the Buffalo men or women (68\% vs. $30.5 \%$ and $19.8 \%$, respectively). More male officers were 
married (78.2\% for Buffalo men, $91.7 \%$ for Spokane men) than female officers $(58.5 \%$ for Buffalo women, 55.6\% for Spokane women). More female Buffalo officers were current smokers compared to the other three groups. The mean (SD) CES-D score was 7.5 (6.6) for Buffalo men, 6.6 (5.5) for Spokane men, 8.7 (8.2) for Buffalo women, and 5.8 (4.5) for Spokane women.

\subsubsection{METSYN AND ITS COMPONENTS}

The prevalence of each of the MetSyn components tended to be higher for Spokane officers compared to Buffalo officers (Table 3.2). The most notable differences were the higher values for abdominal obesity, elevated triglycerides, and glucose intolerance in Spokane women compared to Buffalo women. The differences were not as large between Spokane and Buffalo men. The mean values for each of the five MetSyn components were higher for Spokane officers compared to Buffalo officers, most notably triglycerides levels for Spokane women $(165.3 \mathrm{mg} / \mathrm{dL})$ compared to Buffalo women $(88.4 \mathrm{mg} / \mathrm{dL})$. The prevalence of MetSyn ( $\geq 3$ components) was highest among Spokane officers, $37.2 \%$ for men and $33.3 \%$ for women, compared to Buffalo officers, $31.6 \%$ for men and $8.5 \%$ for women - half of the Buffalo women did not have any of the MetSyn components. Accordingly, the number of MetSyn components was higher among Spokane officers, 2.1 (1.4) for men and 1.7 (1.9) for women, compared to Buffalo officers, 1.9 (1.4) for men and 0.9 (1.1) for women. 
3.3.3 ASSOCIATION BETWEEN NUMBER OF METSYN COMPONENTS AND CATEGORIES OF CES-D SCORE

The unadjusted number of MetSyn components increased significantly across categories of CES-D for Spokane men (CES-D score 0-8 = $1.9(1.3), 9-15=2.6(1.3), \geq 16=3.1$ (1.6), p-trend $=0.003)($ Table 3.3). This association remained significant after adjustment for age ( $\mathrm{p}$-trend $=0.004)$, and multivariate adjustment for age, smoking and marital status ( $\mathrm{p}$-trend=0.003). No association was found between number of MetSyn components and CES-D score for Buffalo men or women. Analyses could not be conducted for Spokane women due to the low number of participants $(n=9)$. Excluding officers with reported CVD or previous treatment for CVD $(n=11)$ did not alter the associations appreciably (data not shown) nor did excluding officers taking antidepressant medications (available for Buffalo police officers only, $n=32$ ) (data not shown). Separate analyses excluding Buffalo female officers taking exogenous estrogen (birth control medication: $\mathrm{n}=20$ or hormone replacement medication: $\mathrm{n}=4$ ) also did not alter the association (data not shown).

\subsubsection{STRATIFICATION BY AGE AND POLICE RANK}

The association between number of MetSyn components and categories of CES-D score was further stratified by mean age (41 for Buffalo men and women, 49 for Spokane men) (Table 3.4). Spokane women were excluded due to small number of participants. An increasing trend for number of MetSyn components across CES-D categories was found for Buffalo men who were age 40 or younger (multivariate adjusted: $0-8=1.5$ $(0.2), 9-15=1.8(0.3), 2.0(0.4), \mathrm{p}$-trend $=0.124)$. A significant increasing trend was 
found for Spokane men who were older than age 49 (multivariate adjusted: $0-8=1.9$ $(0.3), 9-15=2.8(0.6), 3.4(0.6), \mathrm{p}$-trend $=0.021)$. A similar analysis was conducted by stratifying police rank into "police officers" and "all higher ranks." A significant association was found among Spokane men who were "police officers" (multivariate adjusted: $0-8=2.1(0.3), 9-15=3.6(0.6), 5.3(0.7)$, p-trend $<0.0001)$.

\subsubsection{ODDS RATIOS FOR INDIVIDUAL METSYN COMPONENTS BY CES-D SCORE}

Odds ratios were calculated for having each individual MetSyn component by CES-D score for Spokane men (Table 3.5). For each 5-unit increase in CES-D score, the odds of having abdominal obesity increased by $42 \%$. Multivariate adjustment for age, smoking and marital status slightly attenuated the association $(\mathrm{OR}=1.338,95 \% \mathrm{CI}=0.932-$ 1.917). For each 5-unit increase in CES-D score, the multivariate adjusted odds for having elevated triglycerides increased by $47.6 \%(\mathrm{OR}=1.476,95 \% \mathrm{CI}=1.025-2.119)$ and $51.8 \%$ for having hypertension $(\mathrm{OR}=1.518,95 \% \mathrm{CI}=1.035-2.221)$. The unadjusted odds of having glucose intolerance was $1.553(1.088-2.202)$; covariate adjustment did not change the odds ratio appreciably.

\subsection{DisCUSSION}

One surprising finding of this study was the low CES-D scores in all groups (range 5.8 8.7) with between $64.2 \%$ and $77.8 \%$ of participants scoring in the low category (0-8). This restricted range may have made the finding of a statistical association with MetSyn less likely. However, the prevalence of depression (CES-D score $\geq 16$ ) was comparable with that reported in the Framingham Heart Study (10\% in men, $17 \%$ in women); $9.1 \%$ 
for Spokane men, $10.2 \%$ for Buffalo men and $16 \%$ for Buffalo women, and the prevalence of MetSyn was notably high for Spokane men and women and Buffalo men (range $31.6 \%-37.2 \%$ ) and low among the Buffalo women (8.5\%) compared to U.S. protective service workers $(26.1 \%) .^{36,37}$

An association between depressive symptoms and number of MetSyn components was observed for male Spokane officers. This finding partially supports two of the study hypotheses: depression is associated with a higher number of MetSyn components, and the association was different between male and female police officers. However, the association was significant only among the male officers at one location, Spokane, indicating that there are potential factors not measured in this study that influenced the results. The association between depressive symptoms and MetSyn found for the Spokane men extends to depressive symptoms in a nonclinical range. ${ }^{9}$ Previous studies have found similar findings in the association between depression and MetSyn among a general population, among young and middle-aged women, among adult male twins, and among those at risk for CVD. ${ }^{7,9,20,24,26,38,39}$ One study, noting the peculiarity of their finding, found an association between depressive symptoms and MetSyn in men but not in women. ${ }^{40}$

While the two geographic cohorts were somewhat similar demographically, the Spokane cohort was older and held higher ranks than the Buffalo officers. It is noteworthy that the association between depressive symptoms and MetSyn was strongest among the older $(>49$ years, $n=59)$ versus younger Spokane men $(\leq 49, n=61)$, and lower 
ranking (police officer, $n=39)$ versus higher ranking Spokane men $(n=81)$. It is possible that the Spokane male officers were experiencing high job demand and low job control, although this construct was not included in the current study. Perceived work stress has been associated with depression among older, mostly male police officers, and high job strain has been significantly associated with depression among a national sample of working men. ${ }^{2,41}$ Vitaliano et al suggested that chronic stress leads to depression which increases the risk of MetSyn and subsequently CVD. ${ }^{16}$

For Spokane men, the odds of having four of the MetSyn components (abdominal obesity, hypertriglyceridemia, hypertension, glucose intolerance) increased by at least $40 \%$ for every 5-unit increase in CES-D score. The association with abdominal obesity was slightly attenuated by adjustment for age, smoking status and marital status, while HDL-C was not associated with depressive symptoms. This finding is supported by previous studies which have found that depression was associated with abdominal obesity, hypertriglyceridemia, hypertension and glucose intolerance. ${ }^{7,15,27,38,42,43}$ The association between depression and MetSyn and its components among these diverse populations suggests that the pathophysiology of both conditions may overlap, yet the mechanisms may vary by MetSyn component. Several potential mechanisms could be considered. $^{44}$

Dysfunction of the hypothalamic-pituitary-adrenal (HPA) axis has been the most commonly cited mechanism for the association between depression and MetSyn. ${ }^{27,44}$ Hyperactivity of the HPA axis leads to increased cortisol secretion which has been 
associated with depression, the MetSyn and its individual components. ${ }^{7,13,30,31,44,45}$ Hypercortisolemic depression has been associated with an increased prevalence of MetSyn, particularly abdominal obesity, hypertriglyceridemia and reduced HDL-C among older adults and increased visceral fat in a study of women aged 45 and older. ${ }^{27,46}$ Castillo-Quan et al suggest that insulin may also be a key factor in the association between depressive symptoms and MetSyn. ${ }^{47}$ Freuhwald-Schultes et al have shown that hyperinsulinemia activates the HPA axis and increases cortisol secretion. ${ }^{48}$ HPA axis hyperactivity and hyperinsulinemia have been found in those with depression, abdominal obesity and diabetes. ${ }^{48,49}$ Perhaps the Spokane men with higher depression scores exhibited patterns of elevated cortisol and/or hyperinsulinemia; however, we were not able to assess cortisol or insulin levels for the Spokane officers in the current study.

Inflammation, particularly elevated levels of C-reactive protein (CRP), has been associated with depressive symptoms in younger men, and in elderly men and women. ${ }^{50}$ Inflammation has also been acknowledged as a key factor underlying development of MetSyn. ${ }^{20,44}$ CRP levels could be reduced among women who take oral contraceptives and thus inflammation may serve as a more prominent factor in the pathway between depression and MetSyn found in men. ${ }^{40,51}$ In the current study, Buffalo women were on average 41 years old and had the lowest prevalence of MetSyn at 8.5\%. Additionally, excluding Buffalo women who reported taking birth control or hormone replacement medication did not alter the non-significant finding. Due to the small number of participants $(n=9)$, we were not able to assess the association in the Spokane women who were about six years older on average than the Buffalo women. 
As a means of coping, depressed individuals may engage in poor health behaviors, such as sedentary lifestyle, poor nutrition, cigarette smoking, excessive alcohol intake or inadequate sleep, and these behaviors may lead to the development of MetSyn. ${ }^{7,15}$ Of these behaviors, only smoking status was available in the current study and it was the Buffalo women who had the highest percent of current and former smokers $(57.3 \%)$ compared to the other groups (all less than 37\%). Consistent with previous studies, smoking status was included as a potential covariate in multivariate analyses although adjustment attenuated the association minimally across all groups.

One of the strengths of the current study was the ability to examine the association between depressive symptoms and MetSyn separately for men and women officers. The relationship has frequently been found among women with mixed results in men. Additionally, the study population was relatively young (mean age 49 for Spokane, 41 for Buffalo) and we were able to exclude those who have CVD or have received clinical interventions for CVD, enabling us to affirm that the relationship was unlikely attributable to CVD. ${ }^{7}$

The current study utilized the most recent definition of MetSyn: the National Cholesterol Education Program Adult Treatment Panel III definition with modifications recommended by the American Heart Association and the National Heart, Lung, and Blood Institute. ${ }^{35}$ MetSyn was defined as the count of the number of components for each individual instead of limiting the assessment to presence/absence of MetSyn for the 
current study. This approach provides an interpretable measure of association and is more sensitive in the detection of associations. ${ }^{52}$

Several limitations of the study should be noted. The CES-D provides a self-report measure of depressive symptoms as opposed to measuring clinical depression. Underreporting depressive symptoms is of concern with this occupational group. However, the CES-D has been widely used as a measure for assessing depressive symptoms in epidemiological studies. This study was cross-sectional; therefore, we cannot determine whether depressive symptoms preceded the development of MetSyn and its components or make causal inferences. Others have reported that the MetSyn may lead to depression, specifically that hyperglycemia increases HPA axis activity causing arousal of the central nervous system and thus, promoting development of depression. $^{40}$

In summary, depressive symptoms were associated with an increasing number of MetSyn components and with higher odds of having the individual MetSyn components among Spokane men. Future studies should explore potential mediators for this association, including the role of the HPA axis and cortisol, inflammatory processes, and hyperinsulinemia, as these have been cited as potential mechanisms by others. It is particularly important to understand the association between depression and MetSyn among police officers, given the high stress nature of their job and the higher prevalence of CVD. It is also important to explore the gender-specific differences between male and female police officers. Depressive symptomatology and MetSyn are early indicators of 
future chronic health problems and the results could assist in the development of future gender-specific prevention and intervention efforts among police officers. 


\section{REFERENCES}

1. Deschamps F, Paganon-Badinier I, Marchand A-C, Merle C. Sources and assessment of occupational stress in the police. J Occup Health. 2003;45:358-364.

2. Gershon RR, Lin S, Li X. Work stress in aging police officers. J Occup Environ Med.. 2002;44:160-7.

3. Chandola T, Heraclides A, Kumari M. Psychophysiological biomarkers of workplace stress. Neurosci Biobehav Rev. 2010;35:51-57.

4. Cohen BE, Panguluri P, Na B, Whooley MA. Psychological risk factors and the metabolic syndrome in patients with coronary heart disease: Findings from the Heart and Soul Study. Psychiatry Res. 2010;175:133-137.

5. Heiskanen TH, Niskanan LK, Hintikka JJ, et al. Metabolic syndrome and depression: A cross-sectional analysis. J Clin Psychiatry. 2006;67:422-1427.

6. Igna CV, Julkunen J, Vanhanen H, Keskivaara P, Verkasalo M. Depressive symptoms and serum lipid fractions in middle-aged men: Physiologic and health behavior links. Psychosom Med. 2008;70:960-966.

7. Kinder LS, Carnethon MR, Palaniappan LP, King AC, Fortmann SP. Depression and the metabolic syndrome in young adults: Findings from the Third National Health and Nutrition Examination Survey. Psychosom Med. 2004;66:316-322.

8. Lett HS, Blumenthal JA, Babyak MA, et al. Depression as a risk factor for coronary artery disease: Evidence, mechanisms, and treatment. Psychosom Med. 2004;66:305315.

9. McCaffery JM, Niaura R, Todaro JF, Swan GE, Darmelli D. Depressive symptoms and metabolic risk in adult male twins enrolled in the National Heart, Lung, and Blood Institute Twin Study. Psychosom Med. 2003;65:490-497.

10. Mezick EJ, Hall M, Matthews KA. Are sleep and depression independent or overlapping risk factors for cardiometabolic disease? Sleep Med Rev. 2010;in press.

11. Muhtz C, Zyriax B-C, Klahn T, Windler E, Otte C. Depressive symptoms and metabolic risk: Effects of cortisol and gender. Psychoneuroendocrinology. 2009;34:1004-1011.

12. Pan A, Lucas M, Sun Q, et al. Increased mortality risk in women with depression and diabetes mellitus. Arch Gen Psychiatry. 2011;68:42-50.

13. Rozanski A, Blumenthal JA, Kaplan J. Impact of psychological factors on the pathogenesis of cardiovascular disease and implications for therapy. Circulation. 1999;99:2192-2217.

14. Toker S, Shirom A, Melamed S. Depression and the metabolic syndrome: Genderdependent associations. Depress Anxiety. 2008;25:661-669. 
15. Vaccarino V, McClure C, Johnson D, et al. Depression, the metabolic syndrome and cardiovascular risk. Psychosom Med. 2008;70:40-48.

16. Vitaliano PP, Scanlan JM, Zhang J, Savage MV, Hirsch IB, Siegler IC. A path model of chronic stress, the metabolic syndrome, and coronary heart disease. Psychosom Med. 2002;64:418-435.

17. Franke WD, Collins SA, Hinz PN. Cardiovascular disease morbidity in an Iowa law enforcement cohort, compared with general Iowa population. J Occup Environ Med. 1998;40:441-444.

18. Violanti JM, Vena JE, Petralia S. Mortality of a police cohort: 1950-1990. Am J Ind Med. 1998;33:366-373.

19. Reaven GM. Banting lecture 1988: Role of insulin resistance in human disease. Diabetes. 1988;37:1595-1607.

20. Capuron L, Su S, Miller AH, et al. Depressive symptoms and metabolic syndrome: Is inflammation the underlying link? Biol Psychiatry. 2007;64:896-9900.

21. East C, Willis BL, Barlow CE, et al. Depressive symptoms and metabolic syndrome in preventive healthcare: The Cooper Center Longitudinal Study. Metab Syndr Relat Disord. 2010;8:451-457.

22. Herva A, Rasanen P, Mieuttunen J, et al. Co-occurrence of metabolic syndrome with depression and anxiety in young adults: The Northern Finland, 1966 Birth Cohort Study. Psychosom Med. 2006;68:213-216.

23. Laudisio A, Marzetti E, Pagano F, Pozzi G, Barnabei R, Zuccala G. Depressive symptoms and metabolic syndrome: Selective association in older women. J Geriatr Psychiatry Neurol. 2009;22:215-222.

24. Raikkonen K, Matthews K, Kuller LH. The relationship between psychological risk attributes and the metabolic syndrome in healthy women: Antecedent or consequence? Metabolism. 2002;51:1573-1577.

25. Raikkonen K, Matthews KA, Kuller LH. Depressive symptoms and stressful life events predict metabolic syndrome among middle-aged women. Diabetes Care. 2007;30:872-877.

26. Skilton MR, Moulin P, Terra J-L, Bonnet B. Associations between anxiety, depression, and the metabolic syndrome. Biol Psychiatry. 2007;62:1251-1257.

27. Vogelzangs N, Suthers K, Ferrucci L, et al. Hypercortisolemic depression is associated with the metabolic syndrome in late-life. Psychoneuroendocrinology. 2007;32:151-159.

28. Nicholson A, Kuper H, Hemingway H. Depression as an aetiologic and prognostic factor in coronary heart disease: A meta-analysis of 6362 events among 146,538 participants in 54 observational countries. Eur Heart J. 2006;27:2763-2774. 
29. Zhang J, Niaura R, Dyer JR, et al. Hostility and urine norepinephrine interact to predict insulin resistance: The VA Normative Aging Study. Psychosom Med. 2006;68:718-726.

30. Rosmond R, Bjorntorp P. The hypothalamic-pituitary-adrenal axis activity as a predictor of cardiovascular disease, type 2 diabetes and stroke. J Intern Med. 2000;247:188-197.

31. Holsboer F. Stress, hypercortisolism and corticosteroid receptors in depression: Implications for therapy. J Affect Disord. 2001;62:77-91.

32. Bjorntorp P. Do stress reactions cause abdominal obesity and comorbidities? Obes Rev. 2001;2:73-86.

33. Mikolaenko I, Benson E, Konrad RJ, Chaffin C, Robinson CA, Hardy RW. Evaluation of the Beekman Coulter LX20 clinical chemistry analyzer. Lab Med. 2000;31:387-393.

34. Radloff LS. The CES-D scale: A self-report depression scale for research in the general population. Applied Psychological Measure. 1977;1:385-401.

35. Grundy SM, Cleeman JI, Daniels SR, et al. Diagnosis and management of the metabolic syndrome. An American Heart Assocation/National Heart, Lung, and Blood Institute Scientific Statement. Circulation. 2005;112:2735-2752.

36. Wuslin LR, Evans JC, Ramachandran SV, Murabito JM, Kelly-Hayes M, Benjamin EJ. Depressive symptoms, coronary heart disease, and overall mortality in the Framingham Heart Study. Psychosom Med. 2005;67:697-702.

37. Davila EP, Florez H, Fleming LE, et al. Prevalence of the metabolic syndrome among US workers. Diabetes Care. 2010;33:2390-2395.

38. Miettola J, Niskanan LE, Viinamaki H, Kumpusalo E. Metabolic syndrome is associated with self-perceived depression. Scand J Prim Health Care. 2008;26:203210.

39. Goldbacher EM, Bromberger J, Matthews KA. Lifetime history of major depression predicts the development of the metabolic syndrome in middle-aged women. Psychosom Med. 2009;71:266-272.

40. Viinamaki H, Heiskanan T, Lehto SM, et al. Association of depressive symptoms and metabolic syndrome in men. Acta Psychiatr Scand. 2009;120: 23-29.

41. Blackmore ER, Stansfeld SA, Weller L, Munce S, Zagorski BM, Stewart DE. Major depressive episodes and work stress: Results from a national population survey. Am J Public Health. 2007;97:2088-2093.

42. Gil K, Radzillowicz P, Zdrojewski T, et al. Relationship between the prevalence of depressive symptoms and metabolic syndrome: Results of the SOPKARD Project. Kardiol Pol. 2006;64:464-469.

43. Richter N, Juckel G, Assion H-J. Metabolic syndrome: A follow-up study of acute depressive inpatients. Eur Arch Psychiatry Clin Neurosci. 2010;260:41-49. 
44. McIntyre RS, Rasgon NL, Kemp DE, et al. Metabolic syndrome and major depressive disorder: Co-occurrence and pathophysiological overlap. Curr Diab Rep. 2009;9:51-59.

45. Deuschle M, Weber B, Colla M, Depner M, Heuser, I. Effects of major depression, aging and gender upon calculated diurnal free plasma cortisol concentrations: A reevaluation study. Stress. 1998;2:281-287.

46. Weber-Hamaan B, Hentschel F, et al. Hypercortisolemic depression is associated with increased intra-abdominal fat. Psychosom Med. 2002;64:274-277.

47. Castillo-Quan JI, Perez-Osorio JM, Herrera-Gonzalez A. Letter to the Editor: Insulin-cortisol interaction in depression and other neurological diseases: An alternative hypothesis. Psychoneuroendocrinology. 2007;32:854-855.

48. Freuhwald-Schultes B, Kern W, Bong W, et al. Supraphysiological hyperinsulinemia acutely increases hypothalamic-pituitary-adrenal secretory activity in humans. J Clin Endocrinol Metab. 1999;84:3041-3046.

49. Everson-Rose SA, Meyer PM, Powell LH, et al. Depressive symptoms, insulin resistance, and risk of diabetes in women at midlife. Diabetes Care. 2004;27:28562862.

50. Liukkonen T, Silvennoinen-Kassinen S, Jokelainen J, et al. The association between C-reactive protein levels and depression: Results from the Northern Finland 1966 Birth Cohort Study. Biol Psychiatry. 2006;60:825-830.

51. Jilma B, Dirnberger E, Loscher I, et al. Menstrual cycle-associated changes in blood levels of interleukin-6, alpha1 acid glycoprotein, and C-reactive protein. J Lab Clin Med. 1997;130:69-75.

52. Fekedulegn D, Andrew M, Violanti J, Hartley T, Charles L, Burchfiel C. Comparison of statistical approaches to evaluate factors associated with metabolic syndrome. J Clin Hypertens. 2010;12:363-373. 


\section{TABLES}

* The working tables can be found in Appendix B. 
Table 3.1. Demographic characteristics by location and gender.

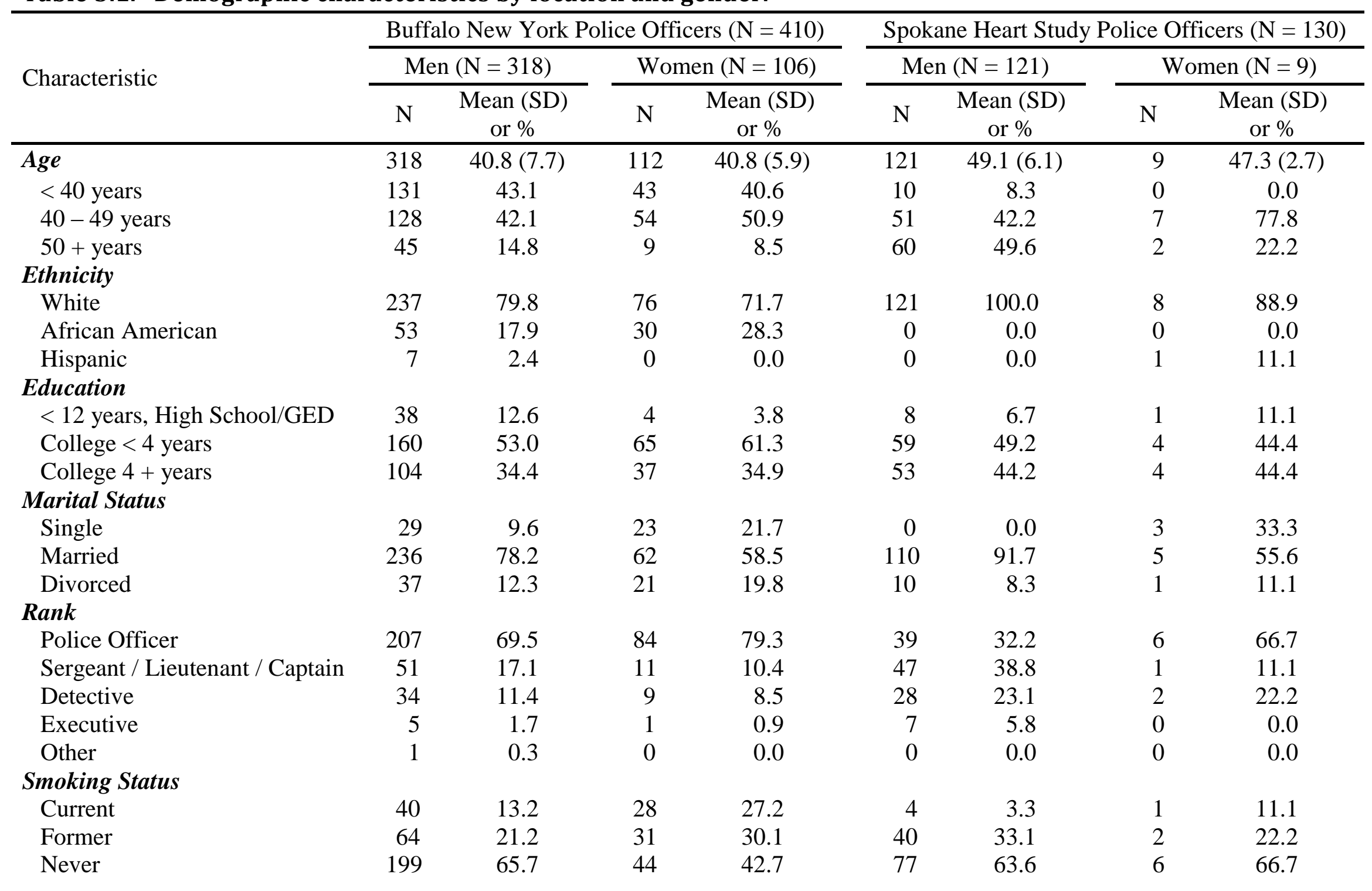




\begin{tabular}{|c|c|c|c|c|c|c|c|c|}
\hline Body Mass Index, $\mathrm{kg} / \mathrm{m}^{2}$ & 304 & $30.3(4.2)$ & 106 & $26.0(4.7)$ & 124 & $29.8(3.9)$ & 9 & $28.9(4.6)$ \\
\hline$<25$ & 23 & 7.6 & 53 & 50.0 & 5 & 4.1 & 0 & 0.0 \\
\hline $25-30$ & 137 & 45.1 & 36 & 34.0 & 65 & 53.7 & 7 & 77.8 \\
\hline$>30$ & 144 & 47.4 & 17 & 16.0 & 51 & 42.2 & 2 & 22.2 \\
\hline Low Score: $0-8$ & 203 & 66.8 & 68 & 64.2 & 88 & 72.7 & 7 & 77.8 \\
\hline Middle Score: $9-15$ & 70 & 23.0 & 21 & 19.8 & 22 & 18.2 & 2 & 22.2 \\
\hline High Score (Depression): 16+ & 31 & 10.2 & 17 & 16.0 & 11 & 9.1 & 0 & 0.0 \\
\hline
\end{tabular}


Table 3.2. Mean levels and prevalence of metabolic syndrome by gender and geographic location.

\begin{tabular}{|c|c|c|c|c|c|c|c|c|c|c|c|c|c|c|c|c|c|}
\hline \multirow{4}{*}{ Metabolic Syndrome Component } & \multirow{4}{*}{$\begin{array}{l}\text { Component } \\
\text { Cutpoint (Must meet } \\
\geq 1 \text { of the cutpoints } \\
\text { per component) }\end{array}$} & \multicolumn{12}{|c|}{ Prevalence } & \multicolumn{4}{|c|}{ Mean (SD) } \\
\hline & & \multicolumn{6}{|c|}{ Buffalo } & \multicolumn{6}{|c|}{ Spokane } & \multicolumn{2}{|c|}{ Buffalo } & \multicolumn{2}{|c|}{ Spokane } \\
\hline & & \multicolumn{2}{|c|}{ Men } & \multicolumn{2}{|c|}{ Women } & \multicolumn{2}{|c|}{ Overall } & \multicolumn{2}{|c|}{ Men } & \multicolumn{2}{|c|}{ Women } & \multicolumn{2}{|c|}{ Overall } & \multirow{2}{*}{$\begin{array}{c}\text { Men } \\
(\mathrm{N}=304)\end{array}$} & \multirow{2}{*}{$\begin{array}{l}\text { Women } \\
(\mathrm{N}=106)\end{array}$} & \multirow{2}{*}{$\begin{array}{c}\text { Men } \\
(\mathrm{N}=121)\end{array}$} & \multirow{2}{*}{$\begin{array}{l}\text { Women } \\
(\mathrm{N}=9)\end{array}$} \\
\hline & & $\mathrm{N}$ & $\% *$ & $\mathrm{~N}$ & $\% *$ & $\mathrm{~N}$ & $\% *$ & $\mathrm{~N}$ & $\% *$ & $\mathrm{~N}$ & $\% *$ & $\mathrm{~N}$ & $\% *$ & & & & \\
\hline Abdominal obesity & & 113 & 37.2 & 18 & 17.0 & 131 & 32.0 & 48 & 39.7 & 5 & 55.6 & 53 & 40.8 & & & & \\
\hline Waist circumference, $\mathrm{cm}$ & $\begin{array}{l}\geq 102 \text { Men, } \geq 88 \\
\quad \text { Women }\end{array}$ & & & & & & & & & & & & & $99.3(11.4)$ & $79.9(11.5)$ & $100.3(10.8)$ & $87.5(9.9)$ \\
\hline Elevated triglycerides & & 117 & 38.5 & 9 & 8.5 & 126 & 30.7 & 52 & 43.0 & 3 & 33.3 & 55 & 42.3 & & & & \\
\hline Triglycerides, mg/dL & $\geq 150$ & 113 & 37.2 & 9 & 8.5 & 122 & 28.6 & 53 & 42.7 & 3 & 30.0 & 56 & 41.8 & $153.8(127.4)$ & $88.4(130.0)$ & $157.6(102.7)$ & $165.3(150.6)$ \\
\hline $\begin{array}{l}\text { Self-reported fibrates or nicotinic } \\
\text { acid medication, } \%\end{array}$ & Yes & 6 & 2.0 & 1 & 0.9 & 7 & 1.7 & 5 & 4.1 & 0 & 0.0 & 5 & 3.8 & & & & \\
\hline Reduced HDL cholesterol & & 143 & 47.0 & 28 & 26.4 & 171 & 41.7 & 53 & 43.8 & 2 & 22.2 & 55 & 42.3 & & & & \\
\hline HDL cholesterol, mg/dL & $<40$ Men, <50 Women & 142 & 46.7 & 28 & 24.8 & 170 & 40.0 & 54 & 43.5 & 2 & 20.0 & 56 & 41.8 & $42.2(12.0)$ & $58.3(15.7)$ & $42.6(12.4)$ & $56.0(16.1)$ \\
\hline $\begin{array}{l}\text { Self-reported fibrates or nicotinic } \\
\text { acid medication, } \%\end{array}$ & Yes & 6 & 2.0 & 1 & 0.9 & 7 & 1.7 & 5 & 4.1 & 0 & 0.0 & 5 & 3.8 & & & & \\
\hline Glucose intolerance & & 83 & 27.3 & 12 & 11.3 & 95 & 23.2 & 46 & 38.0 & 3 & 33.3 & 49 & 37.7 & & & & \\
\hline Fasting glucose, $\mathrm{mg} / \mathrm{dL}$ & $\geq 100$ & 81 & 26.6 & 11 & 10.4 & 92 & 21.9 & 48 & 38.7 & 3 & 30.0 & 51 & 38.1 & $94.7(14.0)$ & $86.4(8.4)$ & $98.9(10.7)$ & $93.4(10.3)$ \\
\hline $\begin{array}{l}\text { Self-reported diabetes medication, } \\
\%\end{array}$ & Yes & 7 & 2.3 & 1 & 0.9 & 8 & 2.0 & 4 & 3.3 & 0 & 0.0 & 4 & 3.1 & & & & \\
\hline Hypertension & & 129 & 42.4 & 27 & 25.5 & 156 & 38.1 & 55 & 45.5 & 2 & 22.2 & 57 & 43.9 & & & & \\
\hline Systolic blood pressure, $\mathrm{mmHg}$ & $\geq 130$ & 69 & 22.7 & 18 & 17.0 & 87 & 20.9 & 37 & 29.8 & 3 & 30.0 & 40 & 29.9 & $122.2(11.3)$ & $116.7(13.3)$ & $125.0(10.3)$ & $121.8(10.1)$ \\
\hline Diastolic blood pressure, $\mathrm{mmHg}$ & $\geq 85$ & 79 & 26.0 & 17 & 16.0 & 96 & 23.3 & 35 & 28.2 & 0 & 0.0 & 35 & 26.1 & $78.7(10.2)$ & $74.6(9.6)$ & $81.1(8.5)$ & $78.9(4.7)$ \\
\hline $\begin{array}{l}\text { Self-reported hypertension with } \\
\text { antihypertensive medication, } \%\end{array}$ & Yes & 45 & 14.8 & 7 & 6.6 & 52 & 12.7 & 17 & 14.0 & 0 & 0.0 & 17 & 13.0 & & & & \\
\hline Number of Components & & & & & & & & & & & & & & $1.9(1.4)$ & $0.9(1.1)$ & $2.1(1.4)$ & $1.7(1.9)$ \\
\hline & 0 & 54 & 17.8 & 53 & 50.0 & 107 & 26.1 & 14 & 11.6 & 4 & 44.4 & 18 & 13.9 & & & & \\
\hline & 1 & 75 & 24.7 & 25 & 23.6 & 100 & 24.4 & 32 & 26.5 & 1 & 11.1 & 33 & 25.4 & & & & \\
\hline & 2 & 79 & 26.0 & 19 & 17.9 & 98 & 23.9 & 30 & 24.8 & 1 & 11.1 & 31 & 23.9 & & & & \\
\hline & 3 & 48 & 15.8 & 6 & 5.7 & 54 & 13.2 & 22 & 18.2 & 1 & 11.1 & 23 & 17.7 & & & & \\
\hline & 4 & 32 & 10.5 & 2 & 1.9 & 34 & 8.3 & 19 & 15.7 & 1 & 11.1 & 20 & 15.4 & & & & \\
\hline & 5 & 16 & 5.3 & 1 & 0.9 & 17 & 4.2 & 4 & 3.3 & 1 & 11.1 & 5 & 3.9 & & & & \\
\hline & Prevalence $(\geq 3)$ & 96 & 31.6 & 9 & 8.5 & 105 & 25.6 & 45 & 37.2 & 3 & 33.3 & 48 & 36.9 & & & & \\
\hline
\end{tabular}


Table 3.3. Unadjusted and adjusted number of metabolic syndrome components by categories of CES-D score by location and gender.

\begin{tabular}{|c|c|c|c|c|c|c|c|c|c|}
\hline \multirow{3}{*}{$\begin{array}{l}\text { Categories } \\
\text { of CES-D }\end{array}$} & \multicolumn{9}{|c|}{ Number of Metabolic Syndrome Components } \\
\hline & \multicolumn{3}{|c|}{ Unadjusted } & \multicolumn{3}{|c|}{ Age-Adjusted } & \multicolumn{3}{|c|}{ Multivariate Adjusted* } \\
\hline & $\mathrm{N}$ & Mean (SD) & p-value** & $\mathrm{N}$ & Mean (SD) & p-value** & $\mathrm{N}$ & Mean (SD) & p-value** \\
\hline \multicolumn{10}{|c|}{ Buffalo Men } \\
\hline $0-8$ & 203 & $1.8(1.4)$ & & 203 & $1.8(0.1)$ & & 202 & $1.9(0.1)$ & \\
\hline $9-15$ & 70 & $2.2(1.3)$ & 0.431 & 70 & $2.2(0.2)$ & 0.379 & 69 & $2.3(0.2)$ & 0.390 \\
\hline$\geq 16$ & 31 & $1.9(1.5)$ & & 31 & $2.0(0.2)$ & & 31 & $2.0(0.3)$ & \\
\hline \multicolumn{10}{|c|}{ Buffalo Women } \\
\hline $0-8$ & 68 & $0.8(1.1)$ & & 68 & $0.8(0.1)$ & & 65 & $0.8(0.1)$ & \\
\hline $9-15$ & 21 & $1.1(1.4)$ & 0.376 & 21 & $1.1(0.2)$ & 0.377 & 21 & $1.2(0.3)$ & 0.610 \\
\hline$\geq 16$ & 17 & $0.9(0.9)$ & & 17 & $0.9(0.3)$ & & 17 & $0.7(0.3)$ & \\
\hline \multicolumn{10}{|c|}{ Spokane Men } \\
\hline $0-8$ & 88 & $1.9(1.3)$ & & 88 & $1.9(0.1)$ & & 88 & $1.8(0.3)$ & \\
\hline $9-15$ & 22 & $2.6(1.3)$ & 0.003 & 22 & $2.6(0.3)$ & 0.004 & 21 & $2.7(0.4)$ & 0.003 \\
\hline$\geq 16$ & 11 & $3.1(1.6)$ & & 11 & $3.0(0.4)$ & & 11 & $3.0(0.5)$ & \\
\hline
\end{tabular}

\footnotetext{
* Adjusted for age, smoking status and marital status

** p-values are based on the continuous CES-D score
} 
Table 3.4. Multivariate adjusted* number of metabolic syndrome components by categories of CES-D score by location and gender stratified by age and police rank.

\begin{tabular}{|c|c|c|c|c|c|c|c|c|c|c|c|c|}
\hline \multirow{2}{*}{$\begin{array}{l}\text { Categories } \\
\text { of CES-D }\end{array}$} & \multicolumn{3}{|c|}{ Age $\leq 40$} & \multicolumn{3}{|c|}{ Age $>40$} & \multicolumn{3}{|c|}{ Police Officer } & \multicolumn{3}{|c|}{ All Higher Ranks } \\
\hline & $\mathrm{N}$ & $\begin{array}{l}\text { Mean } \\
\text { (SD) }\end{array}$ & $\begin{array}{c}\mathrm{p}^{-} \\
\text {value } * *\end{array}$ & $\mathrm{~N}$ & $\begin{array}{l}\text { Mean } \\
\text { (SD) }\end{array}$ & $\begin{array}{c}\text { p- } \\
\text { value }{ }^{* *}\end{array}$ & $\mathrm{~N}$ & $\begin{array}{l}\text { Mean } \\
\text { (SD) }\end{array}$ & $\begin{array}{c}\mathrm{p}- \\
\text { value }{ }^{* *}\end{array}$ & $\mathrm{~N}$ & $\begin{array}{l}\text { Mean } \\
(\mathrm{SD})\end{array}$ & $\begin{array}{c}\mathrm{p}^{-} \\
\text {value }\end{array}$ \\
\hline \multicolumn{13}{|l|}{ Buffalo Men } \\
\hline $9-15$ & 32 & $1.8(0.3)$ & 0.124 & 37 & $2.5(0.3)$ & 0.850 & 48 & $2.0(0.2)$ & 0.588 & 21 & $2.9(0.5)$ & 0.752 \\
\hline $16+$ & 15 & $2.0(0.4)$ & & 16 & $1.9(0.4)$ & & 17 & $1.6(0.4)$ & & 14 & $2.8(0.4)$ & \\
\hline \multicolumn{13}{|l|}{ Buffalo Women } \\
\hline \multirow[t]{2}{*}{$16+$} & 9 & $0.6(0.4)$ & & 8 & $0.4(0.4)$ & & 11 & $0.8(0.3)$ & & 6 & $0.5(0.6)$ & \\
\hline & \multicolumn{3}{|c|}{ Age $\leq 49$} & \multicolumn{3}{|c|}{ Age $>49$} & & & & & & \\
\hline Spokane Men & & & & & & & & & & & & \\
\hline $0-8$ & 45 & $2.1(0.4)$ & & 43 & $1.9(0.3)$ & & 30 & $2.1(0.3)$ & & 58 & $1.8(0.4)$ & \\
\hline $9-15$ & 14 & $3.0(0.5)$ & 0.076 & 7 & $2.8(0.6)$ & 0.025 & 6 & $3.6(0.6)$ & $<0.0001$ & 15 & $2.4(0.4)$ & 0.298 \\
\hline
\end{tabular}

* Adjusted for age, smoking and marital status

** p-values are based on the continuous CES-D score 
Table 3.5. Unadjusted and adjusted odds ratios for MetSyn components by CES-D score for Spokane men.

\begin{tabular}{|c|c|c|c|c|c|c|}
\hline \multirow[t]{2}{*}{ MetSyn Component } & \multicolumn{2}{|c|}{$\begin{array}{l}\text { Unadjusted } \\
(\mathrm{N}=121)\end{array}$} & \multicolumn{2}{|c|}{$\begin{array}{l}\text { Age-Adjusted } \\
\qquad(\mathrm{N}=121)\end{array}$} & \multicolumn{2}{|c|}{$\begin{array}{l}\text { Multivariate Adjusted* } \\
\qquad(\mathrm{N}=120)\end{array}$} \\
\hline & Odds Ratio & $95 \% \mathrm{CI}$ & Odds Ratio & $95 \% \mathrm{CI}$ & Odds Ratio & $95 \% \mathrm{CI}$ \\
\hline Abdominal Obesity & 1.422 & $1.010-2.003$ & 1.396 & $0.985-1.977$ & 1.338 & $0.932-1.917$ \\
\hline Elevated Triglycerides & 1.364 & $0.970-1.917$ & 1.449 & $1.020-2.064$ & 1.476 & $1.025-2.119$ \\
\hline Reduced HDL-C & 0.975 & $0.699-1.357$ & 1.010 & $0.718-1.416$ & 1.030 & $0.730-1.456$ \\
\hline Glucose Intolerance & 1.553 & $1.088-2.202$ & 1.456 & $1.005-2.119$ & 1.567 & $1.056-2.327$ \\
\hline Hypertension & 1.396 & $0.985-1.968$ & 1.370 & $0.965-1.942$ & 1.518 & $1.035-2.221$ \\
\hline
\end{tabular}

* Adjusted for age, smoking status and marital status 
CHAPTER 4. METABOLIC SYNDROME AND CAROTID INTIMA MEDIA THICKNESS IN URBAN POLICE OFFICERS 


\section{Coauthors}

Tara A. Hartley, M.P.A., M.P.H.

Biostatistics and Epidemiology Branch, Health Effects Laboratory Division, National Institute for Occupational Safety and Health and the Department of Community Medicine, School of Medicine

Anoop Shankar, M.D., Ph.D.

Department of Community Medicine, School of Medicine, West Virginia University

Desta Fekedulegn, Ph.D.

Biostatistics and Epidemiology Branch, Health Effects Laboratory Division, National Institute for Occupational Safety and Health

John M. Violanti, Ph.D.

Department of Social and Preventive Medicine, School of Public Health and Health Professions, University at Buffalo

Michael E. Andrew, Ph.D.

Biostatistics and Epidemiology Branch, Health Effects Laboratory Division, National Institute for Occupational Safety and Health

Sarah S. Knox, Ph.D.

Department of Community Medicine, School of Medicine and the Mary Babb Randolph Cancer Center, West Virginia University

Cecil M. Burchfiel, Ph.D., M.P.H.

Biostatistics and Epidemiology Branch, Health Effects Laboratory Division, National Institute for Occupational Safety and Health

* Published ahead of print in the Journal of Occupational and Environmental Medicine. doi: 10.1097/JOM.0b013e3182171995. April 18, 2011

* Poster presentation received $1^{\text {st }}$ place at the 2010 West Virginia University Health Sciences Center Van Liere Research Day.

\section{Funding Support}

This work was supported by the National Institute for Occupational Safety and Health (NIOSH) contract number 200-2003-01580.

\section{Disclaimer}

The findings and conclusions in this report are those of the authors and do not necessarily represent the views of NIOSH. 


\subsection{INTRODUCTION}

Metabolic syndrome (MetSyn), a clustering of risk factors including abdominal obesity, hypertension, dyslipidemia and glucose intolerance, has increased over the past two decades. ${ }^{1}$ Individuals with MetSyn have an increased risk of subclinical atherosclerosis, coronary heart disease (CHD), cardiovascular disease (CVD) morbidity and mortality, target organ damage, and total mortality. ${ }^{2-5}$

Changes in vascular structure, including increased carotid arterial wall thickness, are early events in atherosclerosis progression and are increasingly recognized as significant independent predictors of adverse CVD outcomes. ${ }^{6,7}$ Carotid intima media thickness (IMT) is considered a valid index of subclinical atherosclerosis, and ultrasonography of the carotid artery has been shown to be a sensitive, useful, reliable, noninvasive, and reproducible method..$^{3,5,7-10}$

The prevalence of MetSyn, an increase in the number of MetSyn components, and the individual MetSyn components have been shown to be strong independent predictors of greater carotid IMT and carotid IMT progression. ${ }^{3-6,11-16}$ The prevalence of MetSyn is generally similar for men and women; however, triglycerides, central adiposity, and diabetes mellitus have stronger effects on CVD outcomes in women and more women die from CVD annually than men. ${ }^{17-19}$ In line with this, studies have found that the association between MetSyn and carotid IMT is more pronounced in women than in men, although the pathologic mechanisms remain unclear. ${ }^{20-23}$

Epidemiological studies have shown that police officers have an elevated risk of atherosclerotic heart disease, a higher prevalence of MetSyn, higher levels of carotid IMT, higher rates of CVD 
and more adverse CVD risk factor levels, particularly hypertension and hypercholesterolemia, compared to non-police populations. ${ }^{24-32}$ Importantly, Forastiere found an excess risk of ischemic heart disease among officers less than 50 years of age and Violanti observed higher rates of arteriosclerotic heart disease among officers with fewer years of service, indicating greater susceptibility to heart disease among police officers early in their careers. ${ }^{27,33}$

The majority of these studies were conducted in male officers only or among mixed populations, yet CVD risk differs by gender. Levels of stress, particularly work stress, are known risk factors for CVD and may be higher among female officers due to the challenges of working in a male dominated occupation. ${ }^{34-37}$ A recent study found that female officers had higher levels of perceived stress and work stress than their male counterparts, and a higher prevalence of hypercholesterolemia than the general female population. ${ }^{37}$ A recent review identified other studies where jobs characterized as high demand and low control in women were associated with elevated cholesterol levels. $^{38}$

The higher prevalence of hypercholesterolemia found in women in these studies is surprising since estrogen has beneficial effects on traditional CVD risk factors, including reduction of total cholesterol, triglycerides, low density lipoprotein cholesterol (LDL-C), hypertension, abdominal obesity and insulin resistance, and increased high density lipoprotein cholesterol (HDL-C). ${ }^{20,23,39-}$ ${ }^{41}$ This is particularly important given the stronger effects of lipoproteins and abdominal obesity on CVD outcomes in women. ${ }^{17}$ Endogenous estrogen deficiency has been found to be a risk factor for heart disease in premenopausal women who participated in the Women's Ischemia 
Syndrome Evaluation (WISE) Study, whereas, the beneficial effects of exogenous estrogen are conflicting. $^{40,42-44}$

No known studies were identified which have examined the relationship between MetSyn and carotid IMT in police officers, nor specific differences between male and female officers. Addressing these research gaps are important for two reasons: epidemiological studies may provide a better understanding of the gender-specific pathophysiological processes involved in the early stages of atherosclerosis and emphasize the need for early treatment. ${ }^{11,39}$ Moreover, given the increased risk of heart disease among young officers and the fact that the average age of death for male police officers was found to be 64 years, there is clearly a need for early intervention with this group. ${ }^{45}$ If MetSyn is associated with the earlier stages of CVD it is an identifiable area where intervention could provide significant public health benefit.

The aims of this study were to determine: 1) whether an association exists between MetSyn and carotid IMT among police officers, a known high stress occupational group, 2) whether the association varies by gender, and 3) the specific MetSyn components that are most strongly related to carotid IMT. The specific hypotheses were 1) officers with a higher number of MetSyn components will have greater carotid IMT than officers with fewer number of MetSyn components; 2) the association between MetSyn components and carotid IMT will be different in female officers than male officers; 3) the specific MetSyn components associated with carotid IMT will be different between male and female officers. 


\subsection{METHODS}

\subsubsection{STUDY DESIGN AND POPULATION}

As indicated above, police officers are known to experience high levels of stress and suffer from higher rates of CVD than other occupations. With this in mind, the Buffalo Cardio-Metabolic Occupational Police Stress (BCOPS) Study was conducted between 2004 and 2009 to assess whether workplace stress is associated with adverse subclinical metabolic and CV outcomes. The information gained may increase understanding of how stress in the workplace leads to adverse health outcomes. The purpose of this study of urban police officers was to examine the crosssectional association between various police stressors and physiological and psychological health consequences. The Center for Health Research, School of Public Health and Health Professions, State University of New York at Buffalo in Buffalo served as the data collection site. All 710 active duty police officers from the Buffalo, New York, Police Department were invited to participate in the study. Recruitment was conducted by open enrollment during the study period. Between 2004 and 2007, the number of active duty officers decreased to approximately 600 due to retirements and officers leaving the force with no new hiring until January 2008 when 80 recruits were added. No specific inclusion criteria were used for the study, other than that the participant would be a sworn police officer and willing to participate in the study. Two women officers who were pregnant at the time of examination were excluded. Of the 464 officers examined at a single time during this period, 54 were removed from analyses ( 33 retired, 1 missing demographic information, 17 missing MetSyn, 3 missing carotid IMT) leaving a final sample of 410 officers (304 men, 106 women). All participants provided informed consent and all phases, testing, and reports of the study were approved by the State University of New York 
at Buffalo Internal Review Board and the National Institute for Occupational Safety and Health Human Subjects Review Board.

\subsubsection{PROCEDURES AND MEASURES}

Questionnaires were administered to collect demographic and lifestyle information on age, gender, education, rank, marital status, physical activity, smoking, and alcohol use. Participants provided a medical history (including history of heart disease) and a 12 hour fasting blood sample was collected by a certified phlebotomist. Medication use was ascertained through selfreport and by inventory of current medications brought to the clinic. Blood parameters for the MetSyn were measured by standard laboratory techniques on the Beckman Coulter LX20 clinical chemistry analyzer and included a blood lipid panel for HDL-C and triglycerides, and chemistry panels for glucose. ${ }^{46}$ Anthropometric measures were conducted by trained clinic personnel. Waist circumference was measured as abdominal girth at the highest point of the iliac crest and the lowest point of the costal margin in the mid-axillary line. Blood pressure was determined using the average of the second and third of three separate measurements of resting systolic and diastolic blood pressure obtained with a standard sphygmomanometer.

\subsubsection{METSYN}

The MetSyn criteria were based on the National Cholesterol Education Program Adult Treatment Panel guidelines with recent modifications from the American Heart Association (AHA) and the National Heart, Lung, and Blood Institute (NHLBI). ${ }^{47}$ The individual MetSyn components included: 1) abdominal obesity (gender-specific waist circumference $\geq 102 \mathrm{~cm}$ in males, $\geq 88 \mathrm{~cm}$ in females), 2) hypertension (systolic blood pressure $\geq 130 \mathrm{mmHg}$, diastolic blood pressure $\geq 85$ 
$\mathrm{mmHg}$ or reported physician-diagnosed hypertension and antihypertensive treatment), 3) reduced HDL-C (gender-specific fasting HDL-C $<40 \mathrm{mg} / \mathrm{dL}$ in men, $<50 \mathrm{mg} / \mathrm{dL}$ in women or reported treatment with nicotinic acid or fibrates), 4) elevated triglycerides (fasting triglycerides $\geq 150$ $\mathrm{mg} / \mathrm{dL}$ or reported treatment with nicotinic acid or fibrates), and 5) glucose intolerance (fasting serum glucose $\geq 100 \mathrm{mg} / \mathrm{dL}$ or reported treatment for diabetes). Participants were categorized according to the number of MetSyn components (0-5). MetSyn was considered present in individuals with three or more components.

\subsubsection{CARotid INTIMA MEDIA THICKNESS}

A standardized ultrasound protocol adopted from the Center for Medical Ultrasound at Wake Forest University was used by certified sonographers. To assess carotid IMT, participants lay in the supine position in a darkened, quiet room. Three electrocardiographic leads were attached to the participant's chest and a plastic arc marked with an angle scale was positioned near the shoulders as a reference to measure the ultrasound transducer interrogation angles during the procedure. High-resolution B-mode ultrasound was performed using a $7.5-$ to $10-\mathrm{MHz}$ transducer and a Biosound Esaote (AU5; Biosound Esaote, Inc., Indianapolis, IN) ultrasound machine. Scans from the head of the examination table were performed on both the right and left extracranial carotid arteries. A preliminary scan was performed to assess the participant's anatomy, distinguish the internal from external carotid arteries on the basis of flow velocity profiles (using Doppler), and determine the optimum angle for the IMT scan. Standardized longitudinal images were acquired of the near and far walls of the distal $10 \mathrm{~mm}$ portion of the common carotid artery (CCA), the carotid bifurcation, and proximal $10 \mathrm{~mm}$ of the internal 
carotid artery at the optimum angle and two additional scanning angles $\left(30^{\circ}-45^{\circ}\right.$ anterior and $30^{\circ}-45^{\circ}$ posterior). A total of 12 arterial segments at three angles per segment were scanned.

Three carotid IMT variables were calculated as continuous variables: 1) mean of the CCA IMT mean common, 2) mean maximum IMT of 36 segments - mean maximum 36 IMT, and 3) mean maximum IMT of 12 segments - mean maximum 12 IMT. The mean CCA IMT was measured in 12 CCA segments approximately $10 \mathrm{~mm}$ in length: the near and far wall, from three interrogation angles, on both the right and left side ( 2 walls $\mathrm{x} 3$ angles $\mathrm{x} 2$ sides $=12$ ). The mean maximum $_{36}$ IMT was measured in the CCA, bulb and internal carotid artery, from three interrogation angles on the right and left side of the near and far walls ( 3 sites x 3 angles x 2 sides x 2 walls $=36$ ) and computed as the average IMT for all 36 image segments. ${ }^{7}$ After all 36 image measurements were obtained a mathematical formula was used to select the largest value from the three interrogation angles for each segment ( 1 angle x 3 sites x 2 sides x 2 walls =12). These 12 maximum values were then averaged to obtain the mean maximum 12 IMT for each participant. ${ }^{31}$

\subsubsection{STATISTICAL METHODS}

Descriptive statistics were used to characterize the study population. Means (standard deviations) and prevalence were calculated for each MetSyn component, and overall prevalence was determined for the MetSyn. Analysis of variance and covariance were used to compare unadjusted and multivariate adjusted mean IMT values across individuals categorized by the number of MetSyn components. Tests for trend were obtained from polynomial orthogonal linear contrasts. Multivariate models included adjustment for age, smoking status and LDL-C given their association with MetSyn and carotid IMT, and evidence in the literature. Similar analyses 
were performed to compare unadjusted and multivariate adjusted mean IMT values between those with and without each of the five MetSyn components. Even though the test of interaction for gender was not statistically significant, results were stratified by gender in order to provide comparisons between male and female officers. All analyses were conducted using the SAS software, Version 9.1 (SAS Institute, Cary NC).

\subsection{RESUlTS}

\subsubsection{DEMOGRAPHIC CHARACTERISTICS}

Male and female officers were similar in age, ethnicity and educational levels (Table 4.1). More male officers were married than female officers (78.2\% vs. $57.6 \%)$. Male officers had more years of police service (mean 15.0 vs. 13.5 years) and held higher rank than female officers (31.0\% vs. $20.8 \%$ at the level of Sergeant or higher). The prevalence of current smoking was $13.2 \%$ in male officers compared with $26.9 \%$ in female officers.

Among male officers, the mean values for four traditional CVD risk factors were higher than the standard values recommended by the AHA: body mass index $=30.3 \mathrm{~kg} / \mathrm{m}^{2}\left(\geq 30.0 \mathrm{~kg} / \mathrm{m}^{2}\right.$ considered obese $)$, total cholesterol $=203.0 \mathrm{mg} / \mathrm{dL}($ goal $<200 \mathrm{mg} / \mathrm{dL})$, triglycerides $=155.0$ $\mathrm{mg} / \mathrm{dL}$ (goal $<150 \mathrm{mg} / \mathrm{dL})$, and systolic blood pressure $=122.3 \mathrm{mmHg}($ goal $<120 \mathrm{mmHg})$

(Table 4.1). ${ }^{48-50}$ The mean values for female officers were all less than the standard values. Male officers also had more adverse levels of each of the MetSyn components than female officers, and consequently, the mean number of MetSyn components was two-fold higher in men than in women (1.9 vs. 0.9). Male officers had greater carotid IMT than female officers. 


\subsubsection{METSYN AND ITS COMPONENTS}

The prevalence for each of the five MetSyn components ranged from 23.2\% for glucose intolerance to $42.4 \%$ for reduced HDL cholesterol (Table 4.2). The overall prevalence of MetSyn was $26.1 \%$. The prevalence for each component was greater, most often two-fold higher, for male than for female officers and correspondingly, the prevalence of MetSyn ( $\geq 3$ components) was $32.2 \%$ for males compared to $8.5 \%$ for females. Half of the female officers had zero MetSyn components compared to $17.8 \%$ of male officers. Nearly all officers with a particular component met the criteria for that component via the measurement level compared with the self-report medication criteria.

\subsubsection{ASSOCIATION BETWEEN CAROTID IMT AND NUMBER OF METSYN COMPONENTS}

Among women, the mean maximum 36 IMT was positively and significantly associated with the number of MetSyn components: $0=0.704 \mathrm{~mm}(0.083), 1=0.735 \mathrm{~mm}(0.087), 2=0.752 \mathrm{~mm}$ $(0.112), \geq 3=0.807 \mathrm{~mm}(0.173) ; \mathrm{p}$-linear trend $=0.004$ (Table 4.3). The association remained significant after multivariate adjustment for age, smoking status and LDL-C ( $\mathrm{p}$-linear trend = 0.006). Similarly, the mean common carotid IMT was positively and significantly associated with the number of MetSyn components: $0=0.564 \mathrm{~mm}(0.068), 1=0.596 \mathrm{~mm}(0.075), 2=$ $0.616 \mathrm{~mm}(0.092), \geq 3=0.636 \mathrm{~mm}(0.065)$, p-linear trend $=0.006$. The association remained significant after multivariate adjustment $(\mathrm{p}$-linear trend $=0.07)$. Although not statistically significant, a similar trend was observed for the multivariate adjusted maximum 12 carotid IMT in women: $0=0.816 \mathrm{~mm}(0.017), 1=0.831 \mathrm{~mm}(0.024), 2=0.832 \mathrm{~mm}(0.026), \geq 3=0.877 \mathrm{~mm}$ $(0.043)$; p-linear trend $=0.214)$. Additional analyses excluding women taking birth control 
medication $(n=20)$ and hormone replacement $(n=4)$ did not alter the association between number of MetSyn components and each carotid IMT measure appreciably (data not shown).

A positive and significant association was also found for male officers in the unadjusted model for all three carotid IMT variables: maximum $_{36}$ IMT p-linear trend $=0.004$, mean maximum 12 IMT p-linear trend $=0.030$, mean common carotid IMT p-linear trend $=0.001$. Nevertheless, adjustment for potential confounders attenuated these associations, which were mostly explained by age. Analysis excluding officers who self-reported any of the following (all were male officers): myocardial infarction $(n=3)$, atherectomy $(n=1)$, angioplasty $(n=4)$, stent (type not specified $=1$, coronary $=3$, carotid $=0)$, or bypass $(n=1)$ did not change the results appreciably (data not shown).

\subsubsection{ASSOCIATION BETWEEN CAROTID IMT AND INDIVIDUAL METSYN COMPONENTS}

Additional analyses involved the association of the three carotid IMT measures with the presence/absence of each of the five MetSyn components. Selected results are presented in Table 4.4. A multivariate adjusted association was found for hypertension (presence/absence) and carotid IMT among female officers: mean maximum ${ }_{36}$ IMT: $0.768 \mathrm{~mm}(0.018) \mathrm{vs} .0 .715 \mathrm{~mm}$ (0.010), p-value $=0.017$; mean maximum 12 IMT: $0.878 \mathrm{~mm}(0.023)$ vs. $0.810 \mathrm{~mm}(0.013), \mathrm{p}-$ value $=0.014 ;$ common carotid IMT: $0.634 \mathrm{~mm}(0.014)$ vs. $0.572 \mathrm{~mm}(0.008)$, p-value $<0.001$. Exclusion of women taking birth control medication and hormone replacement did not alter the association appreciably (data not shown). For men, mean maximum ${ }_{36}$ IMT was significantly larger in officers with hypertension than in officers without hypertension $(0.837 \mathrm{~mm}[0.174] \mathrm{vs}$. 
$0.775 \mathrm{~mm}[0.121], \mathrm{p}$-value $<0.001)$. Multivariate adjustment for age, smoking status and LDL-C (p-value $=0.023)$ slightly attenuated the association.

Women officers with low HDL-C had higher carotid IMT than those with higher HDL-C levels after multivariate adjustment: mean maximum ${ }_{36}$ IMT: $0.777 \mathrm{~mm}(0.017)$ vs. $0.711 \mathrm{~mm}(0.010)$,

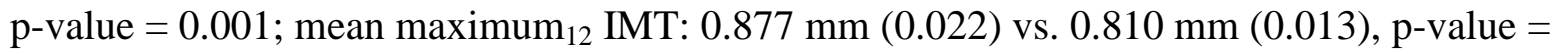
0.009; common carotid IMT: $0.619 \mathrm{~mm}(0.013)$ vs. $0.577 \mathrm{~mm}(0.008)$, p-value $=0.007$. Exclusion of women taking birth control medication and hormone replacement did not alter the association appreciably (data not shown).

\subsection{DisCUSSION}

As hypothesized, MetSyn was positively, significantly and independently associated with carotid IMT. Nevertheless, this association was only found in female officers lending support to our second hypothesis that the association would be stronger in female than in male officers. Both mean maximum 36 IMT and common carotid IMT were associated with a significant and positive increase in the number of MetSyn components among women even after adjustment for potential confounders. A similar relationship was observed for male officers, but only in the unadjusted models. The hypothesis that the association between the specific MetSyn components and carotid IMT would differ among male and female officers was partially met. Carotid IMT was significantly higher in those female officers who had either hypertension or reduced HDL-C, even after adjustment for age, smoking status, and LDL-C. Among men, those with 
hypertension had a thicker mean maximum ${ }_{36}$ carotid intima media layer than those free of hypertension.

Although others have reported similar findings, including differences in the association by gender, the current study is unique in that our study population included young, presumably healthy, adults working in a high stress occupation known to have an elevated risk of atherosclerotic disease..$^{3-6,10,11,13-16,23,51}$ In addition, 26\% of our sample was female permitting the opportunity to focus on police women, a known understudied population.

Noteworthy in the current study was that women officers had a lower prevalence of MetSyn and of each MetSyn component than men, yet MetSyn and two of its components were independently associated with carotid IMT in women only. Several potential explanations can be considered. MetSyn may affect the early progression of atherosclerosis more strongly in women than in men. ${ }^{22}$ This may result from variation in the contribution of each MetSyn component to carotid IMT or gender-specific differences in biologic pathways. ${ }^{3,8,12,20,21}$ There is also the possibility that job stress in women is associated with increased MetSyn prevalence. Research on female cynomolgus macaque monkeys whose CV system is very similar to that of humans has shown that chronic subordination stress is associated with reduction in HDL-C levels and a loss of premenopausal protection against atherosclerosis. ${ }^{52}$

Elevated blood pressure, one of the MetSyn components, and blood flow are major causes of mechanical stresses which affect the arterial wall and lumen. ${ }^{6}$ Mechanical stresses influence arterial wall structure and function in response to disease. ${ }^{6}$ Of the five MetSyn components, 
hypertension was significantly associated with both common carotid and maximum 36 carotid IMT in women and maximum ${ }_{36}$ IMT in men. Others have reported similar findings. ${ }^{3,11,13,14,21}$ From an occupational health perspective, Fujishiro et al. suggest that low job control may affect common carotid IMT through its association with hypertension. ${ }^{53}$ Policing itself is one of the most stressful occupations.

Women officers may face additional sources of stress including lack of influence, lack of acceptance, and lack of role models or mentors. ${ }^{37,54,55}$ In fact, female officers have reported high levels of perceived and work stress with over $40 \%$ attributing gender and occupation to their increased CVD risk. ${ }^{37}$ Policing is a male-dominated occupation with women accounting for only $11.2 \%$ of all sworn law enforcement personnel in the United States. ${ }^{56}$ Nationally, among large police departments (more than 100 officers), women officers hold lower ranks than men with $14.7 \%$ having supervisory positions compared to $20.6 \%$ of men. ${ }^{56}$ Among our police cohort, $31 \%$ of male officers held the rank of Sergeant or higher compared to only $20.8 \%$ of women officers.

The other significant association among the MetSyn components was for HDL-C with common carotid and maximum 36 carotid IMT in female officers. Others have reported similar findings; however, the associations were found for only males or among mixed study populations. ${ }^{16,20,21}$ Unlike hypertension, the role of HDL-C levels in the pathogenesis of atherosclerosis is not as clear. HDL-C has been inversely associated with carotid IMT and higher HDL-C levels are considered a favorable factor for reducing CVD risk, yet interventions increasing HDL-C have had adverse effects on the risk of atherothrombotic events in women. ${ }^{43,57}$ This discrepancy may 
be related to the different mechanisms involved in estrogenic effects. For example, endogenous estrogen is thought to have protective effects on traditional CVD risk factors, such as raising HDL-C and lowering total cholesterol and LDL-C, and on the arterial wall, through improving arterial vasomotion and reducing susceptibility to injury along with diminishing penetration and retention of LDL in the arterial wall. ${ }^{20,39-41}$ However, the benefits of exogenous estrogen use in premenopausal women are not straightforward. Using data from the National Health and Nutrition Examination Survey, Hurwitz found that women taking oral contraceptive pills for an extended period had higher HDL-C, LDL-C, and total cholesterol. ${ }^{44}$ Consistent with this finding, women in the current study who reported taking birth control medication $(n=20)$ had slightly higher HDL-C and LDL-C and significantly higher total cholesterol levels than those women not taking birth control. Excluding these 20 women from study analyses did not change the associations between number of MetSyn components, HDL-C, or hypertension and carotid IMT appreciably. Hormone replacement therapy (HRT) raises HDL-C but may negatively affect $\mathrm{CV}$ outcomes and was shown not to be protective in preventing carotid IMT progression in women with surgical menopause. ${ }^{43}$ In the current study, four female officers reported taking hormone replacement containing estrogen. These women had slightly higher HDL-C, LDL-C and total cholesterol compared to those not taking hormone replacement therapy; however, exclusion of these women from the analyses did not alter the key study findings. Taken together, this suggests that use of exogenous estrogen among women at varying stages of menstruation in the current study did not enhance or diminish the association between MetSyn and subclinical atherosclerosis. 
The prevalence of MetSyn in this study was $26.1 \%$ (107 of 410 officers), the same as reported in a recent study of U.S. protective service workers. ${ }^{32}$ Interestingly, male officers were nearly four times more likely to have MetSyn than female officers $(32.2 \%$ vs. $8.5 \%)$ with half of the female officers having zero MetSyn components. Nearly all officers with a particular MetSyn component met the criteria for that component via the measurement level compared with the self-report criteria. This highlights the number of officers with undiagnosed and/or untreated CV risk factors. Kales et al reported that compared to the general population, the majority of incident CVD events occurs in emergency responders who are initially prehypertensive or mildly hypertensive, yet the reported state guidelines for police officers do not restrict duty until blood pressure reaches $160 \mathrm{mmHg}$ systolic and/or $105 \mathrm{mmHg}$ diastolic. ${ }^{29}$

Lipid lowering and antihypertensive medications could result in a regression of carotid IMT. ${ }^{58}$ With this in mind, additional analyses were conducted to exclude officers who met the MetSyn component criteria by reporting medication to treat the condition. Excluding those taking fibrates $(n=5)$ or nicotinic acid $(n=2)$ to reduce triglycerides or raise HDL-C, or antidiabetic medication $(n=9)$ to reduce blood glucose, did not alter the association between elevated triglycerides, reduced HDL-C, and glucose intolerance with carotid IMT. However, removing women who were taking antihypertensive medication $(n=6)$ altered the significant association between hypertension and mean maximum 12 IMT (p-value $=0.051)$. Similarly, exclusion of men who were taking antihypertensive medication $(n=47)$ altered the association between hypertension and mean maximum 36 IMT (p-value $=0.194)$. 
One strength of the current study is the utilization of the most recent definition of MetSyn: the National Cholesterol Education Program Adult Treatment Panel III definition with modifications recommended by the AHA and NHLB. ${ }^{47}$ Compared to previous definitions, this definition incorporates more inclusive cutpoints for blood pressure and glucose intolerance, uses waist circumference instead of BMI as the measure of abdominal obesity, and does not place emphasis on requiring glucose intolerance but instead requires any combination of three or more components, such as elevated triglycerides, reduced HDL-C , and abdominal obesity. In addition, MetSyn was defined as the count of the number of components for each individual instead of limiting the assessment to presence/absence of MetSyn. This approach provides an interpretable measure of association and is more sensitive in the detection of associations. ${ }^{59}$

An additional strength is the inclusion of three measures of carotid IMT: the mean maximum 12 carotid IMT, mean maximum 36 carotid IMT, and the mean common carotid IMT. Riley noted that the use of multiple angles, the near and far walls, and three segments provides a better predictive index. ${ }^{7}$ The common carotid IMT measure is more reliable, easier to obtain, more representative of systemic atherosclerotic burden, and has been more strongly associated with hypertension than other IMT measures. ${ }^{7,8,16,23}$ Nevertheless, there are anatomical and pathological benefits to measuring the carotid bifurcation and internal carotid segments; they are more sensitive to local atherosclerotic changes and have been associated more strongly with total cholesterol levels than the common carotid. ${ }^{7,8,16}$

This study is not without limitations. The cross-sectional design of the study precludes causal inferences. Participants provided information on demographic and lifestyle characteristics, 
medical history, and medication use via questionnaires, which can introduce recall bias.

Nevertheless, for defining MetSyn, we utilized two sources of medication information: responses to the medical history questionnaire and participants bringing in their medication to the clinic, thus minimizing the level of recall bias. It is possible that participating officers might not be representative of all the Buffalo Police Department. Nevertheless, comparisons between the study population and the Buffalo Police Department resulted in similar frequency distributions for sex, age, and rank: $26 \%$ vs. $23 \%$ women; $26.3 \%$ vs. $28 \%$ above 45 years of age; and $72 \%$ vs. $71 \%$ police officers (vs. higher rank). The findings from this study may not be generalizable to all police officers or other occupations.

Future research efforts could examine how the individual MetSyn components cluster, whether this clustering differs by gender, and whether it is predictive of increased carotid IMT. In this study, only nine female officers had MetSyn ( $\geq 3$ components), yet the number of MetSyn components and particularly hypertension and low HDL-C were significantly associated with increased carotid IMT. Repeating this study in a larger population of female officers, thereby increasing the likelihood of finding more female officers with individual MetSyn components, would allow for such analysis. In this cross-sectional study, we assessed the differences in the association between MetSyn and carotid IMT among male and female police officers. It would be beneficial to conduct a longitudinal analysis to understand the gender-specific mechanisms underlying these results and to develop prevention and intervention efforts that target specific CVD risk factors, perhaps differently for male and female police officers. 


\section{REFERENCES}

1. Third Report of the National Cholesterol Education Program (NCEP) Expert Panel on Detection, Evaluation, and Treatment of High Blood Cholesterol in Adults (Adult Treatment Panel III) Final Report. Circulation. 2002;106:3143.

2. Malik S, Wong ND, Franklin SS, et al. Impact of the metabolic syndrome on mortality from coronary heart disease, cardiovascular disease, and all causes in United States adults. Circulation. 2004;110:1245-1250.

3. Fan AZ. Metabolic syndrome and progression of atherosclerosis among middle-aged US adults. J Atheroscler Thromb. 2006;13(1):46-54.

4. Eguchi K, Schwartz JE, Roman MJ, Devereux RB, Gerin W, Pickering TG. Metabolic syndrome less strongly associated with target organ damage than syndrome components in a healthy, working population. J Clin Hypertens. 2007;9(5):337-344.

5. Adolphe A, Cook LS, Huang X. A cross-sectional study of intima-media thickness, ethnicity, metabolic syndrome, and cardiovascular risk in 2268 study participants. Mayo Clin Proc. 2009;84(3):221-228.

6. Scuteri A, Najjar SS, Muller DC, et al. Metabolic syndrome amplifies the age-associated increases in vascular thickness and stiffness. J Am Coll Cardiol. 2004;43:1388-1395.

7. Riley WA. Carotid intima-media thickness: Risk assessment and scanning protocol. Eur Heart J. 2002;23(12):916-918.

8. Polak JF, Person SD, Wei GS, et al. Segment-specific associations of carotid intima-media thickness with cardiovascular risk factors: The Coronary Artery Risk Development in Young Adults (CARDIA) Study. Stroke. 2010;41:9-15.

9. Hassinen M, Komulainen P, Lakka TA, et al. Metabolic syndrome and the progression of carotid intima-media thickness in elderly women. Arch Intern Med. 2006;166:444-449.

10. Sipila K, Moilanen L, Nieminen T, et al. Metabolic syndrome and carotid intima media thickness in the Health 2000 Survey. Atherosclerosis. 2009;204:276-281.

11. Tzou WS, Douglas PS, Srinivasan SR, et al. Increased subclinical atherosclerosis in young adults with metabolic syndrome: The Bogalusa Heart Study. J Am Coll Cardiol. 2005;46:457-463.

12. Golden SH, Folsom AR, Coresh J, Sharrett AR, Szklo M, Brancati F. Risk factors groupings related to insulin resistance and their synergistic effects on subclinical atherosclerosis: The Atherosclerosis Risk in Communities Study. Diabetes. 2002;51:3069-3076.

13. Czernichow S, Bertrais S, Blacher J, et al. Metabolic syndrome in relation to structure and function of large arteries: A predominant effect of blood pressure: A report from the SU.VI.MAX. Vascular Study. Am J Hypertens. 2005;18:1154-1160.

14. Irace C, Cortese C, Fiaschi E, et al. Components of the metabolic syndrome and carotid atherosclerosis: Role of elevated blood pressure. Hypertension. 2005;45:597-601. 
15. Kawamoto R, Tomita H, Oka Y, Ohtsuka N, Kamitani A. Metabolic syndrome and carotid atherosclerosis: Role of elevated blood pressure. J Atheroscler Thromb. 2005;12:268-275.

16. Koskinen J, Kohonen M, Viikari JSA, et al. Conventional cardiovascular risk factors and metabolic syndrome in predicting carotid intima-media thickness progression in young adults: The Cardiovascular Risk in Young Finns Study. Circulation. 2009;120:229-236.

17. Shaw LJ, Bairey Merz CN, Pepine CJ. Insights from the NHLBI-sponsored Women's Ischemia Syndrome Evaluation (WISE) Study. Part I: gender differences in traditional and novel risk factors, symptom evaluation, and gender-optimized diagnostic strategies. $J \mathrm{Am}$ Coll Cardiol. 2006;47(suppl):S4-S20.

18. Ford ES. Prevalence of the metabolic syndrome defined by the International Diabetes Federation among adults in the U.S. Diabetes Care. 2005;28:2745-2749.

19. Hayes SN. Preventing cardiovascular disease in women. Am Fam Physician. 2006;74(8):1331-1340.

20. Iglseder B, Cip P, Malaimare L, Ladurner G, Paulweber B. The metabolic syndrome is a stronger risk factor for early carotid atherosclerosis in women than in men. Stroke. 2005;36:1212-1217.

21. Kawamoto R, Tomita H, Inoue A, Ohtsuka N, Kamitani A. Metabolic syndrome may be a risk factor for early carotid atherosclerosis in women but not in men. $J$ Atheroscler Thromb. 2007; 14:36-43.

22. Nishida M, Moriyama T, Ishii K, et al. Effects of IL-6, adiponectin, CRP and metabolic syndrome on subclinical atherosclerosis. Clinica Chimica Acta. 2007;384:99-104.

23. Lin H-F, Liu C-K, Liao Y-C, Lin R-T, Chen C-S, Juo S-HH. The risk of the metabolic syndrome on carotid thickness and stiffness: Sex and age specific effects. Atherosclerosis. 2010;210:155-159.

24. Violanti JM, Vena JE, Marshall JR. Disease risk and mortality among police officers: New evidence and contributing factors. J Pol Sci Admin. 1986;14:17-23.

25. Williams MA, Petratis MM, Baechle TR, Ryschon KL, Campain JJ, Sketch MH. Frequency of physical activity, exercise capacity, and atherosclerotic heart disease risk factors in male police officers. J Occup Med. 1987;29:596-600.

26. Franke WD, Collins SA, Hinz PN. Cardiovascular disease morbidity in an Iowa law enforcement cohort, compared with the general Iowa population. J Occup Environ Med. 1998;40(5):441-444.

27. Violanti JM, Vena JE, Petralia S. Mortality of a police cohort: 1950-1990. Am J Ind Med. 1998;33:366-373.

28. Franke WD, Ramey SL, Shelley II MC. Relationship between cardiovascular disease morbidity, risk factors and stress in a law enforcement cohort. J Occup Environ Med. 2002;44:1182-1189.

29. Kales SN, Tsismenakis AJ, Zhang C, Soteriades ES. Blood pressure in firefighters, police officers, and other emergency responders. Am J Hypertens. 2009;22(1):11-20. 
30. Tharkar S, Kumpatla S, Muthukumaran P, Viswanathan V. High prevalence of metabolic syndrome and cardiovascular risk among police personnel compared to general population in India. J Assoc Physicians India. 2008;56:845-849.

31. Joseph PN, Violanti JM, Donahue R, et al. Police work and subclinical atherosclerosis. $J$ Occup Environ Med. 2009;51:700-707.

32. Davila EP, Florez H, Fleming LE, et al. Prevalence of the metabolic syndrome among US workers. Diabetes Care. 2010;33(11):2390-2395.

33. Forastiere F, Perucci CA, DiPietro A, et al. Mortality among urban policemen in Rome. Am J Ind Med. 1994;26(6):785-798.

34. Rozanski A, Blumenthal JA, Kaplan J. Impact of psychological factors on the pathogenesis of cardiovascular disease and implications for therapy. Circulation. 1999;99:2192-2217.

35. Tennant C. Work stress and coronary heart disease. J Cardiovasc Res. 2000;7(4):273-276.

36. Rosvall M, Ostergren P-O, Hedblad B, Isacsson S-O, Janzon L, Berglund G. Work-related psychosocial factors and carotid atherosclerosis. Int J Epidemiol. 2002;31:1169-1178.

37. Yoo H, Franke WD. Stress and cardiovascular disease risk in female law enforcement officers. Int Arch Occup Environ Health. 2011;84(3):279-286.

38. Hansen AM, Larsen AD, Rugulies R, Garde AH, Knudsen LE. A review of the effect of the psychosocial working environment on physiological changes in blood and urine. Basic Clin Pharmacol Toxicol. 2009;105:73-83.

39. Regitz-Zagrosek V, Lehmkuhl E, Mahmoodzadeh S. Gender aspects of the role of the metabolic syndrome as a risk factors for cardiovascular disease. Gend Med. 2007;4(Suppl B):S162-S177.

40. Bush TL, Barrett-Connor E, Cowan LD, et al. Cardiovascular mortality and noncontraceptive use of estrogen in women: Results from the Lipid Research Program Follow-up Study. Circulation. 1987;75:1102-1109.

41. Knopp RH, Zhu X. Multiple beneficial effects of estrogen on lipoprotein metabolism. J Clin Endocrinol Metab. 1997;82:3952-3954.

42. Bairey Merz CN, Johnson BD, Sharaf BL, et al. Hypoestrogenemia of hypothalamic origin and coronary artery disease in premenopausal women: A report from the NHLBI-Sponsored WISE Study. J Am Coll Cardiol. 2003;41(3):413-419.

43. Fan AZ, Dwyer JH. Sex differences in the relation of HDL cholesterol to progression of carotid intima-media thickness: The Los Angeles Atherosclerosis Study. Atherosclerosis. 2007;195:e191-e196.

44. Hurwitz BE, Henry N, Goldberg RB. Long-term oral contraceptive treatment, metabolic syndrome and measures of cardiovascular risk in pre-menopausal women: National Health and Nutrition Examination Survey 1999-2004. Gynecol Endocrinol. 2009;25(7):441-449.

45. Vena JE, Violanti JM, Marshall J, Fiedler RC. Mortality of a municipal worker cohort: III. Police Officers. Am J Ind Med. 1986;10:383-397. 
46. Mikolaenko I, Benson E, Konrad RJ, Chaffin C, Robinson CA, Hardy RW. Evaluation of the Beekman Coulter LX20 clinical chemistry analyzer. Lab Med. 2000;31(7):387-393.

47. Grundy SM, Cleeman JI, Daniels SR, et al. Diagnosis and management of the metabolic syndrome. An American Heart Assocation/National Heart, Lung, and Blood Institute Scientific Statement. Circulation. 2005;112(17):2735-2752.

48. American Heart Association. Body mass index calculator. 2011. Available at: http://www.heart.org/HEARTORG/GettingHealthy/WeightManagement/BodyMassIndex/Bo dy-Mass-Index-BMI-Calculator_UCM_307849_Article.jsp Accessed April 82011.

49. American Heart Association. What your cholesterol levels mean. 2011. Available at: http://www.heart.org/HEARTORG/Conditions/Cholesterol/AboutCholesterol/What-YourCholesterol-Levels-Mean_UCM_305562_Article.jsp Accessed April 82011.

50. American Heart Association. Understanding blood pressure readings. 2011. Available at: http://www.heart.org/HEARTORG/Conditions/HighBloodPressure/AboutHighBloodPressure /Understanding-Blood-Pressure-Readings_UCM_301764_Article.jsp Accessed April 8 2011.

51. Violanti JM, Fekedulegn D, Hartley TA, et al. Police trauma and cardiovascular disease: Associations between PTSD symptoms and metabolic syndrome. Int J Emerg Ment Health. 2006;8;4:227-238.

52. Kaplan JR, Adams MR, Clarkson TB, Manuck SB, Shively CA, Williams JK. Psychosocial factors, sex differences, and atherosclerosis: Lessons from animal models. Psychosom Med. 1996;58(6):598-611.

53. Fujishiro K, Roux AVD, Landsbergis P, et al. Associations of occupation, job control and job demands with intima-media thickness: The Multi-Ethnic Study of Atherosclerosis (MESA) Occup Environ Med. 2011;68:319-326.

54. Morash M, Haarr RN. Gender, workplace problems, and stress in policing. Justice $Q$. 1995;12:113-140.

55. Rabe-Hemp. Survival in an "all boys club": policewomen and their fight for acceptance. Policing. 2008;31:251-270.

56. National Center for Women and Policing (NCWP). Equality denied: the status of women in policing: 2001. New York, NY: Columbia University 2002.

57. Amarenco P, Labreuche J, Touboul P-J. High-density lipoprotein cholesterol and risk of stroke and carotid atherosclerosis: A systematic review. Atherosclerosis. 2008;196:489-496.

58. Daskalopoulou SS, Daskalopoulos ME, Perrea D, Nicolaides AN, Liapis CD. Carotid artery atherosclerosis: What is the evidence for drug action? Curr Pharm Des. 2007;13:1141-1159.

59. Fekedulegn D, Andrew M, Violanti J, Hartley T, Charles L, Burchfiel C. Comparison of statistical approaches to evaluate factors associated with metabolic syndrome. J Clin Hypertens. 2010;12:363-373. 
TABLES

* The working tables can be found in Appendix C. 
Table 4.1. Demographic characteristics and selected anthropometric, blood and ultrasound measures by gender.

\begin{tabular}{|c|c|c|c|c|}
\hline \multirow[b]{2}{*}{ Characteristic or Measure } & \multicolumn{2}{|c|}{$\operatorname{Men}(N=304)$} & \multicolumn{2}{|c|}{ Women $(\mathrm{N}=106)$} \\
\hline & $\mathrm{N}$ & $\begin{array}{c}\text { Mean (SD) } \\
\text { or } \%\end{array}$ & $\mathrm{~N}$ & $\begin{array}{c}\text { Mean (SD) } \\
\text { or } \%\end{array}$ \\
\hline \multicolumn{5}{|l|}{ Age Group } \\
\hline$<40$ years & 130 & 42.8 & 43 & 40.6 \\
\hline $40-49$ years & 127 & 41.8 & 54 & 51.0 \\
\hline $50+$ years & 47 & 15.5 & 9 & 8.5 \\
\hline Mean Age & 304 & $41.2(7.5)$ & 106 & $40.8(5.9)$ \\
\hline \multicolumn{5}{|l|}{ Ethnicity } \\
\hline White & 236 & 79.2 & 76 & 71.7 \\
\hline African American & 55 & 18.5 & 30 & 28.3 \\
\hline Hispanic & 7 & 2.4 & 0 & 0.0 \\
\hline \multicolumn{5}{|l|}{ Education } \\
\hline Less than 12 years, High School/GED & 38 & 12.5 & 4 & 3.8 \\
\hline College $<4$ years & 161 & 53.1 & 64 & 60.4 \\
\hline College $4+$ years & 104 & 34.3 & 38 & 35.9 \\
\hline \multicolumn{5}{|l|}{ Marital Status } \\
\hline Single & 29 & 9.6 & 24 & 22.6 \\
\hline Married & 237 & 78.2 & 61 & 57.6 \\
\hline Divorced & 37 & 12.2 & 21 & 19.8 \\
\hline \multicolumn{5}{|l|}{ Years of Police Service } \\
\hline Mean & 303 & $15.0(7.7)$ & 106 & $13.5(6.6)$ \\
\hline $1-5$ years & 26 & 8.7 & 10 & 9.4 \\
\hline $6-10$ years & 72 & 24.1 & 34 & 32.4 \\
\hline $11-15$ years & 54 & 18.1 & 14 & 13.3 \\
\hline $16-20$ years & 74 & 24.8 & 31 & 29.5 \\
\hline $20+$ years & 73 & 24.4 & 17 & 16.2 \\
\hline \multicolumn{5}{|l|}{ Rank } \\
\hline Police Officer & 209 & 69.0 & 84 & 79.3 \\
\hline Sergeant / Lieutenant & 44 & 14.5 & 11 & 10.4 \\
\hline Captain / Detective / Chief / Commissioner & 50 & 16.5 & 11 & 10.4 \\
\hline Alcohol Intake (drinks/week) & 299 & $5.7(9.2)$ & 104 & $3.4(4.6)$ \\
\hline \multicolumn{5}{|l|}{ Smoking Status } \\
\hline Current & 40 & 13.2 & 28 & 26.9 \\
\hline Former & 65 & 21.4 & 31 & 29.8 \\
\hline Never & 199 & 65.5 & 45 & 43.3 \\
\hline Physical Activity (METS/week) & 302 & $282.9(46.2)$ & 106 & $284.7(43.8)$ \\
\hline \multicolumn{5}{|l|}{ Body Mass Index $\left(\mathrm{kg} / \mathrm{m}^{2}\right)$} \\
\hline Mean & 304 & $30.3(4.2)$ & 106 & $26.0(4.7)$ \\
\hline$<25$ & 22 & 7.2 & 52 & 49.1 \\
\hline $25-30$ & 138 & 45.4 & 37 & 34.9 \\
\hline$>30$ & 144 & 47.4 & 17 & 16.0 \\
\hline
\end{tabular}


Total Cholesterol (mg/dL)

LDL-Cholesterol (mg/dL)*

HOMA-IR*

Metabolic Syndrome Components

Waist circumference, $\mathrm{cm}$

Triglycerides, mg/dL

HDL-Cholesterol, mg/dL*

Fasting glucose, mg/dL

Systolic blood pressure, $\mathrm{mmHg}$

Diastolic blood pressure, $\mathrm{mmHg}$

Mean Number of Components

Carotid Intima Media Thickness

Maximum $_{36}$ Carotid IMT (mm)

Maximum $_{12}$ Carotid IMT (mm)

\begin{tabular}{cccc}
304 & $203.0(37.2)$ & 106 & $194.3(38.7)$ \\
303 & $130.9(33.7)$ & 105 & $119.2(31.6)$ \\
302 & $2.4(2.8)$ & 106 & $1.3(1.1)$ \\
304 & & 106 & \\
& $99.3(11.3)$ & & $80.1(11.6)$ \\
& $155.0(128.4)$ & & $88.2(130.0)$ \\
& $42.1(12.0)$ & & $58.2(15.7)$ \\
& $94.8(14.1)$ & & $86.3(8.4)$ \\
& $122.3(11.4)$ & & $116.7(13.4)$ \\
& $78.7(10.2)$ & & $74.6(9.6)$ \\
304 & $1.9(1.4)$ & & $0.90(1.1)$ \\
& $0.802(0.149)$ & & $0.729(0.103)$ \\
& $0.912(0.180)$ & & $0.828(0.129)$ \\
& $0.627(0.105)$ & & $0.587(0.078)$ \\
\hline
\end{tabular}

$*$ LDL $=$ Low-Density Lipoprotein; HOMA-IR = Homeostatic Model Assessment for Insulin Resistance; HDL = High-Density Lipoprotein 
Table 4.2. Mean levels and prevalence of metabolic syndrome components by gender.

\begin{tabular}{|c|c|c|c|c|c|c|c|}
\hline \multirow{3}{*}{ Metabolic Syndrome Component } & \multirow{3}{*}{ Component Cutpoint } & \multicolumn{6}{|c|}{ Prevalence } \\
\hline & & \multicolumn{2}{|c|}{ Men } & \multicolumn{2}{|c|}{ Women } & \multicolumn{2}{|c|}{ Overall } \\
\hline & & $\mathrm{N}$ & $\%$ & $\mathrm{~N}$ & $\%$ & $\mathrm{~N}$ & $\%$ \\
\hline Waist circumference, $\mathrm{cm}$ & $\geq 102$ Men, $\geq 88$ Women & 113 & 37.2 & 19 & 17.9 & 132 & 32.2 \\
\hline Elevated triglycerides & Either & 118 & 38.8 & 9 & 8.5 & 127 & 31.0 \\
\hline Triglycerides, mg/dL & $\geq 150$ & 114 & 37.5 & 9 & 8.5 & & \\
\hline Self-reported fibrates medication, $\%$ & \multirow{2}{*}{ Yes to either } & 5 & 1.6 & 0 & 0.0 & & \\
\hline Self-reported nicotinic acid medication, $\%$ & & 1 & 0.3 & 1 & 0.9 & & \\
\hline Reduced HDL cholesterol & Either & 145 & 47.7 & 28 & 26.4 & 173 & 42.2 \\
\hline HDL cholesterol, mg/dL & $<40$ Men, $<50$ Women & 144 & 47.4 & 28 & 26.4 & & \\
\hline Self-reported fibrates medication, $\%$ & \multirow{2}{*}{ Yes to either } & 5 & 1.6 & 0 & 0.0 & & \\
\hline Self-reported nicotinic acid medication, \% & & 1 & 0.3 & 1 & 0.9 & & \\
\hline Glucose intolerance & Either & 83 & 27.3 & 12 & 11.3 & 95 & 23.2 \\
\hline Fasting glucose, mg/dL & $\geq 100$ & 81 & 26.6 & 11 & 10.4 & & \\
\hline Self-reported diabetes medication, $\%$ & Yes & 8 & 2.6 & 1 & 0.9 & & \\
\hline Hypertension & $\geq 1$ of the following & 131 & 43.1 & 27 & 25.5 & 158 & 38.5 \\
\hline Systolic blood pressure, $\mathrm{mmHg}$ & $\geq 130$ & 71 & 23.4 & 19 & 17.9 & & \\
\hline Diastolic blood pressure, $\mathrm{mmHg}$ & $\geq 85$ & 81 & 26.6 & 17 & 16.0 & & \\
\hline $\begin{array}{l}\text { Self-reported hypertension with } \\
\text { antihypertensive medication, } \%\end{array}$ & Yes to diagnosis and to medication use & 47 & 15.5 & 6 & 5.7 & & \\
\hline \multicolumn{8}{|l|}{ Number of Components } \\
\hline 0 & & 54 & 17.8 & 53 & 50.0 & 107 & 26.1 \\
\hline 1 & & 74 & 24.3 & 24 & 22.6 & 98 & 23.9 \\
\hline 2 & & 78 & 25.7 & 20 & 18.9 & 98 & 23.9 \\
\hline 3 & & 48 & 15.8 & 6 & 5.7 & 54 & 13.2 \\
\hline 4 & & 34 & 11.2 & 2 & 1.9 & 36 & 8.8 \\
\hline 5 & & 16 & 5.3 & 1 & 0.9 & 17 & 4.2 \\
\hline Prevalence $(\geq 3)$ & & 98 & 32.2 & 9 & 8.5 & 107 & 26.1 \\
\hline
\end{tabular}


Table 4.3. Unadjusted and adjusted mean values of carotid artery thickness by number of metabolic syndrome components and gender.

\begin{tabular}{|c|c|c|c|c|c|}
\hline & \multicolumn{4}{|c|}{ Number of Metabolic Syndrome Components } & \multirow[b]{2}{*}{ p-value* } \\
\hline & 0 & 1 & 2 & $\geq 3$ & \\
\hline \multicolumn{6}{|c|}{ Mean Maximum 36 Carotid IMT } \\
\hline Men & $\mathrm{N}=54$ & $\mathrm{~N}=74$ & $\mathrm{~N}=78$ & $\mathrm{~N}=98$ & \\
\hline Unadjusted & $0.780(0.142)$ & $0.757(0.111)$ & $0.818(0.126)$ & $0.835(0.183)$ & 0.004 \\
\hline Age-Adjusted & $0.808(0.017)$ & $0.776(0.015)$ & $0.809(0.014)$ & $0.812(0.013)$ & 0.488 \\
\hline Multivariate Adjusted $\dagger$ & $0.815(0.018)$ & $0.781(0.016)$ & $0.812(0.015)$ & $0.821(0.014)$ & 0.466 \\
\hline Women & $\mathrm{N}=53$ & $\mathrm{~N}=24$ & $\mathrm{~N}=20$ & $\mathrm{~N}=9$ & \\
\hline Unadjusted & $0.704(0.083)$ & $0.735(0.087)$ & $0.752(0.112)$ & $0.807(0.173)$ & 0.004 \\
\hline Age-Adjusted & $0.711(0.012)$ & $0.732(0.018)$ & $0.744(0.020)$ & $0.794(0.030)$ & 0.013 \\
\hline Multivariate Adjusted $\uparrow$ & $0.708(0.013)$ & $0.733(0.018)$ & $0.745(0.020)$ & $0.808(0.033)$ & 0.006 \\
\hline \multicolumn{6}{|c|}{ Mean Maximum 12 Carotid IMT } \\
\hline \multicolumn{6}{|l|}{ Men } \\
\hline Unadjusted & $0.898(0.176)$ & $0.857(0.128)$ & $0.940(0.160)$ & $0.939(0.218)$ & 0.030 \\
\hline Age-Adjusted & $0.929(0.021)$ & $0.878(0.018)$ & $0.930(0.018)$ & $0.914(0.016)$ & 0.905 \\
\hline Multivariate Adjusted $\dagger$ & $0.936(0.022)$ & $0.886(0.019)$ & $0.931(0.019)$ & $0.926(0.017)$ & 0.866 \\
\hline \multicolumn{6}{|l|}{ Women } \\
\hline Unadjusted & $0.815(0.110)$ & $0.830(0.113)$ & $0.840(0.168)$ & $0.872(0.179)$ & 0.216 \\
\hline Age-Adjusted & $0.823(0.017)$ & $0.827(0.025)$ & $0.831(0.027)$ & $0.857(0.041)$ & 0.435 \\
\hline Multivariate Adjusted $\dagger$ & $0.816(0.017)$ & $0.831(0.024)$ & $0.832(0.026)$ & $0.877(0.043)$ & 0.214 \\
\hline \multicolumn{6}{|l|}{ Mean Common Carotid IMT } \\
\hline \multicolumn{6}{|l|}{ Men } \\
\hline Unadjusted & $0.608(0.122)$ & $0.591(0.079)$ & $0.644(0.114)$ & $0.650(0.098)$ & 0.001 \\
\hline Age-Adjusted & $0.626(0.012)$ & $0.603(0.010)$ & $0.638(0.010)$ & $0.636(0.009)$ & 0.188 \\
\hline Multivariate Adjusted $\dagger$ & $0.634(0.013)$ & $0.609(0.011)$ & $0.643(0.011)$ & $0.644(0.010)$ & 0.189 \\
\hline \multicolumn{6}{|l|}{ Women } \\
\hline Unadjusted & $0.564(0.068)$ & $0.596(0.075)$ & $0.616(0.092)$ & $0.636(0.065)$ & 0.006 \\
\hline
\end{tabular}




$\begin{array}{llllll}\text { Age-Adjusted } & 0.569(0.009) & 0.593(0.013) & 0.610(0.015) & 0.626(0.023) & 0.017 \\ \text { Multivariate Adjusted } \dagger & 0.567(0.010) & 0.595(0.014) & 0.611(0.015) & 0.640(0.025) & 0.007\end{array}$

Note: Values are mean (SD) for unadjusted model or (SE) for adjusted models.

* Test for linear trend based on linear contrast.

$\dagger$ Adjusted for age, smoking status and LDL-C. 
Table 4.4. Unadjusted and adjusted mean values of carotid artery thickness by presence or absence of individual metabolic syndrome components and gender.

\begin{tabular}{|c|c|c|c|c|c|c|}
\hline \multirow{2}{*}{ Metabolic Syndrome Component } & \multicolumn{3}{|c|}{ Men } & \multicolumn{3}{|c|}{ Women } \\
\hline & Absent & Present & p-value* & Absent & Present & p-value* \\
\hline \multicolumn{7}{|l|}{ Mean Maximum 36 Carotid IMT } \\
\hline Low HDL Cholesterol & $\mathrm{N}=159$ & $\mathrm{~N}=145$ & & $\mathrm{~N}=78$ & $\mathrm{~N}=28$ & \\
\hline Unadjusted & $0.795(0.160)$ & $0.810(0.137)$ & 0.380 & $0.713(0.083)$ & $0.775(0.135)$ & 0.005 \\
\hline Age-Adjusted & $0.802(0.010)$ & $0.802(0.010)$ & 0.971 & $0.713(0.010)$ & $0.774(0.017)$ & 0.002 \\
\hline Multivariate Adjusted $\dagger$ & $0.807(0.011)$ & $0.809(0.011)$ & 0.897 & $0.711(0.010)$ & $0.777(0.017)$ & 0.001 \\
\hline Hypertension & $\mathrm{N}=173$ & $\mathrm{~N}=131$ & & $\mathrm{~N}=79$ & $\mathrm{~N}=27$ & \\
\hline Unadjusted & $0.775(0.121)$ & $0.837(0.174)$ & $<0.001$ & $0.711(0.084)$ & $0.781(0.134)$ & 0.002 \\
\hline Age-Adjusted & $0.789(0.009)$ & $0.819(0.011)$ & 0.040 & $0.716(0.010)$ & $0.766(0.018)$ & 0.017 \\
\hline Multivariate Adjusted $\dagger$ & $0.793(0.011)$ & $0.827(0.012)$ & 0.023 & $0.715(0.010)$ & $0.768(0.018)$ & 0.017 \\
\hline \multicolumn{7}{|l|}{ Mean Maximum $_{12}$ Carotid IMT } \\
\hline Low HDL Cholesterol & $\mathrm{N}=159$ & $\mathrm{~N}=145$ & & $\mathrm{~N}=78$ & $\mathrm{~N}=28$ & \\
\hline Unadjusted & $0.901(0.174)$ & $0.924(0.187)$ & 0.271 & $0.813(0.115)$ & $0.871(0.157)$ & 0.040 \\
\hline Age-Adjusted & $0.909(0.012)$ & $0.916(0.013)$ & 0.700 & $0.813(0.013)$ & $0.870(0.022)$ & 0.030 \\
\hline Multivariate Adjusted $\dagger$ & $0.915(0.014)$ & $0.923(0.014)$ & 0.654 & $0.810(0.013)$ & $0.877(0.022)$ & 0.009 \\
\hline Hypertension & $\mathrm{N}=173$ & $\mathrm{~N}=131$ & & $\mathrm{~N}=79$ & $\mathrm{~N}=27$ & \\
\hline Unadjusted & $0.884(0.154)$ & $0.949(0.205)$ & 0.002 & $0.809(0.117)$ & $0.884(0.149)$ & 0.009 \\
\hline Age-Adjusted & $0.900(0.012)$ & $0.929(0.014)$ & 0.114 & $0.814(0.013)$ & $0.869(0.023)$ & 0.045 \\
\hline Multivariate Adjusted $\dagger$ & $0.904(0.014)$ & $0.938(0.015)$ & 0.073 & $0.810(0.013)$ & $0.878(0.023)$ & 0.014 \\
\hline \multicolumn{7}{|l|}{ Mean Common Carotid IMT } \\
\hline Low HDL Cholesterol & $\mathrm{N}=159$ & $\mathrm{~N}=145$ & & $\mathrm{~N}=78$ & $\mathrm{~N}=28$ & \\
\hline Unadjusted & $0.616(0.113)$ & $0.638(0.095)$ & 0.064 & $0.577(0.070)$ & $0.617(0.092)$ & 0.019 \\
\hline Age-Adjusted & $0.620(0.007)$ & $0.633(0.007)$ & 0.214 & $0.577(0.008)$ & $0.616(0.013)$ & 0.010 \\
\hline Multivariate Adjusted $\dagger$ & $0.627(0.008)$ & $0.641(0.008)$ & 0.192 & $0.577(0.008)$ & $0.619(0.013)$ & 0.007 \\
\hline
\end{tabular}




\begin{tabular}{lcccccr} 
Hypertension & $\mathrm{N}=173$ & $\mathrm{~N}=131$ & & $\mathrm{~N}=79$ & $\mathrm{~N}=27$ & \\
Unadjusted & $0.613(0.098)$ & $0.645(0.112)$ & 0.008 & $0.569(0.064)$ & $0.639(0.091)$ & $<0.001$ \\
Age-Adjusted & $0.622(0.007)$ & $0.633(0.008)$ & 0.300 & $0.573(0.007)$ & $0.629(0.013)$ & $<0.001$ \\
Multivariate Adjusted $\dagger$ & $0.628(0.008)$ & $0.641(0.009)$ & 0.219 & $0.572(0.008)$ & $0.634(0.014)$ & $<0.001$ \\
\hline
\end{tabular}

Note: Values are mean (SD) for unadjusted model or (SE) for adjusted models.

* Test for mean differences between groups.

$\dagger$ Adjusted for age, smoking status and LDL-C. 
CHAPTER 5. DisCuSSION 


\subsection{DisCuSSION}

The goal of the three studies in this dissertation was to examine cross-sectional associations between MetSyn and psychological distress and subclinical CVD among police officers. Police officers experience numerous types of work stressors and have been found to have higher rates of CVD mortality. ${ }^{1,2}$ Existing studies have found an association between work-related stress and CVD, and it has been suggested that MetSyn mediates the association. ${ }^{3}$

Using the Spielberger Police Stress Survey, a positive association was found between perceived work stress and the number of MetSyn components in women but not in men. ${ }^{4}$ An association was also found for the stress index for the past month, a more acute stress measure that incorporates both perceived and experienced stress, and number of MetSyn components in women. Of the types of police stress examined, both administrative and organizational pressures as well as lack of support at work were significantly associated with the number of MetSyn components. Police stress was consistently associated with higher odds for abdominal obesity and reduced HDL-C in female officers, findings supported by previous studies. Yoo and Franke found that in female officers, high levels of perceived stress were associated with high cholesterol. ${ }^{5}$ Two studies have found that low job control and low decision latitude were associated with low levels of HDL-C in middle-aged women and perimenopausal women. ${ }^{6,7}$ Chronic work stress was predictive of obesity in British civil servants who participated in the Whitehall II Study. ${ }^{8}$ Officers are aware of the link between policing and CVD. Franke et al found that one-third of officers believe employment as a police officer increased their CVD risk. ${ }^{9}$ 
In the second study, as noted, the CES-D scores were relatively low for all participants with over $60 \%$ scoring in the low category, while the prevalence of MetSyn was much higher for male officers at both locations than for Buffalo women. Unfortunately, the association between depressive symptoms and MetSyn could not be examined for the Spokane women due to the small number of participants. A positive association was found between depressive symptoms and number of MetSyn components among Spokane male officers. Previous studies have found that depressed individuals are more likely to develop and die from CVD than non-depressed individuals. ${ }^{10,11,12,13,14,15,16}$ The association between depression and MetSyn is often stronger in women than in men; ${ }^{17,18,19,20,21}$ in fact only one study was found which reported an association between depression and MetSyn in men but not in women. ${ }^{22}$ Upon closer examination of the association, it was the older (over the age of 49) and lower ranking (vs. higher ranks) Spokane men where the strongest associations were found. It is possible that these lower ranking officers were experiencing high job demand with little job control. Perceived work stress has been associated with depression in older male police officers, and high job strain has been associated with depression in a national sample of men. ${ }^{23,24}$ Work stress may lead to depression which subsequently increases risk for developing MetSyn and CVD. ${ }^{25}$

The third study examined associations between MetSyn and carotid IMT. MetSyn was positively and significantly associated with carotid IMT in female officers. This finding was consistent with previous studies which found the association to be stronger in women than in men. ${ }^{26,27,28,29}$ One potential reason for this is that triglycerides, abdominal obesity and diabetes have stronger effects on CVD outcomes in women than in men. ${ }^{30}$ Carotid IMT was also significantly higher in women who had either hypertension or reduced HDL-C, and in men who had hypertension. A 
current study by Fujishiro and colleagues suggested that low job control may negatively impact common carotid IMT through its association with hypertension. ${ }^{31}$ The association between reduced HDL-C and carotid IMT is not as straightforward. It is interesting and somewhat unexpected that reduced HDL-C was associated with police stress as found in Study 1 and with carotid IMT as reported in Study 3 in female officers only. It is possible that male officers were more likely to be aware of having an adverse CVD risk factor, such as hypertension, and to have modified their lifestyle in order to decrease their blood pressure and improved their carotid IMT. For example, $21 \%$ of male and $30 \%$ of female officers were former smokers; however, only $13 \%$ of men were current smokers compared to $27 \%$ of women.

In each of the three studies potential mechanisms relating MetSyn with police stress, depressive symptoms or carotid IMT are discussed. These potential mechanisms include hyperactivation of the hypothalamic pituitary adrenal (HPA) axis, autonomic nervous system dysfunction, inflammation, and poor health behaviors. The contribution of each mechanism could be genderspecific and may also be specific to each MetSyn component. For example, response to police stress by the female officers may have led to HPA axis overactivity signaling increased cortisol secretion. ${ }^{32}$ Such prolonged cortisol output may have led to increased fat accumulation and resulted in lipid abnormalities, i.e. reduced HDL-C, and abdominal obesity. ${ }^{33}$ At the same time, increased SNS activity may have led to systemic production of the catecholamines epinephrine and norepinephrine leading to abdominal obesity. ${ }^{34}$ Inflammation may also have a central role in these associations. Perceived stress may increase levels of white blood cells, fibrinogen, inflammatory markers, such as C-reactive protein, and proinflammatory cytokines, such as interleukin-1, interleukin-6 and tumor necrosis factor-alpha. C-reactive protein has been shown 
to promote insulin resistance, hypertriglyceridemia and hypertension, all factors central to MetSyn. ${ }^{34,35}$ A potential indirect mechanism may be related to poor health behaviors. It is well known that depression is associated with poorer health behaviors, e.g. smoking, poor diet. ${ }^{36}$ The Spokane men may have engaged in more adverse health behaviors, including sedentary lifestyle, excessive alcohol intake, poor nutrition or inadequate sleep, as a means of coping and these behaviors have been associated with MetSyn. ${ }^{17}$ For example, physical inactivity in combination with a high sodium, high fat diet can lead to hypertension and glucose intolerance.

Due to the high prevalence of male police officers, existing studies have not been able to address gender patterns or differences in associations between stress and health outcomes. ${ }^{37}$ Yet, gender was found to have a strong effect on the findings in these three studies. In fact, female officers may be more affected by policing than male officers in terms of CVD risk. A recent study by Yoo and Franke found that $42 \%$ of female officers felt that policing and being female contributed to their risk for chronic disease. ${ }^{5}$ Female officers may experience additional sources of stress beyond the nature of the job. Policing is a male-dominated occupation and female officers account for only $11 \%$ of all sworn law enforcement officers in the U.S. ${ }^{38}$ In policing, the upper ranking positions in the hierarchy are predominantly held by men. ${ }^{38}$ In this dissertation, lack of support at work was significantly higher in women than in men. Eighty percent of the female officers were lower ranking, which may indicate lower job control, compared to $68 \%$ of men. Previous studies with female cynomolgus macaque monkeys have found associations between chronic subordination stress and reduced HDL-C levels and loss of premenopausal protection from atherosclerosis. ${ }^{39}$ Work and home life balance may also introduce additional 
challenges. Twenty percent of the female officers were divorced, some of which may be raising children by themselves, and lower ranking officers were more likely to work night shift.

\subsection{MetSyn in Police OfFicers}

From a clinical perspective, there is utility in considering CVD risk factors individually and there are clear guidelines and cutpoints for each of the individual MetSyn components. However, the MetSyn provides a holistic approach that is particularly useful in epidemiological studies to describe disease risk. ${ }^{40} \mathrm{CVD}$ is complex, involving many genes and environmental factors as well as multiple physiological systems. Relying on individual components in isolation may not provide as accurate a representation of disease risk. The five components, each related to increased CVD risk, are interrelated and together offer a more global assessment of CVD risk. The calculation of MetSyn in the BCOPS Study established a baseline assessment of risk and will serve as a key factor in demonstrating effectiveness of future interventions in this occupational group.

The unadjusted prevalence of MetSyn among all police officers participating in the BCOPS Study $(\mathrm{n}=414)$ was $25.9 \%$ (Table 5.1$)$. The age adjusted prevalence was $25.1 \%$. This is similar to a recent study of U.S. protective service workers $-26.1 \%$ and higher than a study of healthy adults $-17 \%{ }^{41,42}$ Previous studies including only male police officers have found the prevalence to be $27.4 \%$ and $57 \%{ }^{43,44}$ Interestingly, in the BCOPS officers, the prevalence of MetSyn was nearly four times higher for male police officers compared to female police officers, $31.1 \%$ vs. 8.2\%. Yet, the prevalence of MetSyn was similar between 20-59 year old male and female 
participants in the National Health and Nutrition Examination Survey (NHANES) 2003-2006, $30.0 \%$ in men and $27.0 \%$ in women. ${ }^{45}$

Among all officers, the prevalence of the individual MetSyn components ranged from $23.4 \%$ for glucose intolerance to $41.8 \%$ for reduced HDL-C (Table 5.1). The prevalence of abdominal obesity, glucose intolerance, reduced HDL-C and hypertension was approximately two-fold higher and the prevalence of elevated triglycerides was over four times higher, $38.4 \%$ vs. $8.4 \%$, in male officers than female officers. In comparison to the NHANES participants, male officers had a higher prevalence of reduced HDL-C (47.2\% vs. $22.2 \%)$ and hypertension (42.7\% vs. $39.0 \%$ ) than the NHANES men. ${ }^{45}$ In women, the prevalence of abdominal obesity and hypertriglyceridemia was about three-fold higher in the NHANES women than the police women. ${ }^{45}$ It should be noted that the criteria for several of the MetSyn components used in the NHANES study varies just slightly from the criteria used in this dissertation (i.e. systolic blood pressure: NHANES $\geq 135 \mathrm{mmHg}, \mathrm{BCOPS} \geq 130 \mathrm{mmHg}$ ), which could account for any small differences in prevalence of the MetSyn components between the two groups.

Police officers with a specific MetSyn component typically met the criteria for the component via the clinical or anthropometric measurement level compared with the self-report criteria. For example, $41.8 \%$ of officers had low serum HDL-C while only $1.7 \%$ of officers reported taking fibrates or nicotinic acid. This same comparison can be observed for elevated triglycerides, glucose intolerance and hypertension, and highlights the potential number of police officers who may have undiagnosed or untreated CVD risk factors. The majority of incident CVD events occur in emergency responders who are initially prehypertensive or mildly hypertensive 
compared to the general population. ${ }^{46}$ However, of the reported physical guidelines for police officers, duty restriction does not occur until blood pressure exceeds $160 \mathrm{mmHg}$ systolic and/or $105 \mathrm{mmHg}$ diastolic. ${ }^{46}$

\subsection{LiMITATIONS AND STRENGTHS}

The limitations for each of the three studies have been discussed in detail in Chapters 2-4; however, they are worth summarizing here. The cross-sectional design of the three studies prevents inferences related to causality. However, the findings are supported by previous crosssectional and longitudinal studies conducted with other populations. The potential for underreporting exists with this occupational group. Both the Spielberger Police Stress Survey and the Center for Epidemiologic Studies-Depression scale are self-report measures. Officers may not disclose information, particularly items related to supervisors or the administration, for fear of reprimand or discrimination, or may provide socially desirable responses.

It is possible that participants in the BCOPS Study may not be representative of the entire Buffalo, New York Police Department. However, comparisons between the study population and the Buffalo Police Department resulted in similar frequency distributions for sex, age, and rank. Data for these studies come from two cohorts of police officers, thus potentially limiting the generalizability of the study findings to smaller or larger sized police departments and potentially other types of emergency responders. There is limited minority representation among the Buffalo police officers with approximately $76 \%$ of the officers being White, $20 \%$ African American and 2\% Hispanic. According to the U.S. Bureau of Justice Statistics, the racial composition of sworn 
officers in local police departments in the U.S. is 69.5\% White, 16.5\% African American, 11.2\% Hispanic, 2.0\% Asian/Pacific Islander, and 0.6\% American Indian/Alaska Native. ${ }^{47}$

The three studies have a number of strengths that also warrant discussion. The focus of these three studies was on early or subclinical CVD. This approach provided a good opportunity to detect associations if they did exist. Second, multiple psychosocial factors, including depressive symptoms and police-specific sources of stress were measured. Specifically, police-specific stressors, including perceived and experienced events and acute and chronic events, were examined in association with MetSyn. Previous studies of police officers have measured general work stress or job demand and control. However, we were able identify sources of stress specific to policing that were associated with MetSyn.

The BCOPS Study included over 100 female police officers. Female officers are an understudied occupational group and previous studies have typically included only male officers. As discussed above, female officers may experience increased stress working in this occupation, and previous studies have noted gender-specific differences in CVD risk. These studies provided the opportunity to focus on the potential gender differences in the relationship between stress and subclinical CVD with significantly different findings. Finally, the three studies included highly standardized outcome measures, MetSyn and carotid IMT. Unlike many previous studies, MetSyn was defined as the count of the number of components for each individual instead of limiting the assessment to presence or absence of MetSyn. This approach was more sensitive to detecting associations if they existed. ${ }^{48}$ Carotid IMT was measured and read using standardized protocols by certified sonographers. 


\subsection{FUTURE RESEARCH}

The prevalence of MetSyn is on the rise, increasing by approximately $11 \%$ from $29.2 \%$ assessed in NHANES III (1988-1994) to 32.3\% for NHANES 1999-2000 among participants aged 20 and older. ${ }^{49}$ Using these prevalence estimates, this equates to an increase from approximately 50 million to 64 million American adults. ${ }^{49}$ The increase is particularly noteworthy in younger women (20-39 years old) where MetSyn rose approximately $77 \%$ during the same time period from $10.8 \%$ to $19.1 \% .{ }^{49}$ Given this and our significant findings in women, future studies involving MetSyn would benefit from a larger sample of female police officers. In addition, the three studies presented in this dissertation provide a cross-sectional view of the association between MetSyn and police stress, depressive symptoms and subclinical CVD. While significant associations were found, the direction of the associations are unclear. Currently, a reexamination of this cohort is underway. This longitudinal approach will allow for the specific mechanisms, including the HPA axis, SNS and inflammation, to be examined and to better understand whether the mechanisms are gender-specific. If gender differences do exist, it would be beneficial to tailor prevention and intervention efforts that target specific CVD risk factors.

\subsection{CONCLUSION}

Police officers are important members of communities across the United States. Existing studies have found that officers experience high levels of work stress and have a higher prevalence of CVD compared to other occupational groups. As demonstrated in this dissertation, MetSyn was associated with police stress, depressive symptomatology and subclinical CVD, all of which 
provide early indication of potential future chronic health problems. The studies presented here also demonstrate the important differences between male and female police officers in terms of $\mathrm{CV}$ health. Understanding the relationship between specific sources of stress and early or subclinical disease will increase the likelihood of improving prevention efforts and allow for early implementation of interventions. 


\section{References}

1. Aaron JDK. Stress and coping in police officers. Police Quarterly. 2000;3:438-450.

2. Violanti JM, Vena JE, Petralia S. Mortality of a police cohort: 1950-1990. Am J Ind Med. 1998;33(4):366-73.

3. Chandola T, Brunner E, Marmot M. Chronic stress at work and the metabolic syndrome: prospective study. BMJ. 2006. doi:10.1136/bmj.38693.435301.80.

4. Spielberger CD, Westberry LG, Grier KS, et al. The Police Stress Survey: sources of stress in law enforcement (Human Resources Institute Monograph Series Three, No. 6). Tampa, FL: University of South Florida, College of Social and Behavioral Sciences; 1981.

5. Yoo H, Franke WD. Stress and cardiovascular disease risk in female law enforcement officers. Int Arch Occup Environ Health. 2011;84(3):279-286.

6. Evolahti A, Hultcrantz M, Collins A. Psychosocial work environment and lifestyle as related to lipid profiles in perimenopausal women. Climacteric. 2009;12:131-145.

7. Wamala SP, Wolk A, Schrnvk-Gustafsson, Orth-Gomer K. Lipid profile and socioeconomic status in healthy middle aged women in Sweden. J Epidemiol Community Health. 1997;51:400-407.

8. Brunner EJ, Chandola T, Marmot M. Prospective effect of job strain on general and central obesity in the Whitehall II study. Am J Epidemiol. 2007;165:828-837.

9. Franke WD, Collins SA, Hinz PN. Cardiovascular disease morbidity in an Iowa law enforcement cohort, compared with general Iowa population. J Occup Environ Med. 1998;40:441-444.

10. Anda R, Williamson D, Jones D, et al. Depressed Affect, Hopelessness, and the Risk of Ischemic-Heart-Disease in A Cohort of United-States Adults. Epidemiology. 1993;4(4):285293.

11. Aromaa A, Raitasalo R, Reunanen A, et al. Depression and Cardiovascular-Diseases. Acta Psychiatr Scand. 1994;89:77-82.

12. Ferketich AK, Schwartzbaum JA, Frid DJ, et al. Depression as an antecedent to heart disease among women and men in the NHANES I study. National Health and Nutrition Examination Survey. Arch Intern Med. 2000;160(9):1261-1268.

13. Ford DE, Mead LA, Chang PP, et al. Depression is a risk factor for coronary artery disease in men - The precursors study. Arch Intern Med.1998;158(13):1422-1426.

14. Hippisley-Cox J, Fielding K, Pringle M. Depression as a risk factor for ischaemic heart disease in men: population based case-control study. BMJ. 1998;316(7146):1714-1719.

15. Lett HS, Blumenthal JA, Babyak MA, et al. Depression as a risk factor for coronary artery disease: Evidence, mechanisms, and treatment. Psychosom Med. 2004;66(3):305-315.

16. Penninx BW, Beekman AT, Honig A, et al. Depression and cardiac mortality: results from a community-based longitudinal study. Arch Gen Psychiatry. 2001;58(3):221-227. 
17. Kinder LS, Carnethon MR, Palaniappan LP, King AC, Fortmann SP. Depression and the metabolic syndrome in young adults: Findings from the Third National Health and Nutrition Examination Survey. Psychosom Med. 2004;66:316-322.

18. Laudisio A, Marzetti E, Pagano F, Pozzi G, Barnabei R, Zuccala G. Depressive symptoms and metabolic syndrome: Selective association in older women. J Geriatr Psychiatry Neurol. 2009;22:215-222.

19. Muhtz C, Zyriax B-C, Klahn T, Windler E, Otte C. Depressive symptoms and metabolic risk: Effects of cortisol and gender. Psychoneuroendocrinology. 2009;34:1004-1011.

20. Raikkonen K, Matthews K, Kuller LH. The relationship between psychological risk attributes and the metabolic syndrome in healthy women: Antecedent or consequence? Metabolism. 2002;51:1573-1577.

21. Toker S, Shirom A, Melamed S. Depression and the metabolic syndrome: Gender-dependent associations. Depress Anxiety. 2008;25:661-669.

22. Viinamaki H, Heiskanan T, Lehto SM, et al. Association of depressive symptoms and metabolic syndrome in men. Acta Psychiatrica Scandinavica.2009;120:23-29.

23. Gershon RR, Lin S, Li X. Work stress in aging police officers. J Occup Environ Med. 2002;44:160-7.

24. Blackmore ER, Stansfeld SA, Weller L, Munce S, Zagorski BM, Stewart DE. Major depressive episodes and work stress: Results from a national population survey. Am J Public Health. 2007;97:2088-2093.

25. Vitaliano PP, Scanlan JM, Zhang J, Savage MV, Hirsch IB, Siegler IC. A path model of chronic stress, the metabolic syndrome, and coronary heart disease. Psychosom Med. 2002;64:418-435.

26. Iglseder B, Cip P, Malaimare L, Ladurner G, Paulweber B. The metabolic syndrome is a stronger risk factor for early carotid atherosclerosis in women than in men. Stroke. 2005;36:1212-1217.

27. Kawamoto R, Tomita H, Inoue A, Ohtsuka N, Kamitani A. Metabolic syndrome may be a risk factor for early carotid atherosclerosis in women but not in men. $J$ Atheroscler Thromb. 2007; 14:36-43.

28. Lin H-F, Liu C-K, Liao Y-C, Lin R-T, Chen C-S, Juo S-HH. The risk of the metabolic syndrome on carotid thickness and stiffness: Sex and age specific effects. Atherosclerosis. 2010;210:155-159.

29. Nishida M, Moriyama T, Ishii K, et al. Effects of IL-6, adiponectin, CRP and metabolic syndrome on subclinical atherosclerosis. Clinica Chimica Acta. 2007;384:99-104.

30. Shaw LJ, Bairey Merz CN, Pepine CJ. Insights from the NHLBI-sponsored Women's Ischemia Syndrome Evaluation (WISE) Study. Part I: gender differences in traditional and novel risk factors, symptom evaluation, and gender-optimized diagnostic strategies. $J A m$ Coll Cardiol. 2006;47(suppl):S4-S20. 
31. Fujishiro K, Roux AVD, Landsbergis P, et al. Associations of occupation, job control and job demands with intima-media thickness: The Multi-Ethnic Study of Atherosclerosis (MESA) Occup Environ Med. 2011;68:319-326.

32. Rosmond R, Bjorntorp P. The hypothalamic-pituitary-adrenal axis activity as a predictor of cardiovascular disease, type 2 diabetes and stroke. J Intern Med. 2000;247:188-197.

33. Anagnostis P, Athyros VG, Tziomalos K, Karagiannis A, Mikhailidis DP. The pathogenetic role of cortisol in the metabolic syndrome: A hypothesis. J Clin Endocrinol Metab. 2009;94:2692-2701.

34. Levine TB, Levine AB. Mental stress and the metabolic syndrome. In Metabolic syndrome and cardiovascular disease. Philadelphia, PA: Saunders 2006.

35. Cohen BE, Panguluri P, Na B, Whooley MA. Psychological risk factors and the metabolic syndrome in patients with coronary heart disease: Findings from the Heart and Soul Study. Psychiatry Res. 2010;175:133-137.

36. Vaccarino V, McClure C, Johnson D, et al. Depression, the metabolic syndrome and cardiovascular risk. Psychosom Med. 2008;70:40-48.

37. Collins PA, Gibbs ACC. Stress in police officers: a study of the origins, prevalence and severity of stress-related symptoms within a county police force. Occup Med. 2003;53:256264.

38. National Center for Women and Policing (NCWP). Equality denied: the status of women in policing: 2001. New York, NY: Columbia University 2002.

39. Kaplan JR, Adams MR, Clarkson TB, Manuck SB, Shively CA, Williams JK. Psychosocial factors, sex differences, and atherosclerosis: Lessons from animal models. Psychosom Med. 1996;58(6):598-611.

40. Abraham NG, Brunner EJ, Eriksson JW, et al. Metabolic syndrome: Psychosocial, neuroendocrine, and classical risk factors in type 2 diabetes. Ann NY Acad Sci. 2007; 1113:256-75.

41. Davila EP, Florez H, Fleming LE, et al. Prevalence of the metabolic syndrome among US workers. Diabetes Care. 2010;33:2390-2395.

42. Adolphe A, Cook LS, Huang X. A cross-sectional study of intima-media thickness, ethnicity, metabolic syndrome, and cardiovascular risk in 2268 study participants. Mayo Clin Proc. 2009;84(3):221-228.

43. Humbarger CD, Crouse SF, Womack JW, et al. Frequency of metabolic syndrome in police officers compared to NCEP III prevalence values. Med Sci Sports Exerc. 2004;36:S161.

44. Tharkar S, Kumpatla S, Muthukumaran P, et al. High prevalence of metabolic syndrome and cardiovascular risk among police personnel compared to general population in India. $J$ Assoc Physicians India. 2008;56:845-849

45. Ervin RB. Prevalence of metabolic syndrome among adults 20 years of age and over, by sex, age, race and ethnicity, and body mass index: United States, 2003-2006. National Health Statistics Reports; No 13. Hyattsville, MD: National Center for Health Statistics. 2009. 
46. Kales SN, Tsismenakis AJ, Zhang C, Soteriades ES. Blood pressure in firefighters, police officers, and other emergency responders. Am J Hypertens. 2009;22(1):11-20.

47. Reaves BA. Local Police Departments, 2007. NCJ 231174. Washington, DC: U .S. Department of Justice, Office of Justice Programs, Bureau of Justice Statistics. 2010.

48. Fekedulegn, D., Andrew, M., Violanti, J., Hartley, T., Charles, L., \& Burchfiel, C. (2010). Comparison of statistical approaches to evaluate factors associated with metabolic syndrome. J Clin Hypertens. 2010;12:363-373.

49. Ford ES, Giles WH, Mokdad AH. Increasing prevalence of the metabolic syndrome among U.S. adults. Diabetes Care. 2004;27:2444-2449. 
Table 5.1. Mean levels and prevalence of metabolic syndrome components by gender.

\begin{tabular}{|c|c|c|c|c|c|c|c|c|c|}
\hline \multirow{3}{*}{ Metabolic Syndrome Component } & \multirow{3}{*}{$\begin{array}{l}\text { Component Cutpoint } \\
\text { (Must meet } \geq 1 \text { of the } \\
\text { cutpoints per component) }\end{array}$} & \multicolumn{6}{|c|}{ Prevalence } & \multicolumn{2}{|c|}{ Mean (SD) } \\
\hline & & \multicolumn{2}{|c|}{ Men } & \multicolumn{2}{|c|}{ Women } & \multicolumn{2}{|c|}{ Overall } & \multirow{2}{*}{$\begin{array}{c}\text { Men } \\
(\mathrm{N}=307)\end{array}$} & \multirow{2}{*}{$\begin{array}{c}\text { Women } \\
(\mathrm{N}=107)\end{array}$} \\
\hline & & $\mathrm{N}$ & $\%$ & $\mathrm{~N}$ & $\%$ & $\mathrm{~N}$ & $\%$ & & \\
\hline Abdominal obesity & & 114 & 37.1 & 19 & $\mathbf{1 7 . 8}$ & 133 & 32.1 & & \\
\hline Waist circumference, $\mathrm{cm}$ & $\geq 102$ Men, $\geq 88$ Women & 114 & 37.1 & 19 & 17.8 & 133 & 32.1 & $99.3(11.5)$ & $80.0(11.6)$ \\
\hline Elevated triglycerides & & 118 & 38.4 & 9 & 8.4 & 127 & 30.7 & & \\
\hline Triglycerides, mg/dL & $\geq 150$ & 114 & 37.1 & 9 & 8.4 & 123 & 29.7 & $154.3(128.0)$ & $88.1(129.4)$ \\
\hline Reduced HDL cholesterol & & 145 & 47.2 & 28 & 26.2 & 173 & 41.8 & & \\
\hline HDL cholesterol, mg/dL & $<40$ Men, $<50$ Women & 145 & 47.2 & 28 & 26.2 & 173 & 41.8 & $42.1(12.0)$ & $58.2(15.6)$ \\
\hline Self-reported fibrates or nicotinic acid medication, $\%$ & Yes & 6 & 2.0 & 1 & 0.9 & 7 & 1.7 & & \\
\hline Glucose intolerance & & 85 & 27.7 & 12 & 11.2 & 97 & 23.4 & & \\
\hline Fasting glucose, $\mathrm{mg} / \mathrm{dL}$ & $\geq 100$ & 83 & 27.0 & 11 & 10.3 & 94 & 23.3 & $94.8(14.0)$ & $86.4(8.4)$ \\
\hline Self-reported diabetes medication, $\%$ & Yes & 8 & 2.6 & 1 & 0.9 & 9 & 2.2 & & \\
\hline Hypertension & & 131 & 42.7 & 28 & 26.2 & 159 & 38.4 & & \\
\hline Systolic blood pressure, $\mathrm{mmHg}$ & $\geq 130$ & 71 & 23.1 & 19 & 17.8 & 90 & 22.3 & $122.3(11.4)$ & $116.8(13.4)$ \\
\hline Self-reported hypertension with antihypertensive medication, $\%$ & Yes & 47 & 15.4 & 7 & 6.5 & 54 & 13.1 & & \\
\hline \multirow[t]{7}{*}{ Number of Components } & & & & & & & & $1.9(1.4)$ & $0.9(1.1)$ \\
\hline & 0 & 55 & 17.9 & 53 & 49.5 & 108 & 26.1 & & \\
\hline & 1 & 75 & 24.4 & 25 & 23.4 & 100 & 24.2 & & \\
\hline & 2 & 79 & 25.7 & 20 & 18.7 & 99 & 23.9 & & \\
\hline & 3 & 48 & 15.6 & 6 & 5.6 & 54 & 13.0 & & \\
\hline & 4 & 34 & 11.1 & 2 & 1.9 & 36 & 8.7 & & \\
\hline & 5 & 16 & 5.2 & 1 & 0.9 & 17 & 4.1 & & \\
\hline Unadjusted Prevalence & $(\geq 3)$ & 98 & 31.9 & 9 & 8.4 & 107 & 25.9 & & \\
\hline Age-Adjusted Prevalence & $(\geq 3)$ & & 31.1 & & 8.2 & & 25.1 & & \\
\hline
\end{tabular}


APPENDIX A 
Table A.1. Summary measures of the Spielberger Police Stress Survey for the total and subscale scores by gender. The Buffalo Cardio-Metabolic Occupational Police Stress (BCOPS) Study, $2004-2009$.

\begin{tabular}{|c|c|c|c|c|}
\hline \multirow[t]{2}{*}{ Characteristic } & \multicolumn{2}{|c|}{$\begin{array}{c}\text { Men } \\
(\mathrm{N}=288)\end{array}$} & \multicolumn{2}{|c|}{$\begin{array}{c}\text { Women } \\
(\mathrm{N}=102)\end{array}$} \\
\hline & Mean & SD & Mean & SD \\
\hline \multicolumn{5}{|l|}{ Stress Rating } \\
\hline Total (60 items) & 2254.6 & 1250.2 & 2482.5 & 1324.5 \\
\hline Organizational/Administrative Pressure (23 items) & 769.0 & 452.6 & 811.1 & 467.3 \\
\hline Physical/Psychological Threat (24 items) & 1021.5 & 567.0 & 1138.3 & 604.7 \\
\hline Lack of Support (13 items) & 464.1 & 295.6 & 533.1 & 312.1 \\
\hline \multicolumn{5}{|l|}{ Frequency during past month } \\
\hline Total (60 items) & 95.9 & 61.2 & 89.8 & 61.5 \\
\hline Organizational/Administrative Pressure (23 items) & 42.2 & 30.8 & 37.7 & 29.0 \\
\hline Physical/Psychological Threat (24 items) & 36.8 & 24.8 & 34.9 & 25.4 \\
\hline Lack of Support (13 items) & 17.2 & 14.4 & 17.1 & 14.0 \\
\hline \multicolumn{5}{|l|}{ Frequency during past year } \\
\hline Total (60 items) & 380.5 & 214.9 & 358.0 & 213.3 \\
\hline Organizational/Administrative Pressure (23 items) & 165.7 & 101.9 & 154.6 & 98.1 \\
\hline Physical/Psychological Threat (24 items) & 149.2 & 88.6 & 141.2 & 87.8 \\
\hline Lack of Support (13 items) & 66.7 & 49.5 & 62.2 & 44.1 \\
\hline \multicolumn{5}{|l|}{ Stress Indices, past month } \\
\hline Total (60 items) & 4528.3 & 3946.0 & 4800.5 & 4332.9 \\
\hline Organizational/Administrative Pressure (23 items) & 1960.3 & 1869.7 & 1900.4 & 1933.1 \\
\hline Physical/Psychological Threat (24 items) & 1641.8 & 1530.4 & 1845.6 & 1722.5 \\
\hline Lack of Support (13 items) & 938.8 & 1066.9 & 1054.5 & 1159.0 \\
\hline \multicolumn{5}{|l|}{ Stress Indices, past year } \\
\hline Total (60 items) & 17928.6 & 14410.6 & 18746.1 & 14879.7 \\
\hline Organizational/Administrative Pressure (23 items) & 7661.9 & 6610.8 & 7587.7 & 6599.3 \\
\hline Physical/Psychological Threat (24 items) & 6760.7 & 5627.8 & 7486.1 & 5948.0 \\
\hline Lack of Support (13 items) & 3556.0 & 3587.5 & 3672.3 & 3510.7 \\
\hline
\end{tabular}

Significant differences between men and women for: 1) Lack of Support p-value=0.047. 
Table A.2. Mean values of the Spielberger Police Stress Survey for the total and subscale scores by gender for the Spielberger Police Stress Survey by gender. The Buffalo Cardio-Metabolic Occupational Police Stress (BCOPS) Study, 2004 - 2009.

\begin{tabular}{|c|c|c|c|c|}
\hline \multirow[t]{2}{*}{ Characteristic } & \multicolumn{2}{|c|}{$\begin{array}{c}\text { Men } \\
(\mathrm{N}=288)\end{array}$} & \multicolumn{2}{|c|}{$\begin{array}{c}\text { Women } \\
(\mathrm{N}=102)\end{array}$} \\
\hline & Mean & $\mathrm{SD}$ & Mean & SD \\
\hline \multicolumn{5}{|l|}{ Stress Rating } \\
\hline Total (60 items) & 37.9 & 20.8 & 41.8 & 22.0 \\
\hline Organizational/Administrative Pressure (23 items) & 33.7 & 19.8 & 35.6 & 20.2 \\
\hline Physical/Psychological Threat (24 items) & 42.9 & 23.6 & 47.9 & 25.1 \\
\hline Lack of Support (13 items) & 36.0 & 22.8 & 41.6 & 24.0 \\
\hline \multicolumn{5}{|l|}{ Frequency during past month } \\
\hline Total (60 items) & 1.6 & 1.0 & 1.5 & 1.0 \\
\hline Organizational/Administrative Pressure (23 items) & 1.9 & 1.3 & 1.6 & 1.3 \\
\hline Physical/Psychological Threat (24 items) & 1.5 & 1.0 & 1.5 & 1.1 \\
\hline Lack of Support (13 items) & 1.4 & 1.1 & 1.3 & 1.1 \\
\hline \multicolumn{5}{|l|}{ Frequency during past year } \\
\hline Total (60 items) & 6.5 & 3.6 & 6.0 & 3.6 \\
\hline Organizational/Administrative Pressure (23 items) & 7.4 & 4.5 & 6.8 & 4.3 \\
\hline Physical/Psychological Threat (24 items) & 6.3 & 3.6 & 5.9 & 3.7 \\
\hline Lack of Support (13 items) & 5.3 & 3.9 & 4.9 & 3.5 \\
\hline \multicolumn{5}{|l|}{ Stress Indices, past month } \\
\hline Total (60 items) & 77.8 & 68.8 & 81.6 & 73.8 \\
\hline Organizational/Administrative Pressure (23 items) & 87.5 & 83.8 & 84.2 & 86.4 \\
\hline Physical/Psychological Threat (24 items) & 70.3 & 66.6 & 77.9 & 71.9 \\
\hline Lack of Support (13 items) & 75.1 & 86.2 & 83.1 & 92.3 \\
\hline \multicolumn{5}{|l|}{ Stress Indices, past year } \\
\hline Total (60 items) & 308.3 & 245.7 & 319.8 & 257.3 \\
\hline Organizational/Administrative Pressure (23 items) & 343.2 & 293.4 & 337.2 & 296.2 \\
\hline Physical/Psychological Threat (24 items) & 288.6 & 238.8 & 317.7 & 252.8 \\
\hline Lack of Support (13 items) & 283.3 & 284.7 & 290.9 & 282.7 \\
\hline
\end{tabular}

Significant differences between men and women for: 1) Lack of Support p-value=0.037. 
Table A.4a. Mean Spielberger Police Stress score by demographic and lifestyle characteristics.

\begin{tabular}{|c|c|c|c|c|c|c|c|c|}
\hline & \multicolumn{4}{|c|}{ Stress Index in Past Month } & \multicolumn{4}{|c|}{ Stress Index in Past Year } \\
\hline & Men & p-value & Women & p-value & Men & p-value & Women & $\mathrm{p}$-value \\
\hline \multicolumn{9}{|l|}{ Age Group } \\
\hline$<40$ years & $84.9(65.3)$ & \multirow{3}{*}{$0.270 *$} & $94.4(76.6)$ & \multirow{3}{*}{$0.656^{*}$} & $335.0(227.6)$ & \multirow{3}{*}{$0.101 *$} & $354.4(229.8)$ & \multirow{3}{*}{$0.980 *$} \\
\hline $40-49$ years & $73.4(70.0)$ & & $71.3(72.3)$ & & $299.3(262.3)$ & & $286.9(277.4)$ & \\
\hline $50+$ years & $71.5(73.8)$ & & $82.3(68.2)$ & & $264.2(240.2)$ & & $352.0(258.7)$ & \\
\hline \multicolumn{9}{|l|}{ Ethnicity } \\
\hline White & $79.9(64.2)$ & \multirow{3}{*}{$0.723+$} & $97.2(76.8)$ & \multirow{3}{*}{$0.0005+$} & $320.0(226.5)$ & \multirow{3}{*}{$0.099+$} & $384.6(260.4)$ & \multirow{3}{*}{$<0.0001+$} \\
\hline Black & $71.3(89.9)$ & & $42.2(47.4)$ & & $253.1(282.1)$ & & $156.7(161.0)$ & \\
\hline Hispanic & $75.0(64.8)$ & & - & & $427.5(493.3)$ & & - & \\
\hline \multicolumn{9}{|l|}{ Education } \\
\hline$>12$ years, High School/GED & $63.5(75.5)$ & \multirow{3}{*}{$0.273^{*}$} & $97.6(53.8)$ & \multirow{3}{*}{$0.529 *$} & $249.3(241.2)$ & \multirow{3}{*}{$0.093^{*}$} & $363.1(161.3)$ & \multirow{3}{*}{$0.677^{*}$} \\
\hline College $<4$ years & $81.7(75.2)$ & & $85.4(83.1)$ & & $311.8(260.1)$ & & $324.8(275.7)$ & \\
\hline College $4+$ years & $77.9(54.0)$ & & $72.9(56.8)$ & & $328.5(222.3)$ & & $305.9(235.1)$ & \\
\hline \multicolumn{9}{|l|}{ Marital Status } \\
\hline Single & $78.4(75.9)$ & \multirow{3}{*}{$0.981+$} & $61.5(59.9)$ & \multirow{3}{*}{$0.168+$} & $292.2(231.2)$ & \multirow{3}{*}{$0.833+$} & $280.2(214.5)$ & \multirow{3}{*}{$0.130+$} \\
\hline Married & $77.6(69.7)$ & & $92.8(81.9)$ & & $305.5(250.5)$ & & $360.3(285.1)$ & \\
\hline Divorced & $80.0(59.7)$ & & $69.0(54.4)$ & & $328.2(227.4)$ & & $235.5(178.3)$ & \\
\hline \multicolumn{9}{|l|}{ Years of Police Service } \\
\hline $1-5$ years & $102.5(95.5)$ & \multirow{5}{*}{$0.099 *$} & $53.9(63.9)$ & \multirow{5}{*}{$0.581 *$} & $360.6(300.6)$ & \multirow{5}{*}{$0.199 *$} & $237.0(169.9)$ & \multirow{5}{*}{$0.534^{*}$} \\
\hline $6-10$ years & $82.5(64.5)$ & & $88.6(60.7)$ & & $323.3(234.5)$ & & $338.7(182.6)$ & \\
\hline $11-15$ years & $72.8(52.1)$ & & $81.2(81.5)$ & & $318.8(209.9)$ & & $349.6(293.3)$ & \\
\hline $16-20$ years & $66.7(66.9)$ & & 83.4 (91.6) & & $279.2(249.4)$ & & $293.3(308.9)$ & \\
\hline $20+$ years & 80.7 (75.4) & & $75.8(67.2)$ & & $299.6(262.2)$ & & $335.6(305.4)$ & \\
\hline \multicolumn{9}{|l|}{ Rank } \\
\hline Police Officer & $81.5(72.6)$ & & $85.3(79.0)$ & & $312.6(248.5)$ & & $326.2(267.4)$ & \\
\hline Sergeant / Lieutenant & $63.9(47.3)$ & $0.299+$ & $82.1(52.6)$ & $0.169+$ & $283.5(218.3)$ & $0.768+$ & 351.7 (250.7) & $0.281+$ \\
\hline Capt / Det / Chief / Comm & $75.4(68.7)$ & & $51.0(38.9)$ & & $313.6(260.9)$ & & $232.5(166.5)$ & \\
\hline Alcohol Intake (drinks/week) & & & & & & & & \\
\hline 0 & $72.4(79.9)$ & & $60.9(78.6)$ & & $273.4(276.7)$ & & $228.8(265.6)$ & \\
\hline$<1$ & $78.7(84.9)$ & & $79.9(62.3)$ & & $295.1(261.0)$ & & $302.3(232.2)$ & \\
\hline $1-7$ & $73.9(58.9)$ & $0.509 *$ & $86.0(73.3)$ & $0.225^{*}$ & $288.5(207.3)$ & $0.050 *$ & $335.1(251.4)$ & $0.032 *$ \\
\hline $8-14$ & $95.8(76.2)$ & & $96.8(67.3)$ & & $391.8(262.2)$ & & $421.7(229.8)$ & \\
\hline$>14$ & $76.1(51.7)$ & & $96.0(70.4)$ & & $354.7(295.4)$ & & $437.2(286.9)$ & \\
\hline
\end{tabular}


Smoking Status

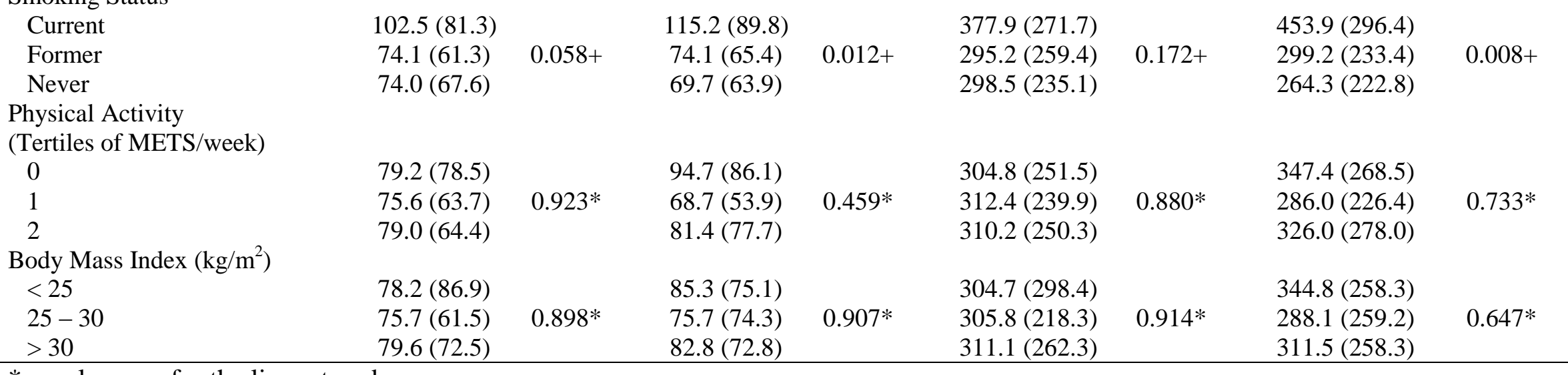

$* \mathrm{p}$-values are for the linear trend

$+p$-values for test of difference 
Table A.4b. Mean number of MetSyn components by demographic and lifestyle characteristics.

\begin{tabular}{|c|c|c|c|c|}
\hline & \multicolumn{4}{|c|}{ Number of MetSyn Components } \\
\hline & Men & p-value & Women & p-value \\
\hline \multicolumn{5}{|l|}{ Age Group } \\
\hline$<40$ years & $1.7(1.4)$ & \multirow{3}{*}{$0.014 *$} & $0.9(1.2)$ & \multirow{3}{*}{$0.190^{*}$} \\
\hline $40-49$ years & $2.2(1.4)$ & & $0.8(1.1)$ & \\
\hline $50+$ years & $2.3(1.5)$ & & $1.4(1.1)$ & \\
\hline \multicolumn{5}{|l|}{ Ethnicity } \\
\hline White & $2.0(1.4)$ & \multirow{3}{*}{$0.942+$} & $0.8(1.2)$ & \multirow{3}{*}{$0.277+$} \\
\hline Black & $2.0(1.5)$ & & $1.1(1.0)$ & \\
\hline Hispanic & $2.1(1.3)$ & & - & \\
\hline \multicolumn{5}{|l|}{ Education } \\
\hline$>12$ years, High School/GED & $1.9(1.3)$ & \multirow{3}{*}{$0.995^{*}$} & $1.0(1.2)$ & \multirow{3}{*}{$0.824 *$} \\
\hline College $<4$ years & $2.0(1.4)$ & & $0.9(1.1)$ & \\
\hline College $4+$ years & $1.9(1.5)$ & & $1.0(1.2)$ & \\
\hline \multicolumn{5}{|l|}{ Marital Status } \\
\hline Single & $1.6(1.2)$ & \multirow{3}{*}{$0.292+$} & $0.5(1.0)$ & \multirow{3}{*}{$0.043+$} \\
\hline Married & $2.0(1.4)$ & & $1.0(1.1)$ & \\
\hline Divorced & $2.2(1.5)$ & & $1.2(1.1)$ & \\
\hline \multicolumn{5}{|l|}{ Years of Police Service } \\
\hline $1-5$ years & $2.1(1.2)$ & \multirow{5}{*}{$0.108^{*}$} & $0.6(0.8)$ & \multirow{5}{*}{$0.088 *$} \\
\hline $6-10$ years & $1.5(1.4)$ & & $0.8(1.1)$ & \\
\hline $11-15$ years & $1.8(1.5)$ & & $0.7(0.9)$ & \\
\hline $16-20$ years & $2.2(1.2)$ & & $1.0(1.4)$ & \\
\hline $20+$ years & $2.4(1.5)$ & & $1.4(0.9)$ & \\
\hline \multicolumn{5}{|l|}{ Rank } \\
\hline Police Officer & $1.8(1.4)$ & \multirow{3}{*}{$0.032+$} & $0.9(1.1)$ & \multirow{3}{*}{$0.246+$} \\
\hline Sergeant / Lieutenant & $2.3(1.4)$ & & $1.1(1.6)$ & \\
\hline Capt / Det / Chief / Comm & $2.3(1.4)$ & & $0.5(0.7)$ & \\
\hline \multicolumn{5}{|l|}{ Alcohol Intake (drinks/week) } \\
\hline 0 & $1.6(1.3)$ & \multirow{5}{*}{$0.441 *$} & $0.9(1.0)$ & \multirow{5}{*}{$0.465^{*}$} \\
\hline$<1$ & $2.1(1.5)$ & & $1.0(1.2)$ & \\
\hline $1-7$ & $2.1(1.3)$ & & $0.9(1.1)$ & \\
\hline $8-14$ & $1.9(1.5)$ & & $0.2(0.4)$ & \\
\hline$>14$ & $2.0(1.8)$ & & $1.7(1.0)$ & \\
\hline \multicolumn{5}{|l|}{ Smoking Status } \\
\hline Current & $2.2(1.5)$ & \multirow{3}{*}{$0.025+$} & $0.9(1.0)$ & \\
\hline Former & $2.4(1.5)$ & & $0.8(1.0)$ & $0.631+$ \\
\hline Never & $1.8(1.4)$ & & $1.0(1.3)$ & \\
\hline Physical Activity (Tertiles of Ml & & & & \\
\hline 0 & $2.1(1.5)$ & & $1.1(1.2)$ & \\
\hline 1 & $2.0(1.3)$ & $0.328 *$ & $0.8(1.0)$ & $0.451^{*}$ \\
\hline 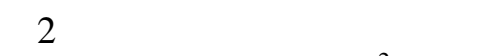 & $1.9(1.4)$ & & $0.9(1.1)$ & \\
\hline Body Mass Index $\left(\mathrm{kg} / \mathrm{m}^{2}\right)$ & & & & \\
\hline$<25$ & $1.0(1.2)$ & & $0.5(0.7)$ & \\
\hline $25-30$ & $1.5(1.3)$ & $<0.0001 *$ & $0.9(1.0)$ & $<0.0001 *$ \\
\hline$>30$ & $2.6(1.3)$ & & $2.1(1.4)$ & \\
\hline
\end{tabular}

$* \mathrm{p}$-values are for the linear trend

+ p-values for test of difference 
Table A.4c. Significant associations between variables of interest and demographic and lifestyle characteristics.

\begin{tabular}{|c|c|c|c|c|c|}
\hline \multirow[b]{2}{*}{ Variable } & \multicolumn{2}{|c|}{ Spielberger } & \multirow{2}{*}{$\begin{array}{c}\text { Number of } \\
\text { MetSyn } \\
\text { Components }\end{array}$} & \multirow[b]{2}{*}{$\begin{array}{l}\text { Interaction } \\
\text { Terms }\end{array}$} & \multirow{2}{*}{$\begin{array}{l}\text { Decision } \\
\text { to Adjust }\end{array}$} \\
\hline & $\begin{array}{c}\text { Index } \\
\text { Past Month }\end{array}$ & $\begin{array}{c}\text { Index } \\
\text { Past Year }\end{array}$ & & & \\
\hline Gender & & & & 0.024 & Stratify \\
\hline Age & & & $\mathrm{M}=0.014$ & & Yes \\
\hline Ethnicity & $\mathrm{F}=0.0005$ & $\begin{array}{l}\mathrm{M}=0.099 \\
\mathrm{~F}<0.0001\end{array}$ & & & No \\
\hline Education & & $\mathrm{M}=0.093$ & & & Try \\
\hline Marital Status & & & $\mathrm{F}=0.043$ & 0.609 & Try \\
\hline $\begin{array}{l}\text { Years of Police Service } \\
\text { Rank }\end{array}$ & $\mathrm{M}=0.099$ & & $\begin{array}{l}\mathrm{F}=0.088 \\
\mathrm{M}=0.032\end{array}$ & 0.781 & $\begin{array}{l}\text { Stratify } \\
\text { Stratify }\end{array}$ \\
\hline Alcohol Intake & & $\begin{aligned} \mathrm{M} & =0.050 \\
\mathrm{~F} & =0.032\end{aligned}$ & & & No \\
\hline Smoking & $\begin{aligned} \mathrm{M} & =0.058 \\
\mathrm{~F} & =0.012\end{aligned}$ & $\mathrm{~F}=0.008$ & $\mathrm{M}=0.025$ & & Yes \\
\hline Physical Activity & & & & & No \\
\hline BMI & & & $\begin{array}{l}\mathrm{M}<0.0001 \\
\mathrm{~F}<0.0001\end{array}$ & & No \\
\hline
\end{tabular}

Key Studies on Work Stress and MetSyn

Chandola 2008 - Work stress and MetSyn, CHD: respondents <50 years; adjusted for age, sex, employment grade, alcohol use, smoking, physical activity, diet

Cohen 2010 - Psychological risk factors and MetSyn in patients with CHD: adjusted for age, sex, race/ethnicity, income, education, physical activity, smoking, alcohol use, BMI

Goldbacher 2007 - Psychological characteristics and MetSyn Review: Moderators: gender, race, SES; Mediators: Behavioral - diet, smoking, physical activity, sleep; Biological - HPA, SAM

Kitaoka-Higashiguchi 2009 - Burnout and arteriosclerotic disease risk: male sample; adjusted for age, alcohol use, smoking, physical activity

Puustinen 2010 - Psychological distress and CV risk scores: gender stratified; no adjusted variables mentioned

Pyykkonen 2010 - Stressful life events and MetSyn: adjusted for sex, age, alcohol consumption, current smoking, exercise, education, family history of diabetes

Sparrenberger 2008 - Stressful life events, current psychological distress and self-reported hypertension: gender stratified; adjusted for age, skin color, physical activity, alcohol abuse, BMI, strong parental history of hypertension, education 
Table A.5a. Unadjusted and adjusted number of metabolic syndrome components by tertiles of Spielberger Police Stress Total Score for men

\begin{tabular}{|c|c|c|c|c|c|c|c|c|c|c|c|c|}
\hline \multirow{2}{*}{$\begin{array}{l}\text { Spielberger Police Stress } \\
\text { Total Score }\end{array}$} & \multicolumn{3}{|c|}{ Unadjusted } & \multicolumn{3}{|c|}{ Age-Adjusted } & \multicolumn{3}{|c|}{$\begin{array}{l}\text { Age and Smoking- } \\
\text { Adjusted }\end{array}$} & \multicolumn{3}{|c|}{$\begin{array}{l}\text { Age, Smoking and } \\
\text { Education-Adjusted }\end{array}$} \\
\hline & $\mathrm{N}$ & Mean (SD) & $\begin{array}{c}\text { p- } \\
\text { value* }\end{array}$ & $\mathrm{N}$ & Mean (SE) & $\begin{array}{c}\mathrm{p}- \\
\text { value* }\end{array}$ & $\mathrm{N}$ & Mean (SE) & $\begin{array}{c}\text { p- } \\
\text { value* }\end{array}$ & $\mathrm{N}$ & $\begin{array}{c}\text { Mean } \\
(\mathrm{SE})\end{array}$ & $\begin{array}{c}\text { p- } \\
\text { value* }\end{array}$ \\
\hline \multicolumn{13}{|l|}{ Stress Rating } \\
\hline Low $(0-26.50)$ & 96 & $2.03(1.42)$ & & 96 & $2.00(0.14)$ & & 96 & $2.10(0.15)$ & & 95 & $2.11(0.16)$ & \\
\hline Middle $(26.53-47.72)$ & 96 & $2.00(1.43)$ & 0.420 & 96 & $2.02(0.14)$ & 0.525 & 96 & $2.15(0.16)$ & 0.539 & 96 & $2.11(0.17)$ & 0.449 \\
\hline High $(47.75-83.00)$ & 96 & $1.93(1.39)$ & & 96 & $1.93(0.14)$ & & 96 & $2.04(0.15)$ & & 96 & $2.01(0.16)$ & \\
\hline \multicolumn{13}{|l|}{ Frequency in Past Month } \\
\hline Low $(0-1.04)$ & 96 & $2.09(1.35)$ & & 96 & $2.02(0.14)$ & & 96 & $2.15(0.16)$ & & 96 & $2.13(0.17)$ & \\
\hline Middle $(1.05-1.91)$ & 96 & $1.91(1.44)$ & 0.418 & 96 & $1.94(0.14)$ & 0.847 & 96 & $2.07(0.16)$ & 0.639 & 95 & $2.08(0.17)$ & 0.516 \\
\hline High $(1.92-5.78)$ & 96 & $1.96(1.44)$ & & 96 & $2.00(0.14)$ & & 96 & $2.07(0.15)$ & & 96 & $2.03(0.16)$ & \\
\hline \multicolumn{13}{|l|}{ Frequency in Past Year } \\
\hline Low $(0-4.28)$ & 96 & $2.04(1.36)$ & & 96 & $1.97(0.14)$ & & 96 & $2.12(0.16)$ & & 96 & $2.10(0.16)$ & \\
\hline Middle (4.29 - 7.98) & 96 & $2.21(1.44)$ & 0.105 & 96 & $2.20(0.14)$ & 0.308 & 96 & $2.36(0.16)$ & 0.215 & 95 & $2.37(0.17)$ & 0.920 \\
\hline High $(7.99-18.25)$ & 96 & $1.71(1.40)$ & & 96 & $1.78(0.14)$ & & 96 & $1.88(0.15)$ & & 96 & $1.85(0.16)$ & \\
\hline \multicolumn{13}{|l|}{ Stress Index for Past Month } \\
\hline Low $(0-40.21)$ & 96 & $2.06(1.27)$ & & 96 & $2.00(0.14)$ & & 96 & $2.12(0.16)$ & & 95 & $2.13(0.17)$ & \\
\hline Middle (40.51 - 89.62) & 96 & $1.91(1.44)$ & 0.992 & 96 & $1.93(0.14)$ & 0.747 & 96 & $2.05(0.16)$ & 0.882 & 96 & $2.02(0.17)$ & 0.970 \\
\hline High $(90.42-406.02)$ & 96 & $1.99(1.52)$ & & 96 & $2.03(0.14)$ & & 96 & $2.11(0.15)$ & & 96 & $2.07(0.16)$ & \\
\hline \multicolumn{13}{|l|}{ Stress Index for Past Year } \\
\hline Low $(0-160.18)$ & 96 & $2.03(1.29)$ & & 96 & $1.98(0.14)$ & & 96 & $2.11(0.16)$ & & 95 & $2.12(0.17)$ & \\
\hline Middle (161.08 - 352.50) & 96 & $1.96(1.46)$ & 0.503 & 96 & $1.95(0.14)$ & 0.766 & 96 & $2.06(0.15)$ & 0.653 & 96 & $2.03(0.16)$ & 0.528 \\
\hline High $(353.08-1435.17)$ & 96 & $1.97(1.48)$ & & 96 & $2.02(0.14)$ & & 96 & $2.12(0.15)$ & & 96 & $2.09(0.16)$ & \\
\hline
\end{tabular}


Table A.5b. Unadjusted and adjusted number of metabolic syndrome components by tertiles of Spielberger Police Stress Total Score for women.

\begin{tabular}{|c|c|c|c|c|c|c|c|c|c|c|c|c|}
\hline \multirow{2}{*}{$\begin{array}{l}\text { Spielberger Police Stress } \\
\text { Total Score }\end{array}$} & \multicolumn{3}{|c|}{ Unadjusted } & \multicolumn{3}{|c|}{ Age-Adjusted } & \multicolumn{3}{|c|}{$\begin{array}{c}\text { Age and Smoking- } \\
\text { Adjusted }\end{array}$} & \multicolumn{3}{|c|}{$\begin{array}{l}\text { Age, Smoking and } \\
\text { Education-Adjusted }\end{array}$} \\
\hline & $\mathrm{N}$ & Mean (SD) & $\begin{array}{c}\text { p- } \\
\text { value* }\end{array}$ & $\mathrm{N}$ & Mean (SE) & $\begin{array}{c}\mathrm{p}- \\
\text { value* }\end{array}$ & $\mathrm{N}$ & $\begin{array}{c}\text { Mean } \\
(\mathrm{SE})\end{array}$ & $\begin{array}{c}\text { p- } \\
\text { value* }\end{array}$ & $\mathrm{N}$ & Mean (SE) & $\begin{array}{c}\mathrm{p}- \\
\text { value* }\end{array}$ \\
\hline \multicolumn{13}{|l|}{ Stress Rating } \\
\hline Low $(0.42-29.08)$ & 34 & $0.53(0.83)$ & & 34 & $0.53(0.18)$ & & 32 & $0.45(0.20)$ & & 32 & $0.52(0.26)$ & \\
\hline Middle $(29.75-55.08)$ & 34 & $0.82(1.00)$ & 0.002 & 34 & $0.86(0.19)$ & 0.003 & 33 & $0.90(0.19)$ & 0.004 & 33 & $0.96(0.25)$ & 0.004 \\
\hline $\operatorname{High}(55.75-86.75)$ & 34 & $1.38(1.33)$ & & 34 & $1.34(0.19)$ & & 34 & $1.32(0.19)$ & & 34 & $1.38(0.25)$ & \\
\hline \multicolumn{13}{|l|}{ Frequency in Past Month } \\
\hline Low $(0.03-0.82)$ & 34 & $0.85(0.93)$ & & 34 & $0.84(0.19)$ & & 32 & $0.86(0.20)$ & & 32 & $0.91(0.27)$ & \\
\hline Middle $(0.86-1.81)$ & 34 & $0.79(1.17)$ & 0.585 & 34 & $0.80(0.19)$ & 0.457 & 33 & $0.79(0.20)$ & 0.491 & 33 & $0.84(0.27)$ & 0.458 \\
\hline High $(1.86-4.78)$ & 34 & $1.09(1.24)$ & & 34 & $1.09(0.19)$ & & 34 & $1.07(0.20)$ & & 34 & $1.15(0.26)$ & \\
\hline \multicolumn{13}{|l|}{ Frequency in Past Year } \\
\hline Low $(0.06-3.88)$ & 34 & $0.97(1.19)$ & & 34 & $0.93(0.19)$ & & 32 & $0.95(0.21)$ & & 32 & $1.00(0.27)$ & \\
\hline Middle $(3.95-7.83)$ & 34 & $0.91(1.08)$ & 0.716 & 34 & $0.93(0.19)$ & 0.844 & 33 & $0.94(0.20)$ & 0.785 & 33 & $1.03(0.28)$ & 0.806 \\
\hline High $(7.91-16.18)$ & 34 & $0.85(1.10)$ & & 34 & $0.88(0.19)$ & & 34 & $0.86(0.20)$ & & 34 & $0.91(0.26)$ & \\
\hline \multicolumn{13}{|l|}{ Stress Index for Past Month } \\
\hline Low $(0-29.36)$ & 34 & $0.71(0.84)$ & & 34 & $0.70(0.19)$ & & 32 & $0.70(0.20)$ & & 32 & $0.71(0.27)$ & \\
\hline Middle $(29.40-94.50)$ & 34 & $0.79(1.20)$ & 0.041 & 34 & $0.80(0.19)$ & 0.033 & 33 & $0.78(0.19)$ & 0.040 & 33 & $0.79(0.28)$ & 0.037 \\
\hline High $(95.33-358.98)$ & 34 & $1.24(1.23)$ & & 34 & $1.23(0.19)$ & & 34 & $1.22(0.19)$ & & 34 & $1.24(0.24)$ & \\
\hline \multicolumn{13}{|l|}{ Stress Index for Past Year } \\
\hline Low $(0-145.76)$ & 34 & $0.76(0.85)$ & & 34 & $0.74(0.19)$ & & 32 & $0.72(0.21)$ & & 32 & $0.77(0.28)$ & \\
\hline Middle $(150.38-385.21)$ & 34 & $0.82(1.19)$ & 0.166 & 34 & $0.86(0.19)$ & 0.160 & 33 & $0.86(0.20)$ & 0.175 & 33 & $0.90(0.26)$ & 0.174 \\
\hline High $(391.00-1195.42)$ & 34 & $1.15(1.26)$ & & 34 & $1.14(0.19)$ & & 34 & $1.12(0.20)$ & & 34 & $1.17(0.26)$ & \\
\hline
\end{tabular}




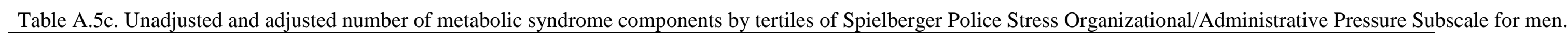

\begin{tabular}{|c|c|c|c|c|c|c|c|c|c|c|c|c|}
\hline \multirow{2}{*}{$\begin{array}{l}\text { Spielberger Police Stress } \\
\text { Organizational/Administrative } \\
\text { Pressure Subscale }\end{array}$} & \multicolumn{3}{|c|}{ Unadjusted } & \multicolumn{3}{|c|}{ Age-Adjusted } & \multicolumn{3}{|c|}{ Age and Smoking-Adjusted } & \multicolumn{3}{|c|}{$\begin{array}{l}\text { Age, Smoking and } \\
\text { Education-Adjusted }\end{array}$} \\
\hline & $\mathrm{N}$ & Mean (SD) & $\begin{array}{c}\text { p- } \\
\text { value* }\end{array}$ & $\mathrm{N}$ & Mean (SE) & $\begin{array}{c}\text { p- } \\
\text { value* }\end{array}$ & $\mathrm{N}$ & Mean (SE) & $\begin{array}{c}\text { p- } \\
\text { value* }\end{array}$ & $\mathrm{N}$ & Mean (SE) & $\begin{array}{c}\text { p- } \\
\text { value* }\end{array}$ \\
\hline \multicolumn{13}{|l|}{ Stress Rating } \\
\hline Low $(0-23.70)$ & 96 & $2.03(1.40)$ & & 96 & $2.02(0.14)$ & & 96 & $2.13(0.15)$ & & 95 & $2.14(0.16)$ & \\
\hline Middle (23.91 - 43.48) & 98 & $2.01(1.38)$ & 0.657 & 98 & $2.01(0.14)$ & 0.780 & 98 & $2.13(0.15)$ & 0.767 & 98 & $2.09(0.17)$ & 0.623 \\
\hline High $(43.70-84.57)$ & 94 & $1.91(1.46)$ & & 94 & $1.93(0.14)$ & & 94 & $2.03(0.15)$ & & 94 & $2.00(0.16)$ & \\
\hline \multicolumn{13}{|l|}{ Frequency in Past Month } \\
\hline Low $(0-1.13)$ & 95 & $1.93(1.28)$ & & 95 & $1.86(0.14)$ & & 95 & $1.98(0.16)$ & & 95 & $1.97(0.17)$ & \\
\hline Middle $(1.15-2.13)$ & 95 & $2.06(1.49)$ & 0.537 & 95 & $2.09(0.14)$ & 0.964 & 95 & $2.19(0.15)$ & 0.754 & 94 & $2.19(0.16)$ & 0.654 \\
\hline High $(2.15-7.70)$ & 97 & $1.98(1.46)$ & & 97 & $2.02(0.14)$ & & 97 & $2.10(0.15)$ & & 97 & $2.07(0.16)$ & \\
\hline \multicolumn{13}{|l|}{ Frequency in Past Year } \\
\hline Low $(0-4.59)$ & 95 & $2.18(1.37)$ & & 95 & $2.12(0.14)$ & & 95 & $2.27(0.16)$ & & 95 & $2.25(0.17)$ & \\
\hline Middle $(4.63-9.15)$ & 96 & $2.07(1.38)$ & 0.073 & 96 & $2.06(0.14)$ & 0.235 & 96 & $2.19(0.16)$ & 0.164 & 96 & $2.16(0.17)$ & 0.141 \\
\hline High $(9.20-22.33)$ & 96 & $1.72(1.46)$ & & 96 & $1.79(0.14)$ & & 96 & $1.88(0.15)$ & & 95 & $1.86(0.16)$ & \\
\hline \multicolumn{13}{|l|}{ Stress Index for Past Month } \\
\hline Low $(0-35.43)$ & 95 & $2.12(1.31)$ & & 95 & $2.07(0.14)$ & & 95 & $2.20(0.16)$ & & 94 & $2.21(0.17)$ & \\
\hline Middle (34.87 - 101.52) & 96 & $1.91(1.42)$ & 0.883 & 96 & $1.90(0.14)$ & 0.618 & 96 & $2.02(0.16)$ & 0.760 & 96 & $1.98(0.17)$ & 0.907 \\
\hline High (102.35 - 427.39) & 96 & $1.95(1.50)$ & & 96 & $2.00(0.14)$ & & 96 & $2.08(0.15)$ & & 96 & $2.04(0.16)$ & \\
\hline \multicolumn{13}{|l|}{ Stress Index for Past Year } \\
\hline Low $(0-156.85)$ & 95 & $2.12(1.34)$ & & 95 & $2.07(0.14)$ & & 95 & $2.21(0.16)$ & & 94 & $2.23(0.17)$ & \\
\hline Middle (157.07 - 393.15) & 96 & $2.00(1.43)$ & 0.453 & 96 & $1.99(0.14)$ & 0.751 & 96 & $2.08(0.15)$ & 0.625 & 96 & $2.04(0.16)$ & 0.492 \\
\hline High $(405.43-1619.13)$ & 96 & $1.85(1.47)$ & & 96 & $1.91(0.14)$ & & 96 & $2.02(0.15)$ & & 96 & $1.97(0.17)$ & \\
\hline
\end{tabular}


Table A.5d. Unadjusted and adjusted number of metabolic syndrome components by tertiles of Spielberger Police Stress Organizational/Administrative Pressure Subscale for women.

\begin{tabular}{|c|c|c|c|c|c|c|c|c|c|c|c|c|}
\hline \multirow{2}{*}{$\begin{array}{l}\text { Spielberger Police Stress } \\
\text { Organizational/Administrative } \\
\text { Pressure Subscale }\end{array}$} & \multicolumn{3}{|c|}{ Unadjusted } & \multicolumn{3}{|c|}{ Age-Adjusted } & \multicolumn{3}{|c|}{ Age and Smoking-Adjusted } & \multicolumn{3}{|c|}{$\begin{array}{l}\text { Age, Smoking and } \\
\text { Education-Adjusted }\end{array}$} \\
\hline & $\mathrm{N}$ & $\begin{array}{c}\text { Mean } \\
(\mathrm{SD})\end{array}$ & $\begin{array}{c}\mathrm{p}- \\
\text { value* }\end{array}$ & $\mathrm{N}$ & Mean (SE) & $\begin{array}{c}\mathrm{p}- \\
\text { value* }\end{array}$ & $\mathrm{N}$ & Mean (SE) & $\begin{array}{c}\mathrm{p}- \\
\text { value* }\end{array}$ & $\mathrm{N}$ & Mean (SE) & p-value* \\
\hline \multicolumn{13}{|l|}{ Stress Rating } \\
\hline Low $(0-23.48)$ & 34 & $0.62(0.85)$ & & 34 & $0.63(0.19)$ & & 33 & $0.59(0.20)$ & & 33 & $0.66(0.27)$ & \\
\hline Middle $(23.91-45.65)$ & 34 & $0.88(1.09)$ & 0.002 & 34 & $0.89(0.19)$ & 0.003 & 32 & $0.92(0.20)$ & 0.003 & 32 & $0.98(0.25)$ & 0.004 \\
\hline High (46.14 - 84.13) & 34 & $1.24(1.30)$ & & 34 & $1.21(0.19)$ & & 34 & $1.19(0.19)$ & & 34 & $1.25(0.26)$ & \\
\hline \multicolumn{13}{|l|}{ Frequency in Past Month } \\
\hline Low $(0-0.98)$ & 34 & $0.79(0.91)$ & & 34 & $0.79(0.19)$ & & 32 & $0.79(0.21)$ & & 32 & $0.84(0.27)$ & \\
\hline Middle $(1.00-1.89)$ & 34 & $0.97(1.27)$ & 0.355 & 34 & $0.96(0.19)$ & 0.278 & 33 & $0.95(0.20)$ & 0.288 & 33 & $1.02(0.28)$ & 0.270 \\
\hline $\operatorname{High}(1.91-5.04)$ & 34 & $0.97(1.17)$ & & 34 & $0.98(0.19)$ & & 34 & $0.98(0.19)$ & & 34 & $1.05(0.25)$ & \\
\hline \multicolumn{13}{|l|}{ Frequency in Past Year } \\
\hline Low $(0-4.24)$ & 34 & $0.88(1.01)$ & & 34 & $0.85(0.19)$ & & 32 & $0.88(0.21)$ & & 32 & $0.94(0.27)$ & \\
\hline Middle $(4.33-8.74)$ & 34 & $1.06(1.25)$ & 0.955 & 34 & $1.08(0.19)$ & 0.903 & 33 & $1.08(0.20)$ & 0.955 & 33 & $1.17(0.27)$ & 0.950 \\
\hline High $(8.89-16.07)$ & 34 & $0.79(1.09)$ & & 34 & $0.81(0.19)$ & & 34 & $0.79(0.20)$ & & 34 & $0.86(0.26)$ & \\
\hline \multicolumn{13}{|l|}{ Stress Index for Past Month } \\
\hline Low $(0-23.91)$ & 34 & $0.65(0.81)$ & & 34 & $0.65(0.19)$ & & 32 & $0.65(0.21)$ & & 32 & $0.69(0.27)$ & \\
\hline Middle $(25.68-99.13)$ & 34 & $0.97(1.24)$ & 0.021 & 34 & $0.98(0.19)$ & 0.018 & 33 & $0.96(0.20)$ & 0.023 & 33 & $1.01(0.28)$ & 0.023 \\
\hline High $(101.52-365.43)$ & 34 & $1.12(1.23)$ & & 34 & $1.11(0.19)$ & & 34 & $1.10(0.19)$ & & 34 & $1.14(0.24)$ & \\
\hline \multicolumn{13}{|l|}{ Stress Index for Past Year } \\
\hline Low $(0-141.24)$ & 34 & $0.74(0.86)$ & & 34 & $0.73(0.19)$ & & 32 & $0.72(0.21)$ & & 32 & $0.76(0.28)$ & \\
\hline Middle (144.35 - 378.48) & 34 & $0.88(1.20)$ & 0.110 & 34 & $0.87(0.19)$ & 0.101 & 33 & $0.86(0.20)$ & 0.118 & 33 & $0.90(0.28)$ & 0.127 \\
\hline High $(389.46-1142.71)$ & 34 & $1.12(1.25)$ & & 34 & $1.13(0.19)$ & & 34 & $1.12(0.20)$ & & 34 & $1.15(0.25)$ & \\
\hline
\end{tabular}

* p-values are for the linear trend 
Table A.5e. Unadjusted and adjusted number of metabolic syndrome components by tertiles of Spielberger Police Stress Physical/Psychological Threat Subscale for men.

\begin{tabular}{|c|c|c|c|c|c|c|c|c|c|c|c|c|}
\hline \multirow{2}{*}{$\begin{array}{l}\text { Spielberger Police Stress } \\
\text { Physical/Psychological } \\
\text { Threat Subscale }\end{array}$} & \multicolumn{3}{|c|}{ Unadjusted } & \multicolumn{3}{|c|}{ Age-Adjusted } & \multicolumn{3}{|c|}{$\begin{array}{l}\text { Age and Smoking- } \\
\text { Adjusted }\end{array}$} & \multicolumn{3}{|c|}{$\begin{array}{l}\text { Age, Smoking and } \\
\text { Education-Adjusted }\end{array}$} \\
\hline & $\mathrm{N}$ & Mean (SD) & $\begin{array}{c}\mathrm{p}- \\
\text { value* }\end{array}$ & $\mathrm{N}$ & Mean (SE) & $\begin{array}{c}\mathrm{p}- \\
\text { value* }\end{array}$ & $\mathrm{N}$ & Mean (SE) & p-value* & $\mathrm{N}$ & Mean (SE) & $\begin{array}{c}\text { p- } \\
\text { value* }\end{array}$ \\
\hline \multicolumn{13}{|l|}{ Stress Rating } \\
\hline Low $(0-31.88)$ & 96 & $2.13(1.40)$ & & 96 & $2.08(0.14)$ & & 96 & $2.18(0.16)$ & & 95 & $2.19(0.16)$ & \\
\hline Middle (32.71 - 57.92) & 97 & $1.91(1.41)$ & 0.231 & 97 & $1.95(0.14)$ & 0.352 & 97 & $2.06(0.15)$ & 0.375 & 97 & $2.03(0.17)$ & 0.322 \\
\hline High $(58.26-86.46)$ & 95 & $1.93(1.42)$ & & 95 & $1.93(0.14)$ & & 95 & $2.04(0.15)$ & & 95 & $2.01(0.16)$ & \\
\hline \multicolumn{13}{|l|}{ Frequency in Past Month } \\
\hline Low $(0-1.00)$ & 95 & $2.08(1.36)$ & & 95 & $1.96(0.15)$ & & 95 & $2.09(0.16)$ & & 94 & $2.10(0.17)$ & \\
\hline Middle $(1.02-1.81)$ & 96 & $2.05(1.48)$ & 0.146 & 96 & $2.08(0.14)$ & 0.620 & 96 & $2.23(0.16)$ & 0.424 & 96 & $2.21(0.17)$ & 0.296 \\
\hline High $(1.83-5.35)$ & 96 & $1.81(1.40)$ & & 96 & $1.91(0.15)$ & & 96 & $2.00(0.15)$ & & 96 & $1.96(0.16)$ & \\
\hline \multicolumn{13}{|l|}{ Frequency in Past Year } \\
\hline Low $(0-4.31)$ & 95 & $2.04(1.41)$ & & 95 & $1.94(0.15)$ & & 95 & $2.08(0.16)$ & & 94 & $2.09(0.16)$ & \\
\hline Middle $(4.33-8.10)$ & 96 & $2.16(1.45)$ & 0.048 & 96 & $2.18(0.14)$ & 0.259 & 96 & $2.33(0.16)$ & 0.174 & 96 & $2.31(0.17)$ & 0.130 \\
\hline High $(8.17-16.19)$ & 96 & $1.75(1.36)$ & & 96 & $1.82(0.14)$ & & 96 & $1.92(0.15)$ & & 96 & $1.88(0.16)$ & \\
\hline \multicolumn{13}{|l|}{ Stress Index for Past Month } \\
\hline Low $(0-32.08)$ & 95 & $2.01(1.33)$ & & 95 & $1.94(0.14)$ & & 95 & $2.08(0.16)$ & & 94 & $2.07(0.17)$ & \\
\hline Middle $(32.29-74.38)$ & 96 & $2.17(1.48)$ & 0.287 & 96 & $2.14(0.14)$ & 0.695 & 96 & $2.28(0.16)$ & 0.574 & 96 & $2.27(0.17)$ & 0.447 \\
\hline High $(74.79-375.91)$ & 96 & $1.77(1.40)$ & & 96 & $1.86(0.14)$ & & 96 & $1.96(0.15)$ & & 96 & $1.91(0.16)$ & \\
\hline \multicolumn{13}{|l|}{ Stress Index for Past Year } \\
\hline Low $(0-144.06)$ & 96 & $2.02(1.36)$ & & 96 & $1.97(0.14)$ & & 96 & $2.10(0.16)$ & & 95 & $2.10(0.17)$ & \\
\hline Middle (144.09 - 341.09) & 95 & $2.21(1.45)$ & 0.152 & 95 & $2.19(0.14)$ & 0.398 & 95 & $2.30(0.16)$ & 0.338 & 95 & $2.28(0.16)$ & 0.260 \\
\hline High $(342.50-1197.92)$ & 96 & $1.72(1.40)$ & & 96 & $1.80(0.14)$ & & 96 & $1.90(0.15)$ & & 96 & $1.88(0.16)$ & \\
\hline
\end{tabular}


Table A.5f. Unadjusted and adjusted number of metabolic syndrome components by tertiles of Spielberger Police Stress Physical/Psychological Threat Subscale for women.

\begin{tabular}{|c|c|c|c|c|c|c|c|c|c|c|c|c|}
\hline \multirow{2}{*}{$\begin{array}{l}\text { Spielberger Police Stress } \\
\text { Physical/Psychological } \\
\text { Threat Subscale }\end{array}$} & \multicolumn{3}{|c|}{ Unadjusted } & \multicolumn{3}{|c|}{ Age-Adjusted } & \multicolumn{3}{|c|}{$\begin{array}{l}\text { Age and Smoking- } \\
\text { Adjusted }\end{array}$} & \multicolumn{3}{|c|}{$\begin{array}{l}\text { Age, Smoking and } \\
\text { Education-Adjusted }\end{array}$} \\
\hline & $\mathrm{N}$ & Mean (SD) & $\begin{array}{c}\text { p- } \\
\text { value* }\end{array}$ & $\mathrm{N}$ & Mean (SE) & $\begin{array}{c}\mathrm{p}- \\
\text { value* }\end{array}$ & $\mathrm{N}$ & Mean (SE) & $\begin{array}{c}\text { p- } \\
\text { value* }\end{array}$ & $\mathrm{N}$ & Mean (SE) & $\begin{array}{c}\text { p- } \\
\text { value* }\end{array}$ \\
\hline \multicolumn{13}{|l|}{ Stress Rating } \\
\hline Low $(0-37.92)$ & 34 & $0.50(0.83)$ & & 34 & $0.51(0.18)$ & & 33 & $0.45(0.20)$ & & 33 & $0.49(0.26)$ & \\
\hline Middle $(38.17-62.71)$ & 34 & $0.88(1.01)$ & 0.007 & 34 & $0.89(0.18)$ & 0.008 & 32 & $0.93(0.19)$ & 0.007 & 32 & $0.96(0.26)$ & 0.009 \\
\hline High $(63.48-89.79)$ & 34 & $1.35(1.32)$ & & 34 & $1.33(0.18)$ & & 34 & $1.31(0.19)$ & & 34 & $1.34(0.24)$ & \\
\hline \multicolumn{13}{|l|}{ Frequency in Past Month } \\
\hline Low $(0-0.73)$ & 34 & $1.03(1.14)$ & & 34 & $0.98(0.19)$ & & 33 & $0.98(0.21)$ & & 33 & $1.05(0.29)$ & \\
\hline Middle $(0.77-1.71)$ & 34 & $0.94(1.13)$ & 0.695 & 34 & $0.97(0.19)$ & 0.863 & 32 & $1.00(0.20)$ & 0.858 & 32 & $1.06(0.26)$ & 0.900 \\
\hline High $(1.75-4.90)$ & 34 & $0.76(1.10)$ & & 34 & $0.78(0.19)$ & & 34 & $0.77(0.19)$ & & 34 & $0.85(0.26)$ & \\
\hline \multicolumn{13}{|l|}{ Frequency in Past Year } \\
\hline Low $(0-3.83)$ & 34 & $0.97(1.14)$ & & 34 & $0.94(0.19)$ & & 33 & $0.96(0.21)$ & & 33 & $1.02(0.27)$ & \\
\hline Middle $(4.42-7.78)$ & 34 & $1.06(1.15)$ & 0.327 & 34 & $1.05(0.19)$ & 0.408 & 32 & $1.09(0.20)$ & 0.389 & 32 & $1.19(0.27)$ & 0.411 \\
\hline High $(8.19-15.88)$ & 34 & $0.71(1.06)$ & & 34 & $0.74(0.19)$ & & 34 & $0.71(0.20)$ & & 34 & $0.78(0.26)$ & \\
\hline \multicolumn{13}{|l|}{ Stress Index for Past Month } \\
\hline Low $(0-30.63)$ & 34 & $0.79(0.84)$ & & 34 & $0.76(0.19)$ & & 32 & $0.77(0.21)$ & & 32 & $0.82(0.28)$ & \\
\hline Middle $(33.92-88.75)$ & 34 & $0.88(1.23)$ & 0.239 & 34 & $0.89(0.19)$ & 0.216 & 33 & $0.88(0.20)$ & 0.229 & 33 & $0.93(0.26)$ & 0.215 \\
\hline High $(94.58-372.08)$ & 34 & $1.06(1.25)$ & & 34 & $1.08(0.19)$ & & 34 & $1.07(0.19)$ & & 34 & $1.12(0.26)$ & \\
\hline \multicolumn{13}{|l|}{ Stress Index for Past Year } \\
\hline Low $(0-146.88)$ & 34 & $0.91(1.11)$ & & 34 & $0.90(0.19)$ & & 33 & $0.87(0.21)$ & & 33 & $0.97(0.29)$ & \\
\hline Middle (158.33 - 412.71) & 34 & $0.71(1.09)$ & 0.403 & 34 & $0.74(0.19)$ & 0.418 & 32 & $0.76(0.20)$ & 0.435 & 32 & $0.83(0.25)$ & 0.420 \\
\hline High (415.63 - 1210.00) & 34 & $1.12(1.15)$ & & 34 & $1.10(0.19)$ & & 34 & $1.09(0.20)$ & & 34 & $1.18(0.27)$ & \\
\hline
\end{tabular}

$* \mathrm{p}$-values are for the linear trend 
Table A.5g. Unadjusted and adjusted number of metabolic syndrome components by tertiles of Spielberger Police Stress Lack of Support Subscale for men.

\begin{tabular}{|c|c|c|c|c|c|c|c|c|c|c|c|c|}
\hline \multirow{2}{*}{$\begin{array}{l}\text { Spielberger Police Stress } \\
\text { Lack of Support Subscale }\end{array}$} & \multicolumn{3}{|c|}{ Unadjusted } & \multicolumn{3}{|c|}{ Age-Adjusted } & \multicolumn{3}{|c|}{$\begin{array}{l}\text { Age and Smoking- } \\
\text { Adjusted }\end{array}$} & \multicolumn{3}{|c|}{$\begin{array}{l}\text { Age, Smoking and } \\
\text { Education-Adjusted }\end{array}$} \\
\hline & $\mathrm{N}$ & Mean (SD) & $\begin{array}{c}\text { p- } \\
\text { value* }\end{array}$ & $\mathrm{N}$ & Mean (SE) & $\begin{array}{c}\text { p- } \\
\text { value* }\end{array}$ & $\mathrm{N}$ & Mean (SE) & $\begin{array}{c}\mathrm{p}- \\
\text { value* }\end{array}$ & $\mathrm{N}$ & Mean (SE) & $\begin{array}{c}\mathrm{p}- \\
\text { value* }\end{array}$ \\
\hline \multicolumn{13}{|l|}{ Stress Rating } \\
\hline Low $(0-21.15)$ & 95 & $1.99(1.35)$ & & 95 & $2.00(0.14)$ & & 95 & $2.10(0.15)$ & & 94 & $2.10(0.16)$ & \\
\hline Middle (21.54 - 48.08) & 97 & $2.02(1.49)$ & 0.667 & 97 & $2.04(0.14)$ & 0.633 & 97 & $2.15(0.15)$ & 0.659 & 97 & $2.12(0.17)$ & 0.584 \\
\hline High $(48.46-90.38)$ & 96 & $1.95(1.40)$ & & 96 & $1.92(0.14)$ & & 96 & $2.04(0.16)$ & & 96 & $2.01(0.16)$ & \\
\hline \multicolumn{13}{|l|}{ Frequency in Past Month } \\
\hline Low $(0-0.69)$ & 98 & $2.08(1.24)$ & & 98 & $2.09(0.14)$ & & 98 & $2.21(0.15)$ & & 98 & $2.19(0.16)$ & \\
\hline Middle $(0.73-1.50)$ & 93 & $1.98(1.47)$ & 0.770 & 93 & $2.00(0.14)$ & 0.989 & 93 & $2.12(0.16)$ & 0.939 & 92 & $2.12(0.17)$ & 0.885 \\
\hline $\operatorname{High}(1.54-6.15)$ & 97 & $1.90(1.52)$ & & 97 & $1.86(0.14)$ & & 97 & $1.96(0.15)$ & & 97 & $1.93(0.16)$ & \\
\hline \multicolumn{13}{|l|}{ Frequency in Past Year } \\
\hline Low $(0-2.96)$ & 96 & $2.05(1.31)$ & & 96 & $2.07(0.14)$ & & 96 & $2.19(0.16)$ & & 96 & $2.17(0.16)$ & \\
\hline Middle $(3.00-6.31)$ & 96 & $2.08(1.48)$ & 0.807 & 96 & $2.08(0.14)$ & 0.803 & 96 & $2.20(0.16)$ & 0.579 & 95 & $2.20(0.17)$ & 0.549 \\
\hline High $(6.35-19.38)$ & 96 & $1.82(1.44)$ & & 96 & $1.81(0.14)$ & & 96 & $1.91(0.15)$ & & 96 & $1.88(0.16)$ & \\
\hline \multicolumn{13}{|l|}{ Stress Index for Past Month } \\
\hline Low $(0-24.62)$ & 96 & $1.95(1.27)$ & & 96 & $1.95(0.14)$ & & 96 & $2.07(0.16)$ & & 95 & $2.07(0.16)$ & \\
\hline Middle $(25.38-82.31)$ & 97 & $2.03(1.44)$ & 0.223 & 97 & $2.07(0.14)$ & 0.383 & 97 & $2.17(0.15)$ & 0.427 & 97 & $2.15(0.16)$ & 0.482 \\
\hline High $(83.08-509.85)$ & 95 & $1.98(1.53)$ & & 95 & $1.94(0.14)$ & & 95 & $2.04(0.16)$ & & 95 & $2.01(0.17)$ & \\
\hline \multicolumn{13}{|l|}{ Stress Index for Past Year } \\
\hline Low $(0-144.06)$ & 96 & $2.02(1.36)$ & & 96 & $1.97(0.14)$ & & 96 & $2.10(0.16)$ & & 95 & $2.10(0.17)$ & \\
\hline Middle (144.09 - 341.09) & 95 & $2.21(1.45)$ & 0.152 & 95 & $2.19(0.14)$ & 0.398 & 95 & $2.30(0.16)$ & 0.338 & 95 & $2.28(0.16)$ & 0.260 \\
\hline High $(342.50-1197.92)$ & 96 & $1.72(1.40)$ & & 96 & $1.80(0.14)$ & & 96 & $1.90(0.15)$ & & 96 & $1.88(0.16)$ & \\
\hline
\end{tabular}


Table A.5h. Unadjusted and adjusted number of metabolic syndrome components by tertiles of Spielberger Police Stress Lack of Support Subscale for women.

\begin{tabular}{|c|c|c|c|c|c|c|c|c|c|c|c|c|}
\hline \multirow{2}{*}{$\begin{array}{l}\text { Spielberger Police Stress } \\
\text { Lack of Support Subscale }\end{array}$} & \multicolumn{3}{|c|}{ Unadjusted } & \multicolumn{3}{|c|}{ Age-Adjusted } & \multicolumn{3}{|c|}{$\begin{array}{l}\text { Age and Smoking- } \\
\text { Adjusted }\end{array}$} & \multicolumn{3}{|c|}{$\begin{array}{l}\text { Age, Smoking and } \\
\text { Education-Adjusted }\end{array}$} \\
\hline & $\mathrm{N}$ & Mean (SD) & $\begin{array}{c}\text { p- } \\
\text { value* }\end{array}$ & $\mathrm{N}$ & Mean (SE) & $\begin{array}{c}\text { p- } \\
\text { value* }\end{array}$ & $\mathrm{N}$ & Mean (SE) & $\begin{array}{c}\mathrm{p}- \\
\text { value* }\end{array}$ & $\mathrm{N}$ & Mean (SE) & $\begin{array}{c}\mathrm{p}- \\
\text { value* }\end{array}$ \\
\hline \multicolumn{13}{|l|}{ Stress Rating } \\
\hline Low $(0-25.00)$ & 34 & $0.62(0.92)$ & & 34 & $0.62(0.19)$ & & 32 & $0.57(0.20)$ & & 32 & $0.65(0.26)$ & \\
\hline Middle (26.15 - 57.69) & 34 & $0.76(0.96)$ & 0.004 & 34 & $0.78(0.19)$ & 0.005 & 33 & $0.82(0.19)$ & 0.006 & 33 & $0.89(0.25)$ & 0.006 \\
\hline High $(58.46-85.77)$ & 34 & $1.35(1.32)$ & & 34 & $1.34(0.19)$ & & 34 & $1.30(0.19)$ & & 34 & $1.38(0.26)$ & \\
\hline \multicolumn{13}{|l|}{ Frequency in Past Month } \\
\hline Low $(0-0.69)$ & 35 & $0.77(1.00)$ & & 35 & $0.77(0.19)$ & & 33 & $0.80(0.20)$ & & 33 & $0.86(0.27)$ & \\
\hline Middle $(0.73-1.50)$ & 33 & $0.97(1.29)$ & 0.218 & 33 & $0.96(0.19)$ & 0.179 & 32 & $0.92(0.20)$ & 0.249 & 32 & $0.98(0.27)$ & 0.227 \\
\hline $\operatorname{High}(1.54-5.83)$ & 34 & $1.00(1.07)$ & & 34 & $1.01(0.19)$ & & 34 & $1.01(0.19)$ & & 34 & $1.07(0.26)$ & \\
\hline \multicolumn{13}{|l|}{ Frequency in Past Year } \\
\hline Low $(0-2.62)$ & 34 & $0.94(0.98)$ & & 34 & $0.90(0.19)$ & & 31 & $0.92(0.21)$ & & 31 & $0.98(0.27)$ & \\
\hline Middle $(2.65-6.23)$ & 34 & $0.91(1.31)$ & 0.785 & 34 & $0.95(0.19)$ & 0.701 & 34 & $0.92(0.20)$ & 0.799 & 34 & $0.99(0.26)$ & 0.774 \\
\hline High $(6.50-17.04)$ & 34 & $0.88(1.07)$ & & 34 & $0.89(0.19)$ & & 34 & $0.89(0.19)$ & & 34 & $0.96(0.27)$ & \\
\hline \multicolumn{13}{|l|}{ Stress Index for Past Month } \\
\hline Low $(0-30.00)$ & 34 & $0.68(0.91)$ & & 34 & $0.69(0.19)$ & & 31 & $0.70(0.20)$ & & 31 & $0.75(0.27)$ & \\
\hline Middle (30.77 - 83.46) & 34 & $0.76(0.96)$ & 0.042 & 34 & $0.75(0.19)$ & 0.033 & 34 & $0.74(0.19)$ & 0.043 & 34 & $0.78(0.26)$ & 0.036 \\
\hline High $(85.58-483.33)$ & 34 & $1.29(1.36)$ & & 34 & $1.30(0.19)$ & & 34 & $1.27(0.19)$ & & 34 & $1.33(0.25)$ & \\
\hline \multicolumn{13}{|l|}{ Stress Index for Past Year } \\
\hline Low $(0-146.88)$ & 34 & $0.91(1.11)$ & & 34 & $0.90(0.19)$ & & & $0.87(0.21)$ & & 33 & $0.97(0.29)$ & \\
\hline Middle $(158.33-412.71)$ & 34 & $0.71(1.09)$ & 0.403 & 34 & $0.74(0.19)$ & 0.418 & & $0.76(0.20)$ & 0.435 & 32 & $0.83(0.25)$ & 0.420 \\
\hline High $(415.63-1210.00)$ & 34 & $1.12(1.15)$ & & 34 & $1.10(0.19)$ & & & $1.09(0.20)$ & & 34 & $1.18(0.27)$ & \\
\hline
\end{tabular}


Table A.5i. Multivariate adjusted number of metabolic syndrome components by tertiles of Spielberger Police Stress Total and Administrative/Organizational Pressure Score by years of police service for men.

\begin{tabular}{|c|c|c|c|c|c|c|c|c|}
\hline \multirow{2}{*}{$\begin{array}{l}\text { Spielberger Police } \\
\text { Stress Survey }\end{array}$} & \multicolumn{4}{|c|}{$\underline{\text { Total Score }}$} & \multicolumn{4}{|c|}{ Administrative/Organizational Pressure Score } \\
\hline & N (Range) & 1-15Years & N (Range) & $>15$ years & N (Range) & 1-15 Years & $\mathrm{N}$ (Range) & $>15$ years \\
\hline \multicolumn{9}{|l|}{ Stress Rating } \\
\hline Low & $45(0.50-26.38)$ & $1.86(0.24)$ & $51(0-26.50)$ & $2.32(0.21)$ & $50(0-23.70)$ & $1.90(0.23)$ & $46(0-22.83)$ & $2.33(0.22)$ \\
\hline Middle & $51(26.53-47.42)$ & $1.78(0.23)$ & $45(26.67-47.72)$ & $2.47(0.23)$ & $47(23.91-43.48)$ & $1.83(0.24)$ & $51(23.91-43.48)$ & $2.36(0.22)$ \\
\hline High & $48(47.75-83.00)$ & $1.68(0.23)$ & $48(49.92-79.17)$ & $2.34(0.21)$ & $47(43.70-84.57)$ & $1.58(0.23)$ & $47(43.70-79.57)$ & $2.41(0.21)$ \\
\hline p-value* & & 0.530 & & 0.781 & & 0.722 & & 0.933 \\
\hline \multicolumn{9}{|c|}{ Frequency in Past Month } \\
\hline Low & $35(0.02-1.03)$ & $1.66(0.28)$ & $61(0-1.04)$ & $2.47(0.20)$ & $39(0.04-1.13)$ & $1.45(0.27)$ & $56(0-1.13)$ & $2.36(0.21)$ \\
\hline Middle & $58(1.05-1.89)$ & $1.83(0.22)$ & $38(1.17-1.91)$ & $2.28(0.25)$ & $55(1.15-2.11)$ & $1.87(0.22)$ & $40(1.17-2.13)$ & $2.47(0.23)$ \\
\hline High & $51(1.92-5.78)$ & $1.76(0.21)$ & $45(1.94-4.80)$ & $2.31(0.22)$ & $50(2.15-7.70)$ & $1.82(0.22)$ & $47(2.15-5.63)$ & $2.30(0.22)$ \\
\hline$p$-value* & & 0.756 & & 0.475 & & 0.588 & & 0.379 \\
\hline \multicolumn{9}{|c|}{ Frequency in Past Year } \\
\hline Low & $35(0.18-4.22)$ & $1.59(0.26)$ & $61(0-4.28)$ & $2.50(0.19)$ & $36(0.30-4.52)$ & $1.87(0.27)$ & $59(0-4.59)$ & $2.58(0.19)$ \\
\hline Middle & $49(4.29-7.88)$ & $1.92(0.24)$ & $47(4.37-7.98)$ & $2.79(0.23)$ & $51(4.63-9.15)$ & $1.63(0.23)$ & $45(4.76-9.04)$ & $2.79(0.22)$ \\
\hline High & $60(7.99-17.76)$ & $1.76(0.20)$ & $36(8.31-18.25)$ & $1.84(0.23)$ & $57(9.20-22.33)$ & $1.84(0.21)$ & $39(9.63-19.76)$ & $1.76(0.20)$ \\
\hline$p$-value* & & 0.995 & & 0.138 & & 0.996 & & 0.073 \\
\hline \multicolumn{9}{|c|}{ Stress Index for Past Month } \\
\hline Low & $40(0.50-39.42)$ & $1.85(0.26)$ & $56(0-40.21)$ & $2.32(0.21)$ & $42(0-35.22)$ & $1.81(0.25)$ & $53(0-35.43)$ & $2.51(0.21)$ \\
\hline Middle & $51(40.51-80.71)$ & $1.47(0.23)$ & $45(40.76-89.62)$ & $2.58(0.22)$ & $52(35.87-101.52)$ & $1.78(0.23)$ & 44 (36.09-95.87) & $2.20(0.23)$ \\
\hline High & $53(92.50-337.64)$ & $1.93(0.21)$ & $43(90.42-406.02)$ & $2.20(0.22)$ & $50(102.35-427.39)$ & $1.73(0.22)$ & $46(103.48-407.50)$ & $2.37(0.21)$ \\
\hline$p$-value* & & 0.832 & & 0.881 & & 0.654 & & 0.945 \\
\hline \multicolumn{9}{|c|}{ Stress Index for Past Year } \\
\hline Low & $40(6.08-153.96)$ & $1.84(0.26)$ & $56(0-160.18)$ & $2.32(0.20)$ & $41(0-154.57)$ & $1.98(0.26)$ & $54(0-156.85)$ & $2.39(0.21)$ \\
\hline Middle & $50(163.75-346.58)$ & $1.60(0.23)$ & $46(161.08-352.50)$ & $2.48(0.22)$ & $52(164.77-393.15)$ & $1.54(0.22)$ & $44(157.07-391.52)$ & $2.64(0.22)$ \\
\hline High & $54(354.67-1183.71$ & $1.87(0.21)$ & $42(353.08-1435.17$ & $2.31(0.23)$ & $51(407.17-1508.15$ & $1.87(0.22)$ & $45(405.43-1619.13)$ & $2.06(0.22)$ \\
\hline$p$-value* & & 0.816 & & 0.446 & & 0.788 & & 0.350 \\
\hline
\end{tabular}

Adjusted values include mean and standard error.

$* \mathrm{p}$-values are for the linear trend 
Table A.5j. Multivariate adjusted number of metabolic syndrome components by tertiles of Spielberger Police Stress Physical/Psychological Threat and Lack of Support Score by years of police service for men.

\begin{tabular}{|c|c|c|c|c|c|c|c|c|}
\hline \multirow{2}{*}{$\begin{array}{l}\text { Spielberger Police } \\
\text { Stress Survey }\end{array}$} & \multicolumn{4}{|c|}{ Physical/Psychological Threat Score } & \multicolumn{4}{|c|}{$\underline{\text { Lack of Support Score }}$} \\
\hline & N (Range) & 1-15 Years & $\mathrm{N}$ (Range) & $>15$ years & $\mathrm{N}$ (Range) & 1-15 Years & N (Range) & $>15$ years \\
\hline \multicolumn{9}{|l|}{ Stress Rating } \\
\hline Low & $42(0.83-31.88)$ & $1.91(0.24)$ & $54(0-31.67)$ & $2.42(0.20)$ & $48(0-20.00)$ & $1.92(0.22)$ & $47(0-21.15)$ & $2.23(0.22)$ \\
\hline Middle & $53(33.33-57.92)$ & $1.68(0.22)$ & $44(32.71-57.92)$ & $2.40(0.24)$ & $55(21.54-48.08)$ & $1.65(0.22)$ & $42(21.54-47.69)$ & $2.64(0.23)$ \\
\hline High & $49(58.26-86.46)$ & $1.74(0.23)$ & $46(58.33-82.78)$ & $2.28(0.22)$ & $41(49.23-82.15)$ & $1.69(0.25)$ & $55(48.46-90.38)$ & $2.30(0.20)$ \\
\hline$p$-value* & & 0.516 & & 0.576 & & 0.368 & & 0.957 \\
\hline \multicolumn{9}{|c|}{ Frequency in Past Month } \\
\hline Low & $26(0-0.98)$ & $1.71(0.31)$ & $69(0-1.00)$ & $2.37(0.18)$ & $53(0-0.69)$ & $2.08(0.22)$ & $45(0-0.69)$ & $2.26(0.23)$ \\
\hline Middle & $55(1.02-1.81)$ & $1.63(0.23)$ & $41(1.02-1.81)$ & $2.92(0.24)$ & $48(0.73-1.50)$ & $1.66(0.23)$ & $45(0.73-1.46)$ & $2.54(0.22)$ \\
\hline High & $63(1.85-5.35)$ & $1.88(0.20)$ & $33(1.83-4.63)$ & $1.92(0.24)$ & $43(1.54-5.23)$ & $1.54(0.24)$ & $54(1.54-6.15)$ & $2.31(0.20)$ \\
\hline$p$-value* & & 0.447 & & 0.144 & & 0.250 & & 0.421 \\
\hline \multicolumn{9}{|c|}{ Frequency in Past Year } \\
\hline Low & $31(0.13-4.27)$ & $1.56(0.28)$ & $64(0-4.31)$ & $2.46(0.19)$ & $49(0-2.96)$ & $1.97(0.23)$ & $47(0-2.96)$ & $2.35(0.22)$ \\
\hline Middle & $53(4.35-8.10)$ & $1.81(0.23)$ & $43(4.33-8.06)$ & $2.89(0.24)$ & $48(3.08-6.31)$ & $1.76(0.24)$ & $48(3.00-6.31)$ & $2.59(0.21)$ \\
\hline High & $60(8.17-14.38)$ & $1.84(0.20)$ & $36(8.40-16.19)$ & $1.83(0.23)$ & $47(6.35-15.92)$ & $1.60(0.23)$ & $49(6.38-19.38)$ & $2.17(0.21)$ \\
\hline$p$-value* & & 0.595 & & 0.046 & & 0.339 & & 0.992 \\
\hline \multicolumn{9}{|c|}{ Stress Index for Past Month } \\
\hline Low & $36(0-32.08)$ & $1.89(0.27)$ & $59(0-32.08)$ & $2.23(0.19)$ & $49(0-24.62)$ & $1.88(0.24)$ & $47(0-21.92)$ & $2.18(0.22)$ \\
\hline Middle & $43(34.69-74.13)$ & $1.65(0.25)$ & $53(32.29-74.38)$ & $2.81(0.21)$ & $55(25.38-82.31)$ & $1.65(0.22)$ & $42(26.54-80.00)$ & $2.72(0.22)$ \\
\hline High & $65(74.79-310.21)$ & $1.78(0.20)$ & $31(75.88-375.91)$ & $2.02(0.25)$ & $40(83.08-372.31)$ & $1.81(0.25)$ & $55(83.85-509.85)$ & $2.23(0.20)$ \\
\hline$p$-value* & & 0.986 & & 0.627 & & 0.954 & & 0.387 \\
\hline \multicolumn{9}{|c|}{ Stress Index for Past Year } \\
\hline Low & $39(4.79-144.06)$ & $1.81(0.26)$ & $57(0-144.06)$ & $2.33(0.19)$ & $39(43.79-144.06)$ & $1.81(0.26)$ & $57(0-144.06)$ & $2.33(0.19)$ \\
\hline Middle & $41(144.09-341.09)$ & $1.75(0.24)$ & $54(146.25-336.98)$ & $2.75(0.21)$ & $41(144.09-341.09)$ & $1.75(0.24)$ & $54(146.25-336.98)$ & $2.75(0.21)$ \\
\hline High & $64(342.50-999.38)$ & $1.76(0.20)$ & $32(358.85-1197.92$ & $1.92(0.25)$ & $64(342.50-999.38)$ & $1.76(0.20)$ & $32(358.85-1197.92$ & $1.92(0.25)$ \\
\hline$p$-value $*$ & & 0.876 & & 0.212 & & 0.876 & & 0.212 \\
\hline
\end{tabular}

Adjusted values include mean and standard error.

$* \mathrm{p}$-values are for the linear trend 
Table A.5k. Multivariate adjusted number of metabolic syndrome components by tertiles of Spielberger Police Stress Total and Administrative/Organizational Pressure Score by years of police service for women.

\begin{tabular}{|c|c|c|c|c|c|c|c|c|}
\hline \multirow{2}{*}{$\begin{array}{l}\text { Spielberger Police } \\
\text { Stress Survey }\end{array}$} & \multicolumn{4}{|c|}{ Total Score } & \multicolumn{4}{|c|}{ Administrative/Organizational Pressure Score } \\
\hline & N (Range) & 1-15 Years & N (Range) & $>15$ years & N (Range) & 1-15 Years & N (Range) & $>15$ years \\
\hline \multicolumn{9}{|l|}{ Stress Rating } \\
\hline Low & $20(0.75-28.50)$ & $0.46(0.24)$ & $12(0.42-29.08)$ & $0.47(0.35)$ & $19(0-23.48)$ & $0.62(0.25)$ & $14(0-22.83)$ & $0.52(0.32)$ \\
\hline Middle & $21(29.75-55.08)$ & $0.58(0.22)$ & $12(30.97-52.83)$ & $1.40(0.35)$ & $20(23.91-45.65)$ & $0.52(0.23)$ & $12(28.26-45.22)$ & $1.57(0.33)$ \\
\hline High & $14(57.25-86.75$ & $1.17(0.27)$ & $20(55.75-80.92)$ & $1.43(0.27)$ & $16(46.14-84.13)$ & $1.00(0.25)$ & $18(48.26-79.78)$ & $1.40(0.28)$ \\
\hline p-value* & & 0.135 & & 0.013 & & 0.118 & & 0.011 \\
\hline \multicolumn{9}{|c|}{ Frequency in Past Month } \\
\hline Low & $14(0.28-0.81)$ & $.62(0.28)$ & $18(0.03-0.82)$ & $1.02(0.30)$ & $15(0.09-0.87)$ & $0.59(0.28)$ & $17(0-0.98)$ & $0.92(0.30)$ \\
\hline Middle & $21(0.86-1.81)$ & $0.51(0.23)$ & $12(0.95-1.56)$ & $1.12(0.37)$ & $18(1.00-1.89)$ & $0.43(0.24)$ & $15(1.02-1.87)$ & $1.48(0.33)$ \\
\hline High & $20(2.01-3.47)$ & $0.94(0.23)$ & $14(1.86-4.78)$ & $1.41(0.34)$ & $22(1.91-4.85)$ & $0.98(0.22)$ & $12(1.98-5.04)$ & $1.15(0.37)$ \\
\hline$p$-value* & & 0.351 & & 0.418 & & 0.322 & & 0.180 \\
\hline \multicolumn{9}{|c|}{ Frequency in Past year } \\
\hline Low & $12(1.19-3.88)$ & $.59(0.32)$ & $20(0.06-3.23)$ & $1.26(0.29)$ & $13(1.04-4.20)$ & $0.71(0.30)$ & $19(0-4.24)$ & $0.99(0.30)$ \\
\hline Middle & $22(3.95-7.83)$ & $0.80(0.23)$ & $11(4.51-6.65)$ & $1.01(0.39)$ & $21(4.37-8.74)$ & $0.83(0.24)$ & $12(4.33-8.74)$ & $1.43(0.36)$ \\
\hline High & $21(7.91-11.78)$ & $0.65(0.23)$ & $13(9.11-16.18)$ & $1.19(0.35)$ & $21(8.89-16.07)$ & $0.57(0.23)$ & $13(9.83-16.04)$ & $1.20(0.35)$ \\
\hline$p$-value* & & 0.885 & & 0.871 & & 0.988 & & 0.565 \\
\hline \multicolumn{9}{|c|}{ Stress Index for Past Month } \\
\hline Low & $16(2.31-28.94)$ & $.54(0.26)$ & $16(0-29.36)$ & $0.82(0.32)$ & $17(0-23.91)$ & $0.49(0.25)$ & $15(0-23.00)$ & $0.76(0.32)$ \\
\hline Middle & $21(29.40-94.50)$ & $0.49(0.22)$ & $12(40.42-84.92)$ & $1.34(0.36)$ & $19(26.52-86.52)$ & $0.50(0.23)$ & $14(25.68-99.13)$ & $1.53(0.32)$ \\
\hline High & $18(95.33-285.83)$ & $1.07(0.24)$ & $16(96.58-358.98)$ & $1.38(0.31)$ & $19(101.52-318.91)$ & $1.06(0.23)$ & $15(101.96-365.43)$ & $1.24(0.31)$ \\
\hline$p$-value* & & 0.032 & & 0.178 & & 0.064 & & 0.057 \\
\hline \multicolumn{9}{|c|}{ Stress Index for Past Year } \\
\hline Low & $13(2.31-123.17)$ & $0.60(0.30)$ & $19(0-145.76$ & $0.88(0.29)$ & $15(0-141.24)$ & $0.62(0.27)$ & $17(0-103.26)$ & $0.77(0.31)$ \\
\hline Middle & $23(150.38-381.29)$ & $0.47(0.21)$ & $10(181.92-385.21)$ & $1.57(0.39)$ & $20(144.35-375.43)$ & $0.38(0.23)$ & $13(185.54-378.48)$ & $1.59(0.33)$ \\
\hline High & $19(391.00-982.25)$ & $1.03(0.24)$ & $15(393.63-1195.42)$ & $1.28(0.32)$ & $20(389.46-1142.71)$ & $1.04(0.22)$ & $14(390.67-1129.57)$ & $1.24(0.32)$ \\
\hline$p$-value $*$ & & 0.115 & & 0.500 & & 0.138 & & 0.300 \\
\hline
\end{tabular}

Adjusted values include mean and standard error.

$* \mathrm{p}$-values are for the linear trend 
Table A.5l. Multivariate adjusted number of metabolic syndrome components by tertiles of Spielberger Police Stress Physical/Psychological Threat and Lack of Support Score by years of police service for women.

\begin{tabular}{|c|c|c|c|c|c|c|c|c|}
\hline \multirow{2}{*}{$\begin{array}{l}\text { Spielberger Police } \\
\text { Stress Survey }\end{array}$} & \multicolumn{4}{|c|}{ Physical/Psychological Threat Score } & \multicolumn{4}{|c|}{ Lack of Support Score } \\
\hline & $\mathrm{N}$ (Range) & 1-15 Years & $\mathrm{N}$ (Range) & $>15$ years & $\mathrm{N}$ (Range) & $1-15$ Years & $\mathrm{N}$ (Range) & $>15$ years \\
\hline \multicolumn{9}{|l|}{ Stress Rating } \\
\hline Low & $21(0-37.92)$ & $0.45(0.22)$ & $12(0-35.00)$ & $0.47(0.35)$ & $20(0-25.00)$ & $0.53(0.24)$ & $12(1.23-23.46)$ & $0.51(0.34)$ \\
\hline Middle & $17(38.33-62.71)$ & $0.54(0.24)$ & $15(40.00-61.67)$ & $1.37(0.30)$ & $20(26.15-57.69)$ & $0.72(0.24)$ & $13(30.77-53.46)$ & $1.03(0.32)$ \\
\hline High & $17(63.54-89.79)$ & $1.15(0.24)$ & $17(63.48-83.33)$ & $1.46(0.29)$ & $15(60.00-85.77)$ & $0.87(0.27)$ & $19(58.46-84.62)$ & $1.68(0.26)$ \\
\hline$p$-value* & & 0.156 & & 0.037 & & 0.076 & & 0.008 \\
\hline \multicolumn{9}{|c|}{ Frequency in Past Month } \\
\hline Low & $13(0-0.71)$ & $0.62(0.30)$ & $20(0-0.71)$ & $1.25(0.29)$ & $21(0-0.69)$ & $0.59(0.22)$ & $12(0-0.69)$ & $1.06(0.38)$ \\
\hline Middle & $19(0.77-1.65)$ & $1.03(0.23)$ & $13(0.79-1.71)$ & $0.86(0.34)$ & $14(0.81-1.50)$ & $0.47(0.27)$ & $18(0.73-1.50)$ & $1.34(0.30)$ \\
\hline High & $23(1.75-3.67)$ & $0.46(0.21)$ & $11(1.88-4.90)$ & $1.42(0.37)$ & $20(1.54-3.85)$ & $0.98(0.23)$ & $14(1.54-5.83)$ & $1.07(0.33)$ \\
\hline$p$-value* & & 0.769 & & 0.651 & & 0.027 & & 0.830 \\
\hline \multicolumn{9}{|c|}{ Frequency in Past Year } \\
\hline Low & $12(0.23-3.83)$ & $0.55(0.29)$ & $21(0-3.35)$ & $1.25(0.29)$ & $13(0-2.62)$ & $0.72(0.29)$ & $18(0-2.54)$ & $1.13(0.29)$ \\
\hline Middle & $22(4.42-7.77)$ & $1.06(0.21)$ & $10(4.65(7.78)$ & $1.01(0.41)$ & $22(2.65-6.23)$ & $0.56(0.22)$ & $12(2.92-5.35)$ & $1.53(0.37)$ \\
\hline High & $21(8.19-11.85)$ & $0.39(0.22)$ & $13(8.58-15.88)$ & $1.19(0.35)$ & $20(6.50-11.27)$ & $0.83(0.23)$ & $14(6.58-17.04)$ & $0.96(0.33)$ \\
\hline$p$-value* & & 0.265 & & 0.976 & & 0.161 & & 0.708 \\
\hline \multicolumn{9}{|c|}{ Stress Index for Past Month } \\
\hline Low & $15(0-30.63)$ & $0.55(0.28)$ & $17(0-26.46)$ & $0.99(0.31)$ & $19(0-30.00)$ & $0.62(0.23)$ & $12(0-23.08)$ & $0.65(0.36)$ \\
\hline Middle & $19(33.92-88.75)$ & $0.66(0.24)$ & $14(38.33-88.33)$ & $1.20(0.33)$ & $18(30.77-82.12)$ & $0.36(0.23)$ & $16(31.15-83.46)$ & $1.23(0.30)$ \\
\hline High & $21(94.58-267.29)$ & $0.82(0.23)$ & $13(96.56-372.08)$ & $1.38(0.34)$ & $18(91.15-344.62)$ & $1.12(0.23)$ & $16(85.58-483.33)$ & $1.50(0.30)$ \\
\hline$p$-value* & & 0.246 & & 0.367 & & 0.004 & & 0.493 \\
\hline \multicolumn{9}{|c|}{ Stress Index for Past Year } \\
\hline Low & $12(0-130.73)$ & $0.57(0.31)$ & $21(0-146.88)$ & $1.11(0.29)$ & $17(0-120.96)$ & $0.72(0.29)$ & $14(0-105.77)$ & $1.13(0.29)$ \\
\hline Middle & $26(158.33-412.71)$ & $0.57(0.20)$ & $6(172.92-354.58)$ & $1.23(0.51)$ & $19(128.46-288.46)$ & $0.56(0.22)$ & $15(128.46-293.65)$ & $1.53(0.37)$ \\
\hline High & $17(415.63-855.31)$ & $0.97(0.25)$ & $17(428.91-1210.00)$ & $1.23(0.30)$ & $19(301-92-1033.46)$ & $0.83(0.230$ & $15(296.35-1371.25)$ & $0.96(0.33)$ \\
\hline$p$-value* & & 0.507 & & 0.636 & & 0.161 & & 0.708 \\
\hline
\end{tabular}

Adjusted values include mean and standard error.

$* \mathrm{p}$-values are for the linear trend 
Table A.5m. Multivariate adjusted number of metabolic syndrome components by Spielberger Police Stress Total and Administrative/Organizational Pressure Score by rank for men.

\begin{tabular}{|c|c|c|c|c|c|c|c|c|}
\hline \multirow{2}{*}{$\begin{array}{l}\text { Spielberger Police } \\
\text { Stress Survey }\end{array}$} & \multicolumn{4}{|c|}{$\underline{\text { Total Score }}$} & \multicolumn{4}{|c|}{ Administrative/Organizational Pressure Score } \\
\hline & N (Range) & Police Officer & $\mathrm{N}$ (Range) & All Higher Ranks & $\mathrm{N}$ (Range) & Police Officer & N (Range) & All Higher Ranks \\
\hline \multicolumn{9}{|l|}{ Stress Rating } \\
\hline Low & $66(0-26.38)$ & $1.82(0.19)$ & $30(0-26.50)$ & $2.64(0.27)$ & $68(0-23.70)$ & $1.89(0.19)$ & $28(0-22.83)$ & $2.60(0.28)$ \\
\hline Middle & $69(26.53-47.67)$ & $2.03(0.20)$ & $27(28.78-47.72)$ & $2.24(0.28)$ & $66(23.91-43.48)$ & $1.98(0.20)$ & $32(23.91-43.48)$ & $2.30(0.26)$ \\
\hline High & $59(47.75-83.00)$ & $1.82(0.20)$ & $37(51.12-79.17)$ & $2.38(0.24)$ & $60(43.70-84.57)$ & $1.80(0.20)$ & $34(43.91-79.57)$ & $2.40(0.25)$ \\
\hline$p$-value* & & 0.872 & & 0.334 & & 0.755 & & 0.317 \\
\hline \multicolumn{9}{|c|}{ Frequency in Past Month } \\
\hline Low & $56(0-1.03)$ & $1.90(0.22)$ & $40(0-1.04)$ & $2.56(0.25)$ & $62(0-1.13)$ & $1.69(0.21)$ & $33(0-1.13)$ & $2.51(0.28)$ \\
\hline Middle & $67(1.05-1.89)$ & $1.95(0.21)$ & $29(1.13-1.91)$ & $2.21(0.26)$ & $64(1.15-2.13)$ & $2.06(0.20)$ & $31(1.17-2.13)$ & $2.33(0.25)$ \\
\hline High & $71(1.92-5.78)$ & $1.84(0.18)$ & $25(1.94-4.80)$ & $2.51(0.29)$ & $68(2.15-7.70)$ & $1.88(0.19)$ & $29(2.15-5.63)$ & $2.48(0.27)$ \\
\hline$p$-value* & & 0.771 & & 0.767 & & 0.913 & & 0.542 \\
\hline \multicolumn{9}{|c|}{ Frequency in Past Year } \\
\hline Low & $62(0-4.28)$ & $1.85(0.20)$ & $34(0-4.23)$ & $2.57(0.25)$ & $65(0-4.59)$ & $2.05(0.20)$ & $30(0-4.41)$ & $2.67(0.27)$ \\
\hline Middle & $58(4.29-7.91)$ & $2.27(0.21)$ & $38(4.37-7.98)$ & $2.47(0.25)$ & $60(4.80-9.15)$ & $1.86(0.21)$ & $36(4.63-9.00)$ & $2.70(0.25)$ \\
\hline High & $74(7.99-17.76)$ & $1.70(0.18)$ & $22(8.31-18.25)$ & $2.17(0.29)$ & $69(9.20-22.33)$ & $1.78(0.19)$ & $27(9.24-19.76)$ & $1.93(0.26)$ \\
\hline$p$-value $*$ & & 0.296 & & 0.516 & & 0.367 & & 0.239 \\
\hline \multicolumn{9}{|c|}{ Stress Index for Past Month } \\
\hline Low & $60(0-39.67)$ & $1.82(0.21)$ & $36(0-40.21)$ & $2.61(0.26)$ & $63(0-35.43)$ & $1.93(0.21)$ & $32(0-35.43)$ & $2.65(0.28)$ \\
\hline Middle & $66(40.51-88.42)$ & $1.79(0.20)$ & $30(44.42-89.62)$ & $2.51(0.26)$ & $64(35.87-101.52)$ & $1.80(0.20)$ & $32(36.09-95.87)$ & $2.37(0.25)$ \\
\hline High & $68(90.42-406.02)$ & $2.01(0.19)$ & $28(96.08-301.00)$ & $2.16(0.26)$ & $67(102.35-427.39)$ & $1.92(0.19)$ & $29(103.26-345.87)$ & $2.30(0.26)$ \\
\hline$p$-value* & & 0.574 & & 0.492 & & 0.399 & & 0.411 \\
\hline \multicolumn{9}{|c|}{ Stress Index for Past Year } \\
\hline Low & $65(0-156.25)$ & $1.85(0.21)$ & $31(0-160.18)$ & $2.53(0.27)$ & $68(0-154.57)$ & $2.00(0.20)$ & $27(0-156.85)$ & $2.63(0.29)$ \\
\hline Middle & $62(161.08-348.00)$ & $1.90(0.20)$ & 34 (174.17-352.50) & $2.32(0.25)$ & 59 (160.00-393.15) & $1.78(0.20)$ & 37 (157.07-391.52) & $2.51(0.24)$ \\
\hline High & $67(353.08-1183.71)$ & $1.90(0.19)$ & $29(362.92-1435.17)$ & $2.43(0.26)$ & $67(405-43-1508.15)$ & $1.88(0.19)$ & $29(409.57-1619.13)$ & $2.18(0.27)$ \\
\hline$p$-value * & & 0.951 & & 0.401 & & 0.983 & & 0.327 \\
\hline
\end{tabular}

Adjusted values include mean and standard error.

* p-values are for the linear trend 
Table A.5n. Multivariate adjusted number of metabolic syndrome components by Spielberger Police Stress Physical/Psychological Threat and Lack of Support Score by rank for men.

\begin{tabular}{|c|c|c|c|c|c|c|c|c|}
\hline \multirow{2}{*}{$\begin{array}{l}\text { Spielberger Police } \\
\text { Stress Survey }\end{array}$} & \multicolumn{4}{|c|}{ Physical/Psychological Threat Score } & \multicolumn{4}{|c|}{ Lack of Support Score } \\
\hline & N (Range) & Police Officer & $\mathrm{N}$ (Range) & All Higher Ranks & N (Range) & Police Officer & $\mathrm{N}$ (Range) & All Higher Ranks \\
\hline \multicolumn{9}{|l|}{ Stress Rating } \\
\hline Low & $66(0-31.88)$ & $1.93(0.20)$ & $30(0-31.18)$ & $2.66(0.27)$ & $70(0-21.15)$ & $1.84(0.19)$ & $25(0-20.77)$ & $2.61(0.29)$ \\
\hline Middle & $71(32.71-57.92)$ & $1.92(0.19)$ & $26(33.33-57.92)$ & $2.19(0.28)$ & $70(21.54-48.08)$ & $1.99(0.19)$ & $27(21.54-47.69)$ & $2.67(0.28)$ \\
\hline High & $57(58.26-86.46)$ & $1.80(0.20)$ & $38(58.33-82.17)$ & $2.40(0.24)$ & $54(49.23-86.08)$ & $1.81(0.22)$ & $42(48.46-90.38)$ & $2.35(0.23)$ \\
\hline$p$-value* & & 0.570 & & 0.369 & & 0.934 & & 0.400 \\
\hline \multicolumn{9}{|c|}{ Frequency in Past Month } \\
\hline Low & $49(0-1.00)$ & $1.87(0.23)$ & $46(0-1.00)$ & $2.42(0.23)$ & $66(0-0.69)$ & $2.03(0.19)$ & $32(0-0.69)$ & $2.49(0.27)$ \\
\hline Middle & $69(1.02-1.81)$ & $1.96(0.21)$ & $27(1.13-1.81)$ & $2.72(0.29)$ & $61(0.73-1.50)$ & $1.96(0.20)$ & $32(0.77-1.46)$ & $2.33(0.26)$ \\
\hline High & $76(1.85-5.35)$ & $1.85(0.18)$ & $20(1.83-4.63)$ & $2.11(0.30)$ & $67(1.54-5.38)$ & $1.68(0.19)$ & $30(1.54-6.15)$ & $2.45(0.26)$ \\
\hline$p$-value* & & 0.563 & & 0.646 & & 0.622 & & 0.728 \\
\hline \multicolumn{9}{|c|}{ Frequency in Past Year } \\
\hline Low & $54(0-4.31)$ & $1.88(0.22)$ & $41(0-4.27)$ & $2.43(0.24)$ & $66(0-2.96)$ & $2.04(0.19)$ & $30(0-2.96)$ & $2.43(0.28)$ \\
\hline Middle & $65(4.35-8.10)$ & $2.10(0.21)$ & $31(4.33-8.06)$ & $2.66(0.28)$ & $62(3.04-6.31)$ & $2.00(0.21)$ & $34(3.00-6.31)$ & $2.48(0.25)$ \\
\hline High & $75(8.17-14.38)$ & $1.76(0.18)$ & $21(8.40-16.19)$ & $2.14(0.30)$ & $66(6.35-18.69)$ & $1.65(0.19)$ & $30(6.50-19.38)$ & $2.35(0.26)$ \\
\hline p-value* & & 0.309 & & 0.357 & & 0.326 & & 0.695 \\
\hline \multicolumn{9}{|c|}{ Stress Index for Past Month } \\
\hline Low & $57(0-32.08)$ & $1.90(0.21)$ & $38(0-32.08)$ & $2.38(0.24)$ & $67(0-24.62)$ & $1.80(0.20)$ & $29(0-23.08)$ & $2.51(0.28)$ \\
\hline Middle & $63(34.27-74.13)$ & $1.97(0.20)$ & $33(32.29-74.38)$ & $2.84(0.27)$ & $67(25.38-82.31)$ & $2.03(0.19)$ & $30(25.77-79.17)$ & $2.35(0.27)$ \\
\hline High & $74(74.79-375.91)$ & $1.82(0.18)$ & $22(75.88-300.63)$ & $2.04(0.29)$ & $60(83.08-509.85)$ & $1.80(0.21)$ & $35(84.62-422.88)$ & $2.41(0.24)$ \\
\hline$p$-value* & & 0.928 & & 0.324 & & 0.416 & & 0.961 \\
\hline \multicolumn{9}{|c|}{ Stress Index for Past Year } \\
\hline Low & $63(0-144.06)$ & $1.97(0.20)$ & $33(0-133.96)$ & $2.31(0.25)$ & $66(0-106.35)$ & $1.89(0.20)$ & $30(0-105.38)$ & $2.42(0.27)$ \\
\hline Middle & $57(144.09-341.09)$ & $1.96(0.21)$ & $38(146.25-336.98)$ & $2.84(0.25)$ & $70(108.46-295.58)$ & $2.03(0.19)$ & $26(119.23-292.50)$ & $2.75(0.27)$ \\
\hline High & $74(342.50-1127.61)$ & $1.78(0.18)$ & $22(362.29-1197.92)$ & $2.00(0.29)$ & $58(299.23-1408.69)$ & $1.70(0.20)$ & $38(296.15-1547.69)$ & $2.16(0.24)$ \\
\hline$p$-value* & (2) (a) & 0.712 & & 0.201 & & 0.702 & & 0.939 \\
\hline
\end{tabular}


Table A.5o. Multivariate adjusted number of metabolic syndrome components by Spielberger Police Stress Total and Administrative/Organizational Pressure Score by rank for women.

\begin{tabular}{|c|c|c|c|c|c|c|c|c|}
\hline \multirow{2}{*}{$\begin{array}{l}\text { Spielberger Police } \\
\text { Stress Survey }\end{array}$} & \multicolumn{4}{|c|}{ Total Score } & \multicolumn{4}{|c|}{ Administrative/Organizational Pressure Score } \\
\hline & N (Range) & Police Officer & $\bar{N}$ (Range) & All Higher Ranks & N (Range) & Police Officer & $\mathrm{N}$ (Range) & All Higher Ranks \\
\hline \multicolumn{9}{|l|}{ Stress Rating } \\
\hline Low & $26(0.75-28.67)$ & $0.46(0.22)$ & $6(0.42-29.08)$ & $0.06(0.70)$ & $28(0-23.48)$ & $0.59(0.21)$ & $5(0-19.22)$ & $0.27(0.70)$ \\
\hline Middle & $28(29.75-55.08)$ & $0.99(0.20)$ & $6(30.97-51.83)$ & $0.27(0.60)$ & $26(23.91-45.65)$ & $1.05(0.21)$ & $6(28.26-45.22)$ & $0.26(0.60)$ \\
\hline High & $24(55.75-86.75)$ & $1.33(0.22)$ & $10(56.10-67.17)$ & $1.59(0.59)$ & $24(46.14-84.13)$ & $1.17(0.22)$ & $10(47.39-63.70)$ & $1.22(0.49)$ \\
\hline$p$-value* & & 0.010 & & 0.139 & & 0.005 & & 0.252 \\
\hline \multicolumn{9}{|c|}{ Frequency in Past Month } \\
\hline Low & $26(0.03-0.81)$ & $0.86(0.22)$ & $6(0.03-0.82)$ & $0.71(0.62)$ & $27(0-0.87)$ & $0.73(0.22)$ & $5(0.09-0.98)$ & $0.77(0.64)$ \\
\hline Middle & $22(0.86-1.81)$ & $0.71(0.24)$ & $11(0.95-1.56)$ & $0.99(0.57)$ & $24(1.00-1.89)$ & $0.89(0.22)$ & $9(1.00-1.87)$ & $1.10(0.59)$ \\
\hline High & $30(1.86-4.78)$ & $1.14(0.20)$ & $4(2.00-3.04)$ & $0.50(0.75)$ & $27(1.91-5.04)$ & $1.14(0.21)$ & $7(1.98-3.20)$ & $0.46(0.58)$ \\
\hline$p$-value* & & 0.473 & & 0.803 & & 0.211 & & 0.889 \\
\hline \multicolumn{9}{|c|}{ Frequency in Past Year } \\
\hline Low & $25(0.08-3.88)$ & $0.78(0.24)$ & $7(0.06-3.51)$ & $1.31(0.56)$ & $26(0-4.20)$ & $0.84(0.23)$ & $6(0.15-4.24)$ & $0.80(0.67)$ \\
\hline Middle & $23(3.95-7.83)$ & $1.11(0.23)$ & $10(4.51-7.58)$ & $0.34(0.59)$ & $23(4.37-8.72)$ & $1.09(0.23)$ & $10(4.33-8.74)$ & $1.05(0.52)$ \\
\hline High & $30(7.91-16.18)$ & $0.91(0.21)$ & $4(9.28-12.30)$ & $0.60(0.72)$ & $29(8.89-16.07)$ & $0.88(0.21)$ & $5(10.83-13.57)$ & $0.31(0.65)$ \\
\hline$p$-value $*$ & & 0.842 & & 0.541 & & 0.552 & & 0.586 \\
\hline \multicolumn{9}{|c|}{ Stress Index for Past Month } \\
\hline Low & $26(1.67-29.36)$ & $0.63(0.22)$ & $6(0-26.92)$ & $0.63(0.78)$ & $29(0-23.91)$ & $0.58(0.21)$ & $3(0-6.26)$ & $0.50(0.89)$ \\
\hline Middle & $24(29.40-94.50)$ & $0.82(0.22)$ & $9(41.13-84.92)$ & $0.71(0.54)$ & $23(26.52-99.13)$ & $0.97(0.22)$ & $10(25.68-96.96)$ & $1.01(0.56)$ \\
\hline High & $28(95.33-358.98)$ & $1.29(0.20)$ & $6(96.58-202.52)$ & $0.88(0.62)$ & $26(101.52-365.43)$ & $1.26(0.21)$ & $8(101.96-207.28)$ & $0.58(0.56)$ \\
\hline$p$-value* & & 0.046 & & 0.462 & & 0.017 & & 0.672 \\
\hline \multicolumn{9}{|c|}{ Stress Index for Past Year } \\
\hline Low & $25(2.31-123.17)$ & $0.65(0.23)$ & $7(0-145.76)$ & $0.81(0.59)$ & $27(0-141.24)$ & $0.71(0.21)$ & $5(0-114.46)$ & $0.39(0.68)$ \\
\hline Middle & $25(150.38-381.29)$ & $0.83(0.22)$ & $8(196.21-385-21)$ & $1.10(0.64)$ & $23(144.35-373.64)$ & $0.66(0.22)$ & $10(168.15-378.48)$ & $1.34(0.49)$ \\
\hline High & $28(391.00-1195.42)$ & $1.25(0.21)$ & $6(393.63-831.90)$ & $0.48(0.63)$ & $28(389.46-1142.71$ & $1.34(0.20)$ & $6(403.80-891.63)$ & $0.14(0.58)$ \\
\hline$p$-value* & & 0.081 & & 0.845 & & 0.034 & & 0.720 \\
\hline
\end{tabular}


Table A.5p. Multivariate adjusted number of metabolic syndrome components by Spielberger Police Stress Physical/Psychological Threat and Lack of Support Score by rank for women.

\begin{tabular}{|c|c|c|c|c|c|c|c|c|}
\hline \multirow{2}{*}{$\begin{array}{l}\text { Spielberger Police } \\
\text { Stress Survey }\end{array}$} & \multicolumn{4}{|c|}{ Physical/Psychological Threat Score } & \multicolumn{4}{|c|}{ Lack of Support Score } \\
\hline & $\mathrm{N}$ (Range) & Police Officer & $\mathrm{N}$ (Range) & All Higher Ranks & N (Range) & Police Officer & $\mathrm{N}$ (Range) & All Higher Ranks \\
\hline \multicolumn{9}{|l|}{ Stress Rating } \\
\hline Low & $27(0.96-37.92)$ & $0.46(0.21)$ & $6(0-35.00)$ & $-0.05(0.74)$ & $26(0-25.00)$ & $0.57(0.22)$ & $6(1.23-23.46)$ & $0.09(0.52)$ \\
\hline Middle & $25(38.33-62.71)$ & $0.96(0.21)$ & $7(41.67-61.67)$ & $0.83(0.51)$ & $25(26.15-57.69)$ & $1.09(0.22)$ & $8(30.77-56.15)$ & $-0.03(0.40)$ \\
\hline High & $26(63.54-89.79)$ & $1.35(0.20)$ & $8(63.48-78.33)$ & $1.09(0.61)$ & 27 (58.46-85.77) & $1.09(0.21)$ & $7(61.92-81.54)$ & $1.89(0.41)$ \\
\hline$p$-value* & & 0.016 & & 0.206 & & 0.038 & & 0.032 \\
\hline \multicolumn{9}{|c|}{ Frequency in Past Month } \\
\hline Low & $22(0.04-0.71)$ & $0.91(0.25)$ & $11(0-0.71)$ & $0.99(0.50)$ & $29(0-0.69)$ & $0.80(0.21)$ & $4(0-0.54)$ & $0.31(0.81)$ \\
\hline Middle & $24(0.77-1.65)$ & $1.18(0.23)$ & $8(1.00-1.71)$ & $0.46(0.54)$ & $22(0.77-1.50)$ & $0.90(0.24)$ & $10(0.73-1.50)$ & $0.91(0.51)$ \\
\hline High & $32(1.75-4.90)$ & $0.75(0.19)$ & $2(2.04-3.08)$ & $0.88(1.11)$ & $27(1.54-5.83)$ & $1.08(0.21)$ & $7(1.81-3.31)$ & $0.74(0.59)$ \\
\hline$p$-value* & & 0.742 & & 0.947 & & 0.244 & & 0.538 \\
\hline \multicolumn{9}{|c|}{ Frequency in Past Year } \\
\hline Low & $24(0.04-3.83)$ & $0.81(0.23)$ & $9(0-3.77)$ & $1.22(0.54)$ & $26(0-2.62)$ & $1.00(0.22)$ & $5(0-2.31)$ & $0.27(0.64)$ \\
\hline Middle & $24(4.42-7.78)$ & $1.26(0.22)$ & $8(4.65-6.81)$ & $0.35(0.62)$ & $25(2.65-6.23)$ & $0.86(0.23)$ & $9(2.92-5.35)$ & $1.21(0.59)$ \\
\hline High & $30(8.19-15.88)$ & $0.75(0.20)$ & $4(8.58-12.69)$ & $0.53(0.72)$ & $27(6.65-17.04)$ & $0.92(0.21)$ & $7(6.50-11.00)$ & $0.83(0.57)$ \\
\hline$p$-value* & & 0.653 & & 0.407 & & 0.634 & & 0.962 \\
\hline \multicolumn{9}{|c|}{ Stress Index for Past Month } \\
\hline Low & $23(0.70-30.63)$ & $0.75(0.24)$ & $9(0-29.58)$ & $0.63(0.54)$ & $26(0-30.00)$ & $0.61(0.22)$ & $5(0-21.54)$ & $0.53(0.73)$ \\
\hline Middle & $25(33.92-88.75)$ & $0.87(0.22)$ & $8(38.33-88.33)$ & $0.90(0.56)$ & $25(31.15-82.12)$ & $0.89(0.21)$ & $9(30.77-83.46)$ & $0.24(0.49)$ \\
\hline High & $30(94.58-372.08)$ & $1.10(0.20)$ & $4(96.56-213.75)$ & $0.80(0.85)$ & $27(91.15-483.33)$ & $1.26(0.21)$ & $7(85.58-203.85)$ & $1.45(0.56)$ \\
\hline$p$-value* & & 0.290 & & 0.589 & & 0.067 & & 0.193 \\
\hline \multicolumn{9}{|c|}{ Stress Index for Past Year } \\
\hline Low & $24(2.08-146.88)$ & $0.68(0.24)$ & $9(0-131.04)$ & $1.24(0.54)$ & $26(0-119.23)$ & $0.72(0.22)$ & $5(0-120.96)$ & $0.26(0.71)$ \\
\hline Middle & $26(158.33-412.71)$ & $0.83(0.22)$ & $6(35.83-403.23)$ & $0.38(0.58)$ & $25(128.46-292.31)$ & $0.73(0.22)$ & $9(137.12-293.65)$ & $1.07(0.52)$ \\
\hline High & $28(415.63-1210.00$ & $1.21(0.21)$ & $6(428.91-891.04)$ & $0.49(0.66)$ & $27(301.92-1371.25)$ & $1.28(0.21)$ & $7(296.35-713.46)$ & $0.63(0.55)$ \\
\hline$p$-value* & & 0.251 & & 0.716 & & 0.148 & & 0.594 \\
\hline
\end{tabular}


Table A.6a. Unadjusted and adjusted odds ratios for MetSyn components by tertiles of Spielberger Police Stress score for men. - TOTAL STRESS RATING

\begin{tabular}{|c|c|c|c|c|c|c|c|c|c|}
\hline \multirow{2}{*}{$\begin{array}{l}\text { MetSyn } \\
\text { Component }\end{array}$} & \multicolumn{4}{|c|}{$\begin{array}{c}\text { Unadjusted } \\
\text { OR (95\% CI) }\end{array}$} & \multicolumn{4}{|c|}{$\begin{array}{l}\text { Age-Adjusted } \\
\text { OR }(95 \% \text { CI })\end{array}$} & \multirow{2}{*}{$\begin{array}{c}\begin{array}{c}\text { Multivariate } \\
\text { Adjusted } \\
\text { OR (95\% CI }) \\
\text { Continuous } \\
(\mathrm{N}=)\end{array}\end{array}$} \\
\hline & $\begin{array}{l}\text { Level } 1 \\
(\mathrm{~N}=96)\end{array}$ & $\begin{array}{l}\text { Level } 2 \\
(\mathrm{~N}=96)\end{array}$ & $\begin{array}{l}\text { Level } 3 \\
(\mathrm{~N}=96)\end{array}$ & $\begin{array}{l}\text { Continuous } \\
(\mathrm{N}=288)\end{array}$ & $\begin{array}{l}\text { Level } 1 \\
(\mathrm{~N}=96)\end{array}$ & $\begin{array}{l}\text { Level } 2 \\
(\mathrm{~N}=96)\end{array}$ & $\begin{array}{l}\text { Level } 3 \\
(\mathrm{~N}=96)\end{array}$ & $\begin{array}{l}\text { Continuous } \\
(\mathrm{N}=288)\end{array}$ & \\
\hline \multirow{2}{*}{$\begin{array}{l}\text { Abdominal } \\
\text { Obesity }\end{array}$} & $\mathrm{N}=36$ & $\mathrm{~N}=37$ & $\mathrm{~N}=39$ & $\mathrm{~N}=112$ & & & & & \\
\hline & 1.0 & $\begin{array}{c}1.045 \\
(0.584-1.872)\end{array}$ & $\begin{array}{c}1.140 \\
(0.638-2.037)\end{array}$ & $\begin{array}{c}1.003 \\
(0.992-1.015)\end{array}$ & 1.0 & $\begin{array}{c}1.094 \\
(0.607-1.970)\end{array}$ & $\begin{array}{c}1.174 \\
(0.654-2.108)\end{array}$ & $\begin{array}{c}1.004 \\
(0.992-1.015)\end{array}$ & $\begin{array}{c}1.004 \\
(0.992-1.015)\end{array}$ \\
\hline \multirow{2}{*}{$\begin{array}{l}\text { Elevated } \\
\text { Triglycerides }\end{array}$} & $\mathrm{N}=33$ & $\mathrm{~N}=43$ & $\mathrm{~N}=38$ & $\mathrm{~N}=114$ & & & & & \\
\hline & 1.0 & $\begin{array}{c}1.549 \\
(0.865-2.773)\end{array}$ & $\begin{array}{c}1.251 \\
(0.695-2.250)\end{array}$ & $\begin{array}{c}1.004 \\
(0.993-1.016)\end{array}$ & 1.0 & $\begin{array}{c}1.622 \\
(0.901-2.921)\end{array}$ & $\begin{array}{c}1.286 \\
(0.712-2.324)\end{array}$ & $\begin{array}{c}1.005 \\
(0.994-1.017)\end{array}$ & $\begin{array}{c}1.005 \\
(0.994-1.017)\end{array}$ \\
\hline \multirow{2}{*}{$\begin{array}{l}\text { Reduced } \\
\text { HDL-C }\end{array}$} & $\mathrm{N}=55$ & $\mathrm{~N}=44$ & $\mathrm{~N}=40$ & $\mathrm{~N}=139$ & & & & & \\
\hline & 1.0 & $\begin{array}{c}0.631 \\
(0.357-1.115)\end{array}$ & $\begin{array}{c}0.532 \\
(0.300-0.944)\end{array}$ & $\begin{array}{c}0.983 \\
(0.972-0.995)\end{array}$ & 1.0 & $\begin{array}{c}0.640 \\
(0.362-1.134)\end{array}$ & $\begin{array}{c}0.537 \\
(0.303-0.953)\end{array}$ & $\begin{array}{c}0.984 \\
(0.972-0.995)\end{array}$ & $\begin{array}{c}0.984 \\
(0.972-0.995)\end{array}$ \\
\hline \multirow{2}{*}{$\begin{array}{l}\text { Glucose } \\
\text { Intolerance }\end{array}$} & $\mathrm{N}=31$ & $\mathrm{~N}=26$ & $\mathrm{~N}=23$ & $\mathrm{~N}=80$ & & & & & \\
\hline & 1.0 & $\begin{array}{c}0.779 \\
(0.419-1.449)\end{array}$ & $\begin{array}{c}0.661 \\
(0.350-1.246)\end{array}$ & $\begin{array}{c}0.993 \\
(0.980-1.005)\end{array}$ & 1.0 & $\begin{array}{c}0.842 \\
(0.447-1.587)\end{array}$ & $\begin{array}{c}0.681 \\
(0.356-1.300)\end{array}$ & $\begin{array}{c}0.993 \\
(0.981-1.006)\end{array}$ & $\begin{array}{c}0.994 \\
(0.981-1.006)\end{array}$ \\
\hline \multirow{2}{*}{ Hypertension } & $\mathrm{N}=40$ & $\mathrm{~N}=42$ & $\mathrm{~N}=45$ & $\mathrm{~N}=127$ & & & & & \\
\hline & 1.0 & $\begin{array}{c}1.089 \\
(0.615-1.929)\end{array}$ & $\begin{array}{c}1.235 \\
(0.698-2.185)\end{array}$ & $\begin{array}{c}1.002 \\
(0.991-1.014)\end{array}$ & 1.0 & $\begin{array}{c}1.155 \\
(0.647-2.062)\end{array}$ & $\begin{array}{c}1.286 \\
(0.721-2.293)\end{array}$ & $\begin{array}{c}1.003 \\
(0.992-1.015)\end{array}$ & $\begin{array}{c}1.003 \\
(0.992-1.015)\end{array}$ \\
\hline
\end{tabular}


Table A.6b. Unadjusted and adjusted odds ratios for MetSyn components by tertiles of Spielberger Police Stress score for women. - TOTAL STRESS RATING

\begin{tabular}{|c|c|c|c|c|c|c|c|c|c|}
\hline \multirow{2}{*}{$\begin{array}{l}\text { MetSyn } \\
\text { Component }\end{array}$} & \multicolumn{4}{|c|}{$\begin{array}{c}\text { Unadjusted } \\
\text { OR (95\% CI) }\end{array}$} & \multicolumn{4}{|c|}{$\begin{array}{l}\text { Age-Adjusted } \\
\text { OR }(95 \% \text { CI })\end{array}$} & \multirow{2}{*}{$\begin{array}{c}\text { Multivariate Adjusted } \\
\text { OR }(95 \% \mathrm{CI})^{*} \\
\begin{array}{c}\text { Continuous } \\
(\mathrm{N}=)\end{array}\end{array}$} \\
\hline & $\begin{array}{l}\text { Level } 1 \\
(\mathrm{~N}=34)\end{array}$ & $\begin{array}{l}\text { Level } 2 \\
(\mathrm{~N}=34)\end{array}$ & $\begin{array}{l}\text { Level } 3 \\
(\mathrm{~N}=34)\end{array}$ & $\begin{array}{l}\text { Continuous } \\
(\mathrm{N}=102)\end{array}$ & $\begin{array}{l}\text { Level } 1 \\
(\mathrm{~N}=34)\end{array}$ & $\begin{array}{l}\text { Level } 2 \\
(\mathrm{~N}=34)\end{array}$ & $\begin{array}{l}\text { Level } 3 \\
(\mathrm{~N}=34)\end{array}$ & $\begin{array}{l}\text { Continuous } \\
(\mathrm{N}=102)\end{array}$ & \\
\hline Abdominal & $\mathrm{N}=3$ & $\mathrm{~N}=4$ & $\mathrm{~N}=11$ & $\mathrm{~N}=18$ & & & & & \\
\hline Obesity & 1.0 & $\begin{array}{c}1.378 \\
(0.284-6.681)\end{array}$ & $\begin{array}{c}4.942 \\
(1.236-19.758)\end{array}$ & $\begin{array}{c}1.033 \\
(1.005-1.062)\end{array}$ & 1.0 & $\begin{array}{c}1.557 \\
(0.315-7.692)\end{array}$ & $\begin{array}{c}4.236 \\
(1.034-17.347)\end{array}$ & $\begin{array}{c}1.030 \\
(1.002-1.059)\end{array}$ & $\begin{array}{c}1.032 \\
(1.004-1.061)\end{array}$ \\
\hline Elevated & $\mathrm{N}=0$ & $\mathrm{~N}=4$ & $\mathrm{~N}=5$ & $\mathrm{~N}=9$ & & & & & \\
\hline Triglycerides & 1.0 & & & $\begin{array}{c}1.041 \\
(1.000-1.083)\end{array}$ & 1.0 & & & $\begin{array}{c}1.046 \\
(1.003-1.091)\end{array}$ & $\begin{array}{c}1.046 \\
(1.002-1.093)\end{array}$ \\
\hline Reduced & $\mathrm{N}=5$ & $\mathrm{~N}=7$ & $\mathrm{~N}=15$ & $\mathrm{~N}=27$ & & & & & \\
\hline HDL-C & 1.0 & $\begin{array}{c}1.504 \\
(0.426-5.310)\end{array}$ & $\begin{array}{c}4.579 \\
(1.427-14.691)\end{array}$ & $\begin{array}{c}1.030 \\
(1.007-1.054)\end{array}$ & 1.0 & $\begin{array}{c}1.451 \\
(0.407-5.173)\end{array}$ & $\begin{array}{c}4.808 \\
(1.468-15.742)\end{array}$ & $\begin{array}{c}1.030 \\
(1.007-1.055)\end{array}$ & $\begin{array}{c}1.029 \\
(1.006-1.054)\end{array}$ \\
\hline Glucose & $\mathrm{N}=3$ & $\mathrm{~N}=2$ & $\mathrm{~N}=7$ & $\mathrm{~N}=12$ & & & & & \\
\hline Intolerance & 1.0 & $\begin{array}{c}0.646 \\
(0.101-4.133)\end{array}$ & $\begin{array}{c}2.679 \\
(0.630-11.393)\end{array}$ & $\begin{array}{c}1.026 \\
(0.994-1.058)\end{array}$ & 1.0 & $\begin{array}{c}0.644 \\
(0.100-4.166)\end{array}$ & $\begin{array}{c}2.687 \\
(0.618-11.682)\end{array}$ & $\begin{array}{c}1.025 \\
(0.993-1.057)\end{array}$ & $\begin{array}{c}1.025 \\
(0.993-1.058)\end{array}$ \\
\hline Hypertension & $\begin{array}{l}\mathrm{N}=7 \\
1.0\end{array}$ & $\begin{array}{c}\mathrm{N}=11 \\
1.844 \\
(0.615-5.534) \\
\end{array}$ & $\begin{array}{c}\mathrm{N}=9 \\
1.388 \\
(0.450-4.287) \\
\end{array}$ & $\begin{array}{c}\mathrm{N}=27 \\
1.004 \\
(0.983-1.024) \\
\end{array}$ & 1.0 & $\begin{array}{c}2.230 \\
(0.712-6.979) \\
\end{array}$ & $\begin{array}{c}1.096 \\
(0.339-3.548) \\
\end{array}$ & $\begin{array}{c}1.001 \\
(0.981-1.022) \\
\end{array}$ & $\begin{array}{c}1.002 \\
(0.981-1.023) \\
\end{array}$ \\
\hline
\end{tabular}


Table A.6c. Unadjusted and adjusted odds ratios for MetSyn components by tertiles of Spielberger Police Stress score for men. - ADMINISTRATIVE STRESS RATING

\begin{tabular}{|c|c|c|c|c|c|c|c|c|c|}
\hline \multirow{2}{*}{$\begin{array}{l}\text { MetSyn } \\
\text { Component }\end{array}$} & \multicolumn{4}{|c|}{$\begin{array}{c}\text { Unadjusted } \\
\text { OR (95\% CI) }\end{array}$} & \multicolumn{4}{|c|}{$\begin{array}{l}\text { Age-Adjusted } \\
\text { OR (95\% CI) }\end{array}$} & \multirow{2}{*}{$\begin{array}{c}\text { Multivariate Adjusted } \\
\text { OR }(95 \% \mathrm{CI})^{*} \\
\begin{array}{c}\text { Continuous } \\
(\mathrm{N}=)\end{array}\end{array}$} \\
\hline & $\begin{array}{l}\text { Level } 1 \\
(\mathrm{~N}=96)\end{array}$ & $\begin{array}{l}\text { Level } 2 \\
(\mathrm{~N}=98)\end{array}$ & $\begin{array}{l}\text { Level } 3 \\
(\mathrm{~N}=94)\end{array}$ & $\begin{array}{l}\text { Continuous } \\
(\mathrm{N}=288)\end{array}$ & $\begin{array}{l}\text { Level } 1 \\
(\mathrm{~N}=96)\end{array}$ & $\begin{array}{l}\text { Level } 2 \\
(\mathrm{~N}=98)\end{array}$ & $\begin{array}{l}\text { Level } 3 \\
(\mathrm{~N}=94)\end{array}$ & $\begin{array}{l}\text { Continuous } \\
(\mathrm{N}=288)\end{array}$ & \\
\hline Abdominal & $\mathrm{N}=41$ & $\mathrm{~N}=30$ & $\mathrm{~N}=41$ & $\mathrm{~N}=112$ & & & & & \\
\hline Obesity & 1.0 & $\begin{array}{c}0.592 \\
(0.328-1.843)\end{array}$ & $\begin{array}{c}1.038 \\
(0.584-1.843)\end{array}$ & $\begin{array}{c}1.003 \\
(0.991-1.016)\end{array}$ & 1.0 & $\begin{array}{c}0.591 \\
(0.326-1.069)\end{array}$ & $\begin{array}{c}1.054 \\
(0.591-1.881)\end{array}$ & $\begin{array}{c}1.004 \\
(0.992-1.016)\end{array}$ & $\begin{array}{c}1.004 \\
(0.992-1.016)\end{array}$ \\
\hline Elevated & $\mathrm{N}=34$ & $\mathrm{~N}=42$ & $\mathrm{~N}=38$ & $\mathrm{~N}=114$ & & & & & \\
\hline Triglycerides & 1.0 & $\begin{array}{c}1.368 \\
(0.767-2.440)\end{array}$ & $\begin{array}{c}1.237 \\
(0.688-2.226)\end{array}$ & $\begin{array}{c}1.008 \\
(0.995-1.020)\end{array}$ & 1.0 & $\begin{array}{c}1.376 \\
(0.769-2.461)\end{array}$ & $\begin{array}{c}1.257 \\
(0.696-2.268)\end{array}$ & $\begin{array}{c}1.008 \\
(0.996-1.020)\end{array}$ & $\begin{array}{c}1.008 \\
(0.996-1.021)\end{array}$ \\
\hline Reduced & $\mathrm{N}=56$ & $\mathrm{~N}=48$ & $\mathrm{~N}=35$ & $\mathrm{~N}=139$ & & & & & \\
\hline HDL-C & 1.0 & $\begin{array}{c}0.686 \\
(0.389-1.209)\end{array}$ & $\begin{array}{c}0.424 \\
(0.237-0.759)\end{array}$ & $\begin{array}{c}0.982 \\
(0.970-0.994)\end{array}$ & 1.0 & $\begin{array}{c}0.686 \\
(0.389-1.210)\end{array}$ & $\begin{array}{c}0.425 \\
(0.237-0.762)\end{array}$ & $\begin{array}{c}0.982 \\
(0.970-0.994)\end{array}$ & $\begin{array}{c}0.982 \\
(0.970-0.994)\end{array}$ \\
\hline Glucose & $\mathrm{N}=24$ & $\mathrm{~N}=32$ & $\mathrm{~N}=24$ & $\mathrm{~N}=80$ & & & & & \\
\hline Intolerance & 1.0 & $\begin{array}{c}1.455 \\
(0.778-2.720)\end{array}$ & $\begin{array}{c}1.029 \\
(0.535-1.979)\end{array}$ & $\begin{array}{c}0.997 \\
(0.984-1.010)\end{array}$ & 1.0 & $\begin{array}{c}1.494 \\
(0.790-2.826)\end{array}$ & $\begin{array}{c}1.058 \\
(0.543-2.062)\end{array}$ & $\begin{array}{c}0.998 \\
(0.984-1.011)\end{array}$ & $\begin{array}{c}0.998 \\
(0.984-1.011)\end{array}$ \\
\hline Hypertension & $\begin{array}{c}\mathrm{N}=40 \\
1.0\end{array}$ & $\begin{array}{c}\mathrm{N}=45 \\
1.189 \\
(0.674-2.097)\end{array}$ & $\begin{array}{c}\mathrm{N}=42 \\
1.131 \\
(0.637-2.008)\end{array}$ & $\begin{array}{c}\mathrm{N}=127 \\
1.003 \\
(0.991-1.015)\end{array}$ & 1.0 & $\begin{array}{c}1.198 \\
(0.675-2.125)\end{array}$ & $\begin{array}{c}1.156 \\
(0.646-2.067)\end{array}$ & $\begin{array}{c}1.004 \\
(0.992-1.016)\end{array}$ & $\begin{array}{c}1.004 \\
(0.992-1.016)\end{array}$ \\
\hline
\end{tabular}




\begin{tabular}{|c|c|c|c|c|c|c|c|c|c|}
\hline \multirow{2}{*}{$\begin{array}{l}\text { MetSyn } \\
\text { Component }\end{array}$} & \multicolumn{4}{|c|}{$\begin{array}{c}\text { Unadjusted } \\
\text { OR (95\% CI) }\end{array}$} & \multicolumn{4}{|c|}{$\begin{array}{l}\text { Age-Adjusted } \\
\text { OR }(95 \% \text { CI })\end{array}$} & \multirow{2}{*}{$\begin{array}{c}\begin{array}{c}\text { Multivariate Adjusted } \\
\text { OR }(95 \% \mathrm{CI})^{*}\end{array} \\
\begin{array}{c}\text { Continuous } \\
(\mathrm{N}=)\end{array}\end{array}$} \\
\hline & $\begin{array}{l}\text { Level } 1 \\
(\mathrm{~N}=34)\end{array}$ & $\begin{array}{l}\text { Level } 2 \\
(\mathrm{~N}=34)\end{array}$ & $\begin{array}{l}\text { Level } 3 \\
(\mathrm{~N}=34)\end{array}$ & $\begin{array}{l}\text { Continuous } \\
(\mathrm{N}=102)\end{array}$ & $\begin{array}{l}\text { Level } 1 \\
(\mathrm{~N}=34)\end{array}$ & $\begin{array}{l}\text { Level } 2 \\
(\mathrm{~N}=34)\end{array}$ & $\begin{array}{l}\text { Level } 3 \\
(\mathrm{~N}=34)\end{array}$ & $\begin{array}{l}\text { Continuous } \\
(\mathrm{N}=102)\end{array}$ & \\
\hline \multirow{2}{*}{$\begin{array}{l}\text { Abdominal } \\
\text { Obesity }\end{array}$} & $\mathrm{N}=3$ & $\mathrm{~N}=7$ & $\mathrm{~N}=8$ & $\mathrm{~N}=18$ & & & & & \\
\hline & 1.0 & $\begin{array}{c}2.679 \\
(0.630-11.392)\end{array}$ & $\begin{array}{c}3.179 \\
(0.764-13.226)\end{array}$ & $\begin{array}{c}1.033 \\
(1.005-1.062)\end{array}$ & 1.0 & $\begin{array}{c}2.590 \\
(0.596-11.257)\end{array}$ & $\begin{array}{c}2.773 \\
(0.649-11.854)\end{array}$ & $\begin{array}{c}1.031 \\
(1.002-1.060)\end{array}$ & $\begin{array}{c}1.033 \\
(1.004-1.063)\end{array}$ \\
\hline \multirow{2}{*}{$\begin{array}{l}\text { Elevated } \\
\text { Triglycerides }\end{array}$} & $\mathrm{N}=2$ & $\mathrm{~N}=2$ & $\mathrm{~N}=5$ & $\mathrm{~N}=9$ & & & & & \\
\hline & 1.0 & $\begin{array}{c}1.000 \\
(0.133-7.540)\end{array}$ & $\begin{array}{c}2.759 \\
(0.496-15.330)\end{array}$ & $\begin{array}{c}1.032 \\
(0.995-1.071)\end{array}$ & 1.0 & $\begin{array}{c}1.003 \\
(0.132-7.646)\end{array}$ & $\begin{array}{c}3.051 \\
(0.539-17.278)\end{array}$ & $\begin{array}{c}1.035 \\
(0.997-1.075)\end{array}$ & $\begin{array}{c}1.035 \\
(0.996-1.076)\end{array}$ \\
\hline \multirow{2}{*}{$\begin{array}{l}\text { Reduced } \\
\text { HDL-C }\end{array}$} & $\mathrm{N}=6$ & $\mathrm{~N}=7$ & $\mathrm{~N}=14$ & $\mathrm{~N}=27$ & & & & & \\
\hline & 1.0 & $\begin{array}{c}1.210 \\
(0.360-4.065)\end{array}$ & $\begin{array}{c}3.267 \\
(1.071-9.965)\end{array}$ & $\begin{array}{c}1.036 \\
(1.011-1.062)\end{array}$ & 1.0 & $\begin{array}{c}1.210 \\
(0.360-4.068)\end{array}$ & $\begin{array}{c}3.271 \\
(1.066-10.039)\end{array}$ & $\begin{array}{c}1.036 \\
(1.011-1.063)\end{array}$ & $\begin{array}{c}1.035 \\
(1.010-1.062)\end{array}$ \\
\hline Glucose & $\mathrm{N}=3$ & $\mathrm{~N}=2$ & $\mathrm{~N}=7$ & $\mathrm{~N}=12$ & & & & & \\
\hline Intolerance & 1.0 & $\begin{array}{c}0.646 \\
(0.101-4.133)\end{array}$ & $\begin{array}{c}2.679 \\
(0.630-11.393)\end{array}$ & $\begin{array}{c}1.027 \\
(0.995-1.060)\end{array}$ & 1.0 & $\begin{array}{c}0.640 \\
(0.100-4.103)\end{array}$ & $\begin{array}{c}2.606 \\
(0.607-11.191)\end{array}$ & $\begin{array}{c}1.026 \\
(0.994-1.060)\end{array}$ & $\begin{array}{c}1.026 \\
(0.994-1.060)\end{array}$ \\
\hline \multirow{2}{*}{ Hypertension } & $\mathrm{N}=7$ & $\mathrm{~N}=12$ & $\mathrm{~N}=8$ & $\mathrm{~N}=27$ & & & & & \\
\hline & 1.0 & $\begin{array}{c}2.104 \\
(0.708-6.251)\end{array}$ & $\begin{array}{c}1.187 \\
(0.376-3.742)\end{array}$ & $\begin{array}{c}1.004 \\
(0.983-1.027)\end{array}$ & 1.0 & $\begin{array}{c}2.070 \\
(0.681-6.293)\end{array}$ & $\begin{array}{c}1.022 \\
(0.314-3.332)\end{array}$ & $\begin{array}{c}1.002 \\
(0.980-1.025)\end{array}$ & $\begin{array}{c}1.002 \\
(0.979-1.025)\end{array}$ \\
\hline
\end{tabular}


Table A.6e. Unadjusted and adjusted odds ratios for MetSyn components by tertiles of Spielberger Police Stress score for men. - DANGER STRESS RATING

\begin{tabular}{|c|c|c|c|c|c|c|c|c|c|}
\hline \multirow{2}{*}{$\begin{array}{l}\text { MetSyn } \\
\text { Component }\end{array}$} & \multicolumn{4}{|c|}{$\begin{array}{c}\text { Unadjusted } \\
\text { OR }(95 \% \mathrm{CI})\end{array}$} & \multicolumn{4}{|c|}{$\begin{array}{l}\text { Age-Adjusted } \\
\text { OR }(95 \% \mathrm{CI})\end{array}$} & \multirow{2}{*}{$\begin{array}{c}\text { Multivariate Adjusted } \\
\text { OR }(95 \% \mathrm{CI})^{*} \\
\begin{array}{c}\text { Continuous } \\
(\mathrm{N}=)\end{array}\end{array}$} \\
\hline & $\begin{array}{l}\text { Level } 1 \\
(\mathrm{~N}=96)\end{array}$ & $\begin{array}{l}\text { Level } 2 \\
(\mathrm{~N}=97)\end{array}$ & $\begin{array}{l}\text { Level } 3 \\
(\mathrm{~N}=95)\end{array}$ & $\begin{array}{l}\text { Continuous } \\
(\mathrm{N}=288)\end{array}$ & $\begin{array}{l}\text { Level } 1 \\
(\mathrm{~N}=96)\end{array}$ & $\begin{array}{l}\text { Level } 2 \\
(\mathrm{~N}=97)\end{array}$ & $\begin{array}{l}\text { Level } 3 \\
(\mathrm{~N}=95)\end{array}$ & $\begin{array}{l}\text { Continuous } \\
(\mathrm{N}=288)\end{array}$ & \\
\hline Abdominal & $\mathrm{N}=36$ & $\mathrm{~N}=36$ & $\mathrm{~N}=40$ & $\mathrm{~N}=112$ & & & & & \\
\hline Obesity & 1.0 & $\begin{array}{c}0.984 \\
(0.549-1.763)\end{array}$ & $\begin{array}{c}1.212 \\
(0.679-2.165)\end{array}$ & $\begin{array}{c}1.002 \\
(0.992-1.013)\end{array}$ & 1.0 & $\begin{array}{c}1.068 \\
(0.590-1.933)\end{array}$ & $\begin{array}{c}1.273 \\
(0.708-2.289)\end{array}$ & $\begin{array}{c}1.003 \\
(0.993-1.013)\end{array}$ & $\begin{array}{c}1.003 \\
(0.993-1.014)\end{array}$ \\
\hline Elevated & $\mathrm{N}=36$ & $\mathrm{~N}=39$ & $\mathrm{~N}=39$ & $\mathrm{~N}=114$ & & & & & \\
\hline Triglycerides & 1.0 & $\begin{array}{c}1.121 \\
(0.628-2.000)\end{array}$ & $\begin{array}{c}1.161 \\
(0.649-2.076)\end{array}$ & $\begin{array}{c}1.002 \\
(0.992-1.012)\end{array}$ & 1.0 & $\begin{array}{c}1.208 \\
(0.671-2.177)\end{array}$ & $\begin{array}{c}1.212 \\
(0.674-2.180)\end{array}$ & $\begin{array}{c}1.003 \\
(0.993-1.013)\end{array}$ & $\begin{array}{c}1.003 \\
(0.993-1.014)\end{array}$ \\
\hline Reduced & $\mathrm{N}=57$ & $\mathrm{~N}=43$ & $\mathrm{~N}=39$ & $\mathrm{~N}=139$ & & & & & \\
\hline HDL-C & 1.0 & $\begin{array}{c}0.545 \\
(0.308-0.965)\end{array}$ & $\begin{array}{c}0.477 \\
(0.268-0.849)\end{array}$ & $\begin{array}{c}0.986 \\
(0.976-0.996)\end{array}$ & 1.0 & $\begin{array}{c}0.557 \\
(0.313-0.991)\end{array}$ & $\begin{array}{c}0.482 \\
(0.270-0.860)\end{array}$ & $\begin{array}{c}0.987 \\
(0.977-0.997)\end{array}$ & $\begin{array}{c}0.987 \\
(0.977-0.997)\end{array}$ \\
\hline Glucose & $\mathrm{N}=32$ & $\mathrm{~N}=26$ & $\mathrm{~N}=22$ & $\mathrm{~N}=80$ & & & & & \\
\hline Intolerance & 1.0 & $\begin{array}{c}0.732 \\
(0.395-1.359)\end{array}$ & $\begin{array}{c}0.603 \\
(0.318-1.141)\end{array}$ & $\begin{array}{c}0.991 \\
(0.980-1.002)\end{array}$ & 1.0 & $\begin{array}{c}0.843 \\
(0.447-1.588)\end{array}$ & $\begin{array}{c}0.638 \\
(0.333-1.223)\end{array}$ & $\begin{array}{c}0.992 \\
(0.981-1.003)\end{array}$ & $\begin{array}{c}0.992 \\
(0.981-1.003)\end{array}$ \\
\hline Hypertension & $\begin{array}{c}\mathrm{N}=43 \\
1.0\end{array}$ & $\begin{array}{c}\mathrm{N}=41 \\
0.902 \\
(0.511-1.595) \\
\end{array}$ & $\begin{array}{c}\mathrm{N}=43 \\
1.019 \\
(0.576-1.802) \\
\end{array}$ & $\begin{array}{c}\mathrm{N}=127 \\
1.000 \\
(0.990-1.010)\end{array}$ & 1.0 & $\begin{array}{c}0.997 \\
(0.558-1.782) \\
\end{array}$ & $\begin{array}{c}1.081 \\
(0.606-1.928) \\
\end{array}$ & $\begin{array}{c}1.001 \\
(0.991-1.011) \\
\end{array}$ & $\begin{array}{c}1.001 \\
(0.991-1.011) \\
\end{array}$ \\
\hline
\end{tabular}


Table A.6f. Unadjusted and adjusted odds ratios for MetSyn components by tertiles of Spielberger Police Stress score for women. - DANGER STRESS RATING

\begin{tabular}{|c|c|c|c|c|c|c|c|c|c|}
\hline \multirow{2}{*}{$\begin{array}{l}\text { MetSyn } \\
\text { Component }\end{array}$} & \multicolumn{4}{|c|}{$\begin{array}{c}\text { Unadjusted } \\
\text { OR (95\% CI) }\end{array}$} & \multicolumn{4}{|c|}{$\begin{array}{l}\text { Age-Adjusted } \\
\text { OR (95\% CI) }\end{array}$} & \multirow{2}{*}{$\begin{array}{c}\begin{array}{c}\text { Multivariate Adjusted } \\
\text { OR }(95 \% \mathrm{CI})^{*}\end{array} \\
\begin{array}{c}\text { Continuous } \\
(\mathrm{N}=)\end{array}\end{array}$} \\
\hline & $\begin{array}{l}\text { Level } 1 \\
(\mathrm{~N}=34)\end{array}$ & $\begin{array}{l}\text { Level } 2 \\
(\mathrm{~N}=34)\end{array}$ & $\begin{array}{l}\text { Level } 3 \\
(\mathrm{~N}=34)\end{array}$ & $\begin{array}{l}\text { Continuous } \\
(\mathrm{N}=102)\end{array}$ & $\begin{array}{l}\text { Level } 1 \\
(\mathrm{~N}=34)\end{array}$ & $\begin{array}{l}\text { Level } 2 \\
(\mathrm{~N}=34)\end{array}$ & $\begin{array}{l}\text { Level } 3 \\
(\mathrm{~N}=34)\end{array}$ & $\begin{array}{l}\text { Continuous } \\
(\mathrm{N}=102)\end{array}$ & \\
\hline \multirow{2}{*}{$\begin{array}{l}\text { Abdominal } \\
\text { Obesity }\end{array}$} & $\mathrm{N}=3$ & $\mathrm{~N}=6$ & $\mathrm{~N}=9$ & $\mathrm{~N}=18$ & & & & & \\
\hline & 1.0 & $\begin{array}{c}2.214 \\
(0.505-9.698)\end{array}$ & $\begin{array}{c}3.720 \\
(0.909-15.218)\end{array}$ & $\begin{array}{c}1.026 \\
(1.001-1.051)\end{array}$ & 1.0 & $\begin{array}{c}2.190 \\
(0.491-9.777)\end{array}$ & $\begin{array}{c}3.320 \\
(0.791-13.935)\end{array}$ & $\begin{array}{c}1.023 \\
(0.999-1.048)\end{array}$ & $\begin{array}{c}1.026 \\
(1.001-1.051)\end{array}$ \\
\hline \multirow{2}{*}{$\begin{array}{l}\text { Elevated } \\
\text { Triglycerides }\end{array}$} & $\mathrm{N}=0$ & $\mathrm{~N}=3$ & $\mathrm{~N}=6$ & $\mathrm{~N}=9$ & & & & & \\
\hline & 1.0 & & & $\begin{array}{c}1.044 \\
(1.003-1.088)\end{array}$ & 1.0 & & & $\begin{array}{c}1.052 \\
(1.005-1.010)\end{array}$ & $\begin{array}{c}1.052 \\
(1.005-1.101)\end{array}$ \\
\hline \multirow{2}{*}{$\begin{array}{l}\text { Reduced } \\
\text { HDL-C }\end{array}$} & $\mathrm{N}=5$ & $\mathrm{~N}=7$ & $\mathrm{~N}=15$ & $\mathrm{~N}=27$ & & & & & \\
\hline & 1.0 & $\begin{array}{c}1.504 \\
(0.426-5.310)\end{array}$ & $\begin{array}{c}4.579 \\
(1.427-14.691)\end{array}$ & $\begin{array}{c}1.024 \\
(1.003-1.045)\end{array}$ & 1.0 & $\begin{array}{c}1.504 \\
(0.426-5.312)\end{array}$ & $\begin{array}{c}4.601 \\
(1.426-14.842)\end{array}$ & $\begin{array}{c}1.024 \\
(1.003-1.045)\end{array}$ & $\begin{array}{c}1.024 \\
(1.003-1.045)\end{array}$ \\
\hline \multirow{2}{*}{$\begin{array}{l}\text { Glucose } \\
\text { Intolerance }\end{array}$} & $\mathrm{N}=3$ & $\mathrm{~N}=2$ & $\mathrm{~N}=7$ & $\mathrm{~N}=12$ & & & & & \\
\hline & 1.0 & $\begin{array}{c}0.646 \\
(0.101-4.133)\end{array}$ & $\begin{array}{c}2.679 \\
(0.630-11.393)\end{array}$ & $\begin{array}{c}1.015 \\
(0.989-1.043)\end{array}$ & 1.0 & $\begin{array}{c}0.644 \\
(0.101-4.122)\end{array}$ & $\begin{array}{c}2.614 \\
(0.609-11.210)\end{array}$ & $\begin{array}{c}1.015 \\
(0.988-1.042)\end{array}$ & $\begin{array}{c}1.015 \\
(0.989-1.043)\end{array}$ \\
\hline \multirow{2}{*}{ Hypertension } & $\mathrm{N}=6$ & $\mathrm{~N}=12$ & $\mathrm{~N}=9$ & $\mathrm{~N}=27$ & & & & & \\
\hline & 1.0 & $\begin{array}{c}2.545 \\
(0.824-7.863)\end{array}$ & $\begin{array}{c}1.680 \\
(0.524-5.388)\end{array}$ & $\begin{array}{c}1.003 \\
(0.986-1.021)\end{array}$ & 1.0 & $\begin{array}{c}2.576 \\
(0.817-8.127)\end{array}$ & $\begin{array}{c}1.487 \\
(0.451-4.907)\end{array}$ & $\begin{array}{c}1.002 \\
(0.984-1.020)\end{array}$ & $\begin{array}{c}1.002 \\
(0.983-1.021)\end{array}$ \\
\hline
\end{tabular}


Table A.6g. Unadjusted and adjusted odds ratios for MetSyn components by tertiles of Spielberger Police Stress score for men. - SUPPORT STRESS RATING

\begin{tabular}{|c|c|c|c|c|c|c|c|c|c|}
\hline \multirow{2}{*}{$\begin{array}{l}\text { MetSyn } \\
\text { Component }\end{array}$} & \multicolumn{4}{|c|}{$\begin{array}{c}\text { Unadjusted } \\
\text { OR }(95 \% \text { CI })\end{array}$} & \multicolumn{4}{|c|}{$\begin{array}{l}\text { Age-Adjusted } \\
\text { OR (95\% CI) }\end{array}$} & \multirow{2}{*}{$\begin{array}{c}\text { Multivariate Adjusted } \\
\text { OR }(95 \% \mathrm{CI})^{*} \\
\begin{array}{c}\text { Continuous } \\
(\mathrm{N}=)\end{array}\end{array}$} \\
\hline & $\begin{array}{l}\text { Level } 1 \\
(\mathrm{~N}=95)\end{array}$ & $\begin{array}{l}\text { Level } 2 \\
(\mathrm{~N}=97)\end{array}$ & $\begin{array}{l}\text { Level } 3 \\
(\mathrm{~N}=96)\end{array}$ & $\begin{array}{l}\text { Continuous } \\
(\mathrm{N}=288)\end{array}$ & $\begin{array}{l}\text { Level } 1 \\
(\mathrm{~N}=95)\end{array}$ & $\begin{array}{l}\text { Level } 2 \\
(\mathrm{~N}=97)\end{array}$ & $\begin{array}{l}\text { Level } 3 \\
(\mathrm{~N}=96)\end{array}$ & $\begin{array}{l}\text { Continuous } \\
(\mathrm{N}=288)\end{array}$ & \\
\hline Abdominal & $\mathrm{N}=37$ & $\mathrm{~N}=36$ & $\mathrm{~N}=39$ & $\mathrm{~N}=112$ & & & & & \\
\hline Obesity & 1.0 & $\begin{array}{c}0.925 \\
(0.516-1.657)\end{array}$ & $\begin{array}{c}1.073 \\
(0.601-1.915)\end{array}$ & $\begin{array}{c}1.003 \\
(0.992-1.013)\end{array}$ & 1.0 & $\begin{array}{c}0.936 \\
(0.521-1.683)\end{array}$ & $\begin{array}{c}1.041 \\
(0.580-1.866)\end{array}$ & $\begin{array}{c}1.003 \\
(0.992-1.013)\end{array}$ & $\begin{array}{c}1.002 \\
(0.992-1.013)\end{array}$ \\
\hline Elevated & $\mathrm{N}=34$ & $\mathrm{~N}=40$ & $\mathrm{~N}=40$ & $\mathrm{~N}=114$ & & & & & \\
\hline Triglycerides & 1.0 & $\begin{array}{c}1.259 \\
(0.703-2.254)\end{array}$ & $\begin{array}{c}1.282 \\
(0.715-2.297)\end{array}$ & $\begin{array}{c}1.003 \\
(0.992-1.013)\end{array}$ & 1.0 & $\begin{array}{c}1.276 \\
(0.710-2.291)\end{array}$ & $\begin{array}{c}1.250 \\
(0.695-2.248)\end{array}$ & $\begin{array}{c}1.003 \\
(0.992-1.013)\end{array}$ & $\begin{array}{c}1.003 \\
(0.992-1.014)\end{array}$ \\
\hline Reduced & $\mathrm{N}=53$ & $\mathrm{~N}=44$ & $\mathrm{~N}=42$ & $\mathrm{~N}=139$ & & & & & \\
\hline HDL-C & 1.0 & $\begin{array}{c}0.658 \\
(0.372-1.162)\end{array}$ & $\begin{array}{c}0.616 \\
(0.348-1.091)\end{array}$ & $\begin{array}{c}0.987 \\
(0.977-0.997)\end{array}$ & 1.0 & $\begin{array}{c}0.661 \\
(0.374-1.168)\end{array}$ & $\begin{array}{c}0.606 \\
(0.342-1.076)\end{array}$ & $\begin{array}{c}0.987 \\
(0.977-0.997)\end{array}$ & $\begin{array}{c}0.987 \\
(0.977-0.997)\end{array}$ \\
\hline Glucose & $\mathrm{N}=29$ & $\mathrm{~N}=29$ & $\mathrm{~N}=22$ & $\mathrm{~N}=80$ & & & & & \\
\hline Intolerance & 1.0 & $\begin{array}{c}0.971 \\
(0.524-1.797)\end{array}$ & $\begin{array}{c}0.677 \\
(0.355-1.291)\end{array}$ & $\begin{array}{c}0.994 \\
(0.983-1.006)\end{array}$ & 1.0 & $\begin{array}{c}0.998 \\
(0.532-1.870)\end{array}$ & $\begin{array}{c}0.624 \\
(0.322-1.211)\end{array}$ & $\begin{array}{c}0.994 \\
(0.982-1.005)\end{array}$ & $\begin{array}{c}0.994 \\
(0.982-1.006)\end{array}$ \\
\hline Hypertension & $\begin{array}{c}\mathrm{N}=36 \\
1.0\end{array}$ & $\begin{array}{c}\mathrm{N}=47 \\
1.541 \\
(0.867-2.737) \\
\end{array}$ & $\begin{array}{c}\mathrm{N}=44 \\
1.387 \\
(0.779-2.470)\end{array}$ & $\begin{array}{c}\mathrm{N}=127 \\
1.006 \\
(0.996-1.016)\end{array}$ & 1.0 & $\begin{array}{c}1.579 \\
(0.883-2.822) \\
\end{array}$ & $\begin{array}{c}1.341 \\
(0.748-2.405 \\
\end{array}$ & $\begin{array}{c}1.006 \\
(0.996-1.017) \\
\end{array}$ & $\begin{array}{c}1.006 \\
(0.996-1.017) \\
\end{array}$ \\
\hline
\end{tabular}


Table A.6h. Unadjusted and adjusted odds ratios for MetSyn components by tertiles of Spielberger Police Stress score for women. - SUPPORT STRESS RATING

\begin{tabular}{|c|c|c|c|c|c|c|c|c|c|}
\hline \multirow{2}{*}{$\begin{array}{l}\text { MetSyn } \\
\text { Component }\end{array}$} & \multicolumn{4}{|c|}{$\begin{array}{c}\text { Unadjusted } \\
\text { OR }(95 \% \mathrm{CI})\end{array}$} & \multicolumn{4}{|c|}{$\begin{array}{l}\text { Age-Adjusted } \\
\text { OR (95\% CI) }\end{array}$} & \multirow{2}{*}{$\begin{array}{c}\begin{array}{c}\text { Multivariate Adjusted } \\
\text { OR }(95 \% \mathrm{CI})^{*}\end{array} \\
\text { Continuous } \\
(\mathrm{N}=)\end{array}$} \\
\hline & $\begin{array}{l}\text { Level } 1 \\
(\mathrm{~N}=34)\end{array}$ & $\begin{array}{l}\text { Level } 2 \\
(\mathrm{~N}=34)\end{array}$ & $\begin{array}{l}\text { Level } 3 \\
(\mathrm{~N}=34)\end{array}$ & $\begin{array}{l}\text { Continuous } \\
(\mathrm{N}=102)\end{array}$ & $\begin{array}{l}\text { Level } 1 \\
(\mathrm{~N}=34)\end{array}$ & $\begin{array}{l}\text { Level } 2 \\
(\mathrm{~N}=34)\end{array}$ & $\begin{array}{l}\text { Level } 3 \\
(\mathrm{~N}=34)\end{array}$ & $\begin{array}{l}\text { Continuous } \\
(\mathrm{N}=102)\end{array}$ & \\
\hline \multirow{2}{*}{$\begin{array}{l}\text { Abdominal } \\
\text { Obesity }\end{array}$} & $\mathrm{N}=4$ & $\mathrm{~N}=4$ & $\mathrm{~N}=10$ & $\mathrm{~N}=18$ & & & & & \\
\hline & 1.0 & $\begin{array}{c}1.000 \\
(0.229-4.373)\end{array}$ & $\begin{array}{c}3.125 \\
(0.871-11.214)\end{array}$ & $\begin{array}{c}1.030 \\
(1.005-1.055)\end{array}$ & 1.0 & $\begin{array}{c}0.979 \\
(0.218-4.401)\end{array}$ & $\begin{array}{c}2.954 \\
(0.803-10.867)\end{array}$ & $\begin{array}{c}1.028 \\
(1.003-1.054)\end{array}$ & $\begin{array}{c}1.030 \\
(1.004-1.056)\end{array}$ \\
\hline \multirow{2}{*}{$\begin{array}{l}\text { Elevated } \\
\text { Triglycerides }\end{array}$} & $\mathrm{N}=1$ & $\mathrm{~N}=2$ & $\mathrm{~N}=6$ & $\mathrm{~N}=9$ & & & & & \\
\hline & 1.0 & $\begin{array}{c}2.062 \\
(0.178-23.882)\end{array}$ & $\begin{array}{c}7.017 \\
(0.803-62.311)\end{array}$ & $\begin{array}{c}1.030 \\
(0.997-1.065)\end{array}$ & 1.0 & $\begin{array}{c}1.921 \\
(0.163-22.652)\end{array}$ & $\begin{array}{c}7.959 \\
(0.884-71.694)\end{array}$ & $\begin{array}{c}1.034 \\
(0.999-1.070)\end{array}$ & $\begin{array}{c}1.034 \\
(0.998-1.070)\end{array}$ \\
\hline \multirow{2}{*}{$\begin{array}{l}\text { Reduced } \\
\text { HDL-C }\end{array}$} & $\mathrm{N}=6$ & $\mathrm{~N}=8$ & $\mathrm{~N}=13$ & $\mathrm{~N}=27$ & & & & & \\
\hline & 1.0 & $\begin{array}{c}1.436 \\
(0.439-4.699)\end{array}$ & $\begin{array}{c}2.889 \\
(0.942-8.860)\end{array}$ & $\begin{array}{c}1.022 \\
(1.002-1.042)\end{array}$ & 1.0 & $\begin{array}{c}1.437 \\
(0.439-4.703)\end{array}$ & $\begin{array}{c}2.881 \\
(0.937-8.856)\end{array}$ & $\begin{array}{c}1.022 \\
(1.002-1.042)\end{array}$ & $\begin{array}{c}1.021 \\
(1.000-1.041)\end{array}$ \\
\hline \multirow{2}{*}{$\begin{array}{l}\text { Glucose } \\
\text { Intolerance }\end{array}$} & $\mathrm{N}=2$ & $\mathrm{~N}=2$ & $\mathrm{~N}=8$ & $\mathrm{~N}=12$ & & & & & \\
\hline & 1.0 & $\begin{array}{c}1.000 \\
(0.133-7.540)\end{array}$ & $\begin{array}{c}4.923 \\
(0.961-25.216)\end{array}$ & $\begin{array}{c}1.032 \\
(1.002-1.063)\end{array}$ & 1.0 & $\begin{array}{c}1.003 \\
(0.133-7.566)\end{array}$ & $\begin{array}{c}4.844 \\
(0.943-24.890)\end{array}$ & $\begin{array}{c}1.032 \\
(1.002-1.063)\end{array}$ & $\begin{array}{c}1.032 \\
(1.001-1.063)\end{array}$ \\
\hline \multirow{2}{*}{ Hypertension } & $\mathrm{N}=8$ & $\mathrm{~N}=10$ & $\mathrm{~N}=9$ & $\mathrm{~N}=27$ & & & & & \\
\hline & 1.0 & $\begin{array}{c}1.354 \\
(0.459-3.998) \\
\end{array}$ & $\begin{array}{c}1.170 \\
(0.390-3.512) \\
\end{array}$ & $\begin{array}{c}1.001 \\
(0.983-1.020) \\
\end{array}$ & 1.0 & $\begin{array}{c}1.374 \\
(0.454-4.158) \\
\end{array}$ & $\begin{array}{c}1.078 \\
(0.351-3.312) \\
\end{array}$ & $\begin{array}{c}1.000 \\
(0.981-1.018) \\
\end{array}$ & $\begin{array}{c}1.001 \\
(0.981-1.020) \\
\end{array}$ \\
\hline
\end{tabular}


Table A.7a. Unadjusted and adjusted odds ratios for MetSyn components by tertiles of Spielberger Police Stress score for men. - STRESS INDEX FOR PAST MONTH

\begin{tabular}{|c|c|c|c|c|c|c|c|c|c|}
\hline \multirow{2}{*}{$\begin{array}{l}\text { MetSyn } \\
\text { Component }\end{array}$} & \multicolumn{4}{|c|}{$\begin{array}{c}\text { Unadjusted } \\
\text { OR }(95 \% \mathrm{CI})\end{array}$} & \multicolumn{4}{|c|}{$\begin{array}{l}\text { Age-Adjusted } \\
\text { OR }(95 \% \mathrm{CI})\end{array}$} & \multirow{2}{*}{$\begin{array}{c}\text { Multivariate Adjusted } \\
\text { OR }(95 \% \mathrm{CI})^{*} \\
\begin{array}{c}\text { Continuous } \\
(\mathrm{N}=)\end{array}\end{array}$} \\
\hline & $\begin{array}{l}\text { Level } 1 \\
(\mathrm{~N}=96)\end{array}$ & $\begin{array}{l}\text { Level } 2 \\
(\mathrm{~N}=96)\end{array}$ & $\begin{array}{l}\text { Level } 3 \\
(\mathrm{~N}=96)\end{array}$ & $\begin{array}{l}\text { Continuous } \\
(\mathrm{N}=288)\end{array}$ & $\begin{array}{l}\text { Level } 1 \\
(\mathrm{~N}=96)\end{array}$ & $\begin{array}{l}\text { Level } 2 \\
(\mathrm{~N}=96)\end{array}$ & $\begin{array}{l}\text { Level } 3 \\
(\mathrm{~N}=96)\end{array}$ & $\begin{array}{l}\text { Continuous } \\
(\mathrm{N}=288)\end{array}$ & \\
\hline Abdominal & $\mathrm{N}=33$ & $\mathrm{~N}=37$ & $\mathrm{~N}=42$ & $\mathrm{~N}=112$ & & & & & \\
\hline Obesity & 1.0 & $\begin{array}{c}1.197 \\
(0.665-2.157)\end{array}$ & $\begin{array}{c}1.485 \\
(0.829-2.660)\end{array}$ & $\begin{array}{c}1.002 \\
(0.998-1.005)\end{array}$ & 1.0 & $\begin{array}{c}1.295 \\
(0.712-2.357)\end{array}$ & $\begin{array}{c}1.644 \\
(0.905-2.986)\end{array}$ & $\begin{array}{c}1.002 \\
(0.999-1.006)\end{array}$ & $\begin{array}{c}1.003 \\
(0.999-1.006)\end{array}$ \\
\hline Elevated & $\mathrm{N}=34$ & $\mathrm{~N}=40$ & $\mathrm{~N}=40$ & $\mathrm{~N}=114$ & & & & & \\
\hline Triglycerides & 1.0 & $\begin{array}{c}1.303 \\
(0.727-2.333)\end{array}$ & $\begin{array}{c}1.303 \\
(0.727-2.333)\end{array}$ & $\begin{array}{c}1.002 \\
(0.999-1.006)\end{array}$ & 1.0 & $\begin{array}{c}1.394 \\
(0.772-2.519)\end{array}$ & $\begin{array}{c}1.419 \\
(0.783-2.570)\end{array}$ & $\begin{array}{c}1.002 \\
(0.999-1.006)\end{array}$ & $\begin{array}{c}1.002 \\
(0.998-1.005)\end{array}$ \\
\hline Reduced & $\mathrm{N}=55$ & $\mathrm{~N}=49$ & $\mathrm{~N}=35$ & $\mathrm{~N}=139$ & & & & & \\
\hline HDL-C & 1.0 & $\begin{array}{c}0.777 \\
(0.440-1.373)\end{array}$ & $\begin{array}{c}0.428 \\
(0.240-0.764)\end{array}$ & $\begin{array}{c}0.996 \\
(0.992-0.999)\end{array}$ & 1.0 & $\begin{array}{c}0.789 \\
(0.445-1.400)\end{array}$ & $\begin{array}{c}0.436 \\
(0.243-0.783)\end{array}$ & $\begin{array}{c}0.996 \\
(0.992-1.000)\end{array}$ & $\begin{array}{c}0.996 \\
(0.992-0.999)\end{array}$ \\
\hline Glucose & $\mathrm{N}=29$ & $\mathrm{~N}=24$ & $\mathrm{~N}=27$ & $\mathrm{~N}=80$ & & & & & \\
\hline Intolerance & 1.0 & $\begin{array}{c}0.770 \\
(0.408-1.453)\end{array}$ & $\begin{array}{c}0.904 \\
(0.485-1.685)\end{array}$ & $\begin{array}{c}1.000 \\
(0.996-1.003)\end{array}$ & 1.0 & $\begin{array}{c}0.864 \\
(0.451-1.657)\end{array}$ & $\begin{array}{c}1.055 \\
(0.555-2.004)\end{array}$ & $\begin{array}{c}1.000 \\
(0.996-1.004)\end{array}$ & $\begin{array}{c}1.000 \\
(0.996-1.004)\end{array}$ \\
\hline Hypertension & $\begin{array}{c}\mathrm{N}=47 \\
1.0\end{array}$ & $\begin{array}{c}\mathrm{N}=33 \\
0.546 \\
(0.305-0.976)\end{array}$ & $\begin{array}{c}\mathrm{N}=47 \\
1.000 \\
(0.568-1.761)\end{array}$ & $\begin{array}{c}\mathrm{N}=127 \\
1.001 \\
(0.997-1.004)\end{array}$ & 1.0 & $\begin{array}{c}0.586 \\
(0.325-1.057)\end{array}$ & $\begin{array}{c}1.109 \\
(0.622-1.978)\end{array}$ & $\begin{array}{c}1.001 \\
(0.998-1.004)\end{array}$ & $\begin{array}{c}1.001 \\
(0.997-1.004)\end{array}$ \\
\hline
\end{tabular}


Table A.7b. Unadjusted and adjusted odds ratios for MetSyn components by tertiles of Spielberger Police Stress score for women. - STRESS INDEX FOR PAST MONTH

\begin{tabular}{|c|c|c|c|c|c|c|c|c|c|}
\hline \multirow{2}{*}{$\begin{array}{l}\text { MetSyn } \\
\text { Component }\end{array}$} & \multicolumn{4}{|c|}{$\begin{array}{c}\text { Unadjusted } \\
\text { OR }(95 \% \mathrm{CI})\end{array}$} & \multicolumn{4}{|c|}{$\begin{array}{l}\text { Age-Adjusted } \\
\text { OR }(95 \% \text { CI })\end{array}$} & \multirow{2}{*}{$\begin{array}{c}\begin{array}{c}\text { Multivariate Adjusted } \\
\text { OR }(95 \% \mathrm{CI})^{*}\end{array} \\
\begin{array}{c}\text { Continuous } \\
(\mathrm{N}=)\end{array}\end{array}$} \\
\hline & $\begin{array}{l}\text { Level } 1 \\
(\mathrm{~N}=34)\end{array}$ & $\begin{array}{l}\text { Level } 2 \\
(\mathrm{~N}=34)\end{array}$ & $\begin{array}{l}\text { Level } 3 \\
(\mathrm{~N}=34)\end{array}$ & $\begin{array}{l}\text { Continuous } \\
(\mathrm{N}=102)\end{array}$ & $\begin{array}{l}\text { Level } 1 \\
(\mathrm{~N}=34)\end{array}$ & $\begin{array}{l}\text { Level } 2 \\
(\mathrm{~N}=34)\end{array}$ & $\begin{array}{l}\text { Level } 3 \\
(\mathrm{~N}=34)\end{array}$ & $\begin{array}{l}\text { Continuous } \\
(\mathrm{N}=102)\end{array}$ & \\
\hline Abdominal & $\mathrm{N}=3$ & $\mathrm{~N}=4$ & $\mathrm{~N}=11$ & $\mathrm{~N}=18$ & & & & & \\
\hline Obesity & 1.0 & $\begin{array}{c}1.378 \\
(0.284-6.681)\end{array}$ & $\begin{array}{c}4.942 \\
(1.236-19.758)\end{array}$ & $\begin{array}{c}1.006 \\
(0.999-1.012)\end{array}$ & 1.0 & $\begin{array}{c}1.373 \\
(0.277-6.813)\end{array}$ & $\begin{array}{c}5.228 \\
(1.266-21.593)\end{array}$ & $\begin{array}{c}1.006 \\
(1.000-1.013)\end{array}$ & $\begin{array}{c}1.008 \\
(1.001-1.015)\end{array}$ \\
\hline Elevated & $\mathrm{N}=1$ & $\mathrm{~N}=3$ & $\mathrm{~N}=5$ & $\mathrm{~N}=9$ & & & & & \\
\hline Triglycerides & 1.0 & $\begin{array}{c}3.194 \\
(0.315-32.356)\end{array}$ & $\begin{array}{c}5.690 \\
(0.628-51.566)\end{array}$ & $\begin{array}{c}1.006 \\
(0.998-1.014)\end{array}$ & 1.0 & $\begin{array}{c}3.141 \\
(0.307-32.121)\end{array}$ & $\begin{array}{c}5.692 \\
(0.622-52.072)\end{array}$ & $\begin{array}{c}1.006 \\
(0.998-1.014)\end{array}$ & $\begin{array}{c}1.006 \\
(0.997-1.015)\end{array}$ \\
\hline Reduced & $\mathrm{N}=8$ & $\mathrm{~N}=7$ & $\mathrm{~N}=12$ & $\mathrm{~N}=27$ & & & & & \\
\hline HDL-C & 1.0 & $\begin{array}{c}0.843 \\
(0.267-2.657)\end{array}$ & $\begin{array}{c}1.773 \\
(0.615-5.115)\end{array}$ & $\begin{array}{c}1.007 \\
(1.001-1.013)\end{array}$ & 1.0 & $\begin{array}{c}0.844 \\
(0.267-2.661)\end{array}$ & $\begin{array}{c}1.774 \\
(0.615-5.119)\end{array}$ & $\begin{array}{c}1.007 \\
(1.001-1.013)\end{array}$ & $\begin{array}{c}1.007 \\
(1.000-1.013)\end{array}$ \\
\hline Glucose & $\mathrm{N}=4$ & $\mathrm{~N}=3$ & $\mathrm{~N}=5$ & $\mathrm{~N}=12$ & & & & & \\
\hline Intolerance & 1.0 & $\begin{array}{c}0.726 \\
(0.150-3.520)\end{array}$ & $\begin{array}{c}1.293 \\
(0.316-5.299)\end{array}$ & $\begin{array}{c}1.004 \\
(0.996-1.011)\end{array}$ & 1.0 & $\begin{array}{c}0.727 \\
(0.150-3.530)\end{array}$ & $\begin{array}{c}1.291 \\
(0.314-5.303)\end{array}$ & $\begin{array}{c}1.004 \\
(0.996-1.011)\end{array}$ & $\begin{array}{c}1.004 \\
(0.996-1.012)\end{array}$ \\
\hline Hypertension & $\begin{array}{c}\mathrm{N}=8 \\
1.0\end{array}$ & $\begin{array}{c}\mathrm{N}=10 \\
1.354 \\
(0.459-3.998)\end{array}$ & $\begin{array}{c}\mathrm{N}=9 \\
1.170 \\
(0.390-3.512)\end{array}$ & $\begin{array}{c}\mathrm{N}=27 \\
0.999 \\
(0.993-1.005)\end{array}$ & 1.0 & $\begin{array}{c}1.372 \\
(0.455-4.136)\end{array}$ & $\begin{array}{c}1.162 \\
(0.378-3.570)\end{array}$ & $\begin{array}{c}0.999 \\
(0.993-1.005)\end{array}$ & $\begin{array}{c}0.999 \\
(0.992-1.005)\end{array}$ \\
\hline
\end{tabular}


Table A.7c. Unadjusted and adjusted odds ratios for MetSyn components by tertiles of Spielberger Police Stress score for men. - ADMINISTRATIVE STRESS INDEX FOR PAST MONTH

\begin{tabular}{|c|c|c|c|c|c|c|c|c|c|}
\hline \multirow{2}{*}{$\begin{array}{l}\text { MetSyn } \\
\text { Component }\end{array}$} & \multicolumn{4}{|c|}{$\begin{array}{c}\text { Unadjusted } \\
\text { OR }(95 \% \text { CI })\end{array}$} & \multicolumn{4}{|c|}{$\begin{array}{l}\text { Age-Adjusted } \\
\text { OR }(95 \% \text { CI })\end{array}$} & \multirow{2}{*}{$\begin{array}{c}\begin{array}{c}\text { Multivariate Adjusted } \\
\text { OR }(95 \% \mathrm{CI}) *\end{array} \\
\begin{array}{c}\text { Continuous } \\
(\mathrm{N}=)\end{array}\end{array}$} \\
\hline & $\begin{array}{l}\text { Level } 1 \\
(\mathrm{~N}=95)\end{array}$ & $\begin{array}{l}\text { Level } 2 \\
(\mathrm{~N}=96)\end{array}$ & $\begin{array}{l}\text { Level } 3 \\
(\mathrm{~N}=96)\end{array}$ & $\begin{array}{l}\text { Continuous } \\
(\mathrm{N}=287)\end{array}$ & $\begin{array}{l}\text { Level } 1 \\
(\mathrm{~N}=95)\end{array}$ & $\begin{array}{l}\text { Level } 2 \\
(\mathrm{~N}=96)\end{array}$ & $\begin{array}{l}\text { Level } 3 \\
(\mathrm{~N}=96)\end{array}$ & $\begin{array}{l}\text { Continuous } \\
(\mathrm{N}=287)\end{array}$ & \\
\hline Abdominal & $\mathrm{N}=37$ & $\mathrm{~N}=34$ & $\mathrm{~N}=41$ & $\mathrm{~N}=112$ & & & & & \\
\hline Obesity & 1.0 & $\begin{array}{c}0.860 \\
(0.478-1.547)\end{array}$ & $\begin{array}{c}1.169 \\
(0.656-2.082)\end{array}$ & $\begin{array}{c}1.001 \\
(0.998-1.004)\end{array}$ & 1.0 & $\begin{array}{c}0.884 \\
(0.489-1.599)\end{array}$ & $\begin{array}{c}1.268 \\
(0.704-2.282)\end{array}$ & $\begin{array}{c}1.001 \\
(0.999-1.004)\end{array}$ & $\begin{array}{c}1.002 \\
(0.999-1.005)\end{array}$ \\
\hline Elevated & $\mathrm{N}=35$ & $\mathrm{~N}=40$ & $\mathrm{~N}=39$ & $\mathrm{~N}=114$ & & & & & \\
\hline Triglycerides & 1.0 & $\begin{array}{c}1.224 \\
(0.684-2.191)\end{array}$ & $\begin{array}{c}1.173 \\
(0.655-2.101)\end{array}$ & $\begin{array}{c}1.002 \\
(0.999-1.005)\end{array}$ & 1.0 & $\begin{array}{c}1.260 \\
(0.701-2.263)\end{array}$ & $\begin{array}{c}1.258 \\
(0.696-2.274)\end{array}$ & $\begin{array}{c}1.002 \\
(0.999-1.005)\end{array}$ & $\begin{array}{c}1.002 \\
(0.999-1.004)\end{array}$ \\
\hline Reduced & $\mathrm{N}=56$ & $\mathrm{~N}=47$ & $\mathrm{~N}=36$ & $\mathrm{~N}=139$ & & & & & \\
\hline HDL-C & 1.0 & $\begin{array}{c}0.668 \\
(0.377-1.184)\end{array}$ & $\begin{array}{c}0.418 \\
(0.234-0.747)\end{array}$ & $\begin{array}{c}0.997 \\
(0.994-1.000)\end{array}$ & 1.0 & $\begin{array}{c}0.673 \\
(0.379-1.193)\end{array}$ & $\begin{array}{c}0.426 \\
(0.237-0.764)\end{array}$ & $\begin{array}{c}0.997 \\
(0.994-1.000)\end{array}$ & $\begin{array}{c}0.997 \\
(0.994-1.000)\end{array}$ \\
\hline Glucose & $\mathrm{N}=29$ & $\mathrm{~N}=23$ & $\mathrm{~N}=27$ & $\mathrm{~N}=79$ & & & & & \\
\hline Intolerance & 1.0 & $\begin{array}{c}0.717 \\
(0.378-1.361)\end{array}$ & $\begin{array}{c}0.891 \\
(0.477-1.661)\end{array}$ & $\begin{array}{c}1.000 \\
(0.997-1.003)\end{array}$ & 1.0 & $\begin{array}{c}0.748 \\
(0.389-1.436)\end{array}$ & $\begin{array}{c}1.018 \\
(0.537-1.932)\end{array}$ & $\begin{array}{c}1.001 \\
(0.998-1.004)\end{array}$ & $\begin{array}{c}1.000 \\
(0.997-1.004)\end{array}$ \\
\hline Hypertension & $\begin{array}{c}\mathrm{N}=44 \\
1.0\end{array}$ & $\begin{array}{c}\mathrm{N}=39 \\
0.793 \\
(0.447-1.407)\end{array}$ & $\begin{array}{c}\mathrm{N}=44 \\
0.981 \\
(0.555-1.733)\end{array}$ & $\begin{array}{c}\mathrm{N}=127 \\
1.001 \\
(0.998-1.004)\end{array}$ & 1.0 & $\begin{array}{c}0.818 \\
(0.458-1.462)\end{array}$ & $\begin{array}{c}1.079 \\
(0.604-1.927)\end{array}$ & $\begin{array}{c}1.001 \\
(0.998-1.004)\end{array}$ & $\begin{array}{c}1.001 \\
(0.998-1.004)\end{array}$ \\
\hline
\end{tabular}




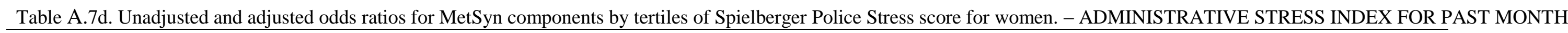

\begin{tabular}{|c|c|c|c|c|c|c|c|c|c|}
\hline \multirow{2}{*}{$\begin{array}{l}\text { MetSyn } \\
\text { Component }\end{array}$} & \multicolumn{4}{|c|}{$\begin{array}{c}\text { Unadjusted } \\
\text { OR }(95 \% \mathrm{CI})\end{array}$} & \multicolumn{4}{|c|}{$\begin{array}{l}\text { Age-Adjusted } \\
\text { OR }(95 \% \text { CI })\end{array}$} & \multirow{2}{*}{$\begin{array}{c}\begin{array}{c}\text { Multivariate Adjusted } \\
\text { OR }(95 \% \mathrm{CI})^{*}\end{array} \\
\begin{array}{c}\text { Continuous } \\
(\mathrm{N}=)\end{array}\end{array}$} \\
\hline & $\begin{array}{l}\text { Level } 1 \\
(\mathrm{~N}=34)\end{array}$ & $\begin{array}{l}\text { Level } 2 \\
(\mathrm{~N}=34)\end{array}$ & $\begin{array}{l}\text { Level } 3 \\
(\mathrm{~N}=34)\end{array}$ & $\begin{array}{l}\text { Continuous } \\
(\mathrm{N}=102)\end{array}$ & $\begin{array}{l}\text { Level } 1 \\
(\mathrm{~N}=34)\end{array}$ & $\begin{array}{l}\text { Level } 2 \\
(\mathrm{~N}=34)\end{array}$ & $\begin{array}{l}\text { Level } 3 \\
(\mathrm{~N}=34)\end{array}$ & $\begin{array}{l}\text { Continuous } \\
(\mathrm{N}=102)\end{array}$ & \\
\hline Abdominal & $\mathrm{N}=2$ & $\mathrm{~N}=7$ & $\mathrm{~N}=9$ & $\mathrm{~N}=18$ & & & & & \\
\hline Obesity & 1.0 & $\begin{array}{c}4.148 \\
(0.794-21.660)\end{array}$ & $\begin{array}{c}5.760 \\
(1.141-29.078)\end{array}$ & $\begin{array}{c}1.005 \\
(1.000-1.010)\end{array}$ & 1.0 & $\begin{array}{c}4.314 \\
(0.807-23.047)\end{array}$ & $\begin{array}{c}5.801 \\
(1.122-30.004)\end{array}$ & $\begin{array}{c}1.005 \\
(1.000-1.011)\end{array}$ & $\begin{array}{c}1.006 \\
(1.000-1.012)\end{array}$ \\
\hline Elevated & $\mathrm{N}=2$ & $\mathrm{~N}=2$ & $\mathrm{~N}=5$ & $\mathrm{~N}=9$ & & & & & \\
\hline Triglycerides & 1.0 & $\begin{array}{c}1.000 \\
(0.133-7.540)\end{array}$ & $\begin{array}{c}2.759 \\
(0.496-15.330)\end{array}$ & $\begin{array}{c}1.006 \\
(1.000-1.013)\end{array}$ & 1.0 & $\begin{array}{c}0.993 \\
(0.130-7.583)\end{array}$ & $\begin{array}{c}2.912 \\
(0.515-16.483)\end{array}$ & $\begin{array}{c}1.006 \\
(1.000-1.013)\end{array}$ & $\begin{array}{c}1.006 \\
(0.999-1.013)\end{array}$ \\
\hline Reduced & $\mathrm{N}=6$ & $\mathrm{~N}=10$ & $\mathrm{~N}=11$ & $\mathrm{~N}=27$ & & & & & \\
\hline HDL-C & 1.0 & $\begin{array}{c}1.944 \\
(0.616-6.139)\end{array}$ & $\begin{array}{c}2.232 \\
(0.716-6.960)\end{array}$ & $\begin{array}{c}1.006 \\
(1.001-1.011)\end{array}$ & 1.0 & $\begin{array}{c}1.945 \\
(0.616-6.143)\end{array}$ & $\begin{array}{c}2.224 \\
(0.713-6.941)\end{array}$ & $\begin{array}{c}1.006 \\
(1.001-1.011)\end{array}$ & $\begin{array}{c}1.005 \\
(1.000-1.011)\end{array}$ \\
\hline Glucose & $\mathrm{N}=3$ & $\mathrm{~N}=4$ & $\mathrm{~N}=5$ & $\mathrm{~N}=12$ & & & & & \\
\hline Intolerance & $\begin{array}{c}1.0 \\
\mathrm{~N}=9\end{array}$ & $\begin{array}{c}1.378 \\
(0.284-6.681) \\
\mathrm{N}=10\end{array}$ & $\begin{array}{c}1.781 \\
(0.390-8.132) \\
\mathrm{N}=8\end{array}$ & $\begin{array}{c}1.002 \\
(0.995-1.008) \\
\mathrm{N}=27\end{array}$ & 1.0 & $\begin{array}{c}1.379 \\
(0.284-6.698)\end{array}$ & $\begin{array}{c}1.759 \\
(0.384-8.051)\end{array}$ & $\begin{array}{c}1.002 \\
(0.995-1.008)\end{array}$ & $\begin{array}{c}1.002 \\
(0.995-1.008)\end{array}$ \\
\hline Hypertension & 1.0 & $\begin{array}{c}1.157 \\
(0.401-3.342)\end{array}$ & $\begin{array}{c}0.855 \\
(0.285-2.566)\end{array}$ & $\begin{array}{c}1.001 \\
(0.996-1.006)\end{array}$ & 1.0 & $\begin{array}{c}1.164 \\
(0.394-3.438)\end{array}$ & $\begin{array}{c}0.812 \\
(0.264-2.499)\end{array}$ & $\begin{array}{c}1.001 \\
(0.996-1.006)\end{array}$ & $\begin{array}{c}1.001 \\
(0.995-1.006)\end{array}$ \\
\hline
\end{tabular}


Table A.7e. Unadjusted and adjusted odds ratios for MetSyn components by tertiles of Spielberger Police Stress score for men. - DANGER STRESS INDEX FOR PAST MONTH

\begin{tabular}{|c|c|c|c|c|c|c|c|c|c|}
\hline \multirow{2}{*}{$\begin{array}{l}\text { MetSyn } \\
\text { Component }\end{array}$} & \multicolumn{4}{|c|}{$\begin{array}{c}\text { Unadjusted } \\
\text { OR }(95 \% \text { CI })\end{array}$} & \multicolumn{4}{|c|}{$\begin{array}{l}\text { Age-Adjusted } \\
\text { OR }(95 \% \text { CI })\end{array}$} & \multirow{2}{*}{$\begin{array}{c}\begin{array}{c}\text { Multivariate Adjusted } \\
\text { OR }(95 \% \mathrm{CI})^{*}\end{array} \\
\begin{array}{c}\text { Continuous } \\
(\mathrm{N}=)\end{array}\end{array}$} \\
\hline & $\begin{array}{l}\text { Level } 1 \\
(\mathrm{~N}=95)\end{array}$ & $\begin{array}{l}\text { Level } 2 \\
(\mathrm{~N}=96)\end{array}$ & $\begin{array}{l}\text { Level } 3 \\
(\mathrm{~N}=96)\end{array}$ & $\begin{array}{l}\text { Continuous } \\
(\mathrm{N}=287)\end{array}$ & $\begin{array}{l}\text { Level } 1 \\
(\mathrm{~N}=96)\end{array}$ & $\begin{array}{l}\text { Level } 2 \\
(\mathrm{~N}=96)\end{array}$ & $\begin{array}{l}\text { Level } 3 \\
(\mathrm{~N}=96)\end{array}$ & $\begin{array}{l}\text { Continuous } \\
(\mathrm{N}=287)\end{array}$ & \\
\hline Abdominal & $\mathrm{N}=35$ & $\mathrm{~N}=39$ & $\mathrm{~N}=37$ & $\mathrm{~N}=112$ & & & & & \\
\hline Obesity & 1.0 & $\begin{array}{c}1.173 \\
(0.655-2.101)\end{array}$ & $\begin{array}{c}1.075 \\
(0.599-1.931)\end{array}$ & $\begin{array}{c}1.001 \\
(0.998-1.005)\end{array}$ & 1.0 & $\begin{array}{c}1.227 \\
(0.681-2.212)\end{array}$ & $\begin{array}{c}1.252 \\
(0.680-2.303)\end{array}$ & $\begin{array}{c}1.002 \\
(0.998-1.005)\end{array}$ & $\begin{array}{c}1.002 \\
(0.999-1.006)\end{array}$ \\
\hline Elevated & $\mathrm{N}=35$ & $\mathrm{~N}=40$ & $\mathrm{~N}=38$ & $\mathrm{~N}=113$ & & & & & \\
\hline Triglycerides & 1.0 & $\begin{array}{c}1.224 \\
(0.684-2.191)\end{array}$ & $\begin{array}{c}1.123 \\
(0.626-2.014)\end{array}$ & $\begin{array}{c}1.001 \\
(0.997-1.004)\end{array}$ & 1.0 & $\begin{array}{c}1.275 \\
(0.709-2.293)\end{array}$ & $\begin{array}{c}1.286 \\
(0.700-2.360)\end{array}$ & $\begin{array}{c}1.001 \\
(0.998-1.005)\end{array}$ & $\begin{array}{c}1.001 \\
(0.997-1.005)\end{array}$ \\
\hline Reduced & $\mathrm{N}=51$ & $\mathrm{~N}=54$ & $\mathrm{~N}=33$ & $\mathrm{~N}=138$ & & & & & \\
\hline HDL-C & 1.0 & $\begin{array}{c}1.109 \\
(0.627-1.962)\end{array}$ & $\begin{array}{c}0.452 \\
(0.252-0.810)\end{array}$ & $\begin{array}{c}0.995 \\
(0.991-0.999)\end{array}$ & 1.0 & $\begin{array}{c}1.110 \\
(0.627-1.967)\end{array}$ & $\begin{array}{c}0.453 \\
(0.248-0.827)\end{array}$ & $\begin{array}{c}0.995 \\
(0.991-0.999)\end{array}$ & $\begin{array}{c}0.995 \\
(0.991-0.999)\end{array}$ \\
\hline Glucose & $\mathrm{N}=27$ & $\mathrm{~N}=30$ & $\mathrm{~N}=23$ & $\mathrm{~N}=80$ & & & & & \\
\hline Intolerance & 1.0 & $\begin{array}{c}1.145 \\
(0.616-2.129)\end{array}$ & $\begin{array}{c}0.794 \\
(0.416-1.515)\end{array}$ & $\begin{array}{c}0.998 \\
(0.993-1.002)\end{array}$ & 1.0 & $\begin{array}{c}1.239 \\
(0.657-2.338)\end{array}$ & $\begin{array}{c}1.027 \\
(0.521-2.025)\end{array}$ & $\begin{array}{c}0.999 \\
(0.995-1.003)\end{array}$ & $\begin{array}{c}0.999 \\
(0.994-1.003)\end{array}$ \\
\hline Hypertension & $\begin{array}{c}\mathrm{N}=43 \\
1.0\end{array}$ & $\begin{array}{c}\mathrm{N}=45 \\
1.067 \\
(0.604-1.885)\end{array}$ & $\begin{array}{c}\mathrm{N}=39 \\
0.827 \\
(0.466-1.468)\end{array}$ & $\begin{array}{c}\mathrm{N}=127 \\
1.000 \\
(0.996-1.003)\end{array}$ & 1.0 & $\begin{array}{c}1.123 \\
(0.631-2.000)\end{array}$ & $\begin{array}{c}0.982 \\
(0.541-1.785)\end{array}$ & $\begin{array}{c}1.000 \\
(0.997-1.004)\end{array}$ & $\begin{array}{c}1.000 \\
(0.997-1.004)\end{array}$ \\
\hline
\end{tabular}


Table A.7f. Unadjusted and adjusted odds ratios for MetSyn components by tertiles of Spielberger Police Stress score for women. - DANGER STRESS INDEX FOR PAST MONTH

\begin{tabular}{|c|c|c|c|c|c|c|c|c|c|}
\hline \multirow{2}{*}{$\begin{array}{l}\text { MetSyn } \\
\text { Component }\end{array}$} & \multicolumn{4}{|c|}{$\begin{array}{c}\text { Unadjusted } \\
\text { OR }(95 \% \text { CI) }\end{array}$} & \multicolumn{4}{|c|}{$\begin{array}{l}\text { Age-Adjusted } \\
\text { OR }(95 \% \mathrm{CI})\end{array}$} & \multirow{2}{*}{$\begin{array}{c}\begin{array}{c}\text { Multivariate Adjusted } \\
\text { OR }(95 \% \mathrm{CI})^{*}\end{array} \\
\begin{array}{c}\text { Continuous } \\
(\mathrm{N}=)\end{array}\end{array}$} \\
\hline & $\begin{array}{l}\text { Level } 1 \\
(\mathrm{~N}=34)\end{array}$ & $\begin{array}{l}\text { Level } 2 \\
(\mathrm{~N}=34)\end{array}$ & $\begin{array}{l}\text { Level } 3 \\
(\mathrm{~N}=34)\end{array}$ & $\begin{array}{l}\text { Continuous } \\
(\mathrm{N}=102)\end{array}$ & $\begin{array}{l}\text { Level } 1 \\
(\mathrm{~N}=34)\end{array}$ & $\begin{array}{l}\text { Level } 2 \\
(\mathrm{~N}=34)\end{array}$ & $\begin{array}{l}\text { Level } 3 \\
(\mathrm{~N}=34)\end{array}$ & $\begin{array}{l}\text { Continuous } \\
(\mathrm{N}=102)\end{array}$ & \\
\hline \multirow{2}{*}{$\begin{array}{l}\text { Abdominal } \\
\text { Obesity }\end{array}$} & $\mathrm{N}=4$ & $\mathrm{~N}=5$ & $\mathrm{~N}=9$ & $\mathrm{~N}=18$ & & & & & \\
\hline & 1.0 & $\begin{array}{c}1.293 \\
(0.316-5.298)\end{array}$ & $\begin{array}{c}2.700 \\
(0.742-9.827)\end{array}$ & $\begin{array}{c}1.004 \\
(0.997-1.010)\end{array}$ & 1.0 & $\begin{array}{c}1.558 \\
(0.366-6.641)\end{array}$ & $\begin{array}{c}3.382 \\
(0.876-13.059)\end{array}$ & $\begin{array}{c}1.004 \\
(0.997-1.011)\end{array}$ & $\begin{array}{c}1.005 \\
(0.998-1.012)\end{array}$ \\
\hline Elevated & $\mathrm{N}=1$ & $\mathrm{~N}=4$ & $\mathrm{~N}=4$ & $\mathrm{~N}=9$ & & & & & \\
\hline Triglycerides & 1.0 & $\begin{array}{c}4.400 \\
(0.465-41.595)\end{array}$ & $\begin{array}{c}4.400 \\
(0.465-41.595)\end{array}$ & $\begin{array}{c}1.003 \\
(0.995-1.012)\end{array}$ & 1.0 & $\begin{array}{c}4.140 \\
(0.434-39.470)\end{array}$ & $\begin{array}{c}3.968 \\
(0.414-38.059)\end{array}$ & $\begin{array}{c}1.003 \\
(0.995-1.012)\end{array}$ & $\begin{array}{c}1.003 \\
(0.994-1.012)\end{array}$ \\
\hline Reduced & $\mathrm{N}=8$ & $\mathrm{~N}=9$ & $\mathrm{~N}=10$ & $\mathrm{~N}=27$ & & & & & \\
\hline HDL-C & 1.0 & $\begin{array}{c}1.170 \\
(0.390-3.512)\end{array}$ & $\begin{array}{c}1.354 \\
(0.459-3.998)\end{array}$ & $\begin{array}{c}1.004 \\
(0.998-1.010)\end{array}$ & 1.0 & $\begin{array}{c}1.189 \\
(0.394-3.588)\end{array}$ & $\begin{array}{c}1.381 \\
(0.464-4.109)\end{array}$ & $\begin{array}{c}1.004 \\
(0.998-1.010)\end{array}$ & $\begin{array}{c}1.004 \\
(0.998-1.010)\end{array}$ \\
\hline Glucose & $\mathrm{N}=4$ & $\mathrm{~N}=3$ & $\mathrm{~N}=5$ & $\mathrm{~N}=12$ & & & & & \\
\hline Intolerance & 1.0 & $\begin{array}{c}0.726 \\
(0.150-1.520)\end{array}$ & $\begin{array}{c}1.293 \\
(0.316-5.299)\end{array}$ & $\begin{array}{c}1.003 \\
(0.995-1.011)\end{array}$ & 1.0 & $\begin{array}{c}0.756 \\
(0.154-3.697)\end{array}$ & $\begin{array}{c}1.355 \\
(0.327-5.621)\end{array}$ & $\begin{array}{c}1.003 \\
(0.996-1.011)\end{array}$ & $\begin{array}{c}1.003 \\
(0.996-1.011)\end{array}$ \\
\hline Hypertension & $\begin{array}{c}\mathrm{N}=10 \\
1.0\end{array}$ & $\begin{array}{c}\mathrm{N}=9 \\
0.864 \\
(0.299-2.495)\end{array}$ & $\begin{array}{c}\mathrm{N}=8 \\
0.738 \\
(0.250-2.180)\end{array}$ & $\begin{array}{c}\mathrm{N}=27 \\
0.999 \\
(0.993-1.005)\end{array}$ & 1.0 & $\begin{array}{c}0.966 \\
(0.326-2.861)\end{array}$ & $\begin{array}{c}0.826 \\
(0.272-2.511)\end{array}$ & $\begin{array}{c}0.999 \\
(0.993-1.005)\end{array}$ & $\begin{array}{c}0.999 \\
(0.992-1.005)\end{array}$ \\
\hline
\end{tabular}


Table A.7g. Unadjusted and adjusted odds ratios for MetSyn components by tertiles of Spielberger Police Stress score for men. - SUPPORT STRESS INDEX FOR PAST MONTH

\begin{tabular}{|c|c|c|c|c|c|c|c|c|c|}
\hline \multirow{2}{*}{$\begin{array}{l}\text { MetSyn } \\
\text { Component }\end{array}$} & \multicolumn{4}{|c|}{$\begin{array}{c}\text { Unadjusted } \\
\text { OR }(95 \% \text { CI })\end{array}$} & \multicolumn{4}{|c|}{$\begin{array}{l}\text { Age-Adjusted } \\
\text { OR }(95 \% \text { CI })\end{array}$} & \multirow{2}{*}{$\begin{array}{c}\begin{array}{c}\text { Multivariate Adjusted } \\
\text { OR }(95 \% \mathrm{CI})^{*}\end{array} \\
\begin{array}{c}\text { Continuous } \\
(\mathrm{N}=)\end{array}\end{array}$} \\
\hline & $\begin{array}{l}\text { Level } 1 \\
(\mathrm{~N}=96)\end{array}$ & $\begin{array}{l}\text { Level } 2 \\
(\mathrm{~N}=97)\end{array}$ & $\begin{array}{l}\text { Level } 3 \\
(\mathrm{~N}=95)\end{array}$ & $\begin{array}{l}\text { Continuous } \\
(\mathrm{N}=288)\end{array}$ & $\begin{array}{l}\text { Level } 1 \\
(\mathrm{~N}=96)\end{array}$ & $\begin{array}{l}\text { Level } 2 \\
(\mathrm{~N}=97)\end{array}$ & $\begin{array}{l}\text { Level } 3 \\
(\mathrm{~N}=95)\end{array}$ & $\begin{array}{l}\text { Continuous } \\
(\mathrm{N}=288)\end{array}$ & \\
\hline Abdominal & $\mathrm{N}=37$ & $\mathrm{~N}=34$ & $\mathrm{~N}=41$ & $\mathrm{~N}=112$ & & & & & \\
\hline Obesity & 1.0 & $\begin{array}{c}0.861 \\
(0.479-1.546)\end{array}$ & $\begin{array}{c}1.211 \\
(0.679-2.157)\end{array}$ & $\begin{array}{c}1.002 \\
(0.999-1.005)\end{array}$ & 1.0 & $\begin{array}{c}0.882 \\
(0.489-1.590)\end{array}$ & $\begin{array}{c}1.172 \\
(0.655-2.097)\end{array}$ & $\begin{array}{c}1.002 \\
(0.999-1.005)\end{array}$ & $\begin{array}{c}1.002 \\
(0.999-1.005)\end{array}$ \\
\hline Elevated & $\mathrm{N}=32$ & $\mathrm{~N}=39$ & $\mathrm{~N}=43$ & $\mathrm{~N}=114$ & & & & & \\
\hline Triglycerides & 1.0 & $\begin{array}{c}1.345 \\
(0.748-2.419)\end{array}$ & $\begin{array}{c}1.654 \\
(0.921-2.971)\end{array}$ & $\begin{array}{c}1.002 \\
(1.000-1.005)\end{array}$ & 1.0 & $\begin{array}{c}1.380 \\
(0.764-2.492)\end{array}$ & $\begin{array}{c}1.611 \\
(0.894-2.903)\end{array}$ & $\begin{array}{c}1.002 \\
(0.999-1.005)\end{array}$ & $\begin{array}{c}1.002 \\
(0.999-1.005)\end{array}$ \\
\hline Reduced & $\mathrm{N}=52$ & $\mathrm{~N}=52$ & $\mathrm{~N}=35$ & $\mathrm{~N}=139$ & & & & & \\
\hline HDL-C & 1.0 & $\begin{array}{c}0.978 \\
(0.555-1.722)\end{array}$ & $\begin{array}{c}0.494 \\
(0.277-0.880)\end{array}$ & $\begin{array}{c}0.998 \\
(0.996-1.001)\end{array}$ & 1.0 & $\begin{array}{c}0.993 \\
(0.563-1.753)\end{array}$ & $\begin{array}{c}0.481 \\
(0.269-0.861)\end{array}$ & $\begin{array}{c}0.998 \\
(0.996-1.001)\end{array}$ & $\begin{array}{c}0.998 \\
(0.995-1.001)\end{array}$ \\
\hline Glucose & $\mathrm{N}=22$ & $\mathrm{~N}=32$ & $\mathrm{~N}=26$ & $\mathrm{~N}=80$ & & & & & \\
\hline Intolerance & 1.0 & $\begin{array}{c}1.656 \\
(0.876-3.131)\end{array}$ & $\begin{array}{c}1.267 \\
(0.658-2.442)\end{array}$ & $\begin{array}{c}1.001 \\
(0.998-1.004)\end{array}$ & 1.0 & $\begin{array}{c}1.799 \\
(0.935-3.461)\end{array}$ & $\begin{array}{c}1.205 \\
(0.618-2.351)\end{array}$ & $\begin{array}{c}1.001 \\
(0.998-1.004)\end{array}$ & $\begin{array}{c}1.001 \\
(0.998-1.004)\end{array}$ \\
\hline Hypertension & $\begin{array}{c}\mathrm{N}=44 \\
1.0\end{array}$ & $\begin{array}{c}\mathrm{N}=40 \\
0.829 \\
(0.469-1.466)\end{array}$ & $\begin{array}{c}\mathrm{N}=43 \\
0.977 \\
(0.553-1.727)\end{array}$ & $\begin{array}{c}\mathrm{N}=127 \\
1.001 \\
(0.998-1.004)\end{array}$ & 1.0 & $\begin{array}{c}0.855 \\
(0.480-1.521)\end{array}$ & $\begin{array}{c}0.932 \\
(0.524-1.659)\end{array}$ & $\begin{array}{c}1.000 \\
(0.998-1.003)\end{array}$ & $\begin{array}{c}1.000 \\
(0.998-1.003)\end{array}$ \\
\hline
\end{tabular}


Table A.7h. Unadjusted and adjusted odds ratios for MetSyn components by tertiles of Spielberger Police Stress score for women. - SUPPORT STRESS INDEX FOR PAST MONTH

\begin{tabular}{|c|c|c|c|c|c|c|c|c|c|}
\hline \multirow{2}{*}{$\begin{array}{l}\text { MetSyn } \\
\text { Component }\end{array}$} & \multicolumn{4}{|c|}{$\begin{array}{c}\text { Unadjusted } \\
\text { OR (95\% CI) }\end{array}$} & \multicolumn{4}{|c|}{$\begin{array}{l}\text { Age-Adjusted } \\
\text { OR (95\% CI) }\end{array}$} & \multirow{2}{*}{$\begin{array}{c}\begin{array}{c}\text { Multivariate Adjusted } \\
\text { OR }(95 \% \mathrm{CI})^{*}\end{array} \\
\begin{array}{c}\text { Continuous } \\
(\mathrm{N}=)\end{array}\end{array}$} \\
\hline & $\begin{array}{l}\text { Level } 1 \\
(\mathrm{~N}=34)\end{array}$ & $\begin{array}{l}\text { Level } 2 \\
(\mathrm{~N}=34)\end{array}$ & $\begin{array}{l}\text { Level } 3 \\
(\mathrm{~N}=34)\end{array}$ & $\begin{array}{l}\text { Continuous } \\
(\mathrm{N}=102)\end{array}$ & $\begin{array}{l}\text { Level } 1 \\
(\mathrm{~N}=34)\end{array}$ & $\begin{array}{l}\text { Level } 2 \\
(\mathrm{~N}=34)\end{array}$ & $\begin{array}{l}\text { Level } 3 \\
(\mathrm{~N}=34)\end{array}$ & $\begin{array}{l}\text { Continuous } \\
(\mathrm{N}=102)\end{array}$ & \\
\hline Abdominal & $\mathrm{N}=3$ & $\mathrm{~N}=4$ & $\mathrm{~N}=11$ & $\mathrm{~N}=18$ & & & & & \\
\hline Obesity & 1.0 & $\begin{array}{c}1.378 \\
(0.284-6.681)\end{array}$ & $\begin{array}{c}4.942 \\
(1.236-19.758)\end{array}$ & $\begin{array}{c}1.004 \\
(1.000-1.009)\end{array}$ & 1.0 & $\begin{array}{c}1.166 \\
(0.231-5.874)\end{array}$ & $\begin{array}{c}5.197 \\
(1.255-21.519)\end{array}$ & $\begin{array}{c}1.005 \\
(1.000-1.010)\end{array}$ & $\begin{array}{c}1.007 \\
(1.001-1.013)\end{array}$ \\
\hline Elevated & $\mathrm{N}=3$ & $\mathrm{~N}=0$ & $\mathrm{~N}=6$ & $\mathrm{~N}=9$ & & & & & \\
\hline Triglycerides & 1.0 & - & $\begin{array}{c}2.214 \\
(0.506-9.699)\end{array}$ & $\begin{array}{c}1.003 \\
(0.997-1.009)\end{array}$ & 1.0 & - & $\begin{array}{c}2.203 \\
(0.496-9.779)\end{array}$ & $\begin{array}{c}1.003 \\
(0.997-1.009)\end{array}$ & $\begin{array}{c}1.003 \\
(0.996-1.009)\end{array}$ \\
\hline Reduced & $\mathrm{N}=7$ & $\mathrm{~N}=7$ & $\mathrm{~N}=13$ & $\mathrm{~N}=27$ & & & & & \\
\hline HDL-C & 1.0 & $\begin{array}{c}1.000 \\
(0.309-3.240)\end{array}$ & $\begin{array}{c}2.388 \\
(0.810-7.041)\end{array}$ & $\begin{array}{c}1.006 \\
(1.002-1.011)\end{array}$ & 1.0 & $\begin{array}{c}0.988 \\
(0.304-3.211)\end{array}$ & $\begin{array}{c}2.388 \\
(0.809-7.045)\end{array}$ & $\begin{array}{c}1.006 \\
(1.002-1.011)\end{array}$ & $\begin{array}{c}1.006 \\
(1.001-1.011)\end{array}$ \\
\hline Glucose & $\mathrm{N}=2$ & $\mathrm{~N}=4$ & $\mathrm{~N}=6$ & $\mathrm{~N}=12$ & & & & & \\
\hline Intolerance & 1.0 & $\begin{array}{c}2.133 \\
(0.364-12.509)\end{array}$ & $\begin{array}{c}3.428 \\
(0.640-18.371)\end{array}$ & $\begin{array}{c}1.005 \\
(0.999-1.010)\end{array}$ & 1.0 & $\begin{array}{c}2.069 \\
(0.351-12.208)\end{array}$ & $\begin{array}{c}3.424 \\
(0.638-18.377)\end{array}$ & $\begin{array}{c}1.005 \\
(0.999-1.010)\end{array}$ & $\begin{array}{c}1.005 \\
(0.999-1.011)\end{array}$ \\
\hline Hypertension & $\begin{array}{c}\mathrm{N}=8 \\
1.0\end{array}$ & $\begin{array}{c}\mathrm{N}=11 \\
1.554 \\
(0.533-4.530)\end{array}$ & $\begin{array}{c}\mathrm{N}=8 \\
1.000 \\
(0.326-3.067)\end{array}$ & $\begin{array}{c}\mathrm{N}=27 \\
0.997 \\
(0.991-1.002)\end{array}$ & 1.0 & $\begin{array}{c}1.431 \\
(0.479-4.274)\end{array}$ & $\begin{array}{c}0.981 \\
(0.314-3.068)\end{array}$ & $\begin{array}{c}0.997 \\
(0.991-1.003)\end{array}$ & $\begin{array}{c}0.996 \\
(0.990-1.002)\end{array}$ \\
\hline
\end{tabular}


Table A.8a. Unadjusted and adjusted odds ratios for MetSyn components by tertiles of Spielberger Police Stress score for men. - TOTAL STRESS INDEX FOR PAST YEAR

\begin{tabular}{|c|c|c|c|c|c|c|c|c|c|}
\hline \multirow{2}{*}{$\begin{array}{l}\text { MetSyn } \\
\text { Component }\end{array}$} & \multicolumn{4}{|c|}{$\begin{array}{c}\text { Unadjusted } \\
\text { OR }(95 \% \mathrm{CI})\end{array}$} & \multicolumn{4}{|c|}{$\begin{array}{l}\text { Age-Adjusted } \\
\text { OR }(95 \% \text { CI })\end{array}$} & \multirow{2}{*}{$\begin{array}{c}\begin{array}{c}\text { Multivariate Adjusted } \\
\text { OR }(95 \% \mathrm{CI})^{*}\end{array} \\
\begin{array}{c}\text { Continuous } \\
(\mathrm{N}=)\end{array}\end{array}$} \\
\hline & $\begin{array}{l}\text { Level } 1 \\
(\mathrm{~N}=96)\end{array}$ & $\begin{array}{l}\text { Level } 2 \\
(\mathrm{~N}=96)\end{array}$ & $\begin{array}{l}\text { Level } 3 \\
(\mathrm{~N}=96)\end{array}$ & $\begin{array}{l}\text { Continuous } \\
(\mathrm{N}=288)\end{array}$ & $\begin{array}{l}\text { Level } 1 \\
(\mathrm{~N}=96)\end{array}$ & $\begin{array}{l}\text { Level } 2 \\
(\mathrm{~N}=96)\end{array}$ & $\begin{array}{l}\text { Level } 3 \\
(\mathrm{~N}=96)\end{array}$ & $\begin{array}{l}\text { Continuous } \\
(\mathrm{N}=288)\end{array}$ & \\
\hline Abdominal & $\mathrm{N}=36$ & $\mathrm{~N}=37$ & $\mathrm{~N}=39$ & $\mathrm{~N}=112$ & & & & & \\
\hline Obesity & 1.0 & $\begin{array}{c}1.045 \\
(0.584-1.872)\end{array}$ & $\begin{array}{c}1.140 \\
(0.638-2.037)\end{array}$ & $\begin{array}{c}1.000 \\
(0.999-1.001)\end{array}$ & 1.0 & $\begin{array}{c}1.086 \\
(0.603-1.956)\end{array}$ & $\begin{array}{c}1.245 \\
(0.690-2.249)\end{array}$ & $\begin{array}{c}1.001 \\
(1.000-1.002)\end{array}$ & $\begin{array}{c}1.001 \\
(1.000-1.002)\end{array}$ \\
\hline Elevated & $\mathrm{N}=32$ & $\mathrm{~N}=40$ & $\mathrm{~N}=42$ & $\mathrm{~N}=114$ & & & & & \\
\hline Triglycerides & 1.0 & $\begin{array}{c}1.429 \\
(0.794-2.570)\end{array}$ & $\begin{array}{c}1.556 \\
(0.866-2.793)\end{array}$ & $\begin{array}{c}1.000 \\
(0.999-1.001)\end{array}$ & 1.0 & $\begin{array}{c}1.488 \\
(0.822-2.692)\end{array}$ & $\begin{array}{c}1.699 \\
(0.935-3.087)\end{array}$ & $\begin{array}{c}1.001 \\
(1.000-1.002)\end{array}$ & $\begin{array}{c}1.001 \\
(1.000-1.002)\end{array}$ \\
\hline Reduced & $\mathrm{N}=56$ & $\mathrm{~N}=44$ & $\mathrm{~N}=39$ & $\mathrm{~N}=139$ & & & & & \\
\hline HDL-C & 1.0 & $\begin{array}{c}0.604 \\
(0.342-1.070)\end{array}$ & $\begin{array}{c}0.489 \\
(0.275-0.868)\end{array}$ & $\begin{array}{c}0.999 \\
(0.998-1.000)\end{array}$ & 1.0 & $\begin{array}{c}0.610 \\
(0.344-1.080)\end{array}$ & $\begin{array}{c}0.499 \\
(0.279-0.892)\end{array}$ & $\begin{array}{c}0.999 \\
(0.998-1.000)\end{array}$ & $\begin{array}{c}0.999 \\
(0.998-1.000)\end{array}$ \\
\hline Glucose & $\mathrm{N}=29$ & $\mathrm{~N}=28$ & $\mathrm{~N}=23$ & $\mathrm{~N}=80$ & & & & & \\
\hline Intolerance & $\begin{array}{c}1.0 \\
\mathrm{~N}=42\end{array}$ & $\begin{array}{c}0.951 \\
(0.512-1.767) \\
\mathrm{N}=39\end{array}$ & $\begin{array}{c}0.728 \\
(0.384-1.380) \\
\mathrm{N}=46\end{array}$ & $\begin{array}{c}0.999 \\
(0.998-1.001) \\
\mathrm{N}=127\end{array}$ & 1.0 & $\begin{array}{c}1.013 \\
(0.538-1.905)\end{array}$ & $\begin{array}{c}0.837 \\
(0.435-1.614)\end{array}$ & $\begin{array}{c}1.000 \\
(0.999-1.001)\end{array}$ & $\begin{array}{c}1.000 \\
(0.999-1.001)\end{array}$ \\
\hline Hypertension & 1.0 & $\begin{array}{c}0.880 \\
(0.496-1.560)\end{array}$ & $\begin{array}{c}1.183 \\
(0.670-2.088)\end{array}$ & $\begin{array}{c}1.000 \\
(0.999-1.001)\end{array}$ & 1.0 & $\begin{array}{c}0.921 \\
(0.515-1.646)\end{array}$ & $\begin{array}{c}1.325 \\
(0.740-2.371)\end{array}$ & $\begin{array}{c}1.000 \\
(0.999-1.001)\end{array}$ & $\begin{array}{c}1.000 \\
(0.999-1.001)\end{array}$ \\
\hline
\end{tabular}


Table A.8b. Unadjusted and adjusted odds ratios for MetSyn components by tertiles of Spielberger Police Stress score for women. - TOTAL STRESS INDEX FOR PAST YEAR

\begin{tabular}{|c|c|c|c|c|c|c|c|c|c|}
\hline \multirow{2}{*}{$\begin{array}{l}\text { MetSyn } \\
\text { Component }\end{array}$} & \multicolumn{4}{|c|}{$\begin{array}{c}\text { Unadjusted } \\
\text { OR }(95 \% \mathrm{CI})\end{array}$} & \multicolumn{4}{|c|}{$\begin{array}{l}\text { Age-Adjusted } \\
\text { OR }(95 \% \text { CI })\end{array}$} & \multirow{2}{*}{$\begin{array}{c}\begin{array}{c}\text { Multivariate Adjusted } \\
\text { OR }(95 \% \mathrm{CI})^{*}\end{array} \\
\begin{array}{c}\text { Continuous } \\
(\mathrm{N}=)\end{array}\end{array}$} \\
\hline & $\begin{array}{l}\text { Level } 1 \\
(\mathrm{~N}=34)\end{array}$ & $\begin{array}{l}\text { Level } 2 \\
(\mathrm{~N}=34)\end{array}$ & $\begin{array}{l}\text { Level } 3 \\
(\mathrm{~N}=34)\end{array}$ & $\begin{array}{l}\text { Continuous } \\
(\mathrm{N}=102)\end{array}$ & $\begin{array}{l}\text { Level } 1 \\
(\mathrm{~N}=34)\end{array}$ & $\begin{array}{l}\text { Level } 2 \\
(\mathrm{~N}=34)\end{array}$ & $\begin{array}{l}\text { Level } 3 \\
(\mathrm{~N}=34)\end{array}$ & $\begin{array}{l}\text { Continuous } \\
(\mathrm{N}=102)\end{array}$ & \\
\hline Abdominal & $\mathrm{N}=3$ & $\mathrm{~N}=6$ & $\mathrm{~N}=9$ & $\mathrm{~N}=18$ & & & & & \\
\hline Obesity & 1.0 & $\begin{array}{c}2.214 \\
(0.505-9.698)\end{array}$ & $\begin{array}{c}3.720 \\
(0.909-15.218)\end{array}$ & $\begin{array}{c}1.001 \\
(1.000-1.003)\end{array}$ & 1.0 & $\begin{array}{c}2.704 \\
(0.599-12.213)\end{array}$ & $\begin{array}{c}3.917 \\
(0.932-16.467)\end{array}$ & $\begin{array}{c}1.001 \\
(0.999-1.003)\end{array}$ & $\begin{array}{c}1.001 \\
(0.999-1.003)\end{array}$ \\
\hline Elevated & $\mathrm{N}=1$ & $\mathrm{~N}=4$ & $\mathrm{~N}=4$ & $\mathrm{~N}=9$ & & & & & \\
\hline Triglycerides & 1.0 & $\begin{array}{c}4.400 \\
(0.465-41.595)\end{array}$ & $\begin{array}{c}4.400 \\
(0.465-41.595)\end{array}$ & $\begin{array}{c}1.001 \\
(0.998-1.003)\end{array}$ & 1.0 & $\begin{array}{c}3.769 \\
(0.387-36.679)\end{array}$ & $\begin{array}{c}4.177 \\
(0.438-39.869)\end{array}$ & $\begin{array}{c}1.001 \\
(0.998-1.003)\end{array}$ & $\begin{array}{c}1.001 \\
(0.998-1.003)\end{array}$ \\
\hline Reduced & $\mathrm{N}=9$ & $\mathrm{~N}=6$ & $\mathrm{~N}=12$ & $\mathrm{~N}=27$ & & & & & \\
\hline HDL-C & 1.0 & $\begin{array}{c}0.595 \\
(0.186-1.909)\end{array}$ & $\begin{array}{c}1.515 \\
(0.537-4.274)\end{array}$ & $\begin{array}{c}1.002 \\
(1.000-1.003)\end{array}$ & 1.0 & $\begin{array}{c}0.597 \\
(0.184-1.940)\end{array}$ & $\begin{array}{c}1.516 \\
(0.537-4.281)\end{array}$ & $\begin{array}{c}1.002 \\
(1.000-1.003)\end{array}$ & $\begin{array}{c}1.002 \\
(1.000-1.003)\end{array}$ \\
\hline Glucose & $\mathrm{N}=4$ & $\mathrm{~N}=2$ & $\mathrm{~N}=6$ & $\mathrm{~N}=12$ & & & & & \\
\hline Intolerance & 1.0 & $\begin{array}{c}0.469 \\
(0.080-2.749)\end{array}$ & $\begin{array}{c}1.607 \\
(0.410-6.299)\end{array}$ & $\begin{array}{c}1.001 \\
(0.999-1.003)\end{array}$ & 1.0 & $\begin{array}{c}0.488 \\
(0.082-2.900)\end{array}$ & $\begin{array}{c}1.621 \\
(0.413-6.364)\end{array}$ & $\begin{array}{c}1.001 \\
(0.999-1.003)\end{array}$ & $\begin{array}{c}1.001 \\
(0.999-1.003)\end{array}$ \\
\hline Hypertension & $\begin{array}{c}\mathrm{N}=9 \\
1.0\end{array}$ & $\begin{array}{c}\mathrm{N}=10 \\
1.157 \\
(0.401-3.342)\end{array}$ & $\begin{array}{c}\mathrm{N}=8 \\
0.855 \\
(0.285-2.566)\end{array}$ & $\begin{array}{c}\mathrm{N}=27 \\
0.999 \\
(0.998-1.001)\end{array}$ & 1.0 & $\begin{array}{c}1.381 \\
(0.463-4.121)\end{array}$ & $\begin{array}{c}0.860 \\
(0.280-2.648)\end{array}$ & $\begin{array}{c}0.999 \\
(0.998-1.001)\end{array}$ & $\begin{array}{c}0.999 \\
(0.998-1.001)\end{array}$ \\
\hline
\end{tabular}


Table A.8c. Unadjusted and adjusted odds ratios for MetSyn components by tertiles of Spielberger Police Stress score for men. - ADMINISTRATIVE STRESS INDEX FOR PAST YEAR

\begin{tabular}{|c|c|c|c|c|c|c|c|c|c|}
\hline \multirow{2}{*}{$\begin{array}{l}\text { MetSyn } \\
\text { Component }\end{array}$} & \multicolumn{4}{|c|}{$\begin{array}{c}\text { Unadjusted } \\
\text { OR }(95 \% \text { CI) }\end{array}$} & \multicolumn{4}{|c|}{$\begin{array}{l}\text { Age-Adjusted } \\
\text { OR }(95 \% \text { CI })\end{array}$} & \multirow{2}{*}{$\begin{array}{c}\text { Multivariate Adjusted } \\
\text { OR }(95 \% \mathrm{CI})^{*} \\
\begin{array}{c}\text { Continuous } \\
(\mathrm{N}=)\end{array}\end{array}$} \\
\hline & $\begin{array}{l}\text { Level } 1 \\
(\mathrm{~N}=95)\end{array}$ & $\begin{array}{l}\text { Level } 2 \\
(\mathrm{~N}=96)\end{array}$ & $\begin{array}{l}\text { Level } 3 \\
(\mathrm{~N}=96)\end{array}$ & $\begin{array}{l}\text { Continuous } \\
(\mathrm{N}=287)\end{array}$ & $\begin{array}{l}\text { Level } 1 \\
(\mathrm{~N}=95)\end{array}$ & $\begin{array}{l}\text { Level } 2 \\
(\mathrm{~N}=96)\end{array}$ & $\begin{array}{l}\text { Level } 3 \\
(\mathrm{~N}=96)\end{array}$ & $\begin{array}{l}\text { Continuous } \\
(\mathrm{N}=287)\end{array}$ & \\
\hline Abdominal & $\mathrm{N}=39$ & $\mathrm{~N}=36$ & $\mathrm{~N}=37$ & $\mathrm{~N}=112$ & & & & & \\
\hline Obesity & 1.0 & $\begin{array}{c}0.862 \\
(0.482-1.541)\end{array}$ & $\begin{array}{c}0.900 \\
(0.504-1.608)\end{array}$ & $\begin{array}{c}1.000 \\
(0.999-1.001)\end{array}$ & 1.0 & $\begin{array}{c}0.881 \\
(0.491-1.582)\end{array}$ & $\begin{array}{c}0.977 \\
(0.542-1.761)\end{array}$ & $\begin{array}{c}1.000 \\
(0.999-1.001)\end{array}$ & $\begin{array}{c}1.000 \\
(1.000-1.001)\end{array}$ \\
\hline Elevated & $\mathrm{N}=34$ & $\mathrm{~N}=41$ & $\mathrm{~N}=39$ & $\mathrm{~N}=114$ & & & & & \\
\hline Triglycerides & 1.0 & $\begin{array}{c}1.337 \\
(0.747-2.395)\end{array}$ & $\begin{array}{c}1.228 \\
(0.684-2.203)\end{array}$ & $\begin{array}{c}1.000 \\
(1.000-1.001)\end{array}$ & 1.0 & $\begin{array}{c}1.373 \\
(0.763-2.469)\end{array}$ & $\begin{array}{c}1.329 \\
(0.733-2.410)\end{array}$ & $\begin{array}{c}1.000 \\
(1.000-1.001)\end{array}$ & $\begin{array}{c}1.000 \\
(1.000-1.001)\end{array}$ \\
\hline Reduced & $\mathrm{N}=57$ & $\mathrm{~N}=45$ & $\mathrm{~N}=37$ & $\mathrm{~N}=139$ & & & & & \\
\hline HDL-C & 1.0 & $\begin{array}{c}0.588 \\
(0.331-1.004)\end{array}$ & $\begin{array}{c}0.418 \\
(0.234-0.747)\end{array}$ & $\begin{array}{c}0.999 \\
(0.998-1.000)\end{array}$ & 1.0 & $\begin{array}{c}0.591 \\
(0.333-1.050)\end{array}$ & $\begin{array}{c}0.426 \\
(0.237-0.766)\end{array}$ & $\begin{array}{c}0.999 \\
(0.998-1.000)\end{array}$ & $\begin{array}{c}0.999 \\
(0.998-1.000)\end{array}$ \\
\hline Glucose & $\mathrm{N}=28$ & $\mathrm{~N}=29$ & $\mathrm{~N}=22$ & $\mathrm{~N}=79$ & & & & & \\
\hline Intolerance & 1.0 & $\begin{array}{c}1.036 \\
(0.557-1.925)\end{array}$ & $\begin{array}{c}0.711 \\
(0.372-1.361)\end{array}$ & $\begin{array}{c}1.000 \\
(0.999-1.001)\end{array}$ & 1.0 & $\begin{array}{c}1.082 \\
(0.575-2.034)\end{array}$ & $\begin{array}{c}0.815 \\
(0.420-1.585)\end{array}$ & $\begin{array}{c}1.000 \\
(0.999-1.001)\end{array}$ & $\begin{array}{c}1.000 \\
(0.999-1.001)\end{array}$ \\
\hline Hypertension & $\begin{array}{c}\mathrm{N}=43 \\
1.0\end{array}$ & $\begin{array}{c}\mathrm{N}=41 \\
0.902 \\
(0.509-1.597)\end{array}$ & $\begin{array}{c}\mathrm{N}=43 \\
0.981 \\
(0.555-1.735)\end{array}$ & $\begin{array}{c}\mathrm{N}=127 \\
1.000 \\
(0.999-1.001)\end{array}$ & 1.0 & $\begin{array}{c}0.929 \\
(0.521-1.656)\end{array}$ & $\begin{array}{c}1.091 \\
(0.610-1.954)\end{array}$ & $\begin{array}{c}1.000 \\
(0.999-1.001)\end{array}$ & $\begin{array}{c}1.000 \\
(0.999-1.001)\end{array}$ \\
\hline
\end{tabular}


Table A.8d. Unadjusted and adjusted odds ratios for MetSyn components by tertiles of Spielberger Police Stress score for women. - ADMINISTRATIVE STRESS INDEX FOR PAST YEAR

\begin{tabular}{|c|c|c|c|c|c|c|c|c|c|}
\hline \multirow{2}{*}{$\begin{array}{l}\text { MetSyn } \\
\text { Component }\end{array}$} & \multicolumn{4}{|c|}{$\begin{array}{c}\text { Unadjusted } \\
\text { OR }(95 \% \mathrm{CI})\end{array}$} & \multicolumn{4}{|c|}{$\begin{array}{l}\text { Age-Adjusted } \\
\text { OR }(95 \% \mathrm{CI})\end{array}$} & \multirow{2}{*}{$\begin{array}{c}\text { Multivariate Adjusted } \\
\text { OR }(95 \% \mathrm{CI})^{*} \\
\begin{array}{c}\text { Continuous } \\
(\mathrm{N}=)\end{array}\end{array}$} \\
\hline & $\begin{array}{l}\text { Level } 1 \\
(\mathrm{~N}=34)\end{array}$ & $\begin{array}{l}\text { Level } 2 \\
(\mathrm{~N}=34)\end{array}$ & $\begin{array}{l}\text { Level } 3 \\
(\mathrm{~N}=34)\end{array}$ & $\begin{array}{l}\text { Continuous } \\
(\mathrm{N}=102)\end{array}$ & $\begin{array}{l}\text { Level } 1 \\
(\mathrm{~N}=34)\end{array}$ & $\begin{array}{l}\text { Level } 2 \\
(\mathrm{~N}=34)\end{array}$ & $\begin{array}{l}\text { Level } 3 \\
(\mathrm{~N}=34)\end{array}$ & $\begin{array}{l}\text { Continuous } \\
(\mathrm{N}=102)\end{array}$ & \\
\hline Abdominal & $\mathrm{N}=2$ & $\mathrm{~N}=8$ & $\mathrm{~N}=8$ & $\mathrm{~N}=18$ & & & & & \\
\hline Obesity & 1.0 & $\begin{array}{c}4.923 \\
(0.961-25.218)\end{array}$ & $\begin{array}{c}4.923 \\
(0.961-25.218)\end{array}$ & $\begin{array}{c}1.001 \\
(1.000-1.003)\end{array}$ & 1.0 & $\begin{array}{c}5.006 \\
(0.957-26.196)\end{array}$ & $\begin{array}{c}5.325 \\
(1.011-28.048)\end{array}$ & $\begin{array}{c}1.001 \\
(1.000-1.003)\end{array}$ & $\begin{array}{c}1.002 \\
(1.000-1.003)\end{array}$ \\
\hline Elevated & $\mathrm{N}=2$ & $\mathrm{~N}=3$ & $\mathrm{~N}=4$ & $\mathrm{~N}=9$ & & & & & \\
\hline Triglycerides & 1.0 & $\begin{array}{c}1.548 \\
(0.242-9.908)\end{array}$ & $\begin{array}{c}2.133 \\
(0.364-12.511)\end{array}$ & $\begin{array}{c}1.001 \\
(0.999-1.003)\end{array}$ & 1.0 & $\begin{array}{c}1.563 \\
(0.242-10.107)\end{array}$ & $\begin{array}{c}2.023 \\
(0.340-12.030)\end{array}$ & $\begin{array}{c}1.001 \\
(0.999-1.003)\end{array}$ & $\begin{array}{c}1.001 \\
(0.999-1.003)\end{array}$ \\
\hline Reduced & $\mathrm{N}=8$ & $\mathrm{~N}=5$ & $\mathrm{~N}=14$ & $\mathrm{~N}=27$ & & & & & \\
\hline HDL-C & 1.0 & $\begin{array}{c}0.560 \\
(0.163-1.929)\end{array}$ & $\begin{array}{c}2.275 \\
(0.799-6.476)\end{array}$ & $\begin{array}{c}1.001 \\
(1.000-1.003)\end{array}$ & 1.0 & $\begin{array}{c}0.558 \\
(0.162-1.923)\end{array}$ & $\begin{array}{c}2.297 \\
(0.805-6.553)\end{array}$ & $\begin{array}{c}1.001 \\
(1.000-1.003)\end{array}$ & $\begin{array}{c}1.001 \\
(1.000-1.003)\end{array}$ \\
\hline Glucose & $\mathrm{N}=4$ & $\mathrm{~N}=4$ & $\mathrm{~N}=4$ & $\mathrm{~N}=12$ & & & & & \\
\hline Intolerance & 1.0 & $\begin{array}{c}1.000 \\
(0.229-4.373)\end{array}$ & $\begin{array}{c}1.000 \\
(0.229-4.373)\end{array}$ & $\begin{array}{c}1.000 \\
(0.998-1.002)\end{array}$ & 1.0 & $\begin{array}{c}0.993 \\
(0.227-4.350)\end{array}$ & $\begin{array}{c}1.013 \\
(0.231-4.439)\end{array}$ & $\begin{array}{c}1.000 \\
(0.998-1.002)\end{array}$ & $\begin{array}{c}1.000 \\
(0.998-1.002)\end{array}$ \\
\hline Hypertension & $\begin{array}{l}\mathrm{N}=9 \\
1.0\end{array}$ & $\begin{array}{c}\mathrm{N}=10 \\
1.157 \\
(0.401-1.342)\end{array}$ & $\begin{array}{c}\mathrm{N}=8 \\
0.855 \\
(0.285-2.566)\end{array}$ & $\begin{array}{c}\mathrm{N}=27 \\
1.000 \\
(0.998-1.001)\end{array}$ & 1.0 & $\begin{array}{c}1.137 \\
(0.386-3.350)\end{array}$ & $\begin{array}{c}0.873 \\
(0.284-2.684)\end{array}$ & $\begin{array}{c}1.000 \\
(0.998-1.001)\end{array}$ & $\begin{array}{c}1.000 \\
(0.998-1.001)\end{array}$ \\
\hline
\end{tabular}


Table A.8e. Unadjusted and adjusted odds ratios for MetSyn components by tertiles of Spielberger Police Stress score for men. - DANGER STRESS INDEX FOR PAST YEAR

\begin{tabular}{|c|c|c|c|c|c|c|c|c|c|}
\hline \multirow{2}{*}{$\begin{array}{l}\text { MetSyn } \\
\text { Component }\end{array}$} & \multicolumn{4}{|c|}{$\begin{array}{c}\text { Unadjusted } \\
\text { OR (95\% CI) }\end{array}$} & \multicolumn{4}{|c|}{$\begin{array}{l}\text { Age-Adjusted } \\
\text { OR (95\% CI) }\end{array}$} & \multirow{2}{*}{$\begin{array}{c}\begin{array}{c}\text { Multivariate Adjusted } \\
\text { OR }(95 \% \mathrm{CI})^{*}\end{array} \\
\begin{array}{c}\text { Continuous } \\
(\mathrm{N}=)\end{array}\end{array}$} \\
\hline & $\begin{array}{l}\text { Level } 1 \\
(\mathrm{~N}=96)\end{array}$ & $\begin{array}{l}\text { Level } 2 \\
(\mathrm{~N}=95)\end{array}$ & $\begin{array}{l}\text { Level } 3 \\
(\mathrm{~N}=96)\end{array}$ & $\begin{array}{l}\text { Continuous } \\
(\mathrm{N}=287)\end{array}$ & $\begin{array}{l}\text { Level } 1 \\
(\mathrm{~N}=96)\end{array}$ & $\begin{array}{l}\text { Level } 2 \\
(\mathrm{~N}=95)\end{array}$ & $\begin{array}{l}\text { Level } 3 \\
(\mathrm{~N}=96)\end{array}$ & $\begin{array}{l}\text { Continuous } \\
(\mathrm{N}=288)\end{array}$ & \\
\hline Abdominal & $\mathrm{N}=38$ & $\mathrm{~N}=35$ & $\mathrm{~N}=38$ & $\mathrm{~N}=111$ & & & & & \\
\hline Obesity & 1.0 & $\begin{array}{c}0.890 \\
(0.496-1.597)\end{array}$ & $\begin{array}{c}1.000 \\
(0.561-1.783)\end{array}$ & $\begin{array}{c}1.000 \\
(0.999-1.001)\end{array}$ & 1.0 & $\begin{array}{c}0.912 \\
(0.506-1.643)\end{array}$ & $\begin{array}{c}1.131 \\
(0.623-2.053)\end{array}$ & $\begin{array}{c}1.000 \\
(0.999-1.001)\end{array}$ & $\begin{array}{c}1.001 \\
(1.000-1.002)\end{array}$ \\
\hline Elevated & $\mathrm{N}=33$ & $\mathrm{~N}=45$ & $\mathrm{~N}=35$ & $\mathrm{~N}=113$ & & & & & \\
\hline Triglycerides & 1.0 & $\begin{array}{c}1.718 \\
(0.959-3.077)\end{array}$ & $\begin{array}{c}1.095 \\
(0.606-1.979)\end{array}$ & $\begin{array}{c}1.000 \\
(0.999-1.001)\end{array}$ & 1.0 & $\begin{array}{c}1.763 \\
(0.981-3.171)\end{array}$ & $\begin{array}{c}1.214 \\
(0.661-2.230)\end{array}$ & $\begin{array}{c}1.000 \\
(0.999-1.001)\end{array}$ & $\begin{array}{c}1.000 \\
(0.999-1.001)\end{array}$ \\
\hline Reduced & $\mathrm{N}=54$ & $\mathrm{~N}=51$ & $\mathrm{~N}=33$ & $\mathrm{~N}=138$ & & & & & \\
\hline HDL-C & 1.0 & $\begin{array}{c}0.902 \\
(0.510-1.595)\end{array}$ & $\begin{array}{c}0.407 \\
(0.227-0.730)\end{array}$ & $\begin{array}{c}0.998 \\
(0.997-0.999)\end{array}$ & 1.0 & $\begin{array}{c}0.903 \\
(0.510-1.597)\end{array}$ & $\begin{array}{c}0.410 \\
(0.226-0.744)\end{array}$ & $\begin{array}{c}0.998 \\
(0.997-0.999)\end{array}$ & $\begin{array}{c}0.998 \\
(0.997-0.999)\end{array}$ \\
\hline Glucose & $\mathrm{N}=28$ & $\mathrm{~N}=32$ & $\mathrm{~N}=20$ & $\mathrm{~N}=80$ & & & & & \\
\hline Intolerance & 1.0 & $\begin{array}{c}1.234 \\
(0.669-2.275)\end{array}$ & $\begin{array}{c}0.639 \\
(0.330-1.237)\end{array}$ & $\begin{array}{c}0.999 \\
(0.998-1.000)\end{array}$ & 1.0 & $\begin{array}{c}1.297 \\
(0.695-2.420)\end{array}$ & $\begin{array}{c}0.776 \\
(0.392-1.536)\end{array}$ & $\begin{array}{c}0.999 \\
(0.998-1.001)\end{array}$ & $\begin{array}{c}0.999 \\
(0.998-1.001)\end{array}$ \\
\hline Hypertension & $\begin{array}{c}\mathrm{N}=41 \\
1.0\end{array}$ & $\begin{array}{c}\mathrm{N}=47 \\
1.314 \\
(0.743-2.323) \\
\end{array}$ & $\begin{array}{c}\mathrm{N}=39 \\
0.918 \\
(0.517-1.629) \\
\end{array}$ & $\begin{array}{c}\mathrm{N}=127 \\
1.000 \\
(0.999-1.001)\end{array}$ & 1.0 & $\begin{array}{c}1.361 \\
(0.764-2.425) \\
\end{array}$ & $\begin{array}{c}1.062 \\
(0.587-1.921) \\
\end{array}$ & $\begin{array}{c}1.000 \\
(0.999-1.001) \\
\end{array}$ & $\begin{array}{c}1.000 \\
(0.999-1.001) \\
\end{array}$ \\
\hline
\end{tabular}


Table A.8f. Unadjusted and adjusted odds ratios for MetSyn components by tertiles of Spielberger Police Stress score for women. - DANGER STRESS INDEX FOR PAST YEAR

\begin{tabular}{|c|c|c|c|c|c|c|c|c|c|}
\hline \multirow{2}{*}{$\begin{array}{l}\text { MetSyn } \\
\text { Component }\end{array}$} & \multicolumn{4}{|c|}{$\begin{array}{c}\text { Unadjusted } \\
\text { OR }(95 \% \mathrm{CI})\end{array}$} & \multicolumn{4}{|c|}{$\begin{array}{l}\text { Age-Adjusted } \\
\text { OR }(95 \% \text { CI })\end{array}$} & \multirow{2}{*}{$\begin{array}{c}\text { Multivariate Adjusted } \\
\text { OR }(95 \% \mathrm{CI})^{*} \\
\begin{array}{c}\text { Continuous } \\
(\mathrm{N}=)\end{array}\end{array}$} \\
\hline & $\begin{array}{l}\text { Level } 1 \\
(\mathrm{~N}=34)\end{array}$ & $\begin{array}{l}\text { Level } 2 \\
(\mathrm{~N}=34)\end{array}$ & $\begin{array}{l}\text { Level } 3 \\
(\mathrm{~N}=34)\end{array}$ & $\begin{array}{l}\text { Continuous } \\
(\mathrm{N}=102)\end{array}$ & $\begin{array}{l}\text { Level } 1 \\
(\mathrm{~N}=34)\end{array}$ & $\begin{array}{l}\text { Level } 2 \\
(\mathrm{~N}=34)\end{array}$ & $\begin{array}{l}\text { Level } 3 \\
(\mathrm{~N}=34)\end{array}$ & $\begin{array}{l}\text { Continuous } \\
(\mathrm{N}=102)\end{array}$ & \\
\hline Abdominal & $\mathrm{N}=5$ & $\mathrm{~N}=5$ & $\mathrm{~N}=8$ & $\mathrm{~N}=18$ & & & & & \\
\hline Obesity & 1.0 & $\begin{array}{c}1.000 \\
(0.261-3.827)\end{array}$ & $\begin{array}{c}1.785 \\
(0.518-6.145)\end{array}$ & $\begin{array}{c}1.001 \\
(0.999-1.003)\end{array}$ & 1.0 & $\begin{array}{c}1.137 \\
(0.289-4.473)\end{array}$ & $\begin{array}{c}1.768 \\
(0.500-6.247)\end{array}$ & $\begin{array}{c}1.001 \\
(0.999-1.003)\end{array}$ & $\begin{array}{c}1.001 \\
(0.999-1.003)\end{array}$ \\
\hline Elevated & $\mathrm{N}=2$ & $\mathrm{~N}=4$ & $\mathrm{~N}=3$ & $\mathrm{~N}=9$ & & & & & \\
\hline Triglycerides & 1.0 & $\begin{array}{c}2.133 \\
(0.364-12.511)\end{array}$ & $\begin{array}{c}1.548 \\
(0.242-9.908)\end{array}$ & $\begin{array}{c}1.000 \\
(0.998-1.003)\end{array}$ & 1.0 & $\begin{array}{c}1.846 \\
(0.305-11.188)\end{array}$ & $\begin{array}{c}1.507 \\
(0.233-9.742)\end{array}$ & $\begin{array}{c}1.000 \\
(0.997-1.003)\end{array}$ & $\begin{array}{c}1.000 \\
(0.997-1.003)\end{array}$ \\
\hline Reduced & $\mathrm{N}=9$ & $\mathrm{~N}=7$ & $\mathrm{~N}=11$ & $\mathrm{~N}=27$ & & & & & \\
\hline HDL-C & 1.0 & $\begin{array}{c}0.720 \\
(0.233-2.224)\end{array}$ & $\begin{array}{c}1.329 \\
(0.466-3.786)\end{array}$ & $\begin{array}{c}1.001 \\
(0.999-1.003)\end{array}$ & 1.0 & $\begin{array}{c}0.725 \\
(0.233-2.259)\end{array}$ & $\begin{array}{c}1.329 \\
(0.466-3.787)\end{array}$ & $\begin{array}{c}1.001 \\
(0.999-1.003)\end{array}$ & $\begin{array}{c}1.001 \\
(0.999-1.003)\end{array}$ \\
\hline Glucose & $\mathrm{N}=5$ & $\mathrm{~N}=1$ & $\mathrm{~N}=6$ & $\mathrm{~N}=12$ & & & & & \\
\hline Intolerance & $\begin{array}{c}1.0 \\
\mathrm{~N}=10\end{array}$ & $\begin{array}{c}0.176 \\
(0.019-1.593) \\
\mathrm{N}=7\end{array}$ & $\begin{array}{c}1.243 \\
(0.340-4.540) \\
\mathrm{N}=10\end{array}$ & $\begin{array}{c}1.001 \\
(0.999-1.003) \\
\mathrm{N}=27\end{array}$ & 1.0 & $\begin{array}{c}0.180 \\
(0.020-1.644)\end{array}$ & $\begin{array}{c}1.243 \\
(0.340-4.543)\end{array}$ & $\begin{array}{c}1.001 \\
(0.999-1.003)\end{array}$ & $\begin{array}{c}1.001 \\
(0.999-1.003)\end{array}$ \\
\hline Hypertension & 1.0 & $\begin{array}{c}0.622 \\
(0.205-1.891)\end{array}$ & $\begin{array}{c}1.000 \\
(0.352-2.838)\end{array}$ & $\begin{array}{c}0.999 \\
(0.998-1.001)\end{array}$ & 1.0 & $\begin{array}{c}0.691 \\
(0.222-2.145)\end{array}$ & $\begin{array}{c}0.987 \\
(0.341-2.860)\end{array}$ & $\begin{array}{c}0.999 \\
(0.998-1.001)\end{array}$ & $\begin{array}{c}0.999 \\
(0.997-1.001)\end{array}$ \\
\hline
\end{tabular}


Table A.8g. Unadjusted and adjusted odds ratios for MetSyn components by tertiles of Spielberger Police Stress score for men. - SUPPORT STRESS INDEX FOR PAST YEAR

\begin{tabular}{|c|c|c|c|c|c|c|c|c|c|}
\hline \multirow{2}{*}{$\begin{array}{l}\text { MetSyn } \\
\text { Component }\end{array}$} & \multicolumn{4}{|c|}{$\begin{array}{c}\text { Unadjusted } \\
\text { OR }(95 \% \mathrm{CI})\end{array}$} & \multicolumn{4}{|c|}{$\begin{array}{l}\text { Age-Adjusted } \\
\text { OR }(95 \% \text { CI })\end{array}$} & \multirow{2}{*}{$\begin{array}{c}\text { Multivariate Adjusted } \\
\text { OR }(95 \% \text { CI })^{*} \\
\begin{array}{c}\text { Continuous } \\
(\mathrm{N}=)\end{array}\end{array}$} \\
\hline & $\begin{array}{l}\text { Level } 1 \\
(\mathrm{~N}=96)\end{array}$ & $\begin{array}{l}\text { Level } 2 \\
(\mathrm{~N}=96)\end{array}$ & $\begin{array}{l}\text { Level } 3 \\
(\mathrm{~N}=96)\end{array}$ & $\begin{array}{l}\text { Continuous } \\
(\mathrm{N}=288)\end{array}$ & $\begin{array}{l}\text { Level } 1 \\
(\mathrm{~N}=96)\end{array}$ & $\begin{array}{l}\text { Level } 2 \\
(\mathrm{~N}=96)\end{array}$ & $\begin{array}{l}\text { Level } 3 \\
(\mathrm{~N}=96)\end{array}$ & $\begin{array}{l}\text { Continuous } \\
(\mathrm{N}=288)\end{array}$ & \\
\hline Abdominal & $\mathrm{N}=33$ & $\mathrm{~N}=41$ & $\mathrm{~N}=38$ & $\mathrm{~N}=112$ & & & & & \\
\hline Obesity & 1.0 & $\begin{array}{c}1.423 \\
(0.794-2.552)\end{array}$ & $\begin{array}{c}1.251 \\
(0.695-2.250)\end{array}$ & $\begin{array}{c}1.001 \\
(1.000-1.002)\end{array}$ & 1.0 & $\begin{array}{c}1.520 \\
(0.840-2.749)\end{array}$ & $\begin{array}{c}1.246 \\
(0.690-2.250)\end{array}$ & $\begin{array}{c}1.001 \\
(1.000-1.001)\end{array}$ & $\begin{array}{c}1.001 \\
(1.000-1.002)\end{array}$ \\
\hline Elevated & $\mathrm{N}=34$ & $\mathrm{~N}=41$ & $\mathrm{~N}=39$ & $\mathrm{~N}=114$ & & & & & \\
\hline Triglycerides & 1.0 & $\begin{array}{c}1.359 \\
(0.760-2.432)\end{array}$ & $\begin{array}{c}1.248 \\
(0.696-2.237)\end{array}$ & $\begin{array}{c}1.001 \\
(1.000-1.001)\end{array}$ & 1.0 & $\begin{array}{c}1.437 \\
(0.797-2.590)\end{array}$ & $\begin{array}{c}1.242 \\
(0.691-2.234)\end{array}$ & $\begin{array}{c}1.000 \\
(1.000-1.001)\end{array}$ & $\begin{array}{c}1.000 \\
(1.000-1.001)\end{array}$ \\
\hline Reduced & $\mathrm{N}=54$ & $\mathrm{~N}=48$ & $\mathrm{~N}=37$ & $\mathrm{~N}=139$ & & & & & \\
\hline HDL-C & 1.0 & $\begin{array}{c}0.778 \\
(0.441-1.373)\end{array}$ & $\begin{array}{c}0.488 \\
(0.274-0.868)\end{array}$ & $\begin{array}{c}0.999 \\
(0.999-1.000)\end{array}$ & 1.0 & $\begin{array}{c}1.798 \\
(0.451-1.413)\end{array}$ & $\begin{array}{c}0.484 \\
(0.272-0.863)\end{array}$ & $\begin{array}{c}0.999 \\
(0.999-1.000)\end{array}$ & $\begin{array}{c}0.999 \\
(0.999-1.000)\end{array}$ \\
\hline Glucose & $\mathrm{N}=26$ & $\mathrm{~N}=35$ & $\mathrm{~N}=19$ & $\mathrm{~N}=80$ & & & & & \\
\hline Intolerance & $\begin{array}{c}1.0 \\
\mathrm{~N}=44\end{array}$ & $\begin{array}{c}1.545 \\
(0.837-2.851) \\
\mathrm{N}=42\end{array}$ & $\begin{array}{c}0.664 \\
(0.338-1.304) \\
\mathrm{N}=41\end{array}$ & $\begin{array}{c}1.000 \\
(0.999-1.001) \\
\mathrm{N}=127\end{array}$ & 1.0 & $\begin{array}{c}1.791 \\
(0.947-3.388)\end{array}$ & $\begin{array}{c}0.655 \\
(0.329-1.304)\end{array}$ & $\begin{array}{c}1.000 \\
(0.999-1.001)\end{array}$ & $\begin{array}{c}1.000 \\
(0.999-1.001)\end{array}$ \\
\hline Hypertension & 1.0 & $\begin{array}{c}0.919 \\
(0.520-1.624)\end{array}$ & $\begin{array}{c}0.881 \\
(0.498-1.558)\end{array}$ & $\begin{array}{c}1.000 \\
(0.999-1.001)\end{array}$ & 1.0 & $\begin{array}{c}0.985 \\
(0.552-1.756)\end{array}$ & $\begin{array}{c}0.870 \\
(0.489-1.547)\end{array}$ & $\begin{array}{c}1.000 \\
(0.999-1.001)\end{array}$ & $\begin{array}{c}1.000 \\
(0.999-1.001)\end{array}$ \\
\hline
\end{tabular}


Table A.8h. Unadjusted and adjusted odds ratios for MetSyn components by tertiles of Spielberger Police Stress score for women. - SUPPORT STRESS INDEX FOR PAST YEAR

\begin{tabular}{|c|c|c|c|c|c|c|c|c|c|}
\hline \multirow{2}{*}{$\begin{array}{l}\text { MetSyn } \\
\text { Component }\end{array}$} & \multicolumn{4}{|c|}{$\begin{array}{c}\text { Unadjusted } \\
\text { OR (95\% CI) }\end{array}$} & \multicolumn{4}{|c|}{$\begin{array}{l}\text { Age-Adjusted } \\
\text { OR (95\% CI) }\end{array}$} & \multirow{2}{*}{$\begin{array}{c}\text { Multivariate Adjusted } \\
\text { OR }(95 \% \mathrm{CI})^{*} \\
\begin{array}{c}\text { Continuous } \\
(\mathrm{N}=)\end{array}\end{array}$} \\
\hline & $\begin{array}{l}\text { Level } 1 \\
(\mathrm{~N}=34)\end{array}$ & $\begin{array}{l}\text { Level } 2 \\
(\mathrm{~N}=34)\end{array}$ & $\begin{array}{l}\text { Level } 3 \\
(\mathrm{~N}=34)\end{array}$ & $\begin{array}{l}\text { Continuous } \\
(\mathrm{N}=102)\end{array}$ & $\begin{array}{l}\text { Level } 1 \\
(\mathrm{~N}=34)\end{array}$ & $\begin{array}{l}\text { Level } 2 \\
(\mathrm{~N}=34)\end{array}$ & $\begin{array}{l}\text { Level } 3 \\
(\mathrm{~N}=34)\end{array}$ & $\begin{array}{l}\text { Continuous } \\
(\mathrm{N}=102)\end{array}$ & \\
\hline \multirow{2}{*}{$\begin{array}{l}\text { Abdominal } \\
\text { Obesity }\end{array}$} & $\mathrm{N}=2$ & $\mathrm{~N}=7$ & $\mathrm{~N}=9$ & $\mathrm{~N}=18$ & & & & & \\
\hline & 1.0 & $\begin{array}{c}4.148 \\
(0.794-21.660)\end{array}$ & $\begin{array}{c}5.760 \\
(1.141-29.078)\end{array}$ & $\begin{array}{c}1.001 \\
(1.000-1.003)\end{array}$ & 1.0 & $\begin{array}{c}4.435 \\
(0.828-23.762)\end{array}$ & $\begin{array}{c}6.257 \\
(1.204-32.530)\end{array}$ & $\begin{array}{c}1.001 \\
(1.000-1.003)\end{array}$ & $\begin{array}{c}1.002 \\
(1.000-1.004)\end{array}$ \\
\hline \multirow{2}{*}{$\begin{array}{l}\text { Elevated } \\
\text { Triglycerides }\end{array}$} & $\mathrm{N}=3$ & $\mathrm{~N}=1$ & $\mathrm{~N}=5$ & $\mathrm{~N}=9$ & & & & & \\
\hline & 1.0 & $\begin{array}{c}0.313 \\
(0.031-3.173)\end{array}$ & $\begin{array}{c}1.782 \\
(0.390-8.132)\end{array}$ & $\begin{array}{c}1.001 \\
(0.998-1.003)\end{array}$ & 1.0 & $\begin{array}{c}0.277 \\
(0.027-2.899)\end{array}$ & $\begin{array}{c}1.686 \\
(0.363-7.841)\end{array}$ & $\begin{array}{c}1.001 \\
(0.998-1.003)\end{array}$ & $\begin{array}{c}1.001 \\
(0.998-1.003)\end{array}$ \\
\hline \multirow{2}{*}{$\begin{array}{l}\text { Reduced } \\
\text { HDL-C }\end{array}$} & $\mathrm{N}=7$ & $\mathrm{~N}=8$ & $\mathrm{~N}=12$ & $\mathrm{~N}=27$ & & & & & \\
\hline & 1.0 & $\begin{array}{c}1.187 \\
(0.376-3.742)\end{array}$ & $\begin{array}{c}2.104 \\
(0.708-6.251)\end{array}$ & $\begin{array}{c}1.002 \\
(1.000-1.003)\end{array}$ & 1.0 & $\begin{array}{c}1.194 \\
(0.378-3.770)\end{array}$ & $\begin{array}{c}2.114 \\
(0.711-6.288)\end{array}$ & $\begin{array}{c}1.002 \\
(1.000-1.003)\end{array}$ & $\begin{array}{c}1.002 \\
(1.000-1.004)\end{array}$ \\
\hline \multirow{2}{*}{$\begin{array}{l}\text { Glucose } \\
\text { Intolerance }\end{array}$} & $\mathrm{N}=3$ & $\mathrm{~N}=4$ & $\mathrm{~N}=5$ & $\mathrm{~N}=12$ & & & & & \\
\hline & $\begin{array}{c}1.0 \\
\mathrm{~N}=10\end{array}$ & $\begin{array}{c}1.378 \\
(0.284-6.681) \\
\mathrm{N}=9\end{array}$ & $\begin{array}{c}1.782 \\
(0.390-8.132) \\
\mathrm{N}=8\end{array}$ & $\begin{array}{c}1.001 \\
(0.999-1.003) \\
\mathrm{N}=27\end{array}$ & 1.0 & $\begin{array}{c}1.398 \\
(0.288-6.795)\end{array}$ & $\begin{array}{c}1.802 \\
(0.394-8.244)\end{array}$ & $\begin{array}{c}1.001 \\
(0.999-1.003)\end{array}$ & $\begin{array}{c}1.002 \\
(0.999-1.004)\end{array}$ \\
\hline Hypertension & 1.0 & $\begin{array}{c}0.864 \\
(0.299-2.495)\end{array}$ & $\begin{array}{c}0.738 \\
(0.250-2.180)\end{array}$ & $\begin{array}{c}0.999 \\
(0.997-1.000)\end{array}$ & 1.0 & $\begin{array}{c}0.883 \\
(0.299-2.607)\end{array}$ & $\begin{array}{c}0.744 \\
(0.246-2.245)\end{array}$ & $\begin{array}{c}0.999 \\
(0.997-1.001)\end{array}$ & $\begin{array}{c}0.998 \\
(0.997-1.000)\end{array}$ \\
\hline
\end{tabular}


ApPEndix B 
Table B.1. Mean depression score by demographic and lifestyle characteristics.

\begin{tabular}{|c|c|c|c|c|c|c|c|c|}
\hline & \multicolumn{8}{|c|}{ Depression Score, Mean (SD) } \\
\hline & \multicolumn{4}{|c|}{ Buffalo } & \multicolumn{4}{|c|}{ Spokane } \\
\hline & Men & $\begin{array}{c}\mathrm{p}- \\
\text { value }\end{array}$ & Women & $\begin{array}{c}\mathrm{p}- \\
\text { value }\end{array}$ & Men & $\begin{array}{c}\mathrm{p}- \\
\text { value }\end{array}$ & Women & $\begin{array}{c}\mathrm{p}- \\
\text { value }\end{array}$ \\
\hline \multicolumn{9}{|l|}{ Age Group } \\
\hline$<40$ years & $7.4(6.6)$ & & $10.0(8.8)$ & & $3.6(4.0)$ & & - & \\
\hline $40-49$ years & $7.2(6.5)$ & 0.974 & $7.5(7.8)$ & 0.972 & $6.2(4.4)$ & $0.062 *$ & $6.6(4.8)$ & 0.604 \\
\hline $50+$ years & $7.6(6.5)$ & & $9.7(5.4)$ & & $7.3(6.3)$ & & $6.7(6.7)$ & \\
\hline \multicolumn{9}{|l|}{ Ethnicity } \\
\hline White & $7.6(6.9)$ & & $9.1(7.7)$ & & $6.5(5.5)$ & & $7.3(4.7)$ & \\
\hline Black & $5.9(4.3)$ & 0.221 & $7.9(9.3)$ & 0.516 & - & -- & 0.0 & 0.176 \\
\hline Hispanic & $7.9(4.3)$ & & - & & - & & - & \\
\hline \multicolumn{9}{|l|}{ Education } \\
\hline > 12 years, High School/GED & $6.9(5.5)$ & & $8.3(10.0)$ & & $8.3(7.8)$ & & $4.0(-)$ & \\
\hline College $<4$ years & $7.4(6.8)$ & 0.824 & $8.5(6.8)$ & 0.875 & $7.2(5.4)$ & 0.137 & $8.0(5.7)$ & 0.767 \\
\hline College $4+$ years & $7.6(6.5)$ & & $9.3(10.2)$ & & $5.4(5.1)$ & & $6.0(5.2)$ & \\
\hline \multicolumn{9}{|l|}{ Marital Status } \\
\hline Single & $9.1(8.5)$ & & $7.7(5.2)$ & & - & & $9.3(5.5)$ & \\
\hline Married & $7.1(6.2)$ & 0.238 & $8.8(8.3)$ & 0.638 & $6.6(5.6)$ & 0.518 & $5.6(4.2)$ & 0.306 \\
\hline Divorced & $8.1(7.3)$ & & $10.0(10.4)$ & & $5.4(3.9)$ & & $1.0(-)$ & \\
\hline \multicolumn{9}{|l|}{ Rank } \\
\hline Police Officer & $7.1(6.1)$ & & $8.1(7.8)$ & & $6.1(5.0)$ & & $6.3(5.2)$ & \\
\hline Sergeant / Lieutenant / Captain & $7.5(6.9)$ & & $13.5(11.4)$ & & $6.6(5.5)$ & & $8.0(-)$ & \\
\hline Detective & $9.6(8.7)$ & $0.364 * *$ & $8.4(4.7)$ & $0.177+$ & $6.8(6.1)$ & 0.909 & $3.0(2.8)$ & 0.645 \\
\hline Executive & $8.0(7.1)$ & & $8.0(-)$ & & $7.4(5.9)$ & & - & \\
\hline Other & $10.0(-)$ & & - & & - & & - & \\
\hline \multicolumn{9}{|l|}{ Smoking Status } \\
\hline Current & $9.0(7.4)$ & & $9.0(6.9)$ & & $10.3(6.0)$ & & $13.0(-)$ & \\
\hline Former & $6.7(6.4)$ & 0.214 & $8.9(8.4)$ & 0.998 & $6.9(5.8)$ & 0.290 & $8.7(6.8)$ & 0.213 \\
\hline Never & $7.3(6.4)$ & & $8.9(8.9)$ & & $6.1(5.2)$ & & $4.5(3.2)$ & \\
\hline \multicolumn{9}{|l|}{ Body Mass Index $\left(\mathrm{kg} / \mathrm{m}^{2}\right)$} \\
\hline$<25$ & $8.2(6.3)$ & & $8.6(6.6)$ & & $6.0(4.5)$ & & - & \\
\hline $25-30$ & $7.6(7.6)$ & 0.576 & $7.8(9.2)$ & 0.564 & $5.9(5.5)$ & 0.064 & $6.1(5.0)$ & 0.789 \\
\hline$>30$ & $7.3(5.5)$ & & $10.8(9.8)$ & & $7.4(5.5)$ & & $8.5(6.4)$ & \\
\hline
\end{tabular}

* Significant differences between Spokane men $<40$ compared to Spokane men $\geq 50$

** Significant differences between Buffalo men who are police officers compared to Buffalo men who are detectives

+ Significant differences between Buffalo women who are police officers compared to Buffalo women who are Sgt/Lt/Capt 
Table B.2. Mean number of metabolic syndrome components by demographic and lifestyle characteristics.

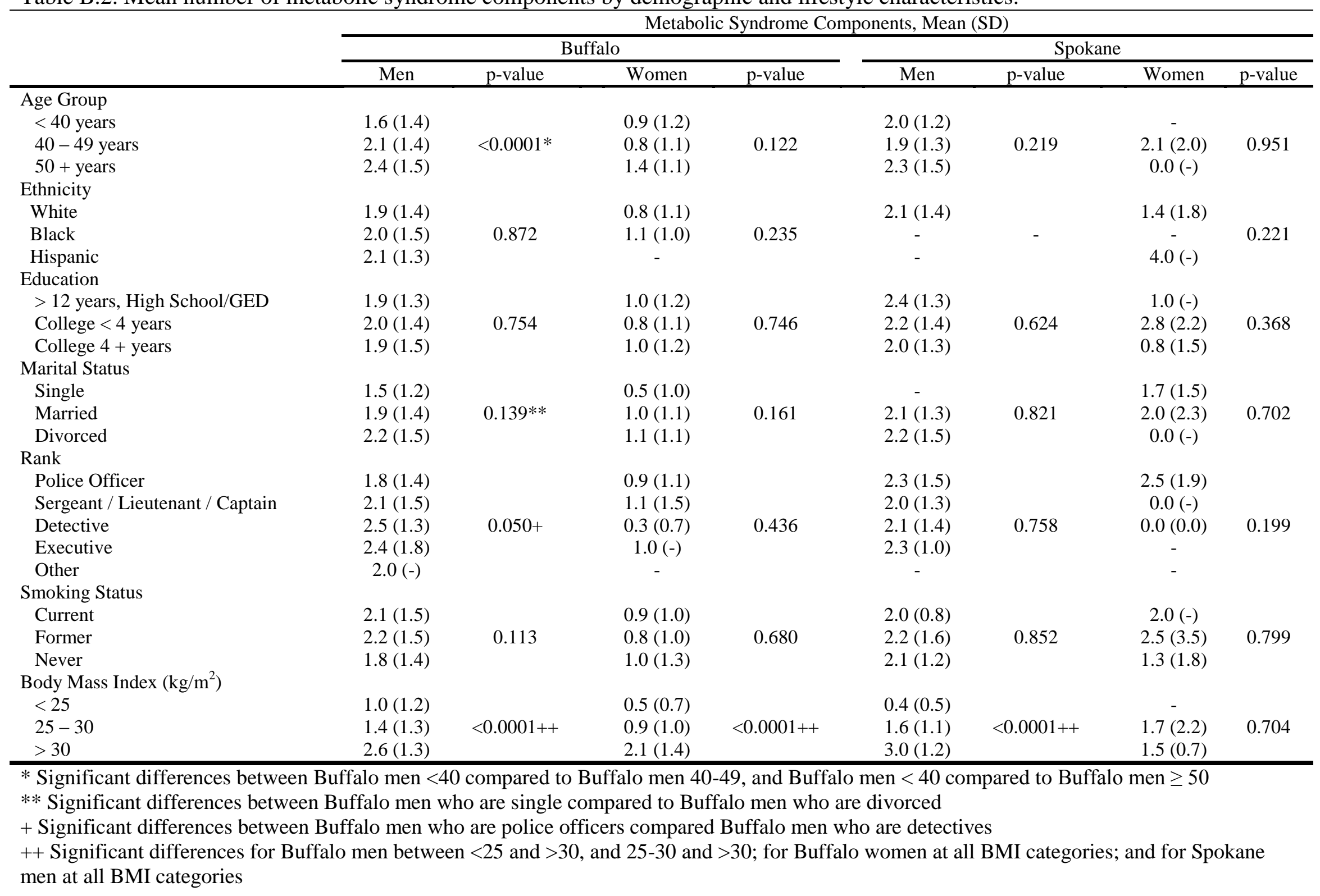


Table B.3. Significant associations between variables of interest and demographic and lifestyle characteristics.

\begin{tabular}{lccr}
\hline Variable & CES-D Score & Number of MetSyn components & Decision to A \\
\hline Age & Spokane men $(0.062)$ & Buffalo men $(<0.0001)$ & Yes
\end{tabular}

Ethnicity

No

Education

$? ?$

Marital Status

Yes

Rank

Buffalo men (0.050)

No

Smoking

Yes

BMI

Buffalo men and women, Spokane men $(<0.0001)$

No

\section{$\underline{\text { Key Studies }}$}

Cohen et al: age, sex, race, SES, physical activity, smoking, alcohol use, BMI

Dunbar et al: age, sex, smoking, alcohol, physical activity, marital status, education

Herva et al: gender, smoking, alcohol use, marital status, education, physical activity

Hildrum et al: age, gender, education, physical activity, smoking, pulse rate

Skilton et al: age, prior CVD, employment status, marital status, smoking, dietary score, physical activity, BMI

van Reedt Dortland et al: age, sex, education, clinic site, OC use, smoking, alcohol use, physical activity 


\section{Exploratory Analyses}

1. Gender-specific differences in CES-D score by location (Buffalo, Spokane)

For women: $\mathrm{t}$-test $=0.4277$

For men: $t$-test $=0.1844$ (use unequal value because equality of variances was significant)

2. Interaction effect of location (Buffalo, Spokane) on relationship between CES-D score and demographics

For all, Gender: Interaction $=0.586$

For women, $\quad$ Age: Interaction $=0.735$

Race: Interaction $=0.536$

Education: Interaction $=0.858$

Marital Status: Interaction $=0.471$

Police Rank: Interaction $=0.603$

Smoking Status: Interaction $=0.570$

BMI: Interaction $=0.983$

For men, $\quad$ Age: Interaction $=\mathbf{0 . 1 5 1}$

Race: Interaction $=\mathbf{0 . 1 1 1}$

Education: Interaction $=0.214$

Marital Status: Interaction $=0.360$

Police Rank: Interaction $=0.647$

Smoking Status: Interaction $=0.532$

BMI: Interaction $=\mathbf{0 . 0 9 3}$

3. Gender-specific differences in number of MetSyn components by location (Buffalo, Spokane)

For women: $t$-test $=0.272$ (use unequal value because equality of variances was significant)

For men: t-test $=0.287$

4. Interaction effect of location (Buffalo, Spokane) on relationship between number of MetSyn components and demographics

For all,

Gender: Interaction $=0.217$

For women,

Age: Interaction $=0.772$

Race: Interaction $=$ -

Education: Interaction $=\mathbf{0 . 0 3 8}$

Marital Status: Interaction $=0.226$

Police Rank: Interaction $=\mathbf{0 . 0 6 5}$

Smoking Status: Interaction $=0.379$

BMI: Interaction $=0.329$

For men,

Age: Interaction $=0.296$

Race: Interaction $=$ -

Education: Interaction $=0.858$

Marital Status: Interaction $=0.754$

Smoking Status: Interaction $=0.715$

BMI: Interaction $=\mathbf{0 . 0 3 6}$ 
Table B.4. Unadjusted number of metabolic syndrome components by categories of CES-D score by location and gender.

\begin{tabular}{|c|c|c|c|c|c|c|c|c|c|}
\hline \multirow[t]{2}{*}{$\begin{array}{l}\text { Categories of } \\
\text { CES-D }\end{array}$} & \multicolumn{3}{|c|}{$\begin{array}{l}\text { Number of Metabolic } \\
\text { Syndrome Components }\end{array}$} & \multicolumn{3}{|c|}{$\begin{array}{c}\text { Number of Metabolic } \\
\text { Syndrome Components } \\
\text { After removing officers } \\
\text { with CVD or received } \\
\text { CVD treatment }\end{array}$} & \multicolumn{3}{|c|}{$\begin{array}{l}\text { Number of Metabolic } \\
\text { Syndrome Components } \\
\text { After removing officers } \\
\text { taking anti-depressant } \\
\text { medications }\end{array}$} \\
\hline & $\mathrm{N}$ & $\begin{array}{c}\text { Mean } \\
\text { (SD) }\end{array}$ & p-value* & $\mathrm{N}$ & $\begin{array}{c}\text { Mean } \\
(\mathrm{SD})\end{array}$ & p-value* & $\mathrm{N}$ & $\begin{array}{c}\text { Mean } \\
\text { (SD) }\end{array}$ & p-value* \\
\hline \multicolumn{10}{|l|}{ Buffalo Men } \\
\hline $0-8$ & 203 & $1.8(1.4)$ & & 195 & $1.7(1.4)$ & & 194 & $1.8(1.4)$ & \\
\hline $9-15$ & 70 & $2.2(1.3)$ & $0.431 * *$ & 70 & $2.2(1.3)$ & 0.387 & 65 & $2.2(1.3)$ & 0.625 \\
\hline$\geq 16$ & 31 & $1.9(1.5)$ & & 30 & $1.9(1.5)$ & & 25 & $1.8(1.5)$ & \\
\hline \multicolumn{10}{|l|}{ Spokane Men } \\
\hline $0-8$ & 88 & $1.9(1.3)$ & & 87 & $1.8(1.2)$ & & & & \\
\hline $9-15$ & 22 & $2.6(1.3)$ & $0.003+$ & 22 & $2.6(1.3)$ & 0.001 & & & \\
\hline$\geq 16$ & 11 & $3.1(1.6)$ & & 11 & $3.1(1.6)$ & & & & \\
\hline \multicolumn{10}{|l|}{ All Men } \\
\hline $0-8$ & 291 & $1.8(1.4)$ & & 282 & $1.8(1.3)$ & & & & \\
\hline $9-15$ & 92 & $2.3(1.3)$ & $0.050++$ & 92 & $2.3(1.3)$ & 0.033 & & & \\
\hline$\geq 16$ & 42 & $2.2(1.6)$ & & 41 & $2.2(1.6)$ & & & & \\
\hline \multicolumn{10}{|c|}{ Buffalo Women } \\
\hline $0-8$ & 68 & $0.8(1.1)$ & & 68 & $0.8(1.1)$ & & 63 & $0.7(0.9)$ & \\
\hline $9-15$ & 21 & $1.1(1.4)$ & 0.376 & 21 & $1.1(1.4)$ & 0.381 & 19 & $0.9(1.3)$ & 0.431 \\
\hline$\geq 16$ & 17 & $0.9(0.9)$ & & 16 & $0.9(0.9)$ & & 12 & $0.8(0.9)$ & \\
\hline \multicolumn{10}{|c|}{ Spokane Women } \\
\hline $0-8$ & 7 & $1.1(1.7)$ & & 7 & $1.1(1.7)$ & & & & \\
\hline $9-15$ & 2 & $3.5(2.1)$ & 0.874 & 2 & $3.5(2.1)$ & 0.874 & & & \\
\hline$\geq 16$ & 0 & - & & & & & & & \\
\hline \multicolumn{10}{|l|}{ All Women } \\
\hline $0-8$ & 75 & $0.8(1.1)$ & & 75 & $0.8(1.1)$ & & & & \\
\hline $9-15$ & 23 & $1.3(1.6)$ & 0.509 & 23 & $1.3(1.6)$ & 0.512 & & & \\
\hline$\geq 16$ & 17 & $0.9(0.9)$ & & 16 & $0.9(0.9)$ & & & & \\
\hline
\end{tabular}

$*$ p-values are based on the continuous CES-D score

** Significant differences for Buffalo men in 0-8 vs. 9-15 CES-D categories

+ Significant differences for Spokane men in 0-8 vs. 9-15 and 0-8 vs. $\geq 16$ CES-D categories

++ Significant differences for All men in 0-8 vs. 9-15 CES-D categories 
Table B.5. Age-adjusted number of metabolic syndrome components by categories of CES-D score by location and gender.

Number of Metabolic

Categories of CES-D \begin{tabular}{c}
\multicolumn{2}{c}{ Syndrome Components } \\
\cline { 2 - 3 }
\end{tabular}

\begin{tabular}{lrll}
\hline Buffalo Men & & & \\
$0-8$ & 203 & $1.8(0.1)$ & \\
$9-15$ & 70 & $2.2(0.2)$ & 0.379 \\
$\geq 16$ & 31 & $2.0(0.2)$ &
\end{tabular}

\section{Spokane Men}

$0-8$

$88 \quad 1.9(0.1)$

$9-15$

$22 \quad 2.6(0.3)$

$\geq 16$

$113.0(0.4)$

0.004

All Men

$\begin{array}{lrrr}0-8 & 291 & 1.8(0.1) & \\ 9-15 & 92 & 2.3(0.1) & 0.041 \\ \geq 16 & 42 & 2.2(0.2) & \end{array}$

\section{Buffalo Women}

$0-8$

$9-15$

$68 \quad 0.8(0.1)$

$21 \quad 1.1(0.2)$

$17 \quad 0.9(0.3)$

0.377

$\geq 16$

$\begin{array}{lc}7 & 1.1(0.7) \\ 2 & 3.5(1.3) \\ 0 & -\end{array}$

0.893

Spokane Women

$0-8$

$9-15$

$\geq 16$

\section{All Women}

$0-8$

$75 \quad 0.8(0.1)$

$9-15$

$23 \quad 1.3(0.2)$

$17 \quad 0.9(0.3)$

0.466

$\geq 16$

$0.9(0.3)$

$* \mathrm{p}$-values are based on the continuous CES-D score 
Table B.6. Multivariate-adjusted* number of metabolic syndrome components by categories of CES-D score by location and gender.

Number of Metabolic

Categories of CES-D \begin{tabular}{c}
\multicolumn{2}{c}{ Syndrome Components } \\
\cline { 2 - 3 }
\end{tabular}

\begin{tabular}{lrll}
\hline Buffalo Men & & & \\
$0-8$ & 202 & $1.9(0.1)$ & \\
$9-15$ & 69 & $2.3(0.2)$ & 0.390 \\
$\geq 16$ & 31 & $2.0(0.3)$ &
\end{tabular}

\section{Spokane Men}

$0-8$

$88 \quad 1.8(0.3)$

$9-15$

$21 \quad 2.7(0.4)$

$\geq 16$

$11 \quad 3.0(0.5)$

0.003

All Men

$0-8$

$9-15$

$290 \quad 1.8(0.1)$

$90 \quad 2.4(0.2)$

$\geq 16$

$42 \quad 2.3(0.3)$

0.039

\section{Buffalo Women}

$0-8$

$9-15$

$65 \quad 0.8(0.1)$

$21 \quad 1.2(0.3)$

$17 \quad 0.7(0.3)$

$\geq 16$

$$
0.7(0.3)
$$

0.610

\section{Spokane Women}

$0-8$

$9-15$

$\geq 16$

$\begin{array}{ll}7 & - \\ 2 & - \\ 0 & -\end{array}$

\section{All Women}

$0-8$

$72 \quad 0.8(0.2)$

$9-15$

$23 \quad 1.4(0.3)$

$17 \quad 0.7(0.3)$

$\geq 16$

$0.7(0.3)$

0.642

* Adjusted for age, smoking status and marital status

** p-values are based on the continuous CES-D score 
Table B.7. Unadjusted odds ratios for individual MetSyn components by CES-D score by location and gender

\begin{tabular}{|c|c|c|c|c|c|c|c|c|c|c|c|}
\hline \multirow{2}{*}{ CES-D Score } & \multirow[b]{2}{*}{$\mathrm{N}$} & \multicolumn{2}{|c|}{ Abdominal Obesity } & \multicolumn{2}{|c|}{ Elevated Triglycerides } & \multicolumn{2}{|c|}{ Reduced HDL-C } & \multicolumn{2}{|c|}{ Glucose Intolerance } & \multicolumn{2}{|c|}{ Hypertension } \\
\hline & & Odds Ratio & $95 \% \mathrm{CI}$ & Odds Ratio & $95 \% \mathrm{CI}$ & Odds Ratio & $95 \% \mathrm{CI}$ & Odds Ratio & $95 \% \mathrm{CI}$ & Odds Ratio & $95 \% \mathrm{CI}$ \\
\hline \multicolumn{12}{|l|}{ Buffalo Men } \\
\hline $0-8$ & 202 & Referent & & Referent & & Referent & & Referent & & Referent & \\
\hline $9-15$ & 69 & 1.91 & $1.10-3.32$ & 1.73 & $1.0-3.01$ & 1.14 & $0.66-1.96$ & 1.30 & $0.72-2.35$ & 1.16 & $0.67-2.01$ \\
\hline$\geq 16$ & 31 & 0.67 & $0.28-1.57$ & 1.82 & $0.85-3.90$ & 0.82 & $0.38-1.76$ & 0.98 & $0.42-2.33$ & 1.56 & $0.73-3.32$ \\
\hline Continuous & 304 & 1.00 & $0.97-1.04$ & 1.02 & $0.99-1.06$ & 0.99 & $0.95-1.02$ & 1.00 & $0.97-1.04$ & 1.03 & $0.99-1.06$ \\
\hline \multicolumn{12}{|l|}{ Spokane Men } \\
\hline $0-8$ & 88 & Referent & & Referent & & Referent & & Referent & & Referent & \\
\hline $9-15$ & 21 & 3.10 & $1.18-8.09$ & 2.34 & $0.90-6.05$ & 1.07 & $0.42-2.73$ & 1.64 & $0.64-4.23$ & 1.47 & $0.58-3.76$ \\
\hline$\geq 16$ & 11 & 3.75 & $1.01-13.87$ & 1.94 & $0.55-6.85$ & 1.07 & $0.30-3.76$ & 3.44 & $0.93-12.69$ & 6.63 & $1.35-32.47$ \\
\hline Continuous & 122 & 1.07 & $1.00-1.15$ & 1.06 & $0.99-1.14$ & 0.99 & $0.93-1.06$ & 1.09 & $1.01-1.17$ & 1.07 & $1.00-1.14$ \\
\hline \multicolumn{12}{|c|}{ Buffalo Women } \\
\hline $0-8$ & 65 & Referent & & Referent & & Referent & & Referent & & Referent & \\
\hline $9-15$ & 21 & 1.19 & $0.34-4.20$ & 6.77 & $1.46-31.34$ & 0.94 & $0.30-2.94$ & 4.00 & $1.03-15.51$ & 0.74 & $0.24-2.26$ \\
\hline$\geq 16$ & 17 & 1.65 & $0.45-6.01$ & 1.35 & $0.13-13.90$ & 1.64 & $0.53-5.10$ & 1.71 & $0.30-9.66$ & 0.33 & $0.07-1.59$ \\
\hline Continuous & 109 & 1.05 & $0.99-1.11$ & 1.01 & $0.94-1.10$ & 1.03 & $0.98-1.08$ & 1.02 & $0.95-1.09$ & 0.97 & $0.91-1.03$ \\
\hline \multicolumn{12}{|c|}{ Spokane Women } \\
\hline $0-8$ & 7 & Referent & - & Referent & - & Referent & - & Referent & - & Referent & - \\
\hline $9-15$ & 2 & - & & 1.25 & $0.07-22.88$ & 3.0 & $0.12-73.6$ & 12.0 & $0.49-294.5$ & 12.0 & $0.49-294.5$ \\
\hline$\geq 16$ & 0 & - & & - & & - & & - & & - & \\
\hline Continuous & 9 & 1.03 & $0.75-1.40$ & 0.85 & $0.61-1.19$ & 0.99 & $0.72-1.38$ & 1.10 & $0.82-1.47$ & 1.12 & $0.83-1.51$ \\
\hline
\end{tabular}


Table B.8. Unadjusted number of metabolic syndrome components by categories of CES-D score by location, gender and age

Number of Metabolic Syndrome Components

\begin{tabular}{|c|c|c|c|c|c|c|}
\hline \multirow[t]{2}{*}{ Categories of CES-D } & \multicolumn{3}{|c|}{ Age $<=40$} & \multicolumn{3}{|c|}{ Age $>40$} \\
\hline & $\mathrm{N}$ & Mean (SD) & p-value* & $\mathrm{N}$ & Mean (SD) & p-value* \\
\hline \multicolumn{7}{|l|}{ Buffalo Men } \\
\hline $0-8$ & 104 & $1.5(1.3)$ & & 99 & $2.2(1.5)$ & \\
\hline $9-15$ & 32 & $1.9(1.2)$ & 0.091 & 38 & $2.5(1.4)$ & 0.567 \\
\hline $16+$ & 15 & $2.0(1.6)$ & & 16 & $1.9(1.3)$ & \\
\hline \multicolumn{7}{|l|}{ Buffalo Women } \\
\hline $0-8$ & 34 & $0.6(0.9)$ & & 34 & $1.0(1.2)$ & \\
\hline $9-15$ & 11 & $1.3(1.6)$ & 0.325 & 10 & $1.0(1.3)$ & 0.766 \\
\hline \multirow[t]{2}{*}{$16+$} & 9 & $0.9(0.9)$ & & 8 & $0.9(0.8)$ & \\
\hline & \multicolumn{3}{|c|}{ Age $<=49$} & \multicolumn{3}{|c|}{ Age $>49$} \\
\hline \multicolumn{7}{|l|}{ Spokane Men } \\
\hline $0-8$ & 45 & $1.8(1.2)$ & & 43 & $1.9(1.3)$ & \\
\hline $9-15$ & 14 & $2.6(1.3)$ & 0.095 & 8 & $2.6(1.5)$ & 0.026 \\
\hline $16+$ & 2 & $1.5(0.7)$ & & 9 & $3.4(1.5)$ & \\
\hline \multicolumn{7}{|l|}{ Spokane Women } \\
\hline $0-8$ & 4 & $1.0(1.4)$ & & 3 & $1.3(2.3)$ & \\
\hline $9-15$ & 1 & $5.0(-)$ & 0.771 & 1 & $2.0(-)$ & 0.926 \\
\hline $16+$ & - & - & & - & - & \\
\hline
\end{tabular}

$*$ p-values are based on the continuous CES-D score

Interaction: Age and CESD

BCOPS Men: $p$-value $=0.330$

BCOPS Women: $p$-value $=0.883$

Spokane Men: $\mathrm{p}$-value $=0.960$

Spokane Women: $\mathrm{p}$-value $=0.798$ 
Table B.9. Unadjusted number of metabolic syndrome components by categories of CES-D score by location, gender and police rank

\begin{tabular}{|c|c|c|c|c|c|c|}
\hline \multirow{3}{*}{ Categories of CES-D } & \multicolumn{6}{|c|}{ Number of Metabolic Syndrome Components } \\
\hline & \multicolumn{3}{|c|}{ Police Officer } & \multicolumn{3}{|c|}{ All Other Ranks } \\
\hline & $\mathrm{N}$ & Mean (SD) & p-value* & $\mathrm{N}$ & Mean (SD) & p-value* \\
\hline \multicolumn{7}{|l|}{ Buffalo Men } \\
\hline $0-8$ & 142 & $1.7(1.4)$ & & 55 & $2.2(1.5)$ & \\
\hline $9-15$ & 48 & $2.1(1.4)$ & 0.706 & 22 & $2.5(1.1)$ & 0.763 \\
\hline $16+$ & 17 & $1.6(1.3)$ & & 14 & $2.4(1.5)$ & \\
\hline \multicolumn{7}{|l|}{ Buffalo Women } \\
\hline $0-8$ & 57 & $0.8(1.0)$ & & 11 & $1.1(1.5)$ & \\
\hline $9-15$ & 16 & $1.5(1.5)$ & 0.181 & 5 & $0.0(0.0)$ & 0.844 \\
\hline $16+$ & 11 & $0.9(0.8)$ & & 6 & $0.8(1.0)$ & \\
\hline \multicolumn{7}{|l|}{ Spokane Men } \\
\hline $0-8$ & 30 & $1.8(1.2)$ & & 58 & $1.9(1.3)$ & \\
\hline $9-15$ & 6 & $3.2(1.7)$ & $<0.0001$ & 16 & $2.4(1.4)$ & 0.273 \\
\hline $16+$ & 3 & $5.0(0.0)$ & & 8 & $2.4(1.9)$ & \\
\hline \multicolumn{7}{|l|}{ Spokane Women } \\
\hline $0-8$ & 4 & $2.0(1.8)$ & & 3 & $0(0)$ & \\
\hline $9-15$ & 2 & $3.5(2.1)$ & 0.876 & - & - & - \\
\hline $16+$ & - & - & & - & - & \\
\hline
\end{tabular}

\section{Interaction: Police Rank and CESD}

BCOPS Men: $p$-value $=0.762$

BCOPS Women: $\mathrm{p}$-value $=0.282$

Spokane Men: $\mathrm{p}$-value $=0.061$

Spokane Women: $\mathrm{p}$-value $=0.480$ 
Table B.10. Unadjusted number of metabolic syndrome components by categories of CES-D score by location, gender and marital status

\begin{tabular}{|c|c|c|c|c|c|c|}
\hline \multirow{3}{*}{ Categories of CES-D } & \multicolumn{6}{|c|}{ Number of Metabolic Syndrome Components } \\
\hline & \multicolumn{3}{|c|}{ Married } & \multicolumn{3}{|c|}{ Single or Divorced } \\
\hline & $\mathrm{N}$ & Mean (SD) & p-value* & $\mathrm{N}$ & Mean (SD) & p-value* \\
\hline \multicolumn{7}{|l|}{ Buffalo Men } \\
\hline $0-8$ & 163 & $1.8(1.5)$ & & 39 & $1.8(1.3)$ & \\
\hline $9-15$ & 51 & $2.3(1.3)$ & 0.305 & 18 & $2.1(1.4)$ & 0.887 \\
\hline $16+$ & 22 & $1.9(1.2)$ & & 9 & $2.0(2.0)$ & \\
\hline \multicolumn{7}{|l|}{ Buffalo Women } \\
\hline $0-8$ & 39 & $0.7(1.1)$ & & 29 & $0.9(1.1)$ & \\
\hline $9-15$ & 12 & $1.5(1.4)$ & 0.080 & 9 & $0.7(1.4)$ & 0.416 \\
\hline $16+$ & 11 & $1.2(0.9)$ & & 6 & $0.3(0.5)$ & \\
\hline \multicolumn{7}{|l|}{ Spokane Men } \\
\hline $0-8$ & 80 & $1.9(1.2)$ & & 8 & $1.9(1.5)$ & \\
\hline $9-15$ & 19 & $2.6(1.3)$ & 0.004 & 2 & $3.5(0.7)$ & 0.125 \\
\hline $16+$ & 11 & $3.1(1.6)$ & & - & - & \\
\hline \multicolumn{7}{|l|}{ Spokane Women } \\
\hline $0-8$ & 4 & $1.3(1.9)$ & & 3 & $1.0(1.7)$ & \\
\hline $9-15$ & 1 & $5.0(-)$ & 0.902 & 1 & $2.0(-)$ & 0.921 \\
\hline $16+$ & - & - & & - & - & \\
\hline
\end{tabular}

Interaction: Marital Status and CESD

BCOPS Men: $p$-value $=0.492$

BCOPS Women: $\mathrm{p}$-value $=0.082$

Spokane Men: $\mathrm{p}$-value $=0.259$

Spokane Women: $\mathrm{p}$-value $=0.956$ 
Table B.11. Unadjusted number of metabolic syndrome components by categories of CES-D score by location, gender and smoking status

Number of Metabolic Syndrome Components

\begin{tabular}{|c|c|c|c|c|c|c|}
\hline \multirow[t]{2}{*}{ Categories of CES-D } & \multicolumn{3}{|c|}{ Ever } & \multicolumn{3}{|c|}{ Never } \\
\hline & $\mathrm{N}$ & Mean (SD) & p-value* & $\mathrm{N}$ & Mean (SD) & p-value* \\
\hline \multicolumn{7}{|l|}{ Buffalo Men } \\
\hline $0-8$ & 67 & $2.1(1.5)$ & & 135 & $1.7(1.4)$ & \\
\hline $9-15$ & 24 & $2.4(1.4)$ & 0.555 & 46 & $2.1(1.3)$ & 0.640 \\
\hline $16+$ & 13 & $2.1(1.7)$ & & 18 & $1.8(1.3)$ & \\
\hline \multicolumn{7}{|l|}{ Buffalo Women } \\
\hline $0-8$ & 37 & $0.8(1.0)$ & & 28 & $0.9(1.2)$ & \\
\hline $9-15$ & 14 & $0.7(1.1)$ & 0.152 & 7 & $2.0(1.7)$ & 0.891 \\
\hline $16+$ & 8 & $1.3(0.9)$ & & 9 & $0.6(0.7)$ & \\
\hline \multicolumn{7}{|l|}{ Spokane Men } \\
\hline $0-8$ & 30 & $1.9(1.5)$ & & 58 & $1.8(1.1)$ & \\
\hline $9-15$ & 8 & $2.4(1.5)$ & 0.022 & 14 & $2.7(1.3)$ & 0.070 \\
\hline $16+$ & 6 & $3.5(1.4)$ & & 5 & $2.6(1.8)$ & \\
\hline \multicolumn{7}{|l|}{ Spokane Women } \\
\hline $0-8$ & 1 & $0.0(-)$ & & 6 & $1.3(1.8)$ & \\
\hline $9-15$ & 2 & $3.5(2.1)$ & 0.506 & - & - & - \\
\hline $16+$ & - & - & & - & - & \\
\hline
\end{tabular}

* p-values are based on the continuous CES-D score

\section{Interaction: Smoking Status and CESD}

BCOPS Men: $p$-value $=0.819$

BCOPS Women: $\mathrm{p}$-value $=0.312$

Spokane Men: $\mathrm{p}$-value $=0.354$

Spokane Women: $\mathrm{p}$-value $=0.021$ 
APPENDIX C 
Table C.1a. Mean number of metabolic syndrome components by demographic and lifestyle characteristics, BCOPS Study, visit 3.

\begin{tabular}{|c|c|c|c|c|c|c|}
\hline & \multicolumn{6}{|c|}{$\begin{array}{c}\text { Metabolic Syndrome Components } \\
\text { Mean (SD) }\end{array}$} \\
\hline & Men & $\begin{array}{c}\mathrm{p}- \\
\text { value }\end{array}$ & Women & $\begin{array}{c}\mathrm{p}- \\
\text { value }\end{array}$ & Total & $\begin{array}{c}\mathrm{p}- \\
\text { value }\end{array}$ \\
\hline \multicolumn{7}{|l|}{ Gender } \\
\hline Male & & & & & $1.9(1.4)$ & \multirow{2}{*}{$<0.0001$} \\
\hline Female & & & & & $0.9(1.1)$ & \\
\hline \multicolumn{7}{|l|}{ Age Group } \\
\hline$<40$ years & $1.6(1.4)$ & \multirow{3}{*}{0.0014} & $0.9(1.2)$ & \multirow{3}{*}{0.1710} & $1.4(1.3)$ & \multirow{3}{*}{0.0003} \\
\hline $40-49$ years & $2.1(1.4)$ & & $0.8(1.1)$ & & $1.7(1.4)$ & \\
\hline $50+$ years & $2.4(1.5)$ & & $1.4(1.1)$ & & $2.2(1.5)$ & \\
\hline \multicolumn{7}{|l|}{ Education } \\
\hline$>12$ years, High & & & & & & \\
\hline School/GED & $1.9(1.3)$ & \multirow{3}{*}{0.7622} & $1.0(1.2)$ & \multirow{3}{*}{1.0000} & $1.9(1.3)$ & \multirow{3}{*}{0.6676} \\
\hline College $<4$ years & $2.0(1.4)$ & & $0.8(1.1)$ & & $1.7(1.4)$ & \\
\hline College $4+$ years & $1.9(1.5)$ & & $1.0(1.2)$ & & $1.6(1.5)$ & \\
\hline \multicolumn{7}{|l|}{ Marital Status } \\
\hline Single & $1.5(1.2)$ & \multirow{3}{*}{0.1402} & $0.5(1.0)$ & \multirow{3}{*}{0.1642} & $1.1(1.2)$ & \multirow{3}{*}{0.0045} \\
\hline Married & $1.9(1.4)$ & & $1.0(1.1)$ & & $1.7(1.4)$ & \\
\hline Divorced & $2.2(1.5)$ & & $1.1(1.0)$ & & $1.8(1.5)$ & \\
\hline \multicolumn{7}{|l|}{ Years of Police Service } \\
\hline $1-5$ years & $1.6(1.3)$ & \multirow{5}{*}{0.0008} & $0.5(0.7)$ & \multirow{5}{*}{0.0379} & $1.5(1.3)$ & \multirow{5}{*}{0.0011} \\
\hline $6-10$ years & $1.5(1.4)$ & & $0.8(1.1)$ & & $1.3(1.3)$ & \\
\hline $11-15$ years & $1.8(1.5)$ & & $0.7(0.9)$ & & $1.6(1.4)$ & \\
\hline $16-20$ years & $2.1(1.2)$ & & $1.0(1.3)$ & & $1.8(1.4)$ & \\
\hline $20+$ years & $2.4(1.5)$ & & $1.4(0.9)$ & & $2.2(1.5)$ & \\
\hline \multicolumn{7}{|l|}{ Rank } \\
\hline Police Officer & $1.8(1.4)$ & \multirow{3}{*}{0.0196} & $0.9(1.1)$ & \multirow{3}{*}{0.3457} & $1.5(1.4)$ & \multirow{3}{*}{0.0144} \\
\hline Sergeant / Lieutenant & $2.3(1.4)$ & & $1.1(1.6)$ & & $2.0(1.5)$ & \\
\hline Capt / Det / Chief / Comm & $2.3(1.4)$ & & $0.5(0.7)$ & & $2.0(1.5)$ & \\
\hline
\end{tabular}




\begin{tabular}{|c|c|c|c|c|c|c|}
\hline 0 & $1.6(1.4)$ & \multirow{5}{*}{0.4281} & $0.8(1.0)$ & \multirow{5}{*}{0.4190} & $1.3(1.3)$ & \multirow{5}{*}{0.1065} \\
\hline$<1$ & $2.0(1.5)$ & & $1.0(1.2)$ & & $1.7(1.5)$ & \\
\hline $1-7$ & $2.0(1.3)$ & & $0.8(1.1)$ & & $1.8(1.4)$ & \\
\hline $8-14$ & $1.9(1.5)$ & & $0.2(0.4)$ & & $1.6(1.5)$ & \\
\hline$>14$ & $2.0(1.7)$ & & $1.7(1.0)$ & & $1.9(1.6)$ & \\
\hline \multicolumn{7}{|c|}{ Smoking Status } \\
\hline Current & $2.1(1.5)$ & \multirow{3}{*}{0.1133} & $0.9(1.0)$ & \multirow{3}{*}{0.6798} & $1.6(1.5)$ & \multirow{3}{*}{0.7438} \\
\hline Former & $2.2(1.5)$ & & $0.8(1.0)$ & & $1.8(1.5)$ & \\
\hline Never & $1.8(1.4)$ & & $1.0(1.3)$ & & $1.7(1.4)$ & \\
\hline \multirow{2}{*}{\multicolumn{7}{|c|}{$\begin{array}{l}\text { Physical Activity } \\
\text { (Tertiles of METS/week) }\end{array}$}} \\
\hline & & & & & & \\
\hline 0 & $2.0(1.5)$ & \multirow{3}{*}{0.7625} & $1.0(1.2)$ & \multirow{3}{*}{0.4188} & $1.7(1.5)$ & \multirow{3}{*}{0.3341} \\
\hline 1 & $2.0(1.4)$ & & $0.8(1.0)$ & & $1.7(1.4)$ & \\
\hline 2 & $1.8(1.4)$ & & $0.8(1.1)$ & & $1.6(1.4)$ & \\
\hline \multicolumn{7}{|c|}{ Body Mass Index $\left(\mathrm{kg} / \mathrm{m}^{2}\right)$} \\
\hline$<25$ & $1.0(1.2)$ & \multirow{3}{*}{$\begin{array}{c}<0.000 \\
1\end{array}$} & $0.5(0.7)$ & \multirow{3}{*}{$\begin{array}{c}<0.000 \\
1\end{array}$} & $0.6(0.9)$ & \multirow{3}{*}{$<0.0001$} \\
\hline $25-30$ & $1.4(1.3)$ & & $0.9(1.0)$ & & $1.3(1.2)$ & \\
\hline$>30$ & $2.6(1.3)$ & & $2.1(1.4)$ & & $2.5(1.3)$ & \\
\hline
\end{tabular}

${ }^{+} \mathrm{p}$-values compare outcome variables across categories (ANOVA)

* p-values from regression analyses (trend p-values) 
Table C.1b. Mean maximum carotid artery thickness ${ }_{12}$ by demographic and lifestyle characteristics, BCOPS Study, visit 3.

\begin{tabular}{|c|c|c|c|c|c|c|}
\hline & \multicolumn{6}{|c|}{$\begin{array}{l}\text { Mean Maximum Carotid Artery Thickness } \\
\text { Mean (SD) }\end{array}$} \\
\hline & Men & $\begin{array}{c}\mathrm{p}- \\
\text { value }\end{array}$ & Women & $\begin{array}{c}\mathrm{p}- \\
\text { value }\end{array}$ & Total & $\begin{array}{c}\mathrm{p}- \\
\text { value }\end{array}$ \\
\hline \multicolumn{7}{|l|}{ Gender } \\
\hline Male & & & & & $0.91(0.18)$ & $<0.000$ \\
\hline Female & & & & & $0.83(0.13)$ & 1 \\
\hline \multicolumn{7}{|l|}{ Age Group } \\
\hline$<40$ years & $0.83(0.14)$ & \multirow{3}{*}{$<0.0001$} & $0.78(0.11)$ & \multirow{3}{*}{0.0005} & $0.82(0.14)$ & \multirow{3}{*}{$\begin{array}{l}<0.000 \\
1\end{array}$} \\
\hline $40-49$ years & $0.94(0.14)$ & & $0.84(0.13)$ & & $0.91(0.14)$ & \\
\hline $50+$ years & $1.07(0.24)$ & & $0.94(0.15)$ & & $1.05(0.23)$ & \\
\hline \multicolumn{7}{|l|}{ Education } \\
\hline$>12$ years, High & & & $0.84(0.08)$ & \multirow{4}{*}{0.9560} & $0.94(0.18)$ & \multirow{4}{*}{0.1674} \\
\hline School/GED & $0.95(0.19)$ & \multirow{3}{*}{0.1846} & & & & \\
\hline College $<4$ years & $0.91(0.18)$ & & $0.83(0.14)$ & & $0.89(0.18)$ & \\
\hline College $4+$ years & $0.90(0.17)$ & & $0.83(0.11)$ & & $0.88(0.16)$ & \\
\hline \multicolumn{7}{|l|}{ Marital Status } \\
\hline Single & $0.88(0.16)$ & \multirow{3}{*}{0.2996} & $0.82(0.11)$ & \multirow{3}{*}{0.2297} & $0.85(0.14)$ & \multirow{3}{*}{0.1163} \\
\hline Married & $0.91(0.19)$ & & $0.82(0.13)$ & & $0.89(0.18)$ & \\
\hline Divorced & $0.95(0.15)$ & & $0.87(0.13)$ & & $0.92(0.14)$ & \\
\hline \multicolumn{7}{|l|}{ Years of Police Service } \\
\hline $1-5$ years & $0.78(0.15)$ & \multirow{5}{*}{$<0.0001$} & $0.78(0.09)$ & \multirow{5}{*}{0.0111} & $0.78(0.13)$ & \multirow{5}{*}{$\begin{array}{l}<0.000 \\
1\end{array}$} \\
\hline $6-10$ years & $0.87(0.18)$ & & $0.79(0.12)$ & & $0.85(0.16)$ & \\
\hline $11-15$ years & $0.87(0.14)$ & & $0.82(0.12)$ & & $0.86(0.14)$ & \\
\hline $16-20$ years & $0.93(0.14)$ & & $0.85(0.15)$ & & $0.91(0.15)$ & \\
\hline $20+$ years & $1.02(0.20)$ & & $0.88(0.12)$ & & $1.00(0.19)$ & \\
\hline \multicolumn{7}{|l|}{ Rank } \\
\hline Police Officer & $0.89(0.17)$ & \multirow{3}{*}{0.0012} & $0.83(0.14)$ & \multirow{3}{*}{0.9442} & $0.87(0.16)$ & \multirow{3}{*}{0.0005} \\
\hline Sergeant / Lieutenant & $0.96(0.24)$ & & $0.83(0.10)$ & & $0.94(0.22)$ & \\
\hline Capt / Det / Chief / Comm & $0.97(0.15)$ & & $0.84(0.08)$ & & $0.95(0.15)$ & \\
\hline
\end{tabular}




\begin{tabular}{|c|c|c|c|c|c|c|}
\hline 0 & $0.93(0.17)$ & \multirow{5}{*}{0.6136} & $0.86(0.13)$ & \multirow{5}{*}{0.1428} & $0.90(0.16)$ & \multirow{5}{*}{0.6378} \\
\hline$<1$ & $0.92(0.19)$ & & $0.83(0.16)$ & & $0.89(0.19)$ & \\
\hline $1-7$ & $0.91(0.18)$ & & $0.83(0.12)$ & & $0.89(0.17)$ & \\
\hline $8-14$ & $0.92(0.20)$ & & $0.75(0.06)$ & & $0.89(0.19)$ & \\
\hline$>14$ & $0.90(0.16)$ & & $0.80(0.08)$ & & $0.89(0.15)$ & \\
\hline \multicolumn{7}{|c|}{ Smoking Status } \\
\hline Current & $0.94(0.24)$ & \multirow{3}{*}{0.2606} & $0.85(0.12)$ & \multirow{3}{*}{0.2765} & $0.90(0.20)$ & \multirow{3}{*}{0.5542} \\
\hline Former & $0.93(0.20)$ & & $0.83(0.15)$ & & $0.90(0.19)$ & \\
\hline Never & $0.90(0.16)$ & & $0.80(0.10)$ & & $0.88(0.15)$ & \\
\hline \multicolumn{7}{|c|}{$\begin{array}{l}\text { Physical Activity } \\
\text { (Tertiles of METS/week) }\end{array}$} \\
\hline 0 & $0.90(0.17)$ & \multirow{3}{*}{0.0963} & $0.81(0.13)$ & \multirow{3}{*}{0.2894} & $0.87(0.16)$ & \multirow{3}{*}{0.0606} \\
\hline 1 & $0.90(0.20)$ & & $0.83(0.14)$ & & $0.89(0.19)$ & \\
\hline 2 & $0.94(0.16)$ & & $0.84(0.13)$ & & $0.91(0.16)$ & \\
\hline \multicolumn{7}{|c|}{ Body Mass Index $\left(\mathrm{kg} / \mathrm{m}^{2}\right)$} \\
\hline$<25$ & $0.86(0.19)$ & \multirow{3}{*}{0.3857} & $0.83(0.12)$ & \multirow{3}{*}{0.9147} & $0.84(0.15)$ & \multirow{3}{*}{0.0264} \\
\hline $25-30$ & $0.93(0.19)$ & & $0.83(0.12)$ & & $0.91(0.18)$ & \\
\hline$>30$ & $0.90(0.16)$ & & $0.83(0.17)$ & & $0.89(0.16)$ & \\
\hline
\end{tabular}

${ }^{+} \mathrm{p}$-values compare outcome variables across categories (ANOVA)

* p-values from regression analyses (trend p-values) 
Table C.1c. Mean maximum carotid artery thickness 36 by demographic and lifestyle characteristics, BCOPS Study, visit 3.

\begin{tabular}{|c|c|c|c|c|c|c|}
\hline & \multicolumn{6}{|c|}{$\begin{array}{c}\text { Mean Maximum Carotid Artery Thickness } \\
\text { Mean (SD) }\end{array}$} \\
\hline & Men & $\begin{array}{c}\mathrm{p}- \\
\text { value }\end{array}$ & Women & $\begin{array}{c}\mathrm{p}- \\
\text { value }\end{array}$ & Total & $\begin{array}{c}\mathrm{p}- \\
\text { value }\end{array}$ \\
\hline \multicolumn{7}{|l|}{ Gender } \\
\hline Male & & & & & $0.80(0.15)$ & $<0.000$ \\
\hline Female & & & & & $0.73(0.10)$ & 1 \\
\hline \multicolumn{7}{|l|}{ Age Group } \\
\hline$<40$ years & $0.72(0.10)$ & \multirow{3}{*}{$<0.0001$} & $0.69(0.08)$ & \multirow{3}{*}{$\begin{array}{c}<0.000 \\
1\end{array}$} & $0.71(0.10)$ & \multirow{3}{*}{$\begin{array}{c}<0.000 \\
1\end{array}$} \\
\hline $40-49$ years & $0.84(0.13)$ & & $0.74(0.09)$ & & $0.81(0.13)$ & \\
\hline $50+$ years & $0.92(0.19)$ & & $0.85(0.15)$ & & $0.91(0.18)$ & \\
\hline \multicolumn{7}{|l|}{ Education } \\
\hline$>12$ years, High & & & $0.72(0.05)$ & \multirow{4}{*}{0.7524} & $0.81(0.14)$ & \multirow{4}{*}{0.3335} \\
\hline School/GED & $0.82(0.14)$ & \multirow{3}{*}{0.2755} & & & & \\
\hline College $<4$ years & $0.80(0.16)$ & & $0.73(0.11)$ & & $0.78(0.15)$ & \\
\hline College $4+$ years & $0.79(0.13)$ & & $0.73(0.10)$ & & $0.78(0.12)$ & \\
\hline \multicolumn{7}{|l|}{ Marital Status } \\
\hline Single & $0.77(0.13)$ & \multirow{3}{*}{0.3692} & $0.71(0.09)$ & \multirow{3}{*}{0.1941} & $0.74(0.12)$ & \multirow{3}{*}{0.0749} \\
\hline Married & $0.80(0.16)$ & & $0.72(0.11)$ & & $0.79(0.15)$ & \\
\hline Divorced & $0.82(0.12)$ & & $0.76(0.10)$ & & $0.80(0.12)$ & \\
\hline \multicolumn{7}{|l|}{ Years of Police Service } \\
\hline $1-5$ years & $0.68(0.11)$ & \multirow{5}{*}{$<0.0001$} & $0.67(0.08)$ & \multirow{5}{*}{0.0027} & $0.69(0.10)$ & \multirow{5}{*}{$\begin{array}{c}<0.000 \\
1\end{array}$} \\
\hline $6-10$ years & $0.76(0.13)$ & & $0.70(0.09)$ & & $0.74(0.12)$ & \\
\hline $11-15$ years & $0.77(0.10)$ & & $0.72(0.07)$ & & $0.76(0.10)$ & \\
\hline $16-20$ years & $0.81(0.10)$ & & $0.76(0.13)$ & & $0.79(0.11)$ & \\
\hline $20+$ years & $0.91(0.18)$ & & $0.77(0.09)$ & & $0.88(0.18)$ & \\
\hline \multicolumn{7}{|l|}{ Rank } \\
\hline Police Officer & $0.78(0.13)$ & \multirow{3}{*}{$<0.0001$} & $0.73(0.11)$ & \multirow{3}{*}{0.8049} & $0.76(0.12)$ & \multirow{3}{*}{$\begin{array}{c}<0.000 \\
1\end{array}$} \\
\hline Sergeant / Lieutenant & $0.85(0.18)$ & & $0.75(0.08)$ & & $0.83(0.17)$ & \\
\hline Capt / Det / Chief / Comm & $0.87(0.18)$ & & $0.73(0.07)$ & & $0.84(0.17)$ & \\
\hline
\end{tabular}




\begin{tabular}{|c|c|c|c|c|c|c|}
\hline 0 & $0.81(0.13)$ & \multirow{5}{*}{0.7050} & $0.75(0.11)$ & \multirow{5}{*}{0.2422} & $0.79(0.13)$ & \multirow{5}{*}{0.6149} \\
\hline$<1$ & $0.80(0.15)$ & & $0.73(0.09)$ & & $0.78(0.14)$ & \\
\hline $1-7$ & $0.79(0.13)$ & & $0.73(0.11)$ & & $0.78(0.13)$ & \\
\hline $8-14$ & $0.81(0.16)$ & & $0.67(0.06)$ & & $0.79(0.16)$ & \\
\hline$>14$ & $0.82(0.22)$ & & $0.72(0.08)$ & & $0.80(0.21)$ & \\
\hline \multicolumn{7}{|c|}{ Smoking Status } \\
\hline Current & $0.81(0.19)$ & \multirow{3}{*}{0.0327} & $0.72(0.10)$ & \multirow{3}{*}{0.2802} & $0.77(0.16)$ & \multirow{3}{*}{0.0619} \\
\hline Former & $0.84(0.20)$ & & $0.75(0.13)$ & & $0.81(0.19)$ & \\
\hline Never & $0.79(0.12)$ & & $0.71(0.08)$ & & $0.77(0.11)$ & \\
\hline \multirow{2}{*}{\multicolumn{7}{|c|}{$\begin{array}{l}\text { Physical Activity } \\
\text { (Tertiles of METS/week) }\end{array}$}} \\
\hline & & & & & & \\
\hline 0 & $0.78(0.12)$ & \multirow{3}{*}{0.0465} & $0.72(0.10)$ & \multirow{3}{*}{0.4913} & $0.77(0.12)$ & \multirow{3}{*}{0.0444} \\
\hline 1 & $0.80(0.16)$ & & $0.74(0.12)$ & & $0.78(0.15)$ & \\
\hline 2 & $0.83(0.17)$ & & $0.73(0.10)$ & & $0.80(0.15)$ & \\
\hline \multicolumn{7}{|c|}{ Body Mass Index $\left(\mathrm{kg} / \mathrm{m}^{2}\right)$} \\
\hline$<25$ & $0.76(0.15)$ & \multirow{3}{*}{0.1464} & $0.72(0.10)$ & \multirow{3}{*}{0.0321} & $0.73(0.12)$ & \multirow{3}{*}{0.0002} \\
\hline $25-30$ & $0.80(0.15)$ & & $0.72(0.08)$ & & $0.79(0.14)$ & \\
\hline$>30$ & $0.81(0.15)$ & & $0.78(0.14)$ & & $0.80(0.15)$ & \\
\hline
\end{tabular}

${ }^{+} \mathrm{p}$-values compare outcome variables across categories (ANOVA)

* p-values from regression analyses (trend p-values) 
Table C.1d. Mean common carotid artery thickness by demographic and lifestyle characteristics, BCOPS Study, visit 3.

\begin{tabular}{|c|c|c|c|c|c|c|}
\hline & \multicolumn{6}{|c|}{$\begin{array}{c}\text { Mean Common Carotid Artery Thickness } \\
\text { Mean (SD) }\end{array}$} \\
\hline & Men & $\begin{array}{c}\mathrm{p}- \\
\text { value }\end{array}$ & Women & $\begin{array}{c}\mathrm{p}- \\
\text { value }\end{array}$ & Total & $\begin{array}{c}\mathrm{p}- \\
\text { value }\end{array}$ \\
\hline \multicolumn{7}{|l|}{ Gender } \\
\hline Male & & & & & $0.63(0.11)$ & \multirow{2}{*}{0.0005} \\
\hline Female & & & & & $0.59(0.08)$ & \\
\hline \multicolumn{7}{|l|}{ Age Group } \\
\hline$<40$ years & $0.58(0.07)$ & \multirow{3}{*}{$<0.0001$} & $0.56(0.07)$ & \multirow{3}{*}{0.0003} & $0.57(0.07)$ & \multirow{3}{*}{$\begin{array}{c}<0.000 \\
1\end{array}$} \\
\hline $40-49$ years & $0.65(0.08)$ & & $0.60(0.07)$ & & $0.63(0.08)$ & \\
\hline $50+$ years & $0.71(0.15)$ & & $0.66(0.09)$ & & $0.70(0.14)$ & \\
\hline \multicolumn{7}{|l|}{ Education } \\
\hline$>12$ years, High & & \multirow{4}{*}{0.2397} & $0.59(0.07)$ & \multirow{4}{*}{0.8517} & $063(009)$ & \multirow{4}{*}{0.1815} \\
\hline School/GED & $0.63(0.09)$ & & & & & \\
\hline College $<4$ years & $0.64(0.12)$ & & $0.58(0.08)$ & & $0.62(0.11)$ & \\
\hline College $4+$ years & $0.61(0.09)$ & & $0.59(0.07)$ & & $0.60(0.09)$ & \\
\hline \multicolumn{7}{|l|}{ Marital Status } \\
\hline Single & $0.62(0.11)$ & \multirow{3}{*}{0.1034} & $0.56(0.07)$ & \multirow{3}{*}{0.0478} & $0.60(0.10)$ & \multirow{3}{*}{0.0221} \\
\hline Married & $0.62(0.10)$ & & $0.58(0.07)$ & & $0.61(0.09)$ & \\
\hline Divorced & $0.66(0.14)$ & & $0.62(0.09)$ & & $0.65(0.12)$ & \\
\hline \multicolumn{7}{|l|}{ Years of Police Service } \\
\hline $1-5$ years & $0.56(0.09)$ & \multirow{5}{*}{$<0.0001$} & $0.55(0.07)$ & \multirow{5}{*}{0.0029} & $0.56(0.09)$ & \multirow{5}{*}{$\begin{array}{c}<0.000 \\
1\end{array}$} \\
\hline $6-10$ years & $0.60(0.10)$ & & $0.57(0.08)$ & & $0.59(0.09)$ & \\
\hline $11-15$ years & $0.61(0.07)$ & & $0.59(0.07)$ & & $0.60(0.07)$ & \\
\hline $16-20$ years & $0.63(0.08)$ & & $0.59(0.07)$ & & $0.62(0.82)$ & \\
\hline $20+$ years & $0.69(0.12)$ & & $0.63(0.09)$ & & $0.68(0.12)$ & \\
\hline \multicolumn{7}{|l|}{ Rank } \\
\hline Police Officer & $0.61(0.10)$ & \multirow{3}{*}{0.0023} & $0.58(0.08)$ & \multirow{3}{*}{0.5413} & $0.60(0.09)$ & \multirow{3}{*}{0.0005} \\
\hline Sergeant / Lieutenant & $0.65(0.14)$ & & $0.61(0.07)$ & & $0.64(0.13)$ & \\
\hline Capt / Det / Chief / Comm & $0.66(0.10)$ & & $0.59(0.06)$ & & $0.65(0.10)$ & \\
\hline
\end{tabular}




\begin{tabular}{|c|c|c|c|c|c|c|}
\hline 0 & $0.63(0.10)$ & \multirow{5}{*}{0.7987} & $0.60(0.09)$ & \multirow{5}{*}{0.3093} & $0.62(0.10)$ & \multirow{5}{*}{0.8476} \\
\hline$<1$ & $0.61(0.09)$ & & $0.59(0.07)$ & & $0.60(0.08)$ & \\
\hline $1-7$ & $0.63(0.10)$ & & $0.59(0.08)$ & & $0.62(0.10)$ & \\
\hline $8-14$ & $0.64(0.13)$ & & $0.54(0.06)$ & & $0.62(0.13)$ & \\
\hline$>14$ & $0.62(0.12)$ & & $0.59(0.06)$ & & $0.61(0.11)$ & \\
\hline \multicolumn{7}{|c|}{ Smoking Status } \\
\hline Current & $0.64(0.10)$ & \multirow{3}{*}{0.0205} & $0.59(0.09)$ & \multirow{3}{*}{0.2657} & $0.62(0.10)$ & \multirow{3}{*}{0.0409} \\
\hline Former & $0.65(0.13)$ & & $0.60(0.09)$ & & $0.64(0.12)$ & \\
\hline Never & $0.61(0.10)$ & & $0.57(0.06)$ & & $0.61(0.09)$ & \\
\hline \multicolumn{7}{|c|}{$\begin{array}{l}\text { Physical Activity } \\
\text { (Tertiles of METS/week) }\end{array}$} \\
\hline 0 & $0.62(0.09)$ & \multirow{3}{*}{0.1228} & $0.58(0.07)$ & \multirow{3}{*}{0.4060} & $0.61(0.09)$ & \multirow{3}{*}{0.0897} \\
\hline 1 & $0.62(0.10)$ & & $0.58(0.07)$ & & $0.61(0.10)$ & \\
\hline 2 & $0.64(0.12)$ & & $0.60(0.09)$ & & $0.63(0.11)$ & \\
\hline \multicolumn{7}{|c|}{ Body Mass Index $\left(\mathrm{kg} / \mathrm{m}^{2}\right)$} \\
\hline$<25$ & $0.58(0.08)$ & \multirow{3}{*}{0.0117} & $0.59(0.09)$ & \multirow{3}{*}{0.1257} & $0.58(0.09)$ & \multirow{3}{*}{0.0002} \\
\hline $25-30$ & $0.62(0.11)$ & & $0.57(0.06)$ & & $0.61(0.10)$ & \\
\hline$>30$ & $0.64(0.11)$ & & $0.62(0.07)$ & & $0.64(0.10)$ & \\
\hline
\end{tabular}

${ }^{+} \mathrm{p}$-values compare outcome variables across categories (ANOVA)

$* \mathrm{p}$-values from regression analyses (trend p-values) 
Table C.1e. Mean number of metabolic syndrome components and mean carotid artery thickness ( 3 variables) by potential blood parameters, BCOPS Study, visit 3.

\begin{tabular}{|c|c|c|c|c|c|c|c|c|}
\hline & \multicolumn{2}{|c|}{$\begin{array}{c}\text { Mean Number of } \\
\text { MetSyn Components }\end{array}$} & \multicolumn{2}{|c|}{$\begin{array}{c}\text { Mean Maximum } \\
\text { IMT }_{12}\end{array}$} & \multicolumn{2}{|c|}{$\begin{array}{c}\text { Mean Maximum } \\
\mathrm{IMT}_{36} \\
\end{array}$} & \multicolumn{2}{|c|}{$\begin{array}{c}\text { Mean Common } \\
\text { Carotid IMT } \\
\end{array}$} \\
\hline & $\mathrm{r}$ & p-value & $\mathrm{r}$ & $\mathrm{p}$-value & $\mathrm{r}$ & p-value & $\mathrm{r}$ & p-value \\
\hline \multicolumn{9}{|c|}{ Total Cholesterol } \\
\hline Men & 0.0599 & 0.2979 & 0.0709 & 0.2174 & 0.0780 & 0.1748 & 0.1019 & 0.0759 \\
\hline Women & 0.3517 & 0.0002 & -0.0167 & 0.8651 & 0.0854 & 0.3839 & 0.0975 & 0.3201 \\
\hline Total & 0.1486 & 0.0026 & 0.0726 & 0.1422 & 0.0988 & 0.0457 & 0.1155 & 0.0193 \\
\hline \multicolumn{9}{|c|}{ LDL Cholesterol } \\
\hline Men & -0.1052 & 0.0673 & 0.0927 & 0.1075 & 0.0815 & 0.1568 & 0.0931 & 0.1057 \\
\hline Women & 0.3668 & 0.0001 & 0.1023 & 0.2990 & 0.2172 & 0.0261 & 0.1703 & 0.0824 \\
\hline Total & 0.0386 & 0.4374 & 0.1227 & 0.0132 & 0.1351 & 0.0063 & 0.1304 & 0.0084 \\
\hline \multicolumn{9}{|l|}{ HOMA } \\
\hline Men & 0.4500 & $<0.0001$ & 0.0786 & 0.1732 & 0.0974 & 0.0912 & 0.1491 & 0.0095 \\
\hline Women & 0.5806 & $<0.0001$ & -0.0298 & 0.7614 & 0.1809 & 0.0636 & 0.1422 & 0.1460 \\
\hline Total & 0.4820 & $<0.0001$ & 0.1054 & 0.0334 & 0.1413 & 0.0042 & 0.1738 & 0.0004 \\
\hline
\end{tabular}


Table C.1f. Significant associations between variables of interest and demographic and lifestyle characteristics.

\begin{tabular}{lccccc}
\hline Variable & $\begin{array}{c}\text { Mean Number of } \\
\text { MetSyn Components }\end{array}$ & $\begin{array}{c}\text { Mean Maximum } \\
\text { IMT }_{12}\end{array}$ & $\begin{array}{c}\text { Mean Maximum } \\
\text { IMT }_{36}\end{array}$ & $\begin{array}{c}\text { Mean Common } \\
\text { Carotid IMT }\end{array}$ & Decision to Adjust \\
\hline Gender & Yes & Yes & Yes & Stratify \\
Age & Men & Men, Women, Total & Men, Women, Total & Men, Women, Total & Yes + literature \\
Education & & & & No \\
Marital Status & Total & & & Women, Total & No \\
Police Service & Men, Women, Total & Men, Women, Total & Men, Women, Total & Men, Women, Total & No, $<0.0001$ with age \\
Rank & Men, Total & Men, Total & Men, Total & Men, Total & No, <0.0001 with age \\
Alcohol & & & & No \\
Smoking & & & Men, Total & Yes, literature \\
Physical Activity & & & Men, Total & No \\
BMI & Men, Women, Total & Total & Women, Total & Men, Total & No \\
Total Cholesterol & Women, Total & Total & No \\
LDL-Cholesterol & Women & Total & Women, Total & Total & Yes + literature \\
HOMA-IR & Men, Women, Total & Total & Total & Men, Total & No \\
\hline
\end{tabular}

Kramer, Kawamoto, Ma: age, sex, smoking, LDL-C

Koskinen: age, sex, smoking, CRP, LDL-C, family hx of CAD

Kawamoto: age, BMI, smoking, LDL-C, uric acid; gender-stratified

Tzou: age, gender, race, smoking

Baldassarre: age, gender, individual MetSyn components

Petrulioniene: age, gender, smoking 
Table C.2a. Unadjusted and adjusted mean maximum carotid artery thickness ${ }_{12}$ by number of metabolic syndrome components by gender, BCOPS Study, visit 3.

\begin{tabular}{|c|c|c|c|c|c|}
\hline & \multicolumn{5}{|c|}{ Number of Metabolic Syndrome Components } \\
\hline & 0 & 1 & 2 & $\geq 3$ & p-value* \\
\hline \multicolumn{6}{|l|}{ Men } \\
\hline Model 1: Unadjusted & $0.898(0.176)$ & $0.857(0.128)$ & $0.940(0.160)$ & $0.939(0.218)$ & 0.0299 \\
\hline Model 2: Age-Adjusted & $0.929(0.021)$ & $0.878(0.018)$ & $0.930(0.018)$ & $0.914(0.016)$ & 0.9048 \\
\hline Model 3: Age- and Smoking Adjusted & $0.935(0.022)$ & $0.886(0.019)$ & $0.935(0.019)$ & $0.921(0.017)$ & 0.9448 \\
\hline Model 4: Age- and LDL-C Adjusted & $0.929(0.021)$ & $0.877(0.018)$ & $0.925(0.018)$ & $0.919(0.016)$ & 0.8192 \\
\hline Model 5: Multivariate Adjusted** & $0.936(0.022)$ & $0.886(0.019)$ & $0.931(0.019)$ & $0.926(0.017)$ & 0.8664 \\
\hline \multicolumn{6}{|l|}{ Women } \\
\hline Model 1: Unadjusted & $0.815(0.110)$ & $0.830(0.113)$ & $0.840(0.168)$ & $0.872(0.179)$ & 0.2164 \\
\hline Model 2: Age-Adjusted & $0.823(0.017)$ & $0.827(0.025)$ & $0.831(0.027)$ & $0.857(0.041)$ & 0.4349 \\
\hline Model 3: Age- and Smoking Adjusted & $0.816(0.016)$ & $0.831(0.024)$ & $0.832(0.026)$ & $0.862(0.039)$ & 0.2994 \\
\hline Model 4: Age- and LDL-C Adjusted & $0.822(0.017)$ & $0.827(0.025)$ & $0.832(0.028)$ & $0.876(0.045)$ & 0.2803 \\
\hline Model 5: Multivariate Adjusted** & $0.816(0.017)$ & $0.831(0.024)$ & $0.832(0.026)$ & $0.877(0.043)$ & 0.2142 \\
\hline \multicolumn{6}{|l|}{ Total } \\
\hline Model 1: Unadjusted & $0.857(0.152)$ & $0.850(0.124)$ & $0.919(0.166)$ & $0.934(0.215)$ & $<0.0001$ \\
\hline Model 2: Age- and Gender-Adjusted & $0.878(0.014)$ & $0.843(0.016)$ & $0.886(0.016)$ & $0.877(0.016)$ & 0.5720 \\
\hline Model 3: Age-, Gender- and Smoking Adjusted & $0.878(0.015)$ & $0.850(0.016)$ & $0.888(0.016)$ & $0.880(0.016)$ & 0.5382 \\
\hline Model 4: Age-, Gender- and LDL-C Adjusted & $0.880(0.014)$ & $0.843(0.016)$ & $0.883(0.016)$ & $0.882(0.017)$ & 0.5314 \\
\hline Model 5: Multivariate Adjusted** & $0.882(0.015)$ & $0.850(0.016)$ & $0.885(0.016)$ & $0.885(0.017)$ & 0.5069 \\
\hline
\end{tabular}

Note: Values are mean (SD) for unadjusted model or (SE) for adjusted models.

* Test for linear trend based on linear contrast

** Adjusted for age, smoking status and LDL-C. Total multivariate-adjusted model also included gender. 
Table C.2b. Unadjusted and adjusted mean maximum carotid artery thickness 36 by number of metabolic syndrome components by gender, BCOPS Study, visit 3.

\begin{tabular}{|c|c|c|c|c|c|}
\hline & \multicolumn{5}{|c|}{ Number of Metabolic Syndrome Components } \\
\hline & 0 & 1 & 2 & $\geq 3$ & p-value* \\
\hline \multicolumn{6}{|l|}{ Men } \\
\hline Model 1: Unadjusted & $0.780(0.142)$ & $0.757(0.111)$ & $0.818(0.126)$ & $0.835(0.183)$ & 0.0043 \\
\hline Model 2: Age-Adjusted & $0.808(0.017)$ & $0.776(0.015)$ & $0.809(0.014)$ & $0.812(0.013)$ & 0.4876 \\
\hline Model 3: Age- and Smoking Adjusted & $0.814(0.018)$ & $0.782(0.016)$ & $0.816(0.015)$ & $0.817(0.013)$ & 0.5327 \\
\hline Model 4: Age- and LDL-C Adjusted & $0.807(0.170)$ & $0.775(0.014)$ & $0.805(0.014)$ & $0.816(0.013)$ & 0.4234 \\
\hline Model 5: Multivariate Adjusted** & $0.815(0.018)$ & $0.781(0.016)$ & $0.812(0.015)$ & $0.821(0.014)$ & 0.4662 \\
\hline \multicolumn{6}{|l|}{ Women } \\
\hline Model 1: Unadjusted & $0.704(0.083)$ & $0.735(0.097)$ & $0.752(0.112)$ & $0.807(0.173)$ & 0.0042 \\
\hline Model 2: Age-Adjusted & $0.711(0.012)$ & $0.732(0.018)$ & $0.744(0.020)$ & $0.794(0.030)$ & 0.0128 \\
\hline Model 3: Age- and Smoking Adjusted & $0.706(0.013)$ & $0.735(0.018)$ & $0.745(0.020)$ & $0.800(0.030)$ & 0.0058 \\
\hline Model 4: Age- and LDL-C Adjusted & $0.712(0.013)$ & $0.731(0.019)$ & $0.743(0.020)$ & $0.806(0.033)$ & 0.0107 \\
\hline Model 5: Multivariate Adjusted** & $0.708(0.013)$ & $0.733(0.018)$ & $0.745(0.020)$ & $0.808(0.033)$ & 0.0060 \\
\hline \multicolumn{6}{|l|}{ Total } \\
\hline Model 1: Unadjusted & $0.742(0.122)$ & $0.752(0.106)$ & $0.804(0.126)$ & $0.833(0.182)$ & $<0.0001$ \\
\hline Model 2: Age- and Gender-Adjusted & $0.761(0.011)$ & $0.748(0.012)$ & $0.777(0.013)$ & $0.785(0.013)$ & 0.0695 \\
\hline Model 3: Age-, Gender- and Smoking Adjusted & $0.762(0.012)$ & $0.751(0.013)$ & $0.780(0.013)$ & $0.787(0.013)$ & 0.0621 \\
\hline Model 4: Age-, Gender- and LDL-C Adjusted & $0.764(0.011)$ & $0.748(0.012)$ & $0.775(0.013)$ & $0.789(0.013)$ & 0.0634 \\
\hline Model 5: Multivariate Adjusted** & $0.765(0.012)$ & $0.751(0.013)$ & $0.778(0.013)$ & $0.791(0.013)$ & 0.0580 \\
\hline
\end{tabular}

Note: Values are mean (SD) for unadjusted model or (SE) for adjusted models.

* Test for linear trend based on linear contrast

** Adjusted for age, smoking status and LDL-C. Total multivariate-adjusted model also included gender. 
Table C.2c. Unadjusted and adjusted mean common carotid artery thickness by number of metabolic syndrome components by gender, BCOPS Study, visit 3.

\begin{tabular}{|c|c|c|c|c|c|}
\hline & \multicolumn{5}{|c|}{ Number of Metabolic Syndrome Components } \\
\hline & 0 & 1 & 2 & $\geq 3$ & p-value* \\
\hline \multicolumn{6}{|l|}{ Men } \\
\hline Model 1: Unadjusted & $0.608(0.122)$ & $0.591(0.079)$ & $0.644(0.114)$ & $0.650(0.098)$ & 0.0013 \\
\hline Model 2: Age-Adjusted & $0.626(0.012)$ & $0.603(0.010)$ & $0.638(0.010)$ & $0.636(0.009)$ & 0.1882 \\
\hline Model 3: Age- and Smoking Adjusted & $0.633(0.013)$ & $0.610(0.011)$ & $0.645(0.011)$ & $0.641(0.010)$ & 0.2272 \\
\hline Model 4: Age- and LDL-C Adjusted & $0.626(0.012)$ & $0.602(0.010)$ & $0.635(0.010)$ & $0.638(0.009)$ & 0.1549 \\
\hline Model 5: Multivariate Adjusted** & $0.634(0.013)$ & $0.609(0.011)$ & $0.643(0.011)$ & $0.644(0.010)$ & 0.1887 \\
\hline \multicolumn{6}{|l|}{ Women } \\
\hline Model 1: Unadjusted & $0.564(0.068)$ & $0.596(0.075)$ & $0.616(0.092)$ & $0.636(0.065)$ & 0.0057 \\
\hline Model 2: Age-Adjusted & $0.569(0.009)$ & $0.593(0.013)$ & $0.610(0.015)$ & $0.626(0.023)$ & 0.0169 \\
\hline Model 3: Age- and Smoking Adjusted & $0.568(0.010)$ & $0.595(0.014)$ & $0.611(0.015)$ & $0.629(0.023)$ & 0.0106 \\
\hline Model 4: Age- and LDL-C Adjusted & $0.569(0.010)$ & $0.594(0.014)$ & $0.610(0.015)$ & $0.638(0.025)$ & 0.0098 \\
\hline Model 5: Multivariate Adjusted** & $0.567(0.010)$ & $0.595(0.014)$ & $0.611(0.015)$ & $0.640(0.025)$ & 0.0072 \\
\hline \multicolumn{6}{|l|}{ Total } \\
\hline Model 1: Unadjusted & $0.586(0.101)$ & $0.592(0.078)$ & $0.638(0.110)$ & $0.649(0.095)$ & $<0.0001$ \\
\hline Model 2: Age- and Gender-Adjusted & $0.599(0.008)$ & $0.592(0.009)$ & $0.623(0.009)$ & $0.623(0.009)$ & 0.0107 \\
\hline Model 3: Age-, Gender- and Smoking Adjusted & $0.602(0.009)$ & $0.596(0.009)$ & $0.627(0.009)$ & $0.625(0.009)$ & 0.0115 \\
\hline Model 4: Age-, Gender- and LDL-C Adjusted & $0.601(0.008)$ & $0.592(0.009)$ & $0.622(0.009)$ & $0.625(0.010)$ & 0.0098 \\
\hline Model 5: Multivariate Adjusted** & $0.604(0.009)$ & $0.596(0.009)$ & $0.626(0.009)$ & $0.628(0.010)$ & 0.0109 \\
\hline
\end{tabular}

Note: Values are mean (SD) for unadjusted model or (SE) for adjusted models.

* Test for linear trend based on linear contrast

** Adjusted for age, smoking status and LDL-C. Total multivariate-adjusted model also included gender. 
Table C.3a. Unadjusted and adjusted mean maximum carotid artery thickness ${ }_{12}$ by presence or absence of individual metabolic syndrome components and gender, BCOPS Study, visit 3.

\begin{tabular}{|c|c|c|c|c|c|c|c|c|c|}
\hline \multirow{2}{*}{ Metabolic Syndrome Component } & \multicolumn{3}{|c|}{ Men } & \multicolumn{3}{|c|}{ Women } & \multicolumn{3}{|c|}{ Total* } \\
\hline & Absent & Present & p-value & Absent & Present & p-value & Absent & Present & $\mathrm{p}$-value \\
\hline Elevated Waist Circumference & $\mathrm{N}=191$ & $\mathrm{~N}=113$ & & $\mathrm{~N}=87$ & $\mathrm{~N}=19$ & & $\mathrm{~N}=278$ & $\mathrm{~N}=132$ & \\
\hline Model 1: Unadjusted & $0.912(0.184)$ & $0.912(0.173)$ & 0.9863 & $0.831(0.119)$ & $0.816(0.170)$ & 0.6436 & $0.887(0.171)$ & $0.897(0.176)$ & 0.5365 \\
\hline Model 2: Age-Adjusted & $0.922(0.011)$ & $0.895(0.015)$ & 0.1391 & $0.836(0.013)$ & $0.792(0.028)$ & 0.1588 & $0.880(0.009)$ & $0.849(0.014)$ & 0.0517 \\
\hline Model 3: Age- and Smoking Adjusted & $0.927(0.013)$ & $0.902(0.016)$ & 0.1663 & $0.832(0.012)$ & $0.800(0.027)$ & 0.2622 & $0.881(0.009)$ & $0.853(0.015)$ & 0.0811 \\
\hline Model 4: Age- and LDL-C Adjusted & $0.922(0.011)$ & $0.895(0.015)$ & 0.1485 & $0.836(0.013)$ & $0.794(0.029)$ & 0.1983 & $0.881(0.009)$ & $0.850(0.014)$ & 0.0557 \\
\hline Model 5: Multivariate Adjusted** & $0.928(0.013)$ & $0.903(0.016)$ & 0.1781 & $0.833(0.013)$ & $0.800(0.028)$ & 0.2921 & $0.883(0.010)$ & $0.855(0.015)$ & 0.0862 \\
\hline High Triglycerides & $\mathrm{N}=186$ & $\mathrm{~N}=118$ & & $\mathrm{~N}=97$ & $\mathrm{~N}=9$ & & $\mathrm{~N}=283$ & $\mathrm{~N}=127$ & \\
\hline Model 1: Unadjusted & $0.905(0.184)$ & $0.923(0.173)$ & 0.3975 & $0.832(0.131)$ & $0.780(0.102)$ & 0.2486 & $0.880(0.171)$ & $0.913(0.173)$ & 0.0748 \\
\hline Model 2: Age-Adjusted & $0.915(0.011)$ & $0.908(0.014)$ & 0.7186 & $0.831(0.012)$ & $0.796(0.040)$ & 0.4135 & $0.873(0.009)$ & $0.866(0.015)$ & 0.6566 \\
\hline Model 3: Age- and Smoking Adjusted & $0.922(0.014)$ & $0.914(0.015)$ & 0.6396 & $0.829(0.012)$ & $0.800(0.039)$ & 0.4043 & $0.877(0.010)$ & $0.867(0.015)$ & 0.5521 \\
\hline Model 4: Age- and LDL-C Adjusted & $0.914(0.011)$ & $0.909(0.014)$ & 0.7792 & $0.831(0.012)$ & $0.802(0.044)$ & 0.5255 & $0.874(0.009)$ & $0.868(0.015)$ & 0.7289 \\
\hline Model 5: Multivariate Adjusted** & $0.922(0.014)$ & $0.915(0.015)$ & 0.6808 & $0.830(0.012)$ & $0.797(0.042)$ & 0.4535 & $0.878(0.010)$ & $0.869(0.015)$ & 0.6021 \\
\hline Low HDL Cholesterol & $\mathrm{N}=159$ & $N=145$ & & $\mathrm{~N}=78$ & $\mathrm{~N}=28$ & & $N=237$ & $\mathrm{~N}=173$ & \\
\hline Model 1: Unadjusted & $0.901(0.174)$ & $0.924(0.187)$ & 0.2705 & $0.813(0.115)$ & $0.871(0.157)$ & 0.0399 & $0.872(0.162)$ & $0.915(0.183)$ & 0.0116 \\
\hline Model 2: Age-Adjusted & $0.908(0.012)$ & $0.916(0.013)$ & 0.6996 & $0.813(0.013)$ & $0.870(0.022)$ & 0.0295 & $0.864(0.010)$ & $0.883(0.013)$ & 0.2203 \\
\hline Model 3: Age- and Smoking Adjusted & $0.916(0.014)$ & $0.921(0.014)$ & 0.7732 & $0.810(0.013)$ & $0.872(0.021)$ & 0.0120 & $0.867(0.011)$ & $0.885(0.013)$ & 0.2337 \\
\hline Model 4: Age- and LDL-C Adjusted & $0.907(0.012)$ & $0.917(0.013)$ & 0.5799 & $0.813(0.013)$ & $0.876(0.023)$ & 0.0196 & $0.865(0.010)$ & $0.885(0.013)$ & 0.1775 \\
\hline Model 5: Multivariate Adjusted** & $0.915(0.014)$ & $0.923(0.014)$ & 0.6544 & $0.810(0.013)$ & $0.877(0.022)$ & 0.0092 & $0.868(0.011)$ & $0.888(0.013)$ & 0.1907 \\
\hline Glucose Intolerance & $\mathrm{N}=221$ & $\mathrm{~N}=83$ & & $\mathrm{~N}=94$ & $\mathrm{~N}=12$ & & $\mathrm{~N}=315$ & $\mathrm{~N}=95$ & \\
\hline Model 1: Unadjusted & $0.903(0.160)$ & $0.935(0.224)$ & 0.1701 & $0.837(0.126)$ & $0.757(0.139)$ & 0.0429 & $0.884(0.153)$ & $0.913(0.223)$ & 0.1483 \\
\hline Model 2: Age-Adjusted & $0.915(0.011)$ & $0.905(0.017)$ & 0.6331 & $0.838(0.012)$ & $0.749(0.034)$ & 0.0146 & $0.875(0.009)$ & $0.855(0.017)$ & 0.2501 \\
\hline Model 3: Age- and Smoking Adjusted & $0.921(0.013)$ & $0.912(0.018)$ & 0.6395 & $0.836(0.012)$ & $0.751(0.032)$ & 0.0145 & $0.878(0.010)$ & $0.858(0.017)$ & 0.2556 \\
\hline Model 4: Age- and LDL-C Adjusted & $0.913(0.011)$ & $0.908(0.017)$ & 0.8227 & $0.840(0.012)$ & $0.746(0.034)$ & 0.0115 & $0.876(0.009)$ & $0.858(0.017)$ & 0.3158 \\
\hline Model 5: Multivariate Adjusted** & $0.921(0.013)$ & $0.915(0.018)$ & 0.8060 & $0.838(0.012)$ & $0.747(0.033)$ & 0.0103 & $0.879(0.010)$ & $0.861(0.017)$ & 0.3185 \\
\hline Hypertension & $\mathrm{N}=173$ & $\mathrm{~N}=131$ & & $\mathrm{~N}=79$ & $\mathrm{~N}=27$ & & $\mathrm{~N}=252$ & $\mathrm{~N}=158$ & \\
\hline
\end{tabular}


Model 1: Unadjusted

Model 2: Age-Adjusted

Model 3: Age- and Smoking Adjusted

Model 4: Age- and LDL-C Adjusted

Model 5: Multivariate Adjusted**
$0.884(0.154) \quad 0.949(0.205) \quad 0.0019$

$0.900(0.112) \quad 0.929(0.014) \quad 0.1136$

$0.906(0.014) \quad 0.934(0.015) \quad 0.1281$

$0.897(0.012) \quad 0.932(0.014) \quad 0.0619$ $0.904(0.014) \quad 0.938(0.015) \quad 0.0730$
$0.809(0.117) \quad 0.884(0.149)$

$0.814(0.013) \quad 0.869(0.023)$

$0.811(0.013) \quad 0.871(0.022)$

$0.813(0.014) \quad 0.878(0.025)$

$0.810(0.013) \quad 0.878(0.023)$

\begin{tabular}{llll}
0.0087 & $0.861(0.147)$ & $0.938(0.197)$ & $<0.0001$ \\
0.0453 & $0.859(0.010)$ & $0.894(0.013)$ & 0.0267 \\
0.0194 & $0.862(0.010)$ & $0.900(0.013)$ & 0.0250 \\
0.0265 & $0.860(0.010)$ & $0.897(0.013)$ & 0.0182 \\
0.0141 & $0.863(0.010)$ & $0.899(0.013)$ & 0.0172 \\
\hline
\end{tabular}

0.0087

0.0141

* For total sample, Age-Adjusted model is also adjusted for gender.

** Adjusted for age, smoking status and LDL-C. Total multivariate-adjusted model also included gender. 
Table C.3b. Unadjusted and adjusted mean maximum carotid artery thickness 36 by presence or absence of individual metabolic syndrome components and gender, BCOPS Study, visit 3.

\begin{tabular}{|c|c|c|c|c|c|c|c|c|c|}
\hline \multirow{2}{*}{ Metabolic Syndrome Component } & \multicolumn{3}{|c|}{ Men } & \multicolumn{3}{|c|}{ Women } & \multicolumn{3}{|c|}{ Total* } \\
\hline & Absent & Present & p-value & Absent & Present & p-value & Absent & Present & $\mathrm{p}$-value \\
\hline Elevated Waist Circumference & $\mathrm{N}=191$ & $\mathrm{~N}=113$ & & $\mathrm{~N}=87$ & $\mathrm{~N}=19$ & & $\mathrm{~N}=278$ & $N=132$ & \\
\hline Model 1: Unadjusted & $0.792(0.142)$ & $0.818(0.161)$ & 0.1425 & $0.722(0.092)$ & $0.762(0.139)$ & 0.1206 & $0.770(0.132)$ & $0.810(0.159)$ & 0.0077 \\
\hline Model 2: Age-Adjusted & $0.801(0.009)$ & $0.803(0.012)$ & 0.9105 & $0.726(0.010)$ & $0.741(0.022)$ & 0.5412 & $0.766(0.007)$ & $0.769(0.011)$ & 0.7905 \\
\hline Model 3: Age- and Smoking Adjusted & $0.807(0.010)$ & $0.810(0.013)$ & 0.8419 & $0.724(0.010)$ & $0.845(0.022)$ & 0.3855 & $0.767(0.008)$ & $0.773(0.012)$ & 0.6590 \\
\hline Model 4: Age- and LDL-C Adjusted & $0.801(0.009)$ & $0.803(0.012)$ & 0.8829 & $0.727(0.010)$ & $0.742(0.022)$ & 0.5624 & $0.767(0.007)$ & $0.770(0.011)$ & 0.7818 \\
\hline Model 5: Multivariate Adjusted** & $0.807(0.010)$ & $0.810(0.013)$ & 0.8072 & $0.725(0.010)$ & $0.745(0.022)$ & 0.4198 & $0.769(0.008)$ & $0.775(0.012)$ & 0.6503 \\
\hline High Triglycerides & $\mathrm{N}=186$ & $\mathrm{~N}=118$ & & $\mathrm{~N}=97$ & $\mathrm{~N}=9$ & & $\mathrm{~N}=283$ & $\mathrm{~N}=127$ & \\
\hline Model 1: Unadjusted & $0.792(0.143)$ & $0.817(0.158)$ & 0.1558 & $0.731(0.106)$ & $0.710(0.067)$ & 0.5612 & $0.771(0.134)$ & $0.809(0.156)$ & 0.0115 \\
\hline Model 2: Age-Adjusted & $0.801(0.009)$ & $0.803(0.012)$ & 0.8597 & $0.729(0.009)$ & $0.726(0.031)$ & 0.9149 & $0.766(0.007)$ & $0.769(0.012)$ & 0.7832 \\
\hline Model 3: Age- and Smoking Adjusted & $0.808(0.011)$ & $0.808(0.012)$ & 0.9788 & $0.728(0.010)$ & $0.727(0.031)$ & 0.9870 & $0.768(0.008)$ & $0.770(0.012)$ & 0.8751 \\
\hline Model 4: Age- and LDL-C Adjusted & $0.800(0.009)$ & $0.804(0.012)$ & 0.8038 & $0.730(0.009)$ & $0.723(0.033)$ & 0.8401 & $0.766(0.007)$ & $0.771(0.012)$ & 0.7287 \\
\hline Model 5: Multivariate Adjusted** & $0.807(0.011)$ & $0.809(0.012)$ & 0.9321 & $0.729(0.010)$ & $0.723(0.033)$ & 0.8595 & $0.770(0.008)$ & $0.772(0.012)$ & 0.8368 \\
\hline Low HDL Cholesterol & $\mathrm{N}=159$ & $\mathrm{~N}=145$ & & $\mathrm{~N}=78$ & $\mathrm{~N}=28$ & & $\mathrm{~N}=237$ & $\mathrm{~N}=173$ & \\
\hline Model 1: Unadjusted & $0.795(0.160)$ & $0.810(0.137)$ & 0.3797 & $0.713(0.083)$ & $0.775(0.135)$ & 0.0053 & $0.768(0.145)$ & $0.804(0.137)$ & 0.0103 \\
\hline Model 2: Age-Adjusted & $0.802(0.010)$ & $0.802(0.010)$ & 0.9706 & $0.713(0.010)$ & $0.774(0.017)$ & 0.0019 & $0.761(0.008)$ & $0.775(0.010)$ & 0.2347 \\
\hline Model 3: Age- and Smoking Adjusted & $0.808(0.011)$ & $0.808(0.011)$ & 0.9802 & $0.710(0.010)$ & $0.776(0.016)$ & 0.0008 & $0.763(0.008)$ & $0.778(0.010)$ & 0.2309 \\
\hline Model 4: Age- and LDL-C Adjusted & $0.800(0.010)$ & $0.803(0.010)$ & 0.8542 & $0.714(0.010)$ & $0.776(0.017)$ & 0.0022 & $0.762(0.008)$ & $0.777(0.010)$ & 0.1954 \\
\hline Model 5: Multivariate Adjusted** & $0.807(0.011)$ & $0.809(0.011)$ & 0.8966 & $0.711(0.010)$ & $0.777(0.017)$ & 0.0011 & $0.764(0.008)$ & $0.780(0.010)$ & 0.1917 \\
\hline Glucose Intolerance & $\mathrm{N}=221$ & $\mathrm{~N}=83$ & & $\mathrm{~N}=94$ & $\mathrm{~N}=12$ & & $\mathrm{~N}=315$ & $\mathrm{~N}=95$ & \\
\hline Model 1: Unadjusted & $0.790(0.126)$ & $0.832(0.197)$ & 0.0293 & $0.731(0.106)$ & $0.716(0.081)$ & 0.6435 & $0.773(0.123)$ & $0.818(0.190)$ & 0.0068 \\
\hline Model 2: Age-Adjusted & $0.801(0.008)$ & $0.805(0.014)$ & 0.7891 & $0.732(0.009)$ & $0.708(0.027)$ & 0.3950 & $0.766(0.007)$ & $0.767(0.013)$ & 0.9335 \\
\hline Model 3: Age- and Smoking Adjusted & $0.807(0.010)$ & $0.810(0.015)$ & 0.8680 & $0.730(0.010)$ & $0.710(0.027)$ & 0.4652 & $0.769(0.008)$ & $0.769(0.013)$ & 0.9662 \\
\hline Model 4: Age- and LDL-C Adjusted & $0.799(0.008)$ & $0.807(0.014)$ & 0.6165 & $0.733(0.010)$ & $0.702(0.027)$ & 0.2737 & $0.767(0.007)$ & $0.770(0.013)$ & 0.8037 \\
\hline Model 5: Multivariate Adjusted** & $0.806(0.010)$ & $0.813(0.015)$ & 0.6956 & $0.732(0.010)$ & $0.704(0.027)$ & 0.3218 & $0.770(0.008)$ & $0.773(0.013)$ & 0.8343 \\
\hline Hypertension & $\mathrm{N}=173$ & $\mathrm{~N}=131$ & & $\mathrm{~N}=79$ & $\mathrm{~N}=27$ & & $\mathrm{~N}=252$ & $\mathrm{~N}=158$ & \\
\hline
\end{tabular}


Model 1: Unadjusted

Model 2: Age-Adjusted

Model 3: Age- and Smoking Adjusted

Model 4: Age- and LDL-C Adjusted

$0.775(0.121)$

$0.789(0.009)$

$0.795(0.011)$

$0.786(0.009)$

$0.793(0.0)$

$0.837(0.174) \quad 0.0003$

$0.819(0.011) \quad 0.0404$

$0.824(0.012) \quad 0.0458$

$0.821(0.011) \quad 0.0208$

$0.827(0.012) \quad 0.0232$

$0.711(0.084)$

$0.716(0.010)$

$0.714(0.010)$

$0.718(0.010)$

$0.715(0.010)$

Model 5: Multivariate Adjusted**

* For total sample, Age-Adjusted model is also adjusted for gender.

** Adjusted for age, smoking status and LDL-C. Total multivariate-adjusted model also included gender.
$0.755(0.114) \quad 0.827(0.169) \quad<0.0001$

$0.755(0.008) \quad 0.789(0.010) \quad 0.0055$

$0.757(0.008) \quad 0.791(0.011) \quad 0.0050$

$0.755(0.078) \quad 0.791(0.010) \quad 0.0036$ 
Table C.3c. Unadjusted and adjusted mean common carotid artery thickness by presence or absence of individual metabolic syndrome components and gender, BCOPS Study, visit 3.

\begin{tabular}{|c|c|c|c|c|c|c|c|c|c|}
\hline \multirow{2}{*}{ Metabolic Syndrome Component } & \multicolumn{3}{|c|}{ Men } & \multicolumn{3}{|c|}{ Women } & \multicolumn{3}{|c|}{ Total $*$} \\
\hline & Absent & Present & p-value & Absent & Present & $\mathrm{p}$-value & Absent & Present & $\mathrm{p}$-value \\
\hline Elevated Waist Circumference & $\mathrm{N}=191$ & $\mathrm{~N}=113$ & & $\mathrm{~N}=87$ & $\mathrm{~N}=19$ & & $\mathrm{~N}=278$ & $\mathrm{~N}=132$ & \\
\hline Model 1: Unadjusted & $0.615(0.097)$ & $0.646(0.116)$ & 0.0143 & $0.584(0.080)$ & $0.600(0.065)$ & 0.4449 & $0.606(0.093)$ & $0.639(0.111)$ & 0.0015 \\
\hline Model 2: Age-Adjusted & $0.621(0.007)$ & $0.636(0.009)$ & 0.1671 & $0.588(0.008)$ & $0.583(0.016)$ & 0.7973 & $0.604(0.005)$ & $0.616(0.008)$ & 0.2268 \\
\hline Model 3: Age- and Smoking Adjusted & $0.628(0.007)$ & $0.644(0.010)$ & 0.1246 & $0.588(0.008)$ & $0.586(0.017)$ & 0.9243 & $0.608(0.006)$ & $0.621(0.009)$ & 0.1541 \\
\hline Model 4: Age- and LDL-C Adjusted & $0.621(0.007)$ & $0.636(0.009)$ & 0.1593 & $0.589(0.008)$ & $0.534(0.017)$ & 0.7930 & $0.605(0.005)$ & $0.617(0.008)$ & 0.2254 \\
\hline Model 5: Multivariate Adjusted** & $0.628(0.007)$ & $0.645(0.010)$ & 0.1157 & $0.588(0.008)$ & $0.586(0.017)$ & 0.9010 & $0.609(0.006)$ & $0.622(0.009)$ & 0.1532 \\
\hline High Triglycerides & $\mathrm{N}=186$ & $\mathrm{~N}=118$ & & $\mathrm{~N}=97$ & $\mathrm{~N}=9$ & & $\mathrm{~N}=283$ & $\mathrm{~N}=127$ & \\
\hline Model 1: Unadjusted & $0.616(0.109)$ & $0.643(0.097)$ & 0.0256 & $0.585(0.080)$ & $0.610(0.048)$ & 0.3602 & $0.605(0.101)$ & $0.641(0.094)$ & 0.0008 \\
\hline Model 2: Age-Adjusted & $0.621(0.007)$ & $0.635(0.008)$ & 0.2169 & $0.584(0.007)$ & $0.622(0.023)$ & 0.1183 & $0.604(0.005)$ & $0.620(0.009)$ & 0.0019 \\
\hline Model 3: Age- and Smoking Adjusted & $0.629(0.008)$ & $0.640(0.009)$ & 0.3129 & $0.584(0.007)$ & $0.624(0.023)$ & 0.1015 & $0.607(0.006)$ & $0.622(0.009)$ & 0.1270 \\
\hline Model 4: Age- and LDL-C Adjusted & $0.621(0.007)$ & $0.635(0.008)$ & 0.1931 & $0.584(0.007)$ & $00.629(0.025)$ & 0.0927 & $0.604(0.005)$ & $0.621(0.009)$ & 0.0745 \\
\hline Model 5: Multivariate Adjusted** & $0.629(0.008)$ & $0.640(0.009)$ & 0.2878 & $0.584(0.007)$ & $0.630(0.025)$ & 0.0881 & $0.608(0.006)$ & $0.623(0.009)$ & 0.1161 \\
\hline Low HDL Cholesterol & $\mathrm{N}=159$ & $\mathrm{~N}=145$ & & $\mathrm{~N}=78$ & $\mathrm{~N}=28$ & & $\mathrm{~N}=237$ & $\mathrm{~N}=173$ & \\
\hline Model 1: Unadjusted & $0.616(0.113)$ & $0.638(0.095)$ & 0.0644 & $0.577(0.070)$ & $0.617(0.092)$ & 0.0188 & $0.603(0.102)$ & $0.635(0.095)$ & 0.0015 \\
\hline Model 2: Age-Adjusted & $0.620(0.007)$ & $0.633(0.007)$ & 0.2137 & $0.577(0.008)$ & $0.616(0.013)$ & 0.0096 & $0.601(0.006)$ & $0.619(0.007)$ & 0.0304 \\
\hline Model 3: Age- and Smoking Adjusted & $0.628(0.008)$ & $0.639(0.008)$ & 0.2545 & $0.576(0.008)$ & $0.618(0.013)$ & 0.0067 & $0.604(0.006)$ & $0.622(0.007)$ & 0.0341 \\
\hline Model 4: Age- and LDL-C Adjusted & $0.619(0.007)$ & $0.634(0.008)$ & 0.1616 & $0.577(0.008)$ & $0.618(0.013)$ & 0.0094 & $0.601(0.006)$ & $0.621(0.007)$ & 0.0234 \\
\hline Model 5: Multivariate Adjusted ${ }^{* *}$ & $0.627(0.008)$ & $0.641(0.008)$ & 0.1918 & $0.577(0.008)$ & $0.619(0.013)$ & 0.0072 & $0.605(0.006)$ & $0.624(0.008)$ & 0.0264 \\
\hline Glucose Intolerance & $\mathrm{N}=221$ & $\mathrm{~N}=83$ & & $\mathrm{~N}=94$ & $\mathrm{~N}=12$ & & $\mathrm{~N}=315$ & $\mathrm{~N}=95$ & \\
\hline Model 1: Unadjusted & $0.622(0.108)$ & $0.638(0.095)$ & 0.2436 & $0.586(0.081)$ & $0.597(0.052)$ & 0.6584 & $0.611(0.102)$ & $0.633(0.092)$ & 0.0683 \\
\hline Model 2: Age-Adjusted & $0.629(0.006)$ & $0.620(0.010)$ & 0.4458 & $0.587(0.007)$ & $0.591(0.020)$ & 0.8634 & $0.609(0.005)$ & $0.602(0.010)$ & 0.5265 \\
\hline Model 3: Age- and Smoking Adjusted & $0.637(0.007)$ & $0.626(0.010)$ & 0.3612 & $0.587(0.007)$ & $0.592(0.020)$ & 0.8038 & $0.613(0.006)$ & $0.605(0.010)$ & 0.4625 \\
\hline Model 4: Age- and LDL-C Adjusted & $0.628(0.006)$ & $0.622(0.010)$ & 0.5918 & $0.588(0.007)$ & $0.588(0.021)$ & 0.9790 & $0.609(0.005)$ & $0.604(0.010)$ & 0.6280 \\
\hline Model 5: Multivariate Adjusted ${ }^{* *}$ & $0.636(0.007)$ & $0.628(0.011)$ & 0.4887 & $0.588(0.007)$ & $0.590(0.021)$ & 0.9205 & $0.613(0.006)$ & $0.607(0.010)$ & 0.5599 \\
\hline Hypertension & $\mathrm{N}=173$ & $\mathrm{~N}=131$ & & $\mathrm{~N}=79$ & $\mathrm{~N}=27$ & & $\mathrm{~N}=252$ & $\mathrm{~N}=158$ & \\
\hline
\end{tabular}


Model 1: Unadjusted

Model 2: Age-Adjusted

Model 3: Age- and Smoking Adjusted

Model 4: Age- and LDL-C Adjusted

Model 5: Multivariate Adjusted**
$0.613(0.098) \quad 0.645(0.112) \quad 0.0079$

$0.622(0.007) \quad 0.633(0.008) \quad 0.2996$

$0.629(0.008) \quad 0.639(0.009) \quad 0.3405$

$0.620(0.007) \quad 0.634(0.008) \quad 0.1936$

$0.628(0.008) \quad 0.641(0.009) \quad 0.2192$
$0.569(0.064) \quad 0.639(0.091)$

$0.573(0.007) \quad 0.629(0.013)$

$0.573(0.008) \quad 0.630(0.013)$

$0.573(0.008) \quad 0.633(0.014)$

$0.572(0.008) \quad 0.634(0.014)$
$<0.0001$

0.0003

0.0002

0.0003

0.0002 $\begin{array}{lll}0.599(0.091) & 0.644(0.108) & <0.0001\end{array}$

$0.601(0.006) \quad 0.621(0.008) \quad 0.0222$

$0.601(0.006) \quad 0.623(0.008) \quad 0.0159$

* For total sample, Age-Adjusted model is also adjusted for gender.

** Adjusted for age, smoking status and LDL-C. Total multivariate-adjusted model also included gender. 